\title{
WestVirginiaUniversity
}

THE RESEARCH REPOSITORY @ WVU

Graduate Theses, Dissertations, and Problem Reports

2008

\section{Code comparison of methane hydrate reservoir simulators using CMG STARS}

Manohar Gaddipati

West Virginia University

Follow this and additional works at: https://researchrepository.wvu.edu/etd

\section{Recommended Citation}

Gaddipati, Manohar, "Code comparison of methane hydrate reservoir simulators using CMG STARS" (2008). Graduate Theses, Dissertations, and Problem Reports. 1973.

https://researchrepository.wvu.edu/etd/1973

This Thesis is protected by copyright and/or related rights. It has been brought to you by the The Research Repository @ WVU with permission from the rights-holder(s). You are free to use this Thesis in any way that is permitted by the copyright and related rights legislation that applies to your use. For other uses you must obtain permission from the rights-holder(s) directly, unless additional rights are indicated by a Creative Commons license in the record and/ or on the work itself. This Thesis has been accepted for inclusion in WVU Graduate Theses, Dissertations, and Problem Reports collection by an authorized administrator of The Research Repository @ WVU. For more information, please contact researchrepository@mail.wvu.edu. 


\title{
Code Comparison of Methane Hydrate Reservoir Simulators using CMG STARS
}

\author{
Manohar Gaddipati
}

Thesis submitted to the

College of Engineering and Mineral Resources

at West Virginia University

in partial fulfillment of the requirements

for the degree of

Master of Science
in

Chemical Engineering

Dr. Brian J. Anderson

Dr. H. Ilkin Bilgesu

Dr. Wu Zhang

Department of Chemical Engineering

Morgantown, West Virginia

2008

Key words: Gas hydrates, CMG STARS, Code comparison, Methane hydrate reservoir simulators, Gas production from hydrates, Sensitivity analysis, Heterogeneity, Depressurization 


\title{
Code Comparison of Methane Hydrate Reservoir Simulators
}

\author{
using CMG STARS
}

\begin{abstract}
Manohar Gaddipati

Natural gas is an important energy source contributing to $23 \%$ of the total energy consumption in United States. Domestic conventional natural gas production does not keep pace with increase in natural gas demand. Development of new alternatives like natural gas from methane hydrate can play a major role in ensuring adequate future energy supplies in the United States.

Methane hydrates are crystalline solids, very similar to ice, in which non-polar molecules are trapped inside the cages of water molecules. Methane hydrates could be potentially a vast source of energy. It is estimated that the total amount of natural gas trapped inside the hydrate is approximately two times the total unconventional oil-gas reserves in the world. The production of natural gas from hydrates economically poses a big challenge to today's scientific world. Over the years, different reservoir simulators were developed and different approaches have been used to model the gas hydrate dissociation behavior. The National Energy Technology Laboratory (NETL) and the U.S Geological Survey (USGS) gas hydrate code comparison project is the first of its kind and it aims at a worldwide understanding of the hypotheses involved in the gas hydrate modeling and problem solving. This code comparison study is conducted to compare various hydrate reservoir simulators like CMG STARS, TOUGH-Fx/Hydrate, MH21, STOMP, HydrateResSim and a code form University of Houston.
\end{abstract}

The objective of this Project is to generate results for different problems set by the code comparison participants using CMG STARS and to validate its results with other reservoir simulators. Results obtained are in good agreement with other simulators in the study. However minor differences were observed for a problem with ice in the system. Long term simulations were conducted for Mt Elbert, Prudhoe Bay L-PAD like deposits. The Production rates obtained using CMG STARS were in good agreement with other packages.

In addition to the code comparison problems, simulations to analyze the sensitivity to various parameters were performed. Studies were carried out with heterogeneity introduced in the reservoir properties using the Mt. Elbert stratigraphic test well data and results showed that higher production was observed with the incorporation of heterogeneity. Sensitivity analysis of seven reservoir parameters was done using Plackett-Burman design to gain a better understanding on production performance. The reservoir parameters were ranked based on effects of the reservoir parameters on production rates. 


\section{Acknowledgements}

I thank my research advisor Dr. Brian J. Anderson for his encouragement, guidance and his help throughout the course of my research. Besides being my research advisor, he has been of great support in a foreign country to me. I will remain indebted to him for the inspiration he has given me.

Many thanks to Dr. Huseyin I. Bilgesu and Dr. Wu Zhang for being a part of my advisory committee and for all the help and suggestions they have offered.

I sincerely thank George Moridis, Joseph W. Wilder, Scott Wilson, Mark D. White, Mehran Pooladi-Darvish, Kelly Rose, Ray Boswell, Masanori Kurihara for sharing their research results and indirectly supporting my research project. Together it was a perfect team.

It is family that makes a person and I am very lucky to have a wonderful family. I am very grateful to my father, Narasimha Rao, my mother, Nagamani for their love and my brother Samba who has been my role model since childhood. I also express my genuine gratitude to Lavanya Nyayapathi who has always been there for me.

Thank you one and all.

Manohar Gaddipati

October 31, 2008. 


\section{Table of Contents}

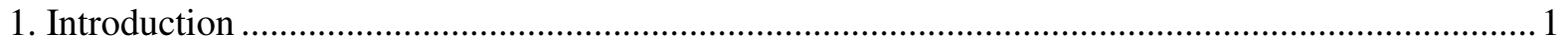

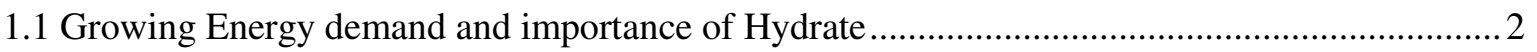

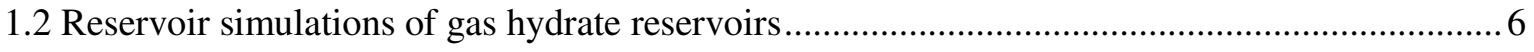

1.3 Recent developments in the production of natural gas from gas hydrates ................................ 8

1.4 International effort for the code comparison project ........................................................ 9

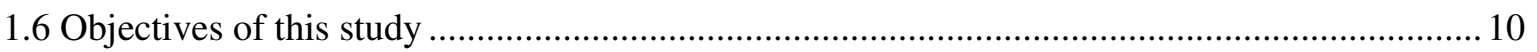

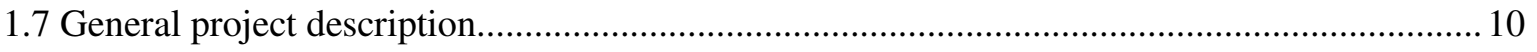

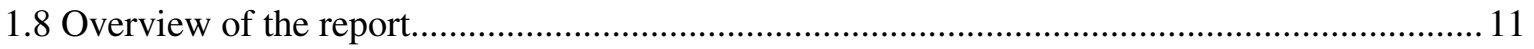

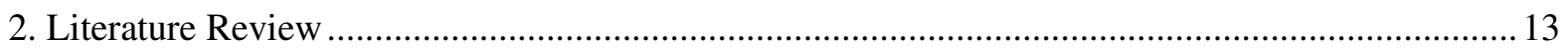

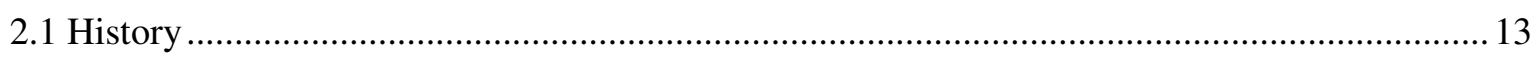

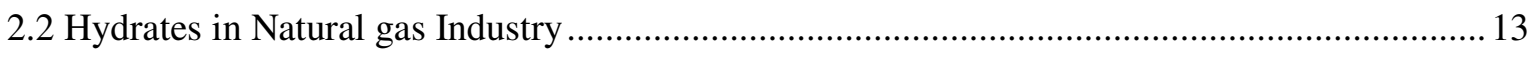

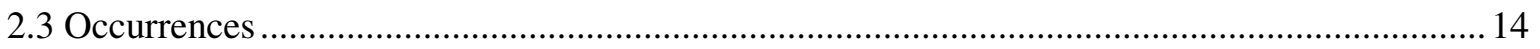

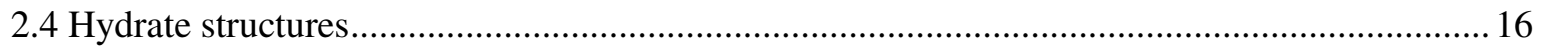

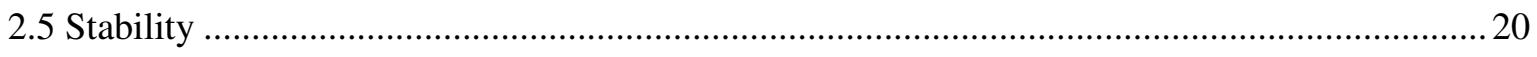

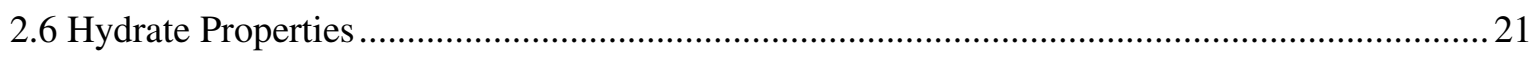

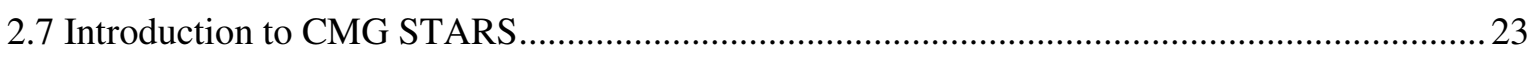

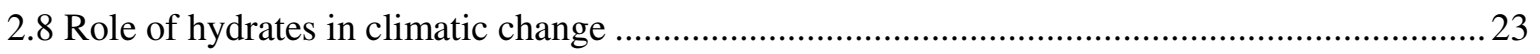

2.9 Conventional methods for producing gas from hydrates......................................................25

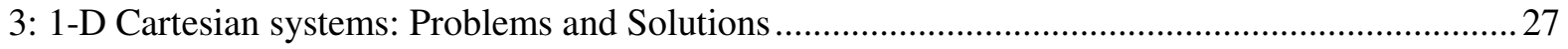

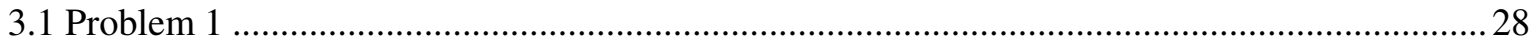

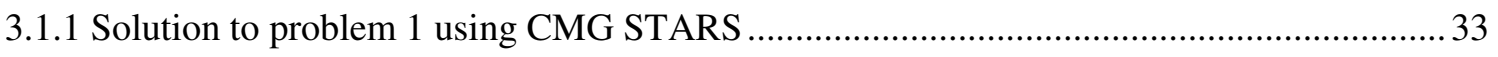

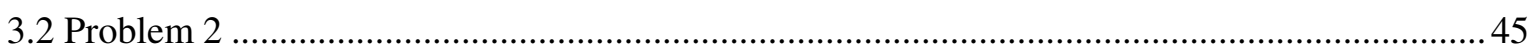

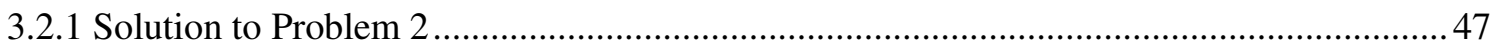

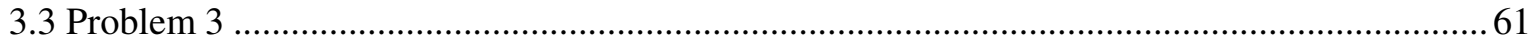

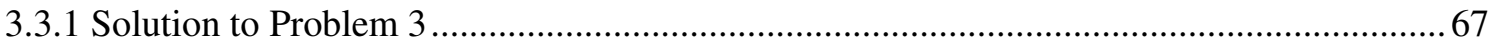

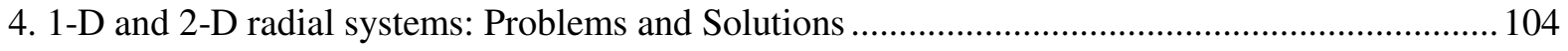

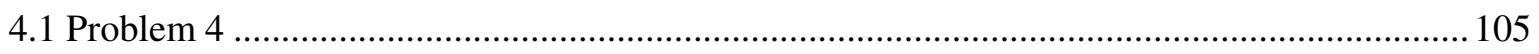

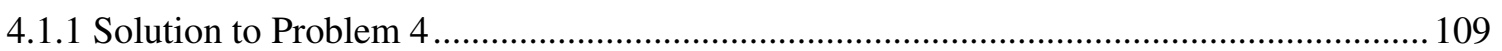

4.1.2 Results of similarity solution study of hydrate dissociation in radial domain................... 114

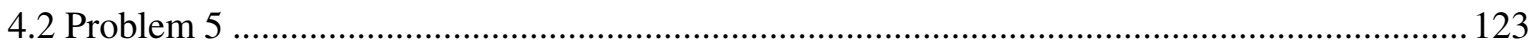

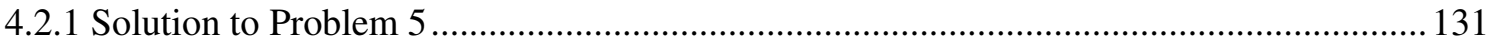

5. Long term simulations on Prudhoe Bay and Mt. Elbert like sites ............................................... 144

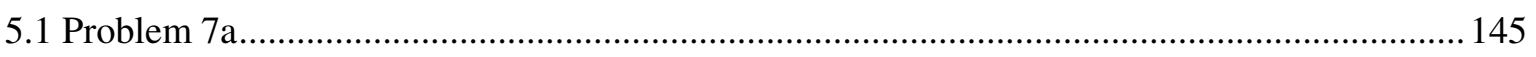

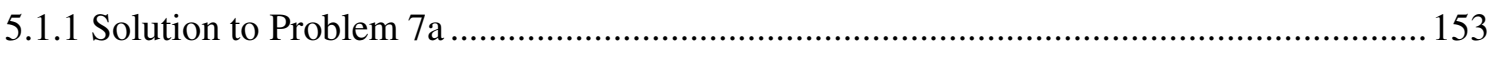

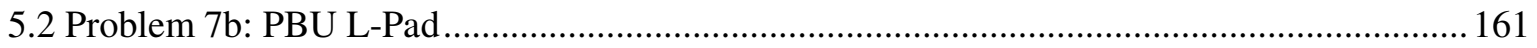




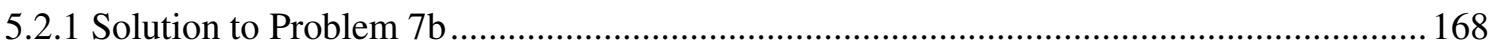

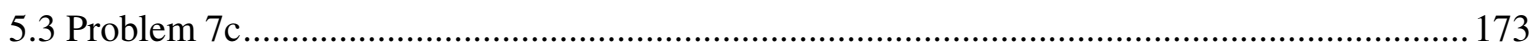

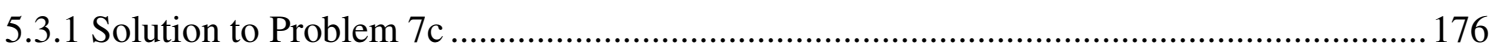

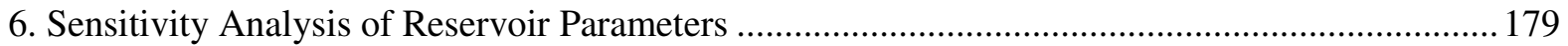

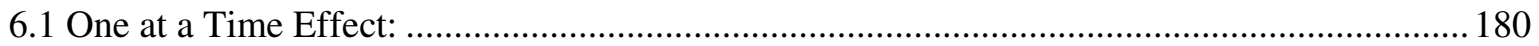

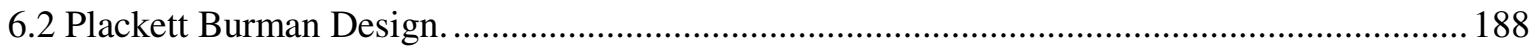

7. Importance and Incorporation of Heterogeneity in Reservoirs ................................................... 197

8. Conclusions Recommendations and Future work ........................................................................ 202

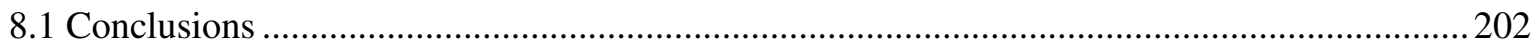

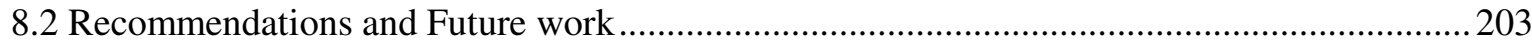

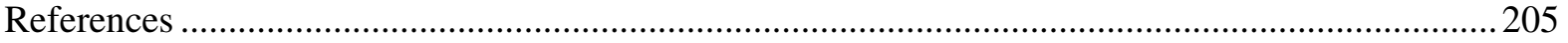




\section{List of Figures}

Figure 1-1 U.S Energy Consumption by Fuel, projected up to 2030 ........................................ 3

Figure 1-2 Average imported crude oil prices................................................................... 4

Figure 1-3 U.S Natural gas consumption and Production. .......................................................5

Figure 1-4 U.S Natural gas production by source, projections up to 2030 .................................6

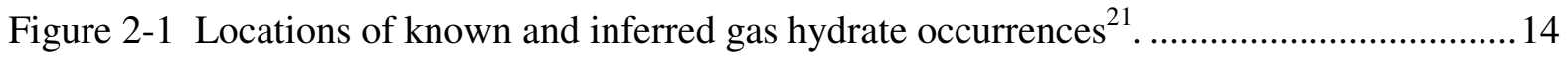

Figure 2-2 Different structures of gas hydrates................................................................ 17

Figure 2-3 Structure I and II type hydrate. ....................................................................... 19

Figure 2-4 Methane Hydrate Stability Zones28 (a) Permafrost Regions (b) Oceanic Regions.....21

Figure 2-5 Equilibrium Pressure-Temperature relationship of methane hydrates ${ }^{3}$...................22

Figure 2-6 Global methane concentration Vs. Time in the atmosphere from 1980 to $2004^{31} \ldots . .24$

Figure 3-1 Schematic diagram of the grid for problem 1......................................................29

Figure 3-2 Capillary Pressures vs. Water Saturation as calculated using the Van Genuchten

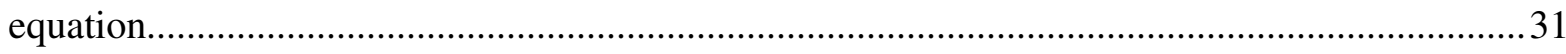

Figure 3-3 Relative permeability of water $\mathrm{k}_{\mathrm{ra}}$ and gas, $\mathrm{k}_{\mathrm{rg}}$ phases as a function of water saturation 32

Figure 3- 4 Aqueous Saturation Curves for different time steps for Problem 1 ........................40

Figure 3- 5 Temperature profiles for different time steps for Problem 1 ..................................41

Figure 3- 6 Aqueous relative permeability for different time steps for problem 1....................42

Figure 3- 7 Aqueous methane mass fraction for different time steps for Problem 1..................43

Figure 3- 8 Gas Pressure at different time steps for Problem 1...............................................44

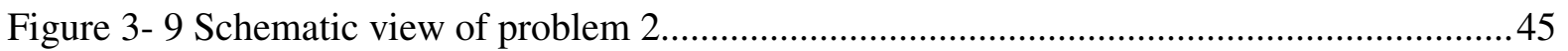

Figure 3- 10 Aqueous Saturation profiles for different time steps for Problem 2.....................54

Figure 3-11 Gas Saturation profiles for different time steps for Problem 2............................55

Figure 3- 12 Hydrate saturation profiles for different time steps for Problem 2......................56

Figure 3-13 Profiles of temperature at different time steps for Problem 2 .............................57

Figure 3-14 Aqueous relative permeability curves at different time steps for Problem 2..........58

Figure 3-15 Aqueous methane mass fraction profiles for different time steps for Problem 2.....59

Figure 3-16 Gas Pressure profiles for different time steps for Problem 2 ..............................60

Figure 3- 17 Schematic representation of grid for Problem 3 ..............................................62

Figure 3-18 Aqueous and Gas Relative permeability curves as a function of Water Saturation.65

Figure 3-19 Capillary Pressure vs. Water Saturation .65 
Figure 3- 20 Profiles of Aqueous saturation at different times for problem 3 Case 1 ................. 77

Figure 3- 21 Profiles of gas saturation at different time steps for Problem 3 Case 1 .................78

Figure 3- 22 Profiles of hydrate saturation at different times for Problem 3 Case 1 .................. 79

Figure 3- 23 Profiles of temperature at different times for Problem 3 Case 1...........................80

Figure 3- 24 Profiles of Aqueous relative permeability at different times for Problem 3 Case 1.81

Figure 3- 25 Profiles of Aqueous methane mass fraction at different times for Problem 3 Case 1

Figure 3- 26 Profiles of Pressure at different times for Problem 3 Case 1 ................................ 83

Figure 3- 27 Profiles of capillary pressure at different times for Problem 3 Case 1 .................84

Figure 3- 28 Production rates for problem 3, Case 2 ........................................................... 85

Figure 3- 29 Aqueous Saturation for different time steps for Problem 3-case-2 .......................86

Figure 3- 30 Gas Saturation for different time steps for Problem 3-case-2 2.............................. 87

Figure 3- 31 Hydrate Saturation for different time steps for Problem 3-case-2 ........................ 88

Figure 3- 32 Temperature for different time steps for Problem 3-case-2 ................................ 89

Figure 3- 33 Aqueous relative permeability at different time steps for Problem 3-case-2..........90

Figure 3- 34 Aqueous relative permeability at different time steps for Problem 3-case-2..........91

Figure 3- 35 Gas Pressure for different time steps for Problem 3-case-2 ................................ 92

Figure 3- 36 Gas-water capillary pressures for different time steps for Problem 3-case-2.........93

Figure 3- 37 Hydrate saturation curves at different time steps for Problem 3- Case -3 ..............96

Figure 3- 38 Aqueous saturation curves at different time steps for Problem 3, Case 3..............97

Figure 3- 39 Aqueous phase relative permeability curves at different time steps for Problem 3,

Case 3

Figure 3-40 Aqueous phase relative permeability curves at different time steps for Problem 3, Case 3. 99

Figure 3- 41 Ice saturation curves at different time steps for Problem 3, Case 3..................... 100

Figure 3- 42 Gas saturation curves at different time steps for Problem 3, Case 3................... 101

Figure 3- 43 Profiles of aqueous phase $\mathrm{CH} 4$ mass fraction at different time steps for Problem 3, Case 3.

Figure 3- 44 Gas Pressure curves at different time steps for Problem 3, Case 3..................... 103

Figure 4-1 Schematic view of the grid for problem 4 ....................................................... 105

Figure 4- 2 Aqueous and gas relative permeability curves as a function of water saturation for Problem 4 107

Figure 4-3 Capillary Pressure vs. Water Saturation for Problem 4. 108 
Figure 4- 4 Profiles of Temperature of Problem 4 case 1 for (a) CMG STARS (b) TOUGHFX/HYDRATE.

Figure 4- 5 Profiles of Hydrate saturation of Problem 4 case 1 for (a) CMG STARS (b) TOUGH-Fx/HYDRATE.

Figure 4- 6 Profiles of Gas saturation of Problem 4 case 1 for (a) CMG STARS (b) TOUGHFX/HYDRATE.

Figure 4- 7 Profiles of Aqueous saturation of Problem 4 case 1 for (a) CMG STARS (b) TOUGH-FX/HYDRATE.

Figure 4- 8 Profiles of Aqueous saturation of Problem 4 case 1 for (a) CMG STARS (b) TOUGH-Fx/HYDRATE.

Figure 4- 9 Profiles of Gas pressure of Problem 4 case 1 for (a) CMG STARS (b) TOUGHFX/HYDRATE.

Figure 4-10 Profiles of Gas pressure of Problem 4 case 2 for (a) CMG STARS (b) TOUGHFX/HYDRATE. 118

Figure 4- 11 Profiles of Temperature of Problem 4 case 2 for (a) CMG STARS (b) TOUGHFX/HYDRATE.

Figure 4- 12 Profiles of aqueous saturation of Problem 4 case 2 for (a) CMG STARS (b) TOUGH-FX/HYDRATE.

Figure 4- 13 Profiles of gas saturation of Problem 4 case 2 for (a) CMG STARS (b) TOUGHFX/HYDRATE.

Figure 4- 14 Profiles of hydrate saturation of Problem 4 case 2 for (a) CMG STARS (b) TOUGH-Fx/HYDRATE.

Figure 4- 15 Profiles of aqueous relative permeability of Problem 4 case 2 for (a) CMG STARS

(b) TOUGH-Fx/HYDRATE.

Figure 4- 16 Profiles of aqueous CH4 mass fraction of Problem 4 case 2 for (a) CMG STARS

(b) TOUGH-Fx/HYDRATE.

Figure 4- 17 Profiles of gas-water capillary pressure of Problem 4 case 2 for (a) CMG STARS

(b) TOUGH-Fx/HYDRATE.

Figure 4-18 Geometry of the cylindrical grid for Problem 5. 123

Figure 4-18 a Case A: Aqueous \& Gas Relative permeability curves. 128

Figure 4-18 b Case B: Aqueous \& Gas Relative permeability curves. 128

Figure 4-19 a Case A: Capillary pressure plotted against water saturation for Problem 5. 129

Figure 4-19 b Case B: Capillary pressure plotted against water Saturation for problem 5 130 
Figure 4-20 Gas Rates for problem 5 Cases A-1, A-2, A-3, A-4. ........................................... 136

Figure 4-21 Gas Rates for problem 5 Cases A-1, A-2, A-3, A-4.......................................... 137

Figure 4-22 Cumulative gas production for problem 5 Cases A-1, A-2, A-3, A-4 ................... 138

Figure 4-23 Cumulative water production for Problem 5 Cases A-1, A-2, A-3, A-4. ............... 139

Figure 4-24 Gas rates for problem 5 Cases B-1, B-2, B-3, B-4 ............................................... 140

Figure 4-25 Water rates for problem 5 Cases B-1, B-2, B-3, B-4........................................ 141

Figure 4-26 Cumulative gas production for problem 5 Cases B-1, B-2, B-3, B-4.................... 142

Figure 4-27 Cumulative water production for problem 5 Cases B-1, B-2, B-3, B-4................. 143

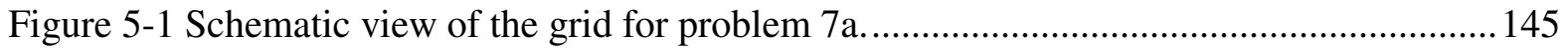

Figure 5-2 Aqueous and Gas relative Permeability curves for Problem 7a............................. 151

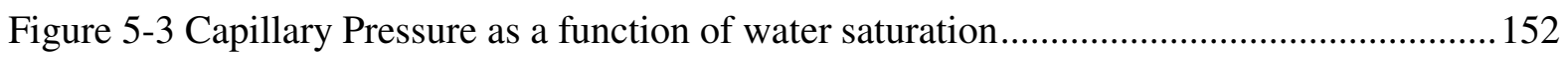

Figure 5-4 Gas rate and cumulative gas rate for 50 years using CMG STARS ........................159

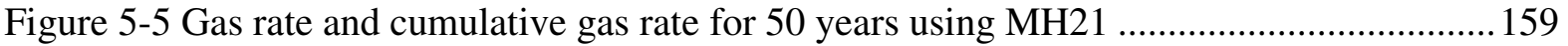

Figure 5-6 Water rate and cumulative water rate for 50 years using CMG STARS .................. 160

Figure 5-7 Water rate and cumulative water rate for 50 years using MH21 ........................... 160

Figure 5- 8 Schematic view of the grid for Problem 7b. ................................................... 161

Figure 5- 9 Aqueous and Gas relative Permeability curves for problem 7b............................ 166

Figure 5-10 Gas rate and cumulative gas rate for 50 years using CMG STARS ...................... 170

Figure 5-11 Gas rate and cumulative gas rate for 50 years using MH21 .............................. 171

Figure 5-12 Water rate and cumulative water rate for 50 years using CMG STARS ................ 171

Figure 5-13 Water rate and cumulative water rate for 50 years using MH21 .......................... 172

Figure 5-14 Gas rate and cumulative gas production for 50 years using CMG STARS ............ 177

Figure 5-15 Gas production rate and cumulative gas production for 50 years using MH21 .......177

Figure 5-16 Water rate and Cumulative water production for 50 years using MH21 ...............178

Figure 5-17 Water rate and Cumulative water production for 50 years using CMG STARS ..... 178

Figure 6-1 Effect of Porosity on gas production.................................................................. 181

Figure 6-2 Effect of permeability on gas production......................................................... 182

Figure 6-3 Effect of hydrate saturation on gas production ................................................... 183

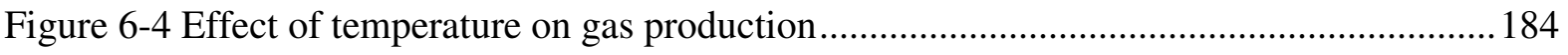

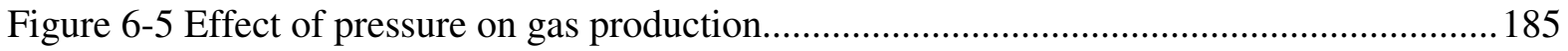

Figure 6-6 Effect of bottom- hole pressure on gas production ............................................... 186

Figure 6-7 Effect of free water saturation on gas production ................................................ 187

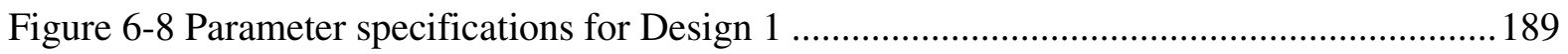




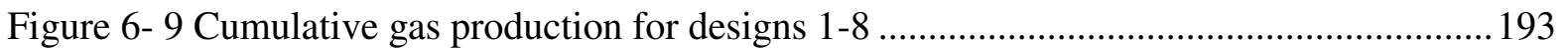

Figure 6-10 Effects of the parameters on gas production......................................................... 195

Figure 7-1 Hydrate saturation and Permeability distribution data from Mt Elbert Stratigraphic test well

Figure 7-2 Porosity and Irreducible water saturation data from Mt Elbert Stratigraphic test well

Figure 7-3 Gas production for Case 1, 2 and 3. Case 1 refers to the reservoir which includes anisotropy in permeability, porosity, hydrate saturation and irreducible water saturation. Only heterogeneity in hydrate saturation is considered in Case 2. Anisotropy in hydrate saturation, porosity and irreducible water saturation (50 layers) is considered in Case 3 .........................201 


\section{List of Tables}

Table 2-1 Different estimates of Methane Hydrates from 1973 to $2005^{22}$.................................. 15

Table 2-2 Worldwide Estimates of Gas Hydrates ${ }^{23}$............................................................... 16

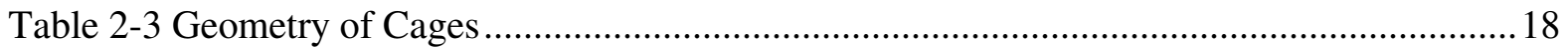

Table 2-4 Physical Properties of Methane Hydrates ${ }^{29}$...............................................................22

Table 3-1 Parameters and Specifications for Problem 1........................................................... 30

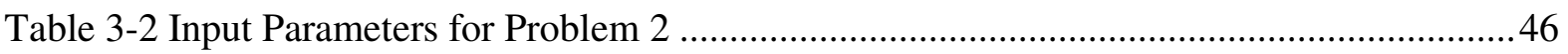

Table 4-1 Input Parameters and Specifications ..................................................................... 106

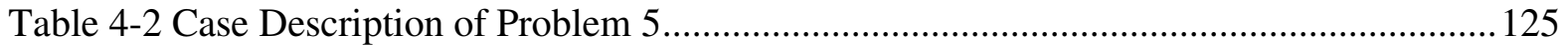

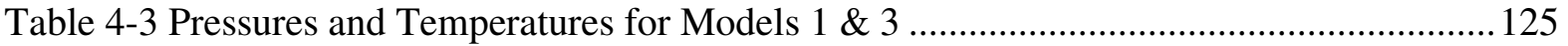

Table 4-4 Pressures and Temperatures for Models $2 \& 4$..................................................... 126

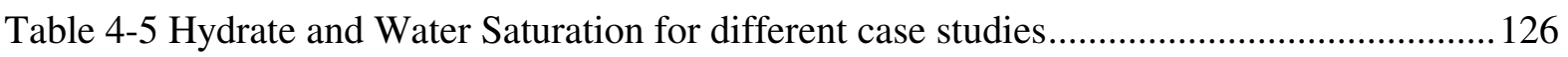

Table 4-6 Hydraulic and Thermal Properties for Problem 5 ................................................ 127

Table 4-7 Effect of discretization on production rates for problem 5..................................... 134

Table 4-8 Effect of hydrate saturation on production rates for Problem 5 ............................... 135

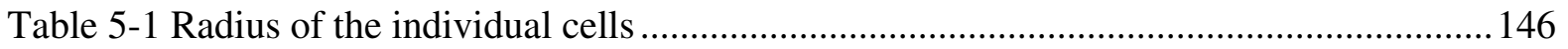

Table 5-2 Cell discretization in the $z$-direction for Problem 7a............................................. 147

Table 5-3 Pressure and Temperature values for the reservoir modeled in Problem 7a .............. 148

Table 5-4 Medium Properties for the Problem 5 ................................................................ 150

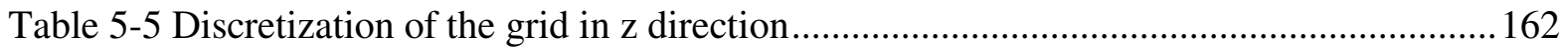

Table 5-6 Pressure and Temperature values for Problem 7b................................................. 163

Table 5-7 Medium Properties for Problem 7b ............................................................................. 166

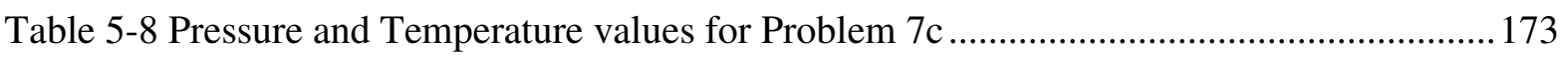

Table 6-1 Factors and their values used for OAAT effect calculations.................................... 180

Table 6- 2 Parameter specifications for different scenarios ..................................................... 190

Table 6-3 Plackett-Burman sensitivity analysis matrix ........................................................ 191

Table 6-4 Effects of variable input parameters on cumulative gas production .......................... 195

Table 6-5 Rankings for different parameters involved in each design .................................... 196 


\section{Introduction}

Gas Hydrates are non stoichiometric combination of gas and water molecules that form under conditions of high pressures and low temperatures. Hydrates are crystalline solids, very similar to ice, in which non-polar molecules are trapped inside the cages of water molecules. Non-polar molecules are typically low molecular weight gases which include natural gases like methane, ethane and propane. Hydrates are formed wherever suitable conditions of temperature and pressure exist. Methane hydrates are generally found in the Arctic and ocean floor at a depths greater than 500m. Naturally-occurring hydrates are mainly methane hydrates due to the availability of low molecular weight natural gas beneath the surface. Methane hydrates receiving increased attention due to increases in gas prices and because of their high energy density. One volume of hydrate on dissociation releases as much of 164 volumes ${ }^{1}$ of natural gas.

Methane hydrates represent a vast source of energy. It is estimated that the total amount of natural gas trapped inside the hydrates is approximately two times the total conventional oilgas reserves in the world ${ }^{2}$. The production of natural gas from hydrates in an economic manner poses a big challenge to today's scientific world. Different numerical reservoir simulators are developed to model the gas hydrate dissociation behavior. Over the years, different approaches have been used to solve the gas hydrate modeling problems but no unanimity reached. Every approach has its pros and cons. The National Energy Technology Laboratory (NETL) and the U.S Geological Survey (USGS) gas hydrate code comparison project $^{2}$ is the first of its kind and it aims at a worldwide understanding of the hypotheses involved in gas hydrate modeling and problem solving. 
Different reservoir simulators used in the code comparison study are

- $\quad$ TOUGH+HYDRATE ${ }^{3}$, developed at the Lawrence Berkeley National Laboratory (LBNL)

- $\mathrm{MH}-21^{4}$ Hydrate Reservoir Simulator (MH-21 HYDRES), developed by the National Institute of Advanced Industrial Science and Technology, Japan Oil Engineering Co., Ltd.

- HydrateResSim ${ }^{5}$ developed at the Lawrence Berkeley National Laboratory (LBNL).

- $\mathrm{CMG}_{\mathrm{STARS}}^{6}$ developed by COMPUTER MODELLING GROUP LTD.

- $\quad$ STOMP $^{7}$ developed by Pacific Northwest National Laboratory (PNNL).

- Code from University of Houston

This project is a part of the "Code Comparison Study of Different Hydrate Reservoir Simulators". It is intended to generate results for CMG STARS and to conduct sensitivity analysis for various reservoir parameters.

\subsection{Growing Energy demand and importance of Hydrate}

Energy is inevitable to human life and energy requirements around the world are ever increasing. Energy supply and demand plays an important role in the economic development of a country. Energy consumption is expected to increase more than $50 \%$ when projected to $2030^{8}$. Energy demand is expected to grow at an annual rate of $3 \%$ from 2004 to $2020^{9}$. Energy demand for developing countries like India and China is projected to grow at a higher rate $\left(3.75 \%\right.$ annually) due to rapid economic growth ${ }^{9}$. The majority of the World's Energy is generated from non-renewable resources like coal, petroleum and natural gas. Figure 1-1 shows energy consumption by fuel of United States starting from 1980 to $2030^{8}$. 


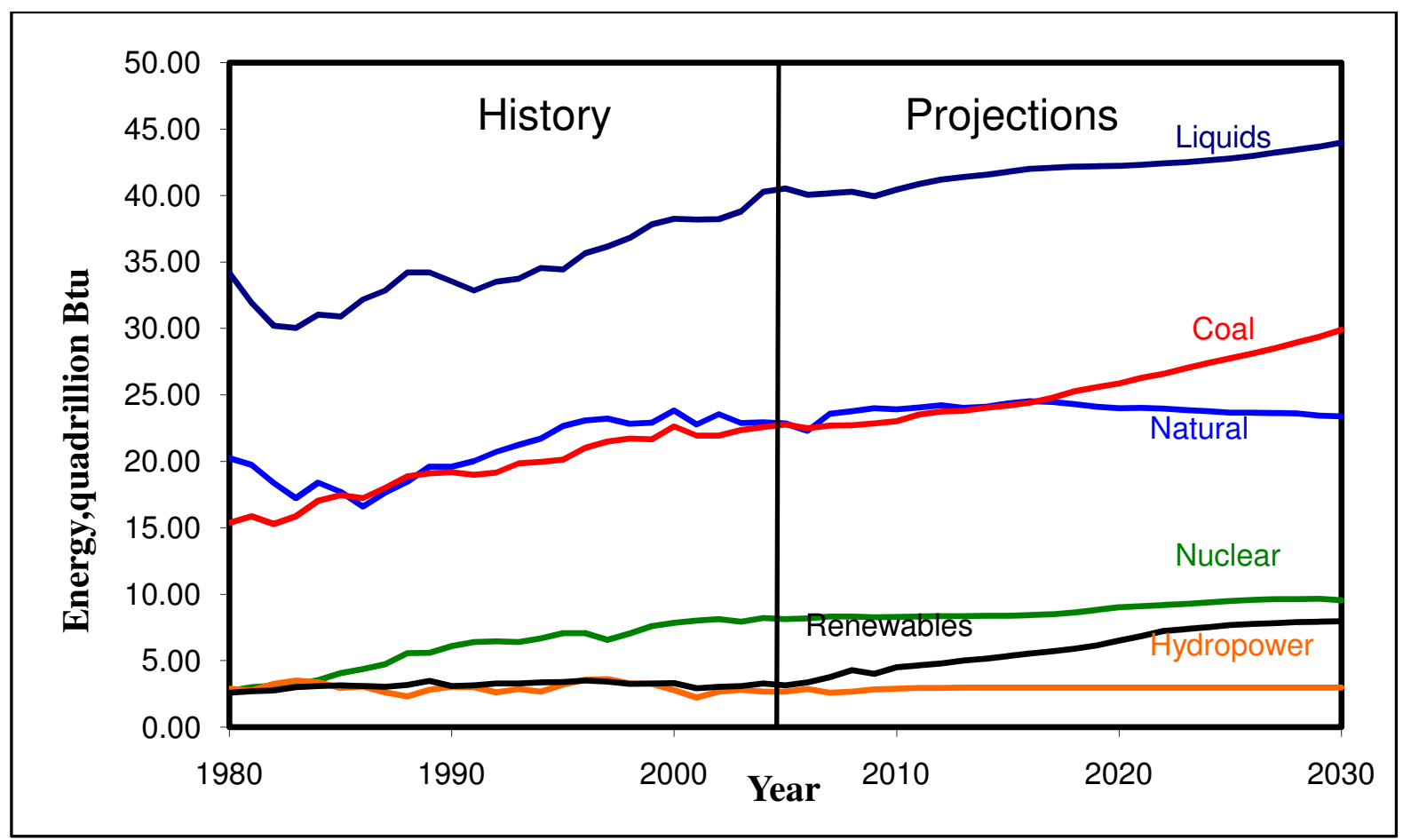

Figure 1-1 U.S Energy Consumption by Fuel, projected up to 2030

There is a significant increase in the projected values for energy consumption. In 2006 renewable energy contributed up to $18 \%$ of the total energy consumption, out of which $13 \%$ came from biomass, 3\% came from hydropower and rest from modern technologies like wind, geothermal and solar ${ }^{9}$. In spite of high gas prices and support from government policies the forecasts do not show much increase in the renewable energy. A small increase of 7.4 to $7.6 \%$ for renewable resources is all that is expected by $2030^{9}$. The three important fossil fuel sources which fuels United States in the future will be crude oil, coal and natural gas. The Energy Information Administration (EIA) reported that, in 2007, the U.S consumed 20 million bbl/day of petroleum products, out of which 12 million bbl/day was imported from other countries ${ }^{10}$. As U.S imports $60 \%$ of the crude oil, a fluctuation in the crude oil price could have a great impact on U.S economy. Figure 1-2 shows crude oil price 
fluctuations in the recent years. In 1994, the U.S imported crude oil at an average price of $\$ 15.54 /$ barrel and now in 2008 the average price is $\$ 116.59 / \mathrm{bbl}^{8}$.

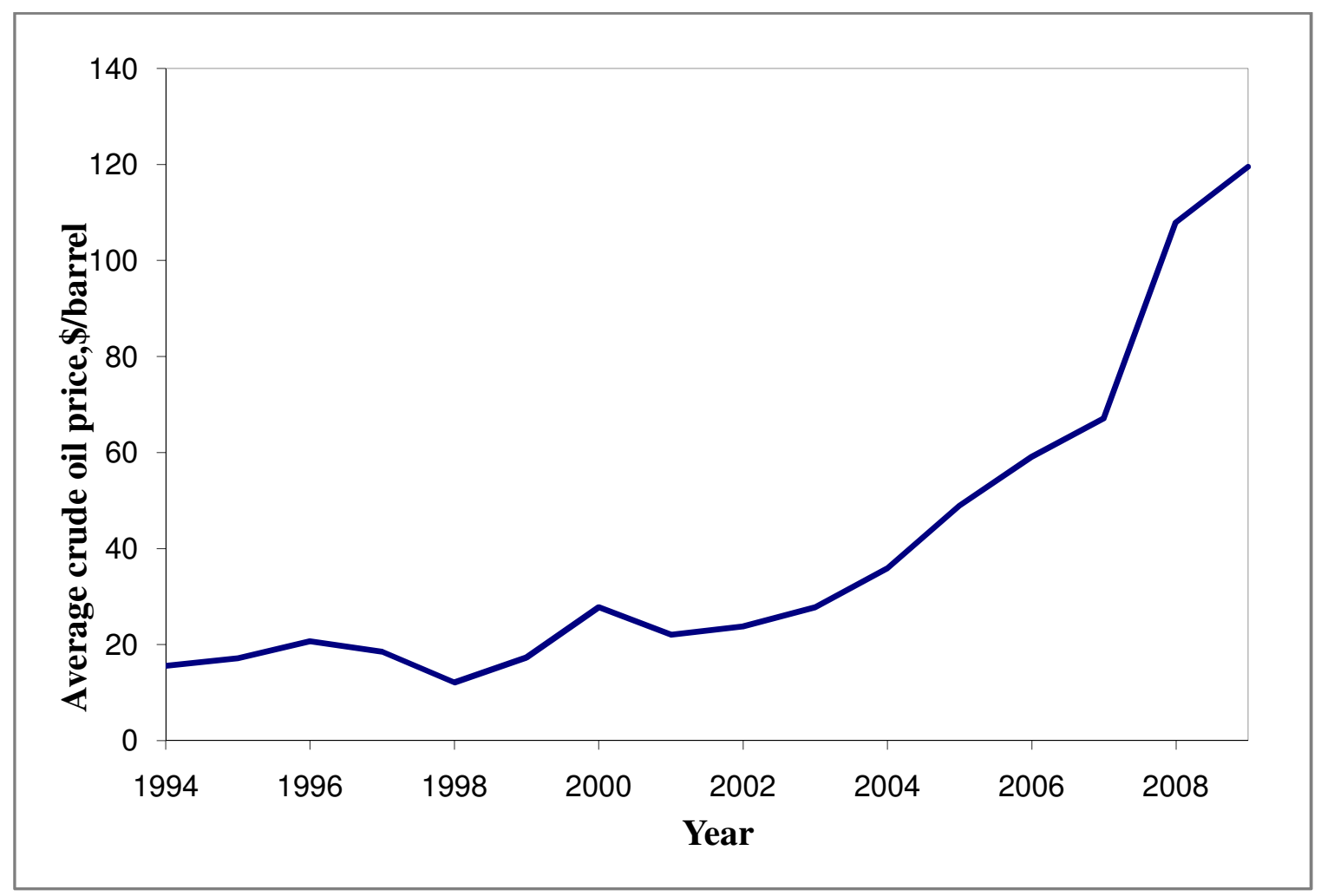

Figure 1-2 Average imported crude oil prices.

Natural gas is an important energy source contributing $23 \%$ of the total energy consumption in United States ${ }^{11}$. Electricity generation from natural gas is expected to increase from 752 billion kilowatt-hours to 930 billion $\mathrm{kWh}$ in $2030^{11}$. Natural gas is an important fuel for a wide range of industries and natural gas contributes to $19 \%$ of the total electricity generation $^{8}$. Compressed natural gas is used as a cleaner alternative to automobile fuels in various countries. U.S and World's natural gas consumption has increased significantly in recent years. The global natural gas consumption in 1990 was 73.4 trillion cubic feet (tcf) and it is projected to be 182 tcf in $2030^{8}$. 
The net imports of natural gas in the U.S. are projected to increase by $21 \%$ by the year 2030 and are shown in Figure $1-3^{8}$. Domestic conventional and unconventional natural gas production does not keep pace with increase in natural gas demand. Development of new alternatives like natural gas from methane hydrate can play major role in ensuring adequate future energy supplies for the U.S.

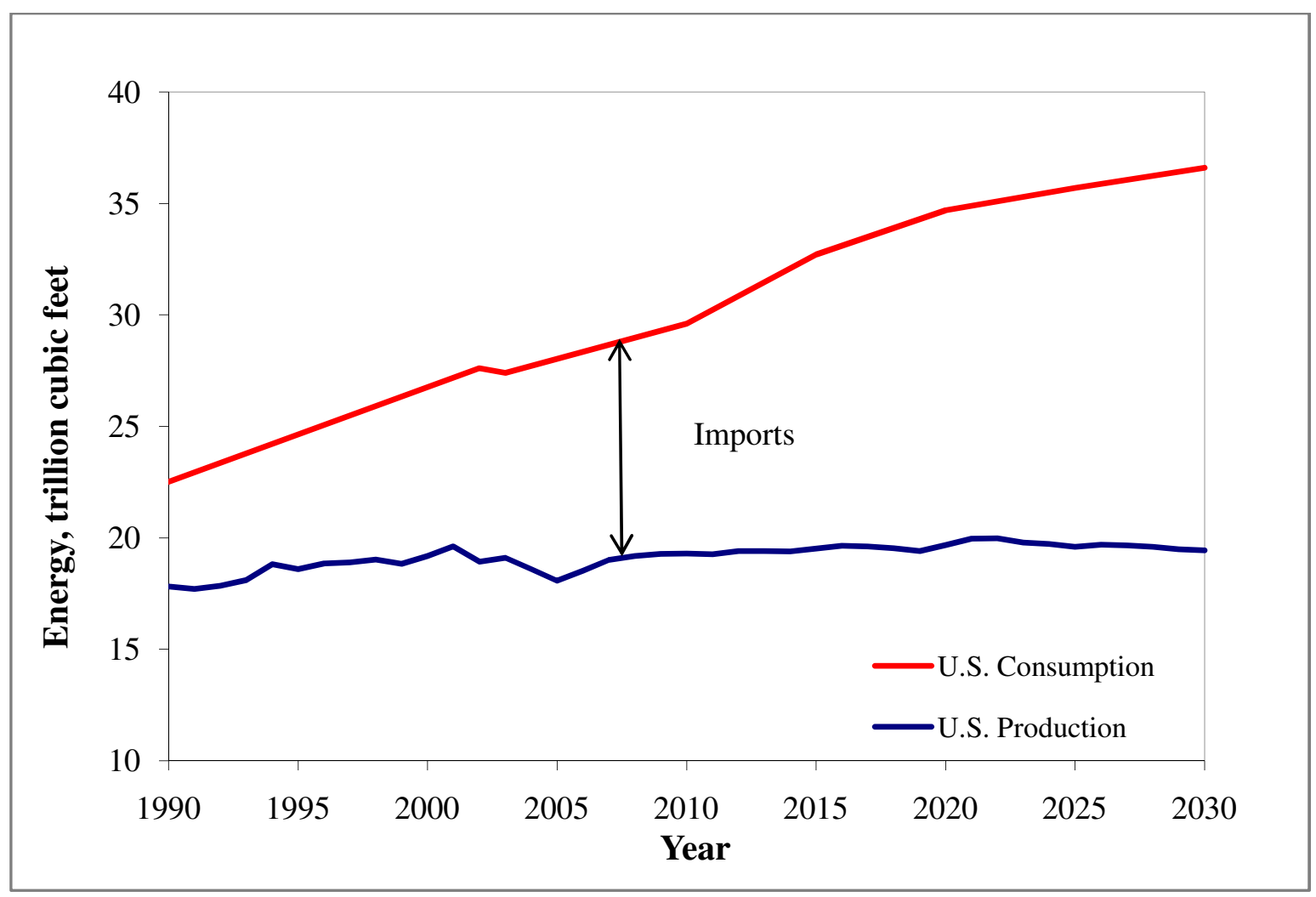

Figure 1-3 U.S Natural gas consumption and Production.

Methane, though it is itself a green house gas produces less carbon dioxide when combusted than other higher hydrocarbons. There is a vast reserve of Hydrate accumulations in the United States itself. A fraction of the methane that is recovered from hydrates can address the energy demand to a great level. The U.S. counts on natural gas a major part of its energy portfolio. Natural gas production by source is shown in Figure 1-4 $4^{8}$. Onshore and offshore conventional resources show a decline from 1990 to 2030. Production of gas from onshore 
unconventional resources like hydrates shows a tremendous increase when projected to 2030 . A large portion of the U.S onshore conventional resources have already been used for producing natural gas. The newly discovered reserves such as in Alaska are very remote and costly to exploit.

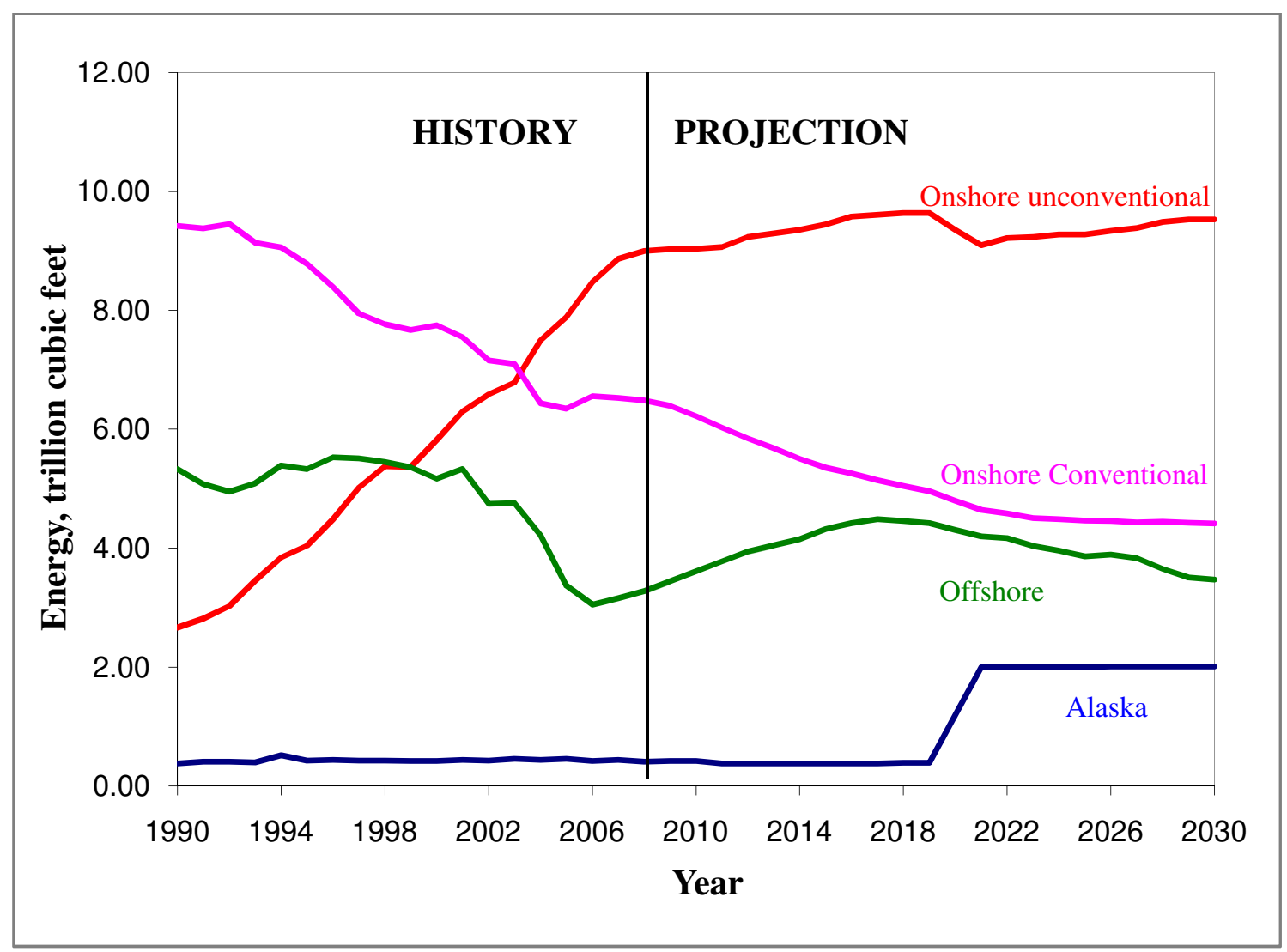

Figure 1-4 U.S Natural gas production by source, projections up to 2030.

\subsection{Reservoir simulations of gas hydrate reservoirs}

Reservoir simulation is a computational method of modeling the flow of fluid in porous media over time. A reservoir simulator is built on different mathematical models which represent the petrophysical properties of a reservoir. Usually a reservoir simulator is 
validated by performing history matching of the data obtained from different production wells. When the reservoir simulator is validated it is used as a tool to predict future production rates which are very important in making investment decisions. Gas Hydrates are a novel field that could potentially produce large amounts of fuel for the mankind but in reality, field scale experiments are prohibitively high. Also, the equipment required for gas production from a hydrate well costs millions of dollars. In this kind of scenario, the best thing that could be done is to get assurance from different reservoir simulators providing motivation for simulating gas hydrates. The crucial decisions about production potentials of hydrate wells have been taken based on reservoir simulations so far.

Gas Hydrate reservoirs require special production techniques due to the low temperature of the reservoir. Secondary hydrate formation and ice formation could make the dissociated gas difficult to produce due to the decreasing permeability of the reservoir due to solid formation. Hence, there are a number of problems like highly coupled heat flow, mass flow, phase transitions, physical and chemical properties that need to be addressed for a successful reservoir model. Based on reservoir simulations, hydrate reservoirs that contain free gas are easier to produce than those with no free gas because free gas can be easily removed from the reservoir. This causes depressurization of the reservoir and promotes hydrate dissociation. Reservoir simulators are an effective tool to decide what technique is best suited to a particular reservoir setting. 


\subsection{Recent developments in the production of natural gas from gas}

\section{hydrates}

The first hydrate test was carried out at the Mallik field in Canada in $1972^{12}$. Minor methane recovery was observed. A collaborative drilling program was carried out at Mallik field in $1998^{12}$ and hydrate bearing core samples were collected for research and laboratory purposes. A high concentration of hydrate was observed as a result of this drilling program. Later, in $2002^{12}$, at the same field a test well was drilled and 6 days of petro-physical data was collected. That test flared gas over a short period indicating that it was actually possible to recover energy through hydrate dissociation.

In 2004, hydrate bearing sediments were recovered by drilling shallow wells at the Nankai Trough in Japan ${ }^{12}$. Before this, in 1999-2000, a deep well was drilled for gas hydrates and conventional oil \& gas exploration as well.

In 2006, in India, coring, drilling and down hole logging of gas hydrates was performed and samples were recovered at ten different sites in order to study the distribution, the nature of gas hydrates, the flow processes and the geological factors that control hydrate formation in marine segments ${ }^{13}$.

In 2007, two days of experimental-scale tests were performed at the Mt. Elbert site on the North Slope ${ }^{14}$. Modular Dynamics Testing was performed and the flow and pressure build-up data collected indicated that gas was produced. The pressure build up data was used to calculate the permeability of the reservoir. At the Mallik site, a collaboration of Japan and Canada conducted a 60 hour flow test which reinforced the notion that production of gas 
from hydrate wells was feasible. In 2008, sustained gas flow was first reported from a hydrate well at the Mallik field and it was concluded that methane gas equivalent to that of coal bed methane well was produced ${ }^{15}$.

The economic viability of gas production from hydrates is not yet established but the tests are conducted to get an insight into technical feasibility of gas hydrates.

\subsection{International effort for the code comparison project}

In order to gain confidence in the predicted productivity of gas hydrate deposits, it is important to have a reliable model that can reliably forecast potential production scenario. To gain such confidence, it is essential that various models be studied and compared paving the way for a code comparison project on the international scale. The initiative of an international comparison of different reservoir simulators to model hydrates has been led by the National Energy Technology Laboratory (NETL) and the U.S. Geological Survey (USGS). The outcome of the project was expected to be the sharing of knowledge, cross validation of results of various simulators, and the acquired self-reliance for future production prediction techniques using those simulators.

The objective set for the participants of the project was to estimate the performance of different model reservoirs of varying properties subject to same reservoir parameters using different reservoir modeling programs. 


\subsection{Objectives of this study}

The international code comparison project is an effort to harmonize various reservoir programs and the study started with formulation of different problems of different complexity levels. The objective of this part of the study is to generate and validate results for the hydrate problems set by the code comparison project using CMG STARS. Various cases studied include homogenous and heterogeneous reservoirs. The sensitivity analysis of production rates as affected by different parameters is discussed.

\subsection{General project description}

A detailed literature review about various techniques of hydrate dissociation indicated that depressurization is the best method for production of gas from gas hydrates. This project explores different methods that are feasible to be used in production from gas hydrates using reservoir simulation techniques using CMG STARS.

The problems addressed in the project are called Problems 1-5 and Problem 7(a, b \& c). Problem 7 is based on the Mt. Elbert site and data from the Prudhoe Bay L-Pad unit and they are all solved using CMG STARS. Problem 1 is a simple one dimensional problem with no hydrate. It is designed to validate the changes of thermodynamic properties in a reservoir. Problem $2 \& 3$ have hydrate phase but different geometries of the 1-D grid. Problem 4 contains a cylindrical grid and both thermal and depressurization methods are modeled in this problem. Problem 5 is about a class II hydrate deposit in which hydrate is bound by two shale zones saturated with water. 
Data from the Mt. Elbert Stratigraphic Test Well inspired the Problem 7 formulation. Three cases of this problem, a, b \& c are studied assuming uniformity of certain parameters such as hydrate saturation, permeability etc. in the reservoir. Later, the effect of homogeneous and heterogeneous reservoirs on production rates is studied. The heterogeneity of the reservoir is recorded from the NMR well log data obtained from Mt. Elbert site. The heterogeneity of porosity, permeability and hydrate saturation is considered in the study.

Gas hydrates reservoir performance is controlled by a complex set of geologic and reservoir parameters. In order to utilize gas hydrate resources it is very important to understand the effect of each reservoir parameter on production rates. For this reason, a parametric study is

conducted for seven most important of the several reservoir parameters using design of experiments. Out of the different techniques studied, the Plackett-Burman design is most suitable to the situation. A Plackett-Burman design of size 8 is implemented since the number of factors is 7 . The seven parameters studied are permeability, porosity, hydrate saturation, bottom-hole pressure, free water saturation, temperature and pressure.

\subsection{Overview of the report}

This thesis documents the project findings and CMG STARS' solutions to problems set by the code comparison project team. A brief overview of the report is given below.

Chapter 1 describes the growing energy demand and importance of hydrates. It outlines the objectives and description of the project and introduces modeling of gas hydrate reservoirs and the importance of the study. 
Chapter 2 deals with literature review done for the project. It tells briefly about basic properties of gas hydrates, the structure of gas hydrates and the conventional methods of production of gas from gas hydrates.

Chapter 3 details the Problem descriptions for 1-D Cartesian systems which were called Problems 1-3 of the code comparison project and discusses their solutions obtained through CMG STARS.

Chapter 4 contains problem descriptions for 1-D and 2-D radial systems (Problem 4\&5) and their results using CMG STARS.

Chapter 5 explains problem descriptions for problem $7(\mathrm{a}, \mathrm{b} \& \mathrm{c})$ which were defined based on Mt. Elbert and Prudhoe Bay L-Pad deposits and the results for the same solved by using CMG STARS.

Chapter 6 presents a sensitivity analysis of different reservoir parameters using a PlackettBurman design.

Chapter 7 describes the importance of introducing heterogeneity to the reservoir.

Chapter 8 summarizes the study, includes conclusions and shows recommendations for future work. 


\section{Literature Review}

\subsection{History}

Gas Hydrates are non stoichiometric combination of Gas and Water molecules that form under conditions of high pressures and low temperatures ${ }^{16}$. The water molecules act as the host and the gas molecules are guest molecules embedded in the cages of ice due to Hydrogen bonding and van der Waal's forces. Specialists believe that in 1810, Sir Humphrey Davy first obtained hydrates by cooling a saturated solution of chlorine in water well below $9^{\circ} \mathrm{C}$. Also, there is evidence that hydrates were retrieved more than 30 years before Davy. Joseph Priestly in $1778^{17}$ had obtained $\mathrm{SO}_{2}$ hydrate by cooling an aqueous solution and by combining the gaseous $\mathrm{SO}_{2}$ in ice as well. Priestly also mentioned the effect of hydrate inhibition ${ }^{17}$.

\subsection{Hydrates in Natural gas Industry}

Natural Gas Hydrates are ice like solids that do not flow but rapidly grow and agglomerate to sizes that can block pipelines ${ }^{18}$. Gas Hydrates are a known menace in gas and oil pipelines since many decades. Hydrates are known to plug the pipelines that could cause unexpected fountains because of pipeline rupture. The formation of gas hydrates in natural gas pipe lines mainly depends on the pressure, temperature, and gas-water composition mixture. Hydrates can form in the pipelines whenever the pertinent temperature and pressure conditions are met. Hydrates can form in valves, lines, elbows etc. Hydrate plugs are formed at the hydrocarbon/water interface which eventually hinders flow and cause shutdown of the pipelines. A shut down cold well is very prone to hydrate formation. Gas Hydrates were known to clog cold area pipelines since 1900. 


\subsection{Occurrences}

Knowledge of occurrence of hydrates is incomplete. Majority of the gas hydrates are marine hydrates. Hydrate estimates in the world are based upon the assumptions made by each estimator. Different gas hydrate estimates by different people are shown in Table 2.1. The first estimate was made by Trofimuk ${ }^{19}$ in 1973 who assumed that hydrates occurred wherever suitable conditions of temperature and pressure exist. The most recent model was developed by klauda and Sandler ${ }^{20}$ in 2005 which estimates $120 \times 10^{15} \mathrm{~m}^{3}$ of methane at standard conditions of temperature and pressure. This is considered as a huge amount as it equals to the energy consumption of United States for 1000 years. This recent estimate includes 68 of 71 occurrences of hydrate. Widespread distribution of worldwide gas hydrate deposits are shown in Figure 2-1.

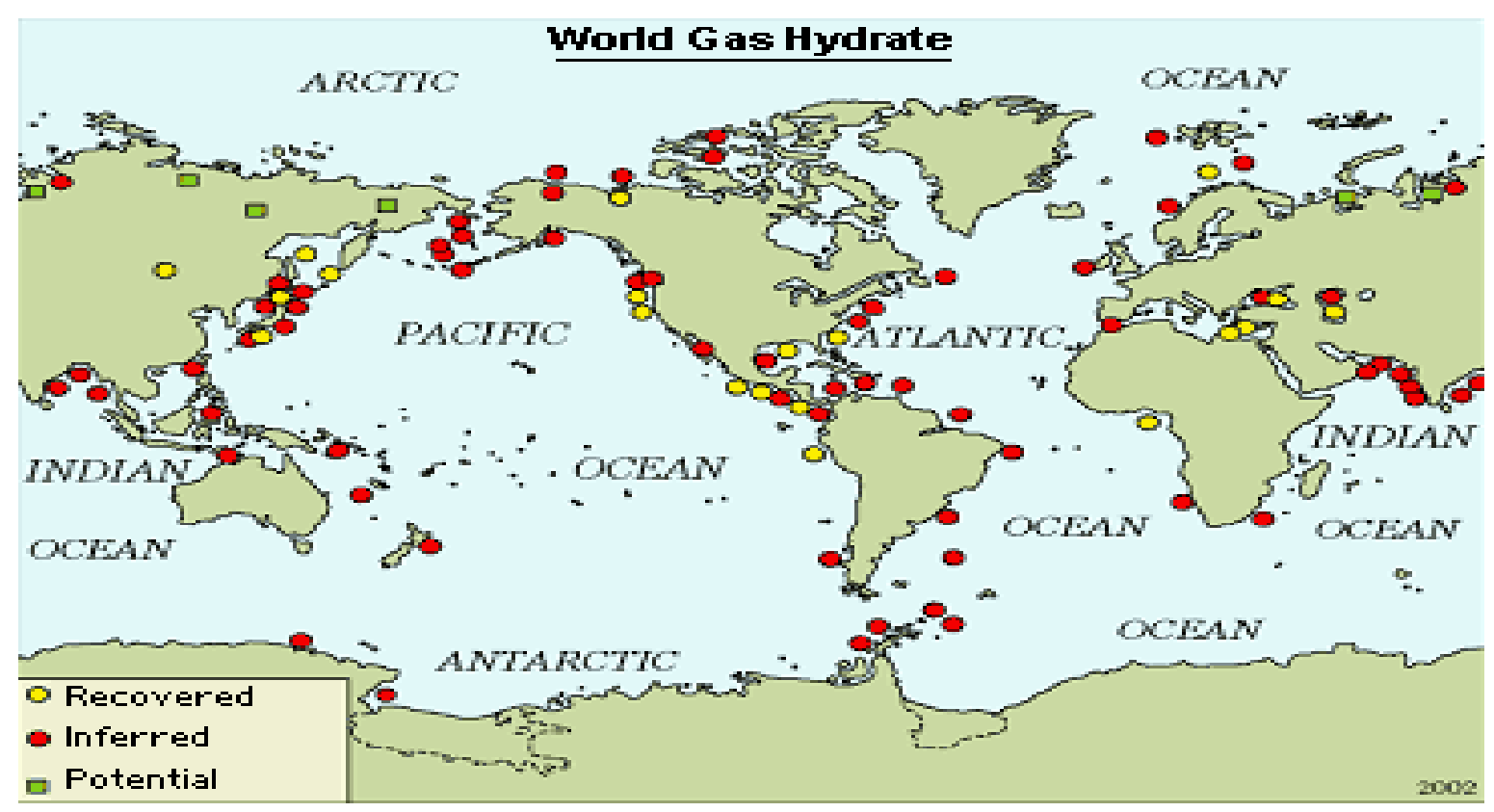

Figure 2-1 Locations of known and inferred gas hydrate occurrences ${ }^{21}$. 
Table 2-1 Different estimates of Methane Hydrates from 1973 to $2005^{22}$

\begin{tabular}{|l|c|l|}
\hline \multicolumn{3}{|c|}{ Estimates of In Situ Methane Hydrates } \\
\hline Year & CH $_{4}$ amount & \multicolumn{1}{|c|}{ citations } \\
\hline 1973 & $10^{15} \mathrm{~m}^{3}$ STP & \\
1977 & 3053 & Trofimuk et al. \\
1982 & 1135 & Trofimuk et al. \\
1981 & 1573 & Cheriskiy et al. \\
1981 & 120 & Trofimuk et al. \\
$1974 / 1981$ & 301 & McIver \\
1982 & 15 & Makogon \\
1988 & 15 & Trofimuk et al. \\
1988 & 40 & Kvenvolden and Claypool \\
1990 & 20 & Kvenvolden \\
1994 & 20 & MacDonald \\
1995 & 26.4 & Gornitz and Fung \\
1995 & 45.4 & Harvey and Huang \\
1996 & 1 & Ginsburg and Soloviev \\
1997 & 6.8 & Holbrook et al. \\
2002 & 15 & Makogon \\
2004 & 0.2 & Soloviev \\
2005 & 2.5 & Milkov \\
\hline
\end{tabular}

Hydrate potential in the world exceeds conventional gas resources and their values are given in Table 2-2. Estimating techniques are far more conservative today than yesterday. More accurate and precise ways of estimating the amount of hydrates present have come up since 1973, and the amount of gas hydrates estimated has been dropping ever since. 
Table 2-2 Worldwide Estimates of Gas Hydrates ${ }^{23}$

\begin{tabular}{|l|l|}
\hline Hydrate Potential & Value, Tcf \\
\hline World-Oceanic hydrate potential & 30,000 to $49,100,000 \times 10^{12}$ \\
United States Hydrate potential & $1,331 \times 10^{12}$ \\
Alaska Hydrate potential & $590 \times 10^{12}$ \\
India Hydrate Potential & $4,307 \times 10^{12}$ \\
Japan Hydrate Potential & $1,765 \times 10^{12}$ \\
World's conventional gas resources & $13,000 \times 10^{12}$ \\
\hline
\end{tabular}

\subsection{Hydrate structures}

Hydrates are formed due to the unusual behavior of water molecule and its orientation. Water molecule consists of one oxygen atom covalently bonded to two hydrogen atoms. The angle between the atoms is $104.5^{\circ}$. There are two unbonded electrons which induces partially negative charge on oxygen atom due to its high electro negativity relative to hydrogen atom. The partially induced charges result in one molecule link up with other water molecule in the form of bond which is called hydrogen bond. When the water molecules line up they arrange themselves in different patterns. Hydrates are formed due to this ability of water to form hydrogen bonds. When hydrates are formed the guest molecules and the host molecules are held together by van der Waals force. There is no bonding between the guest and the host molecules.

In ice water molecules are arranged in a hexagonal pattern. When hydrocarbon and water freezes at low temperatures it forms three different crystal structures (Structure I, II, H) 
depending upon the size of the hydrocarbon. These three different crystal structures are formed by the combination of different basic cavities. The basic cavities of hydrate structures are labeled as $n^{m}$ where $n$ is the number of edges and $m$ is the no of faces.

Pentagonal dodecahedron $\left(5^{12}\right)$ has 12 pentagonal faces with equal edge lengths and angles. Tetrakaidecahedron $\left(5^{12} 6^{2}\right)$ has 12 pentagonal faces and two hexagonal faces. Different other cavities like the irregular dodecahedron $\left(4^{3} 5^{6} 6^{3}\right)$ are given in Table 2-3.
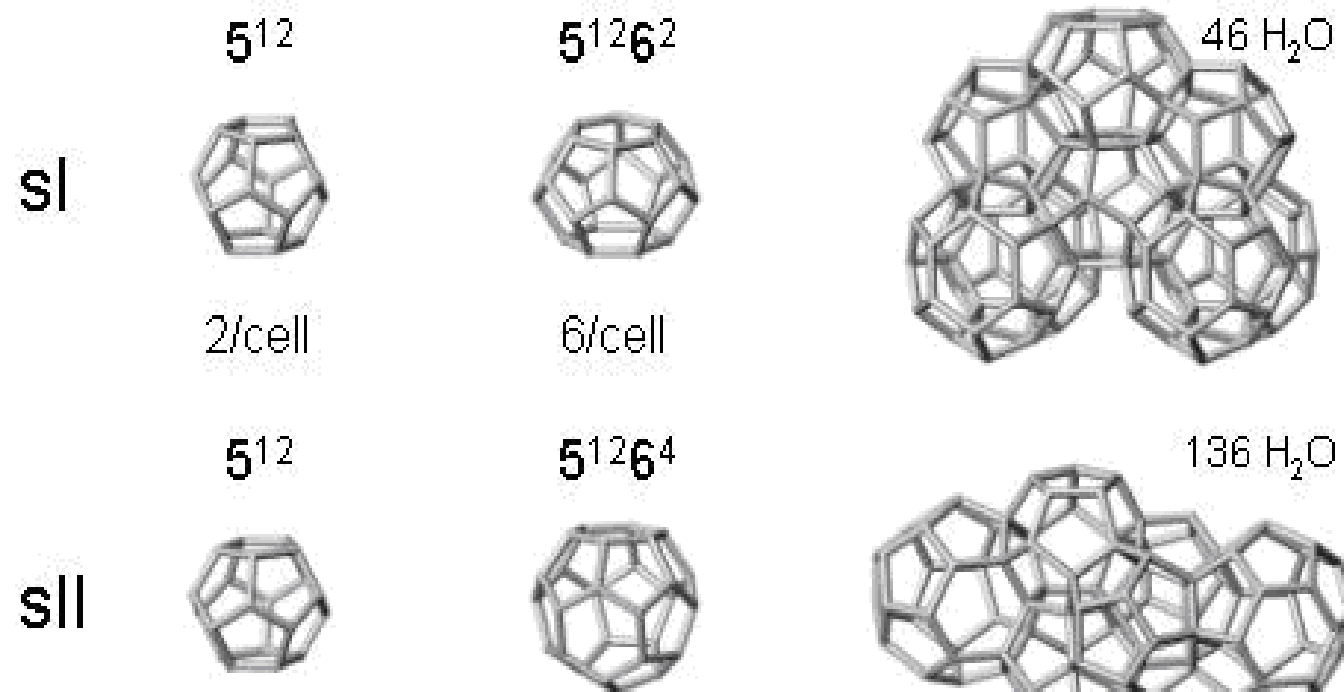

16/cell
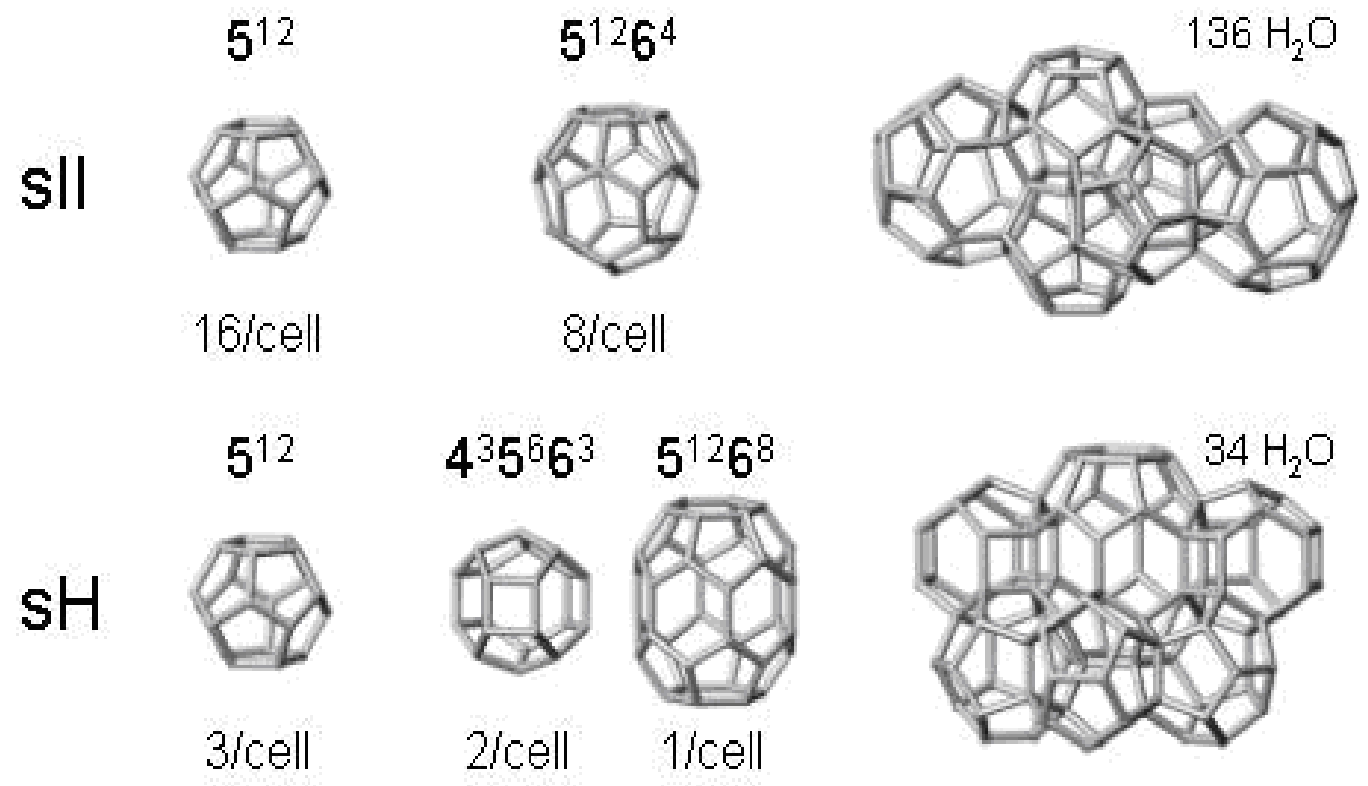

Figure 2-2 Different structures of gas hydrates. 


\section{Structure I}

This structure was first observed for Ethylene oxide hydrate in 1965 by MC Mullam and Jeffre $^{24}$. It is a Base centered cubic structure with a lattice constant of $12 \AA$, formed by smaller guest molecules like $\mathrm{CH}_{4}, \mathrm{C}_{2} \mathrm{H}_{6}, \mathrm{CO}_{2}$ and $\mathrm{H}_{2} \mathrm{~S}$. There are 46 water molecules arranged to accommodate 8 guest molecules of size 4-6 $\AA$ in diameter. There are two small cages of pentagonal dodecahedron and six tetrakaidecahedron. Structural composition is $8 \mathrm{G} .46 \mathrm{H}_{2} \mathrm{O}$ where $\mathrm{G}$ is the guest molecule.

\section{Structure II}

This Structure was observed by Mc Mullan and Jeffrey for a $\mathrm{H}_{2} \mathrm{~S}$ hydrate in 1965. It is a face centered cubic structure which can accommodate 24 guest molecules. It has 16 small and 8 large cages with 136 water molecules per unit cell. Hydrate with guest molecules like propane, Iso-butane usually form this structure. Lattice constant is $17.3 \AA$. Structural composition is $24 \mathrm{G} .136 \mathrm{H}_{2} \mathrm{O}$.

Table 2-3 Geometry of Cages

\begin{tabular}{|c|c|c|c|c|c|c|c|}
\hline Structure & \multicolumn{2}{|c|}{ I } & \multicolumn{2}{|c|}{ II } & \multicolumn{3}{|c|}{$\mathrm{H}$} \\
\hline Cavity & Small & Large & Small & Large & Small & Medium & Large \\
\hline Description & $5^{12}$ & $5^{12} 6^{2}$ & $5^{12}$ & $5^{12} 6^{4}$ & $5^{12}$ & $4^{3} 5^{6} 6^{3}$ & $5^{12} 6^{8}$ \\
\hline Number of & & & & & & & \\
\hline & 2 & 6 & 16 & 8 & 3 & 2 & 1 \\
\hline Average cavity & & & & & & & \\
\hline $\operatorname{radius}(\AA)$ & 3.95 & 4.33 & 3.91 & 4.73 & 3.94 & 4.04 & 5.79 \\
\hline Variation in radius $(\%)$ & 3.4 & 14.4 & 5.5 & 1.73 & 4.0 & 8.5 & 15.1 \\
\hline $\begin{array}{l}\text { No. of water } \\
\text { molecules/cavity }\end{array}$ & 20 & 24 & 20 & 28 & 20 & 20 & 36 \\
\hline
\end{tabular}




\section{Structure H}

It was first identified by Ripmester ${ }^{25}$ in 1987 . These crystals have large volume capacity and can accommodate big molecules like n-butane which has a diameter of $7.1 \AA$. Structure H is composed of three different types of cavities. It contains 34 water molecules associated with three $5^{12}$ cavity guest molecules, two $4^{3} 5^{6} 6^{3}$ cavity guest molecules and one $5^{12} 6^{2}$ cavity guest molecules. Smaller guest molecules, such as $\mathrm{CH} 4, \mathrm{~N} 2$ and $\mathrm{CO} 2$ occupy $5^{12}$ cavities, and large guest molecules such as 2-methylbutane, methylcyclopentane, methylcyclohexane, ethylcyclohexane and cyclooctane occupy $4^{3} 5^{6} 6^{3}$ cavities. It bears repeating, Type $\mathrm{H}$ hydrates only form if another, small molecule is present.

Structure I

Biogenic

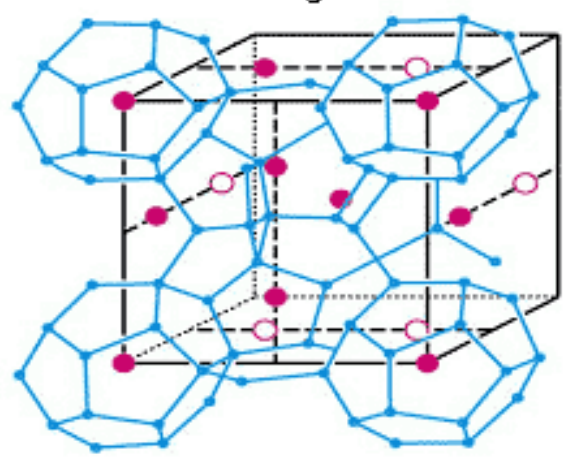

Structure II

Thermogenic

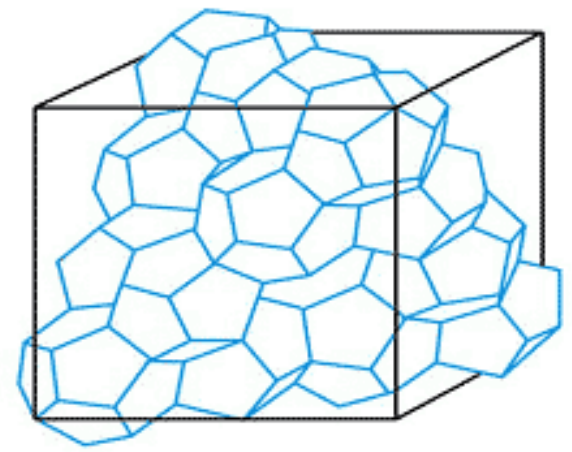

Figure 2-3 Structure I and II type hydrate.

At high pressure it is observed that there is a transition from one structure to the other ${ }^{26}$. For example argon hydrate forms structure II and is stable at normal pressure (<30MPa). When the pressure is increased to $0.5 \mathrm{GPa}$ it forms structure $\mathrm{H}$. Lot of concern in the literature is expressed about the lattice distortions due to change in pressure. 


\subsection{Stability}

Hydrates are formed at conditions of low temperature and high pressure. The required conditions for the hydrate to be stable are

- Low temperature

- High pressure

- Availability of water molecules

- Availability of gas molecules

Gas hydrates are stable in ocean floor sediments at a water depth of $600 \mathrm{~m}$ and in permafrost regions of depth $150 \mathrm{~m}^{27}$.

The figure shows the hydrate stability zone both in permafrost and in oceanic sediments. The dashed line represents geo-thermal gradient. The slopes of the dashed lines are different due to different thermal conductivity which effect thermal gradient. The phase-boundary line is obtained from pressure-temperature Equilibrium curve. The region between the phaseboundary line and the dashed line represents hydrate stability zone. These figures are based upon hydrates which are formed by methane. If we consider other heavy natural gases like propane butane we can observe an increase in the depth of the hydrate stability zone due to the shift of the phase-boundary line. The hydrates which are closer to the phase boundary line dissociates easily. 

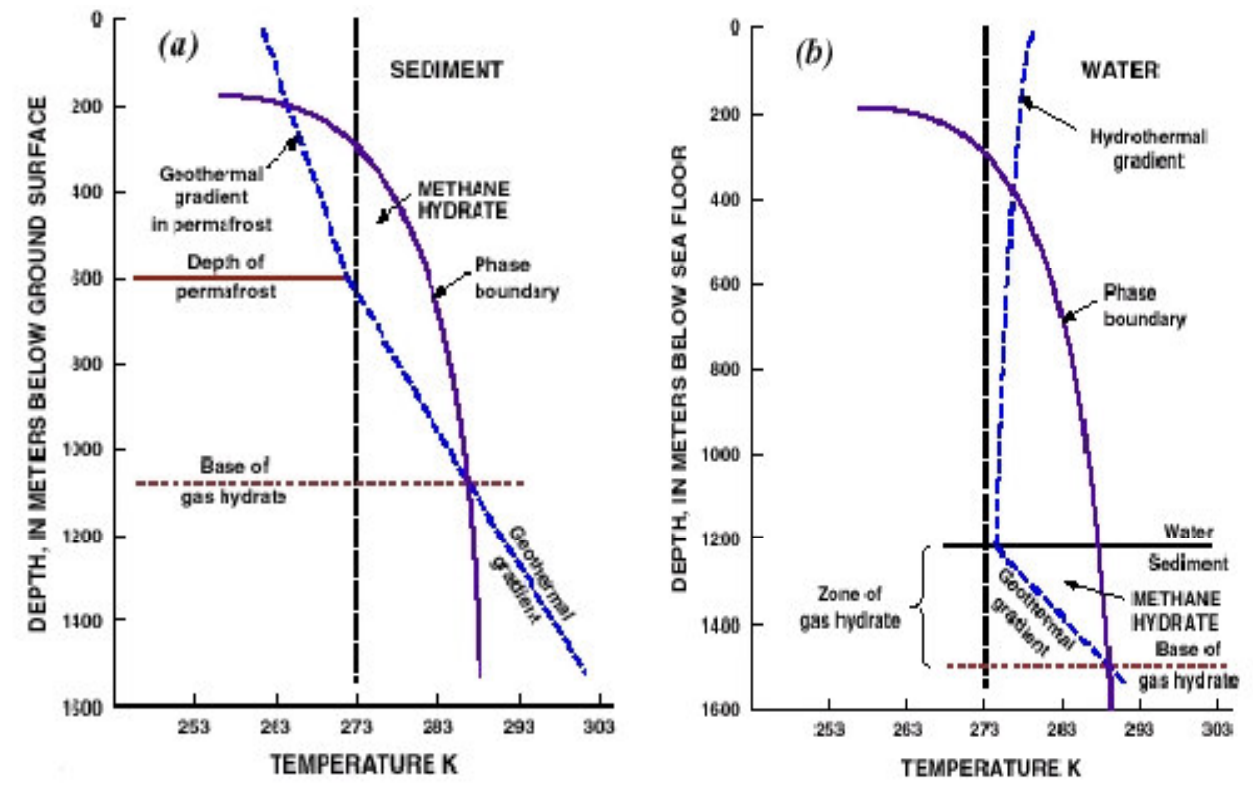

Figure 2-4 Methane Hydrate Stability Zones28 (a) Permafrost Regions (b) Oceanic Regions.

\subsection{Hydrate Properties}

Methane molecules are tightly packed in a lattice of water molecules due to crystallization forces. Methane hydrates has the highest energy density of any naturally occurring from of methane. Density of methane hydrate is a function of methane saturation and is approximately $0.9 \mathrm{~g} / \mathrm{cm}^{3}$. Heat of hydrate formation and dissociation are equal in magnitude but of opposite sign. Methane hydrate formation enthalpy at $273{ }^{\circ} \mathrm{K}$ is $54 \mathrm{~kJ} / \mathrm{mol}^{29}$.Hydrates have a heat capacity of $257 \mathrm{~kJ} / \mathrm{mol}$ at constant pressure. Hydrate properties are similar to ice; Table 2-3 shows physical properties of ice and hydrate. Pressure-Temperature Equilibrium curve is given in Figure 2-5. 
Table 2-4 Physical Properties of Methane Hydrates ${ }^{29}$

\begin{tabular}{|c|c|c|}
\hline Property & Ice & Hydrate \\
\hline Dielectric constant at $273^{\circ} \mathrm{K}$ & 94 & 58 \\
Water molecule reorientation time at $273^{\circ} \mathrm{K}(\mu \mathrm{sec})$ & 21 & 10 \\
Isothermal Young's modulus at $268^{\circ} \mathrm{K}(109 \mathrm{~Pa})$ & 9.5 & 8.4 \\
Poisson' ratio & 0.33 & 0.33 \\
Bulk modulus $\left(272^{\circ} \mathrm{K}\right)$ & 8.8 & 5.6 \\
Shear modulus $\left(272^{\circ} \mathrm{K}\right)$ & 3.9 & 2.4 \\
Bulk density $\left(\mathrm{gm} / \mathrm{cm}^{3}\right)$ & 0.916 & 0.912 \\
Adiabatic bulk compressibility at $273^{\circ} \mathrm{K} 10^{-11} \mathrm{~Pa}$ & 12 & 14 \\
Thermal Conductivity at $263^{\circ} \mathrm{K}(\mathrm{W} / \mathrm{m}-\mathrm{K})$ & 2.25 & $0.49 \pm 0.02$ \\
Heat of Fusion $(\mathrm{KJ} / \mathrm{mol})$ & 6 & $54($ measured $)$, \\
& & 57 (calculated $)$ \\
\hline
\end{tabular}

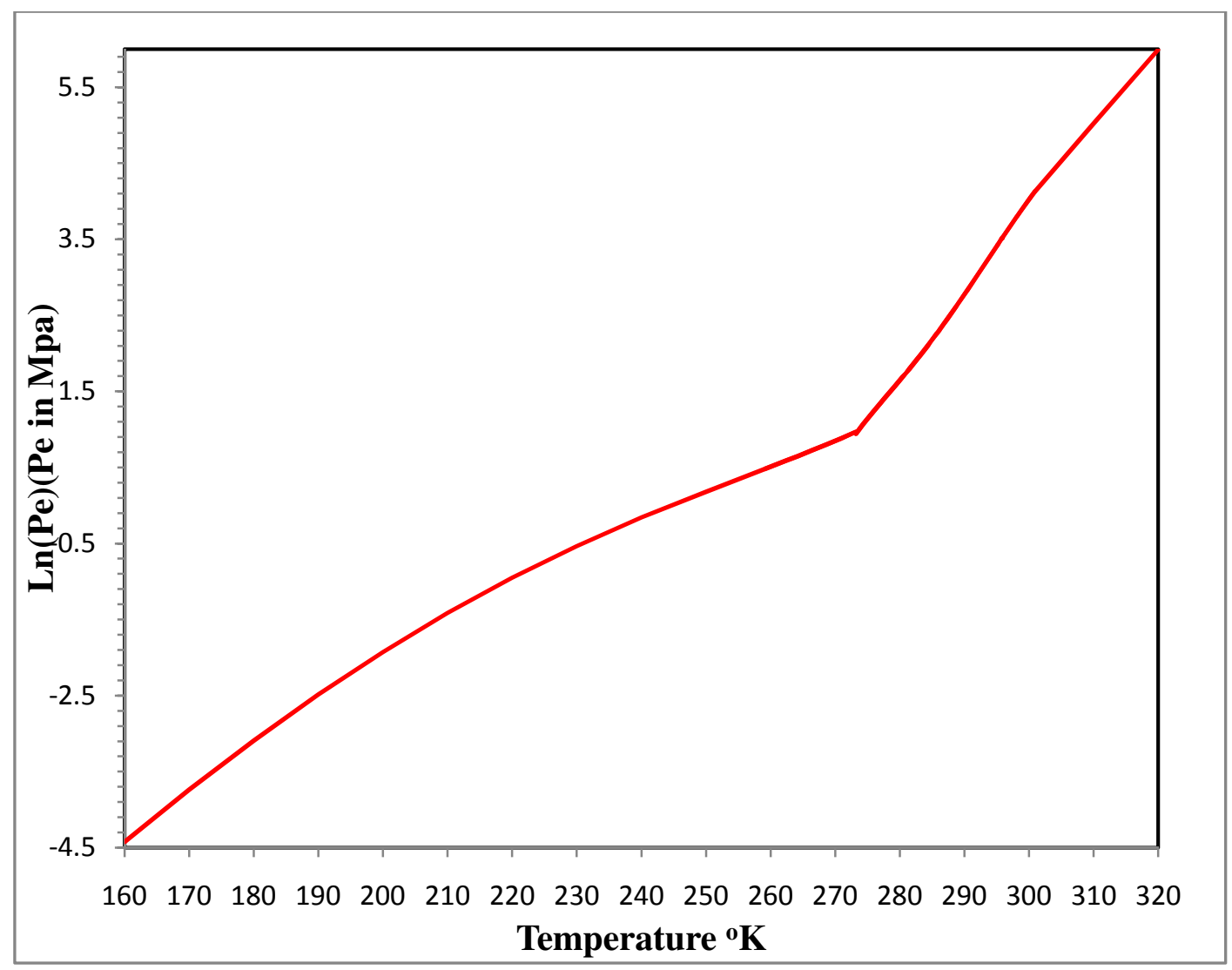

Figure 2-5 Equilibrium Pressure-Temperature relationship of methane hydrates ${ }^{3}$. 


\subsection{Introduction to CMG STARS}

STARS (Steam Thermal and Advanced Processes Reservoir simulator) ${ }^{6}$ are a new generation reservoir simulator developed by Computer Modeling group Ltd for modeling the flow of three phases, multi-component fluids.

STARS can be used to model compositional, steam, geo mechanical, dispersed component (polymers, gels, fines, emulsions, and foams) and in-situ combustion process. STARS uses a discretized wellbore model which improves modeling by discretizing the well bore and solving the resulting coupled well bore and reservoir flow problem simultaneously

The adaptive implicit mode in STARS decides from time-step to time-step which blocks must be solved in implicit or explicit modes. Local Grid Refinement can be applied to Cartesian, cylindrical and mixed coordinates to match as closely as possible to the geological model. Chemical reactions between components can also be specified with fixed rate dependence.

\subsection{Role of hydrates in climatic change}

Gas hydrates are formed at conditions of high pressure and low temperature. They are not stable at room temperatures. Today, gas hydrates are considered as a future energy source because lot of gas is trapped inside the hydrates. The hydrate reservoir is so large that a small fraction of methane release can have a good impact on Earth's climate. Hydrates dissociate to give gas and water when they are out of the stability zone. Rise in sea temperature can trigger hydrate dissociation releasing methane into the atmosphere. Methane is a powerful greenhouse gas, about 20 times stronger than $\mathrm{CO}_{2}{ }^{30}$. Global concentrations have been 
increasing during the past due to various reasons. The figure shows methane concentration in the atmosphere from 1980 to $2004^{31}$.

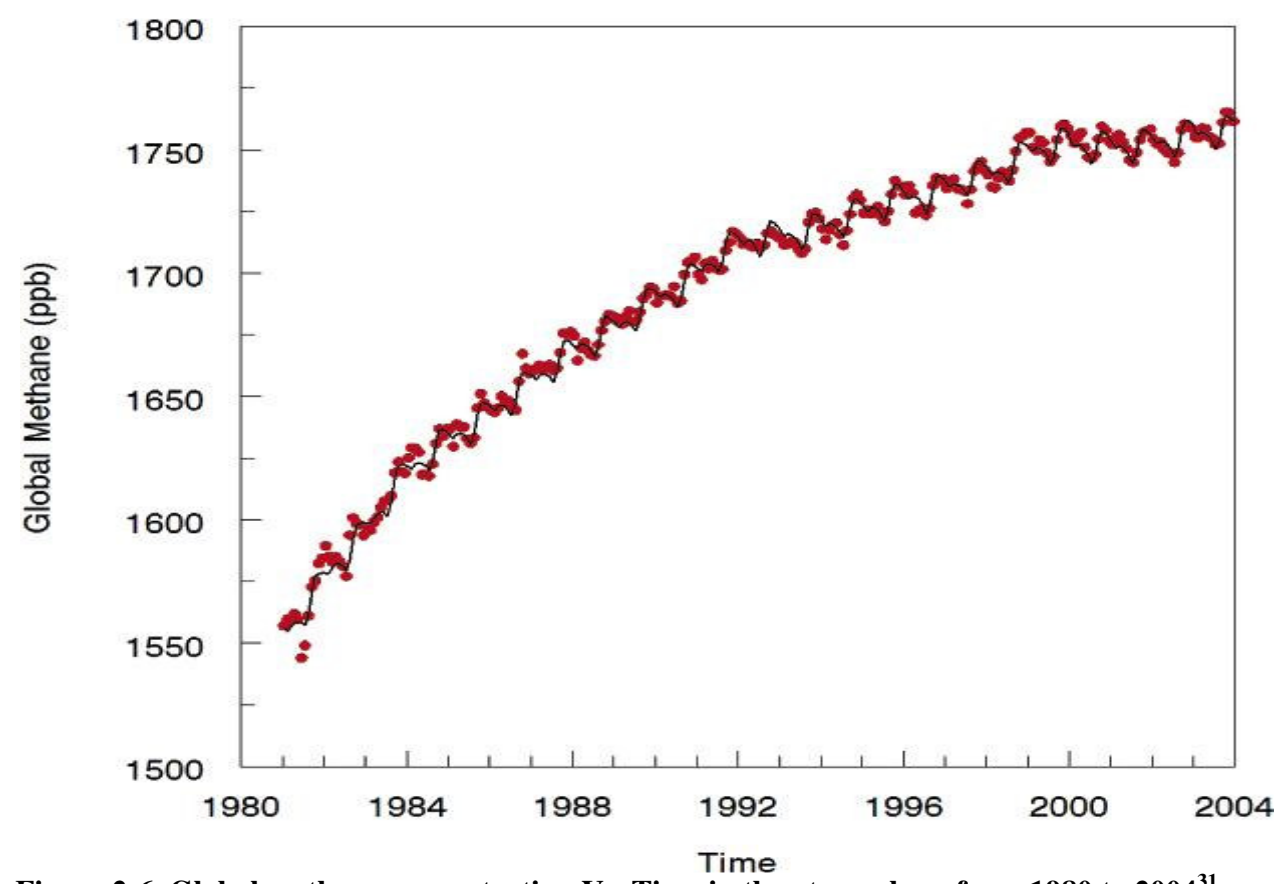

Figure 2-6 Global methane concentration Vs. Time in the atmosphere from 1980 to $2004^{31}$.

$\mathrm{CO}_{2}$ and $\mathrm{CH}_{4}$ are the dominant greenhouse gases in the atmosphere. Methane once released into the atmosphere oxidizes to $\mathrm{CO}_{2}$. The necessary intermediate ' $\mathrm{OH}$ ' for this oxidation process is provided by the sunlight. $\mathrm{CH}_{3}$ is a reactive radical compound which immediately reacts with water vapor and gases to form $\mathrm{CO}_{2}{ }^{32}$.

$$
\mathrm{CH}_{4}+\mathrm{OH} \rightarrow \mathrm{CH}_{3}+\mathrm{H}_{2} \mathrm{O}
$$

Sea Pockmarks are formed when methane gas is explosively vented into the atmosphere by decomposition of hydrates. Warming or sea level fall may trigger hydrate dissociation provoking Landslides, causing tsunamis which have an effect on an entire ocean basin. Some 
calculation also shows that landslides can release up to $5 \mathrm{G}$ tons of methane into the atmosphere ${ }^{33}$.

Deep ocean temperature change has been detected at intermediate depths due to anthropogenic greenhouse gas warming ${ }^{33}$. It is important to take this gas out of the gas hydrates and use it as a fossil fuel before it causes an impact on earth's climate.

\subsection{Conventional methods for producing gas from hydrates}

Methods of dissociation of hydrates are based on shifting the thermodynamic equilibrium of the three phase system (water-hydrate-gas).Gas can be produced from hydrates either by changing the pressure and temperature of the hydrate bearing media or by injection of inhibitors. Three main methods for producing gas from hydrates are Depressurization Pressure is reduced below the equilibrium value at a fixed temperature, Thermal stimulation - Temperature is increased to trigger hydrate dissociation and adding inhibitors which shifts the pressure temperature equilibrium.

\section{Depressurization}

Depressurization is often considered the best method for commercial production of hydrates. In this case a production well is drilled into the hydrate reservoir and a pressure difference is created between the wellbore and adjacent blocks. Pressure reduction frees the methane molecules from hydrate. A reduction in the reservoir pressure is obtained by removing the associated free gas or formation water. Hydrate dissociates giving gas and water molecules, which migrate towards the wellbore. Different models were developed to describe the 
process of hydrate decomposition in the porous media. This method is economically feasible as there is no extra heat to be introduced into the system.

\section{Thermal Injection}

In this method heat is introduced into the hydrate bearing layer through an injector well. Injection wells require high pressure pumps to inject water or steam into the reservoir. The fluids injected are generally hot fluids which rises the temperature of the hydrate layer causing hydrate dissociation. Methane gases mix with hot water and return to the surface. Hydrate bearing layers are generally found in permafrost and in ocean's at a depth of $150 \mathrm{~m}$ and $600 \mathrm{~m}$ respectively. Considering heat loses, lot of energy is being wasted to provide heat to the hydrate layer. It is not economically feasible to produce gas from this method.

\section{Adding Chemical Inhibitors}

Commonly used inhibitors are salts, alcohols and glycols. Injection of inhibitors shifts the pressure-temperature equilibrium leading to rapid dissociation of gas hydrates. In this method of production of gas from gas hydrates inhibitors are injected from the surface to the hydrate bearing sediment. When the inhibitor is added through a well, it does not necessarily come into contact with the entire hydrate bearing sediment but this process of dissociation is well accepted for an initial hydrate dissociation which is later followed by depressurization. 


\section{3: 1-D Cartesian systems: Problems and Solutions}

The problems that will be discussed in this chapter are the result of an effort by the U.S. D.O.E. and U.S.G.S. to reach a consensus between various gas hydrate reservoir simulation codes. They have been collectively formulated by a team of researchers working on gas hydrate reservoir modeling. Certain parameters are fixed in this Code Comparison Project for each problem and these parameters are constant among every reservoir simulator so that all the simulators captured the basic properties of the hydrate model in the same way. The problems start with simple cases and become more advanced and complex as the project proceeds.

The project starts with a relatively simple case and it is named Problem 1, in which there is only one dimension and there is no hydrate phase. The objective of the problem is to study the mass and heat flow in a porous media in the defined one dimensional domain.

The next case, called Problem 2, is a similar grid to that of problem 1; the only difference is the presence of gas hydrate in one half of the domain. There will be a hydrate phase in all the problems of this study hence forth. High temperature in the other half of the domain leads to dissociation of the hydrate and hence the gas-flow in the entire domain. The simulation is continued until equilibrium is attained in the domain.

Problem 3 has three different cases. It is a one dimensional problem with different grid dimensions than Problems $1 \& 2$. The three different cases modeled in this problem are adapted basically from the different techniques proposed to produce gas from hydrate wells. In the third case of Problem 3, the possibility of ice formation is included to make it a more complex situation in the reservoir. 


\subsection{Problem 1}

A closed horizontal, one-dimensional domain, $20 \mathrm{~m}$ in length is considered as the base case for the NETL USGS gas hydrate code comparison project. This simplified horizontal domain is used to remove gravitational body forces from the problem. The gas hydrate phase is not considered in this case to avoid complexities, the only water- $\mathrm{CH}_{4}$ system is selected in the entire domain. The whole $20 \mathrm{~m}$ horizontal domain is discretized uniformly into 20 grid cells each of length $1 \mathrm{~m}$. The grid is defined in such a way that there is no mass and heat flow outside the blocks, like a closed, isolated system. High pressure, temperature gradients and complete aqueous saturation conditions are specified in the first 10 grid cells and aqueous unsaturated conditions in the next 10 grid cells. As the simulation proceeded, equilibrium conditions are obtained in the entire domain due to mass and heat flow in the domain. The results of simulations of methane hydrate formations in geological media mainly depend upon how the tool or the simulator calculates the thermodynamic and transport properties. As there is no gas hydrate there is no dissociation or formation of hydrate.

Different processes simulated in the case are

- Heat transfer in the multi-fluid porous media with phase-advection

- Aqueous-gas multi fluid flow with phase transition from aqueous saturated to unsaturated

- Methane solubility changes with pressure and temperature

- Change in the thermodynamic and transport properties with pressure and temperature. A schematic of the grid is shown in Figure 3-1. Considering $x$ as the horizontal distance, the pressure and temperature at three different locations $(x=0,10 \mathrm{~m}, 20 \mathrm{~m})$ are specified in the 
problem. The same properties for other grid cells are calculated based on their gradients in the horizontal direction.

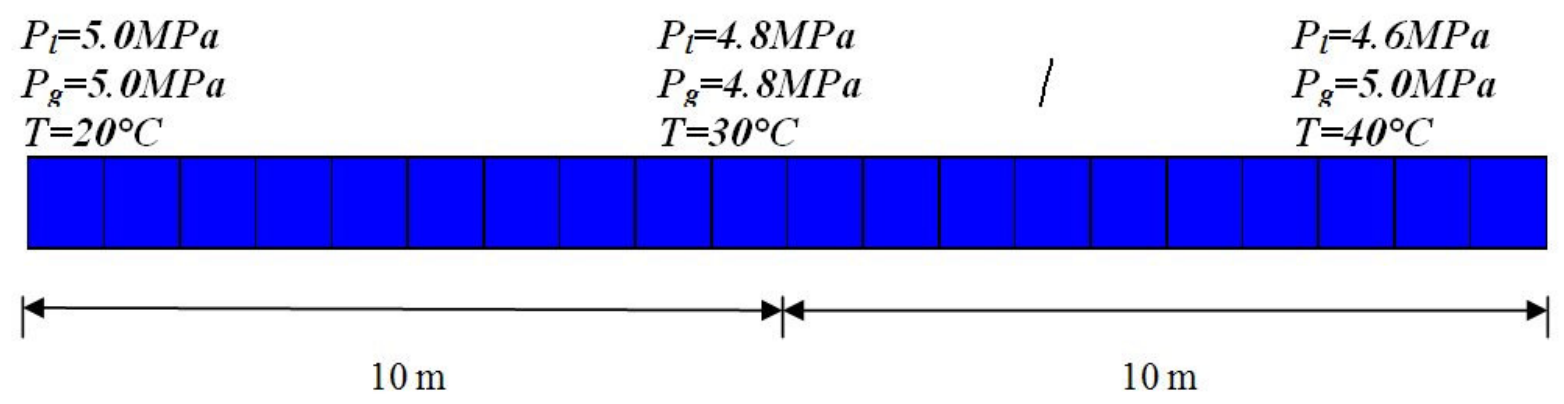

Figure 3-1 Schematic diagram of the grid for problem 1.

The absolute permeability, or the ability to conduct fluids, is set at $100 \mathrm{mD}$ for all the grid cells. The porosity, the ratio of void volume to the bulk volume, $\Phi$ is set at 0.3 for the entire grid. Parameters such as porosity, bulk density, grain density, bulk specific heat, grain specific heat, hydraulic conductivity, dry thermal conductivity, water-saturated thermal conductivity and pore compressibility for the entire domain are specified in Table 3.1. The values of different parameters used in the capillary pressure model and the relative permeability model are also given in Table 3-1.

The aqueous saturation in the first ten grid cells is equal to one. The aqueous saturation for the next ten grid cells is calculated using the capillary pressure head specified for the problem. Gas saturation is calculated from the following equations.

$$
S_{w}+S_{g}+S_{H}=1
$$

However for problem $1 S_{H}=0$ (No hydrate phase)

Therefore $S_{w}+S_{g}=1$ 
Table 3-1 Parameters and Specifications for Problem 1

\begin{tabular}{|l|l|}
\hline Parameter & Value \\
\hline Porosity & 0.3 \\
Bulk Density & $1855 \mathrm{~kg} / \mathrm{m}^{3}$ \\
Grain Density & $2650 \mathrm{~kg} / \mathrm{m}^{3}$ \\
Bulk Specific Heat & $525 \mathrm{~J} / \mathrm{kg} \mathrm{K}$ \\
Grain Specific Heat & $750 \mathrm{~J} / \mathrm{kg} \mathrm{K}$ \\
Hydraulic Conductivity & $0.1 \mathrm{Darcy}$ \\
Dry Thermal Conductivity & $2.0 \mathrm{~W} / \mathrm{m} \mathrm{K}^{-1}$ \\
Water-Saturated Thermal conductivity & $2.18 \mathrm{~W} / \mathrm{m} \mathrm{K}^{-10} \mathrm{~Pa}^{-1}$ \\
pore compressibility & $5.0 \mathrm{x} 10^{-10}$ \\
Capillary Pressure Model & Van Genuchten Equation ${ }^{34}$ \\
$\alpha$ parameter & $0.132 \mathrm{~m}^{-1}$ \\
$n$ parameter & 2.823 \\
$\beta_{\text {gl }}$ parameter & 1 \\
$s_{\text {lr }}$ parameter & 0 \\
Aqueous Relative Permeability Model & Mualem Equations \\
$m$ parameter & 0.6458 \\
Gas Relative Permeability Model & Mualem Equations ${ }^{35}$ \\
$m$ parameter & 0.6458 \\
\hline
\end{tabular}

\section{Capillary Pressure Model}

Capillary pressure is the pressure difference existing across the interface of two immiscible

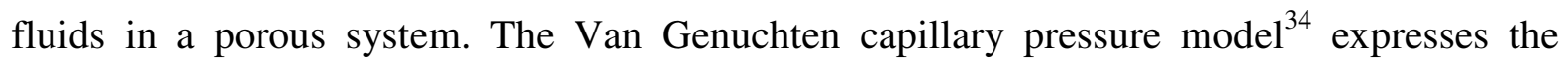
relationship between capillary pressure and aqueous saturation. It is expressed as the following: 
$\bar{s}_{l}=\frac{s_{l}-s_{l r}}{1-s_{l r}}=\left[1+\left(\alpha \beta_{g l} h_{g l}\right)^{n}\right]^{-m}$

where $\bar{s}_{l}$ is the effective aqueous saturation, $s_{l}$ is the aqueous saturation, $\beta_{g l}$ is the interfacial tension scaling factor, and $h_{g l}$ is the gas-aqueous capillary pressure head. Figure 3-2 illustrates the relation between Capillary Pressure and Water Saturation.

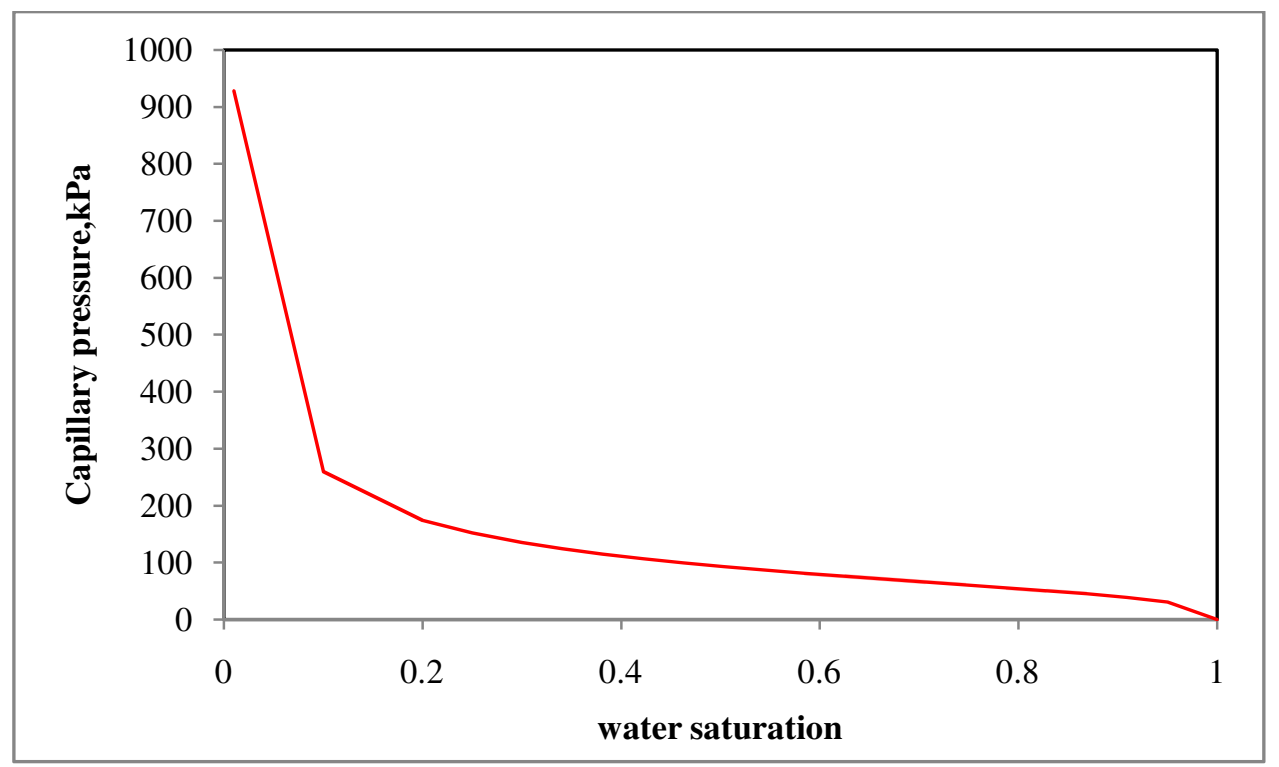

Figure 3-2 Capillary Pressures vs. Water Saturation as calculated using the Van Genuchten equation

\section{Relative Permeability Functions}

The relative permeability phenomenon is encountered when more than one fluid phase flows through a porous media. Relative permeability is the ratio of the effective permeability of a fluid at any saturation to the permeability at 100 percent saturation. Effective permeability is the ability of the porous material to allow a fluid at saturation less than 100 percent. Relative permeability functions for both aqueous and gas phases are calculated using a combined 
equation of Van Genuchten capillary pressure function and Mualem porosity distribution function $^{35}$. The combined equation is expressed as the following:

$$
\begin{aligned}
& K_{r l}=\left(\bar{s}_{l}\right)^{1 / 2}\left[1-\left\{1-\left(\bar{s}_{l}\right)^{1 / m}\right\}^{m}\right]^{2} \\
& K_{r g}=\left(1-\bar{s}_{l}\right)^{1 / 2}\left[1-\left\{1-\left(\bar{s}_{l}\right)^{1 / m}\right\}^{m}\right]^{2}
\end{aligned}
$$

Where, $\bar{s}_{l}$ is the effective aqueous saturation, $k_{r l}$ is the aqueous phase relative permeability and $k_{r g}$ is the gas phase relative permeability. Figure 3-3 shows a plot between relative permeability and water saturation.

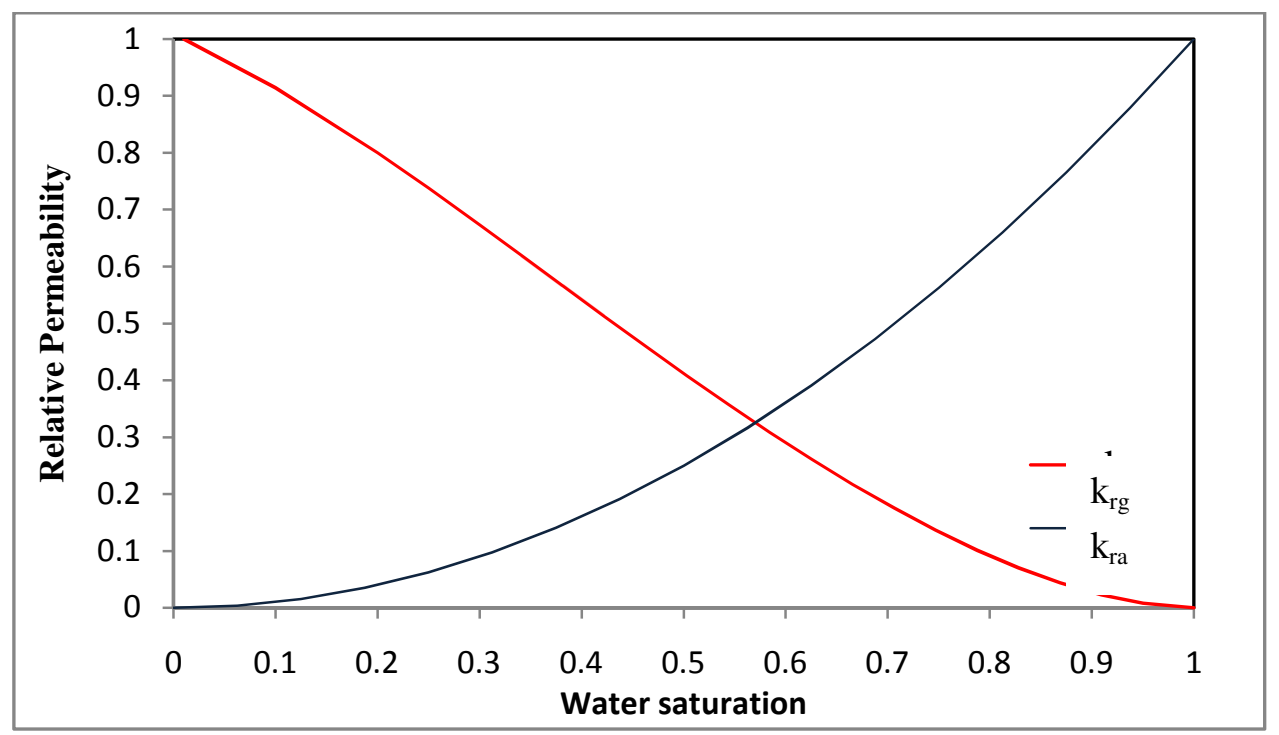

Figure 3-3 Relative permeability of water $k_{r a}$ and gas, $k_{r g}$ phases as a function of water saturation

\section{Data and sampling frequency}

Profiles of water saturation, temperature, aqueous relative permeability, and aqueous methane mass fraction and aqueous pressure are obtained for different time steps. Data is recorded for selected times (0, 1 day, 10 days, 100 days, 1000 days, and 10,000 days). Equilibrium is expected in the entire reservoir after 10,000 days. 


\subsubsection{Solution to problem 1 using CMG STARS}

STARS is basically designed for black-oil models and can be used to model the hydrate dissociation behavior by making some adjustments to the input parameters. There is a step by step procedure to simulate problems and to obtain final equilibrium conditions for the entire grid.

- Constructing the grid using CMG BUILDER.

- Assigning medium and rock properties like permeability, porosity, thermal conductivity, pore-compressibility and volumetric heat capacity.

- Defining components, properties and all the reactions and phase transitions between the components.

- Specifying rock fluid properties, capillary pressure model, and initial conditions like temperature, pressure, water saturation and mole fraction of components in all phases.

- Boundary Conditions specified in the problem by defining wells in the reservoir.

- Running the simulation for different time steps specified in the problem.

Problem 1 is a one dimensional horizontal domain of $20 \mathrm{~m}$ in length and is discretized into 20 cells each of length $1 \mathrm{~m}$. In CMG builder, grid is constructed using "GRID VARI I J K” where I J\&K represents the dimensions in $\mathrm{X} \mathrm{Y}$ and $\mathrm{Z}$ directions. The further discretization of the grid is done by using keywords DI DJ and DK. The thickness of the grid top is taken as 500m.

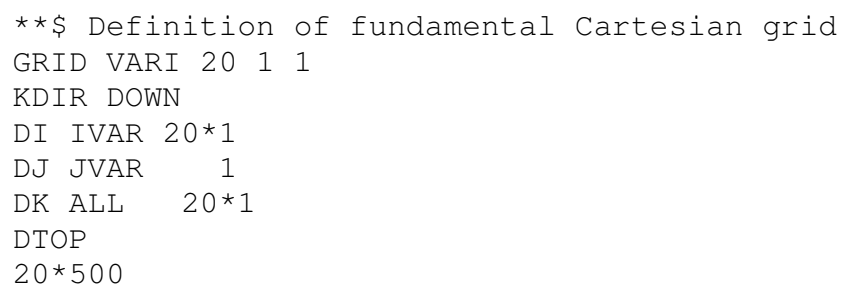

Permeability and porosity for the entire reservoir are constant as specified in the problem description.

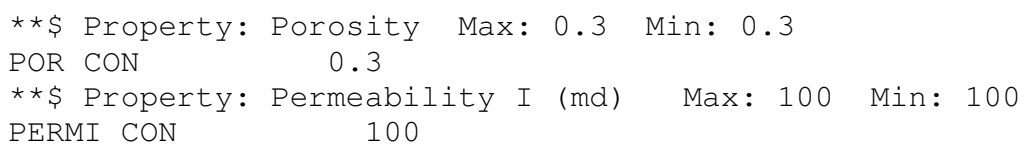




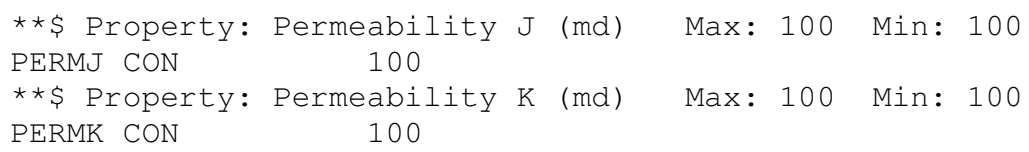

Rock Compressibility, thermal Properties like heat capacity, thermal conductivity are specified by defining a rock type. Different rock types can be defined within a reservoir.

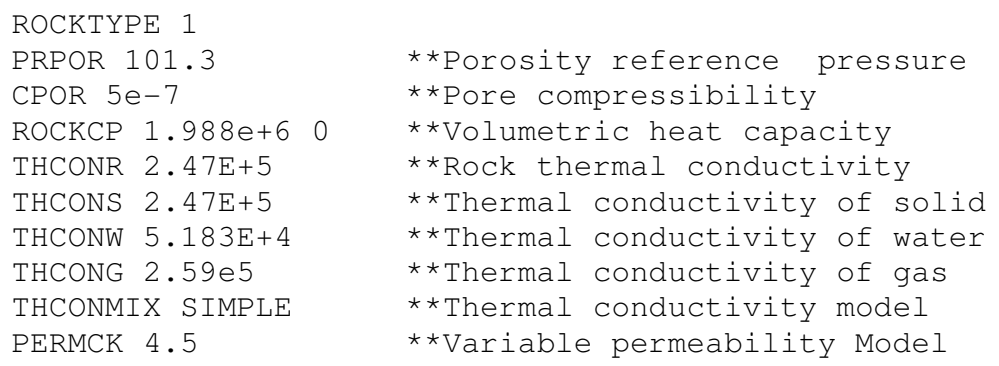

The next step is to specify different components and their properties. In this case only water- $\mathrm{CH}_{4}$ system is considered, which is a 2-component and 2-phase system. Different components and their physical properties can be directly imported from the builder's inbuilt library. A value of ' 0 ' input for any property returns a standard value already set up in the library of the builder. CMM refers to component molecular weight in $\mathrm{Kg} / \mathrm{gmol}$. Densities, gas-liquid $\mathrm{K}$ values, critical temperature and pressure, aqueous and gas phase viscosities are specified as following

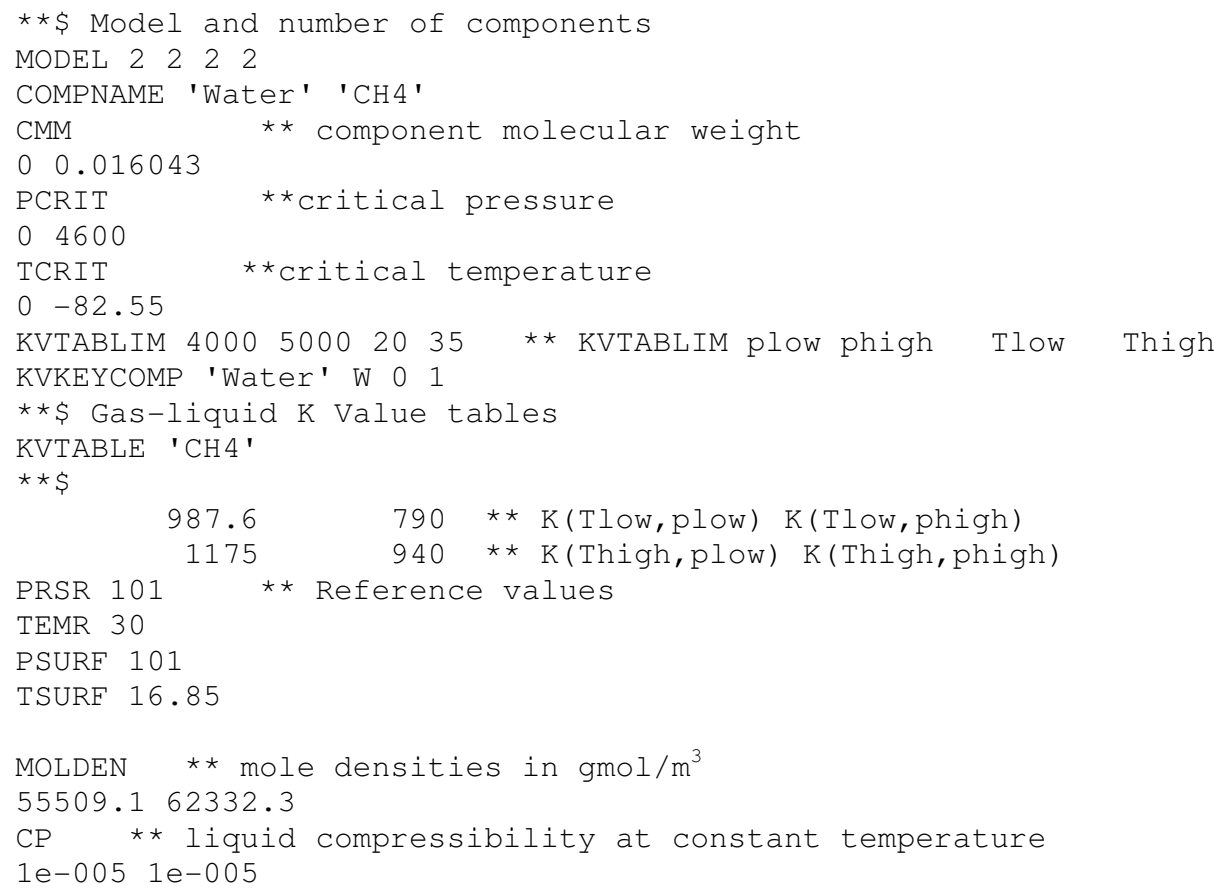


CT1 ** First coefficient of thermal expansion

$2.47148 e-0072.47148 e-007$

Viscosity table for water and methane at different temperatures from $5^{\circ} \mathrm{C}$ to $540^{\circ} \mathrm{C}$

\begin{tabular}{rrrr} 
VISCTABLE* $\$$ temp & \multicolumn{1}{l}{ Water } & $\mathrm{CH}_{4}$ \\
5 & 1.90124 & 1.90124 \\
15 & 1.42069 & 1.42069 \\
25 & 1.1155 & 1.1155 \\
30 & 1 & 1 \\
40 & 0.817524 & 0.817524 \\
65 & 0.542214 & 0.542214 \\
90 & 0.397513 & 0.397513 \\
115 & 0.306284 & 0.306284 \\
140 & 0.244739 & 0.244739 \\
165 & 0.210104 & 0.210104 \\
190 & 0.183079 & 0.183079 \\
215 & 0.1621 & 0.1621 \\
240 & 0.145113 & 0.145113 \\
265 & 0.131269 & 0.131269 \\
290 & 0.117908 & 0.117908 \\
315 & 0.108632 & 0.108632 \\
340 & 0.09987 & 0.09987 \\
365 & 0.092478 & 0.092478 \\
390 & 0.086039 & 0.086039 \\
415 & 0.08034 & 0.08034 \\
440 & 0.075263 & 0.075263 \\
465 & 0.070712 & 0.070712 \\
490 & 0.06661 & 0.06661 \\
515 & 0.062892 & 0.062892 \\
540 & 0.059507 & 0.059507
\end{tabular}

Aqueous and Gas relative permeability values are calculated using the equations mentioned in the problem description. Capillary pressure is calculated from the Van-Genuchten capillary pressure model. These values are entered in the form of tables in the ROCK FLUID section of the data file. Capillary pressure of water-gas is included as PCOG in the gas-oil table. In the absence of hydrate phase or the oil phase there is confusion whether to use capillary pressure as PCOW or PCOG. Using capillary pressure as PCOG gave results which are in agreement with other codes. Vertical Equilibrium calculations are not performed in this problem. 


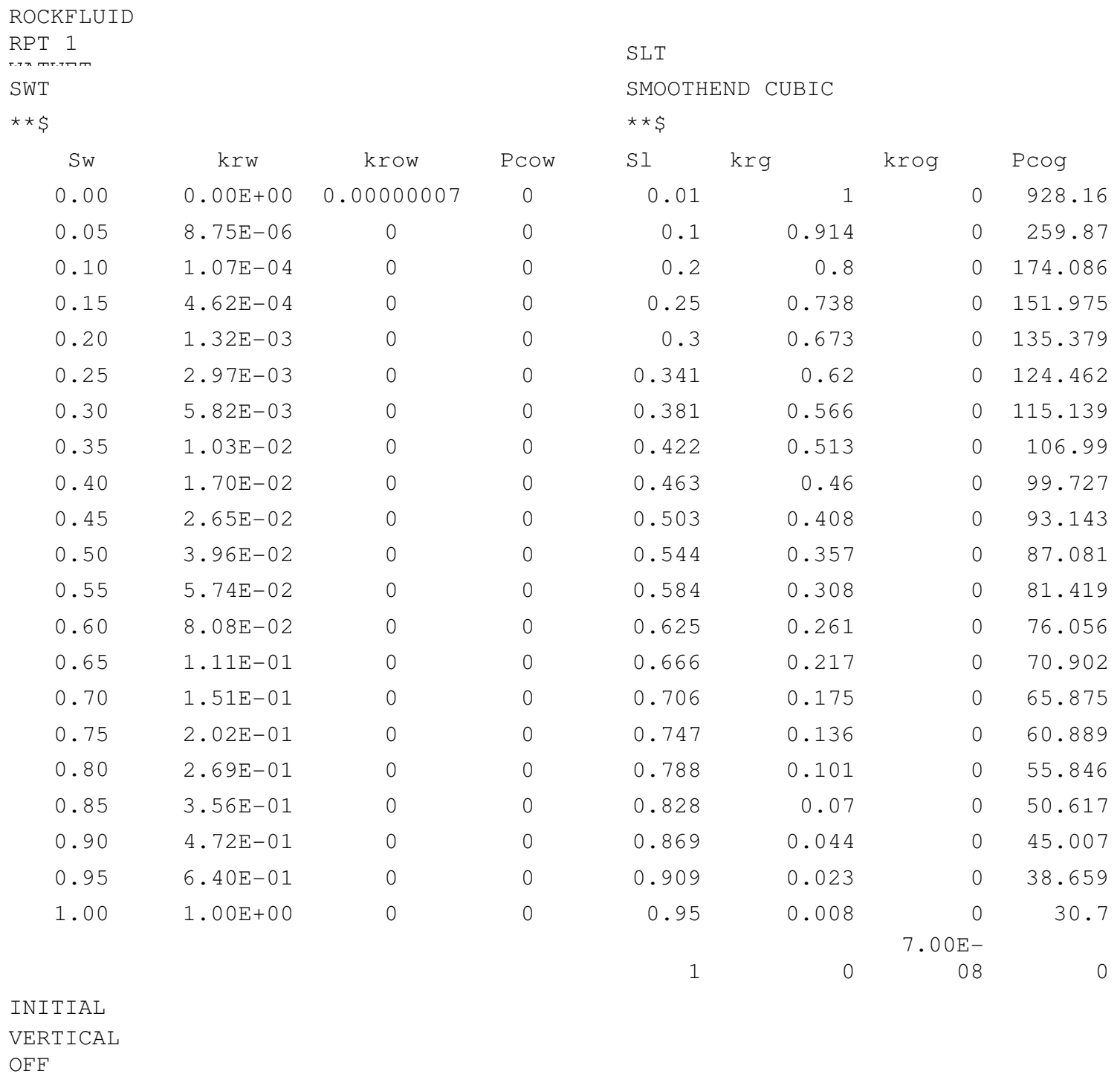

Initial conditions like pressure, temperature, saturations, aqueous and gas mole fractions are initially specified a constant and are then modified by using 'MOD' keyword.

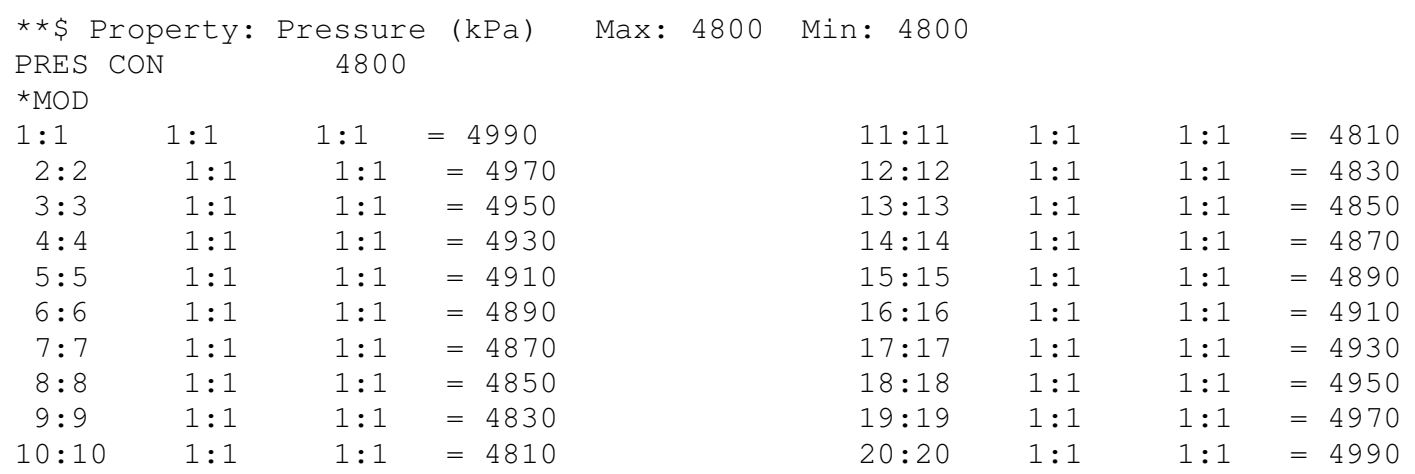




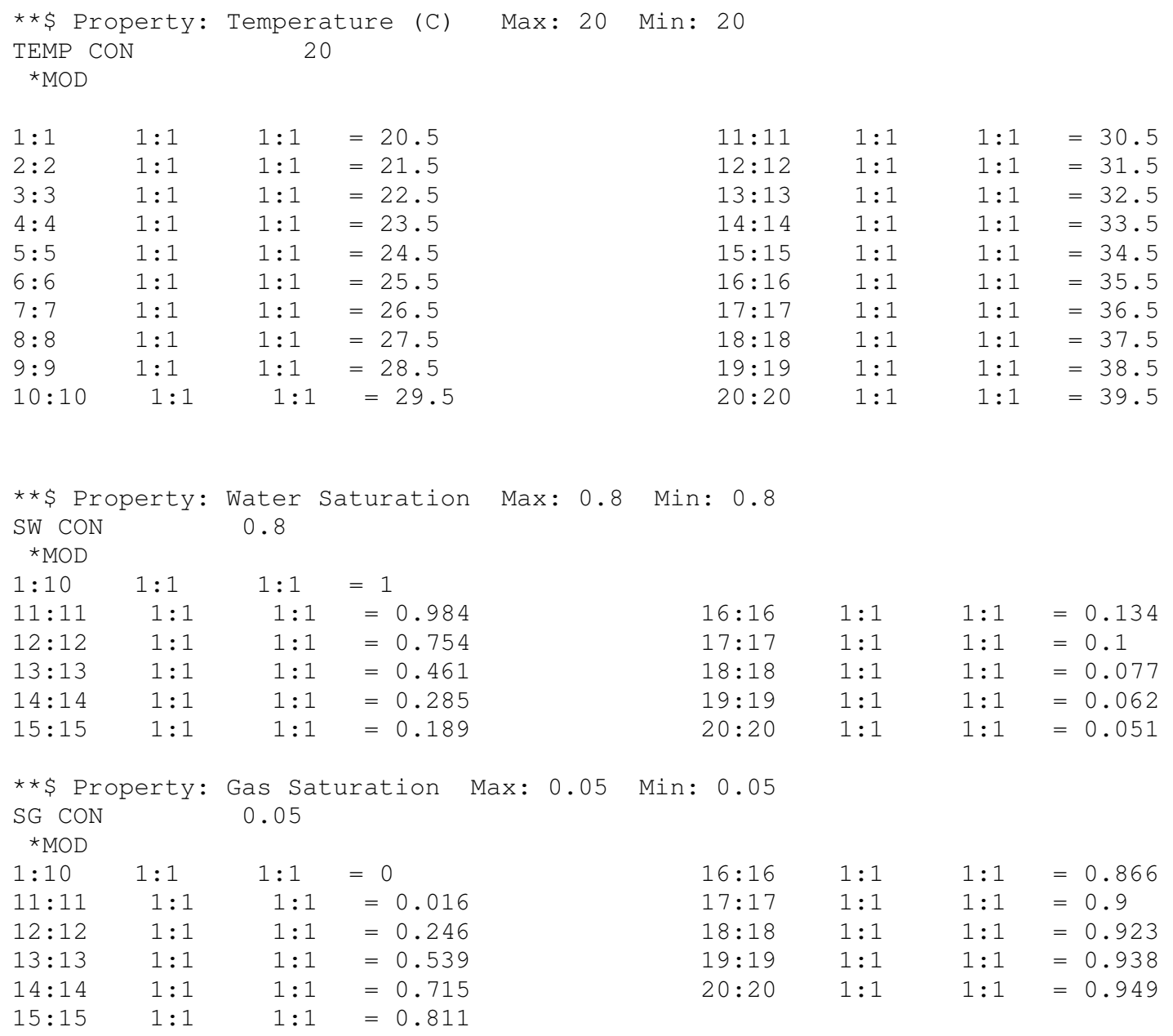

Aqueous and gas mole fraction are calculated based on the pressure and temperature prevailing at that particular cell.

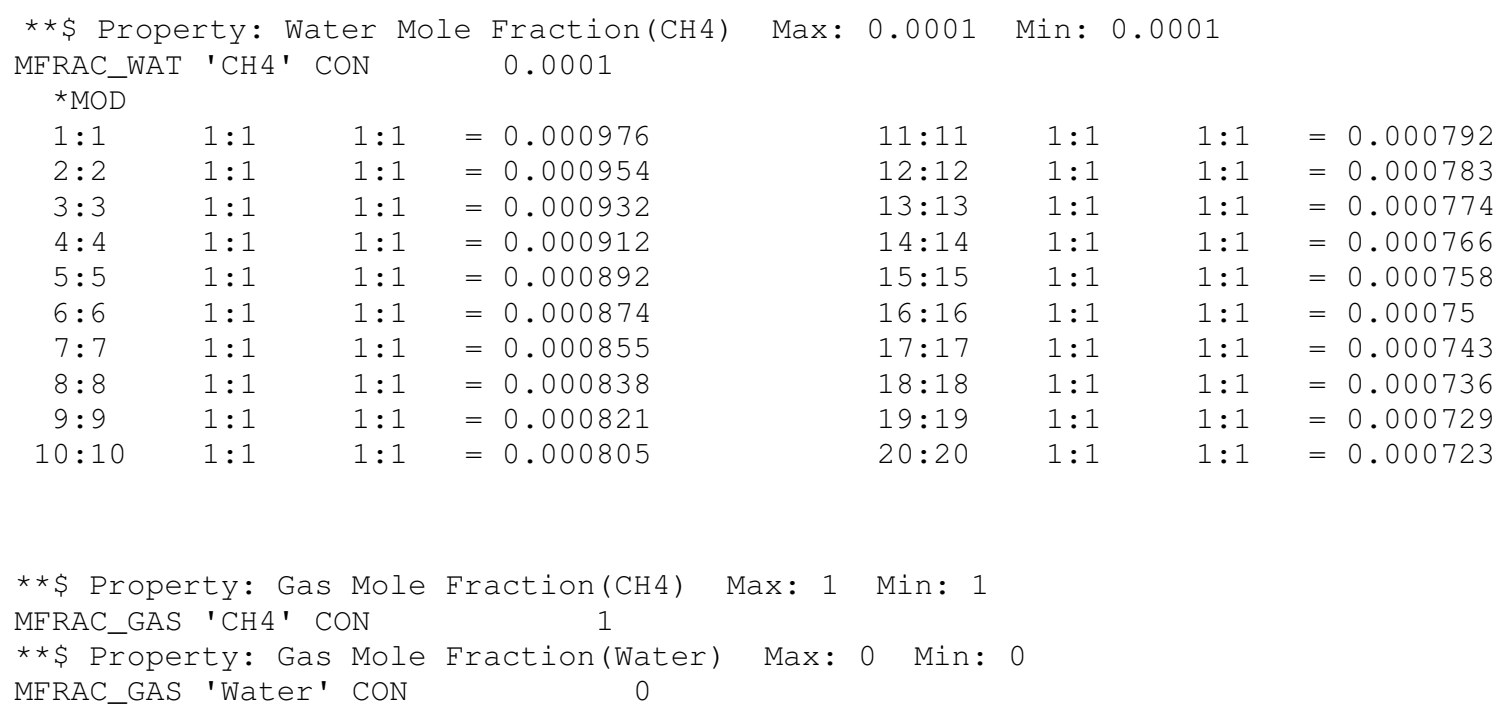


A dummy shut-in well is defined and simulation is run for 10,000 days. The start date is set as Jan $1^{\text {st }}$ 2007. Data is recorded for selected times (i.e. 1, 10, 100, 1000, 10000 days). Equilibrium is reached in 10,000 days. Different time intervals are entered into the data file by using keyword "DATE". Simulation is stopped after 10,000 days (May $19^{\text {th }} 2034$ ). The default geometry of the well is used and is operated at a Bottom hole pressure of $5000 \mathrm{kPa}$.

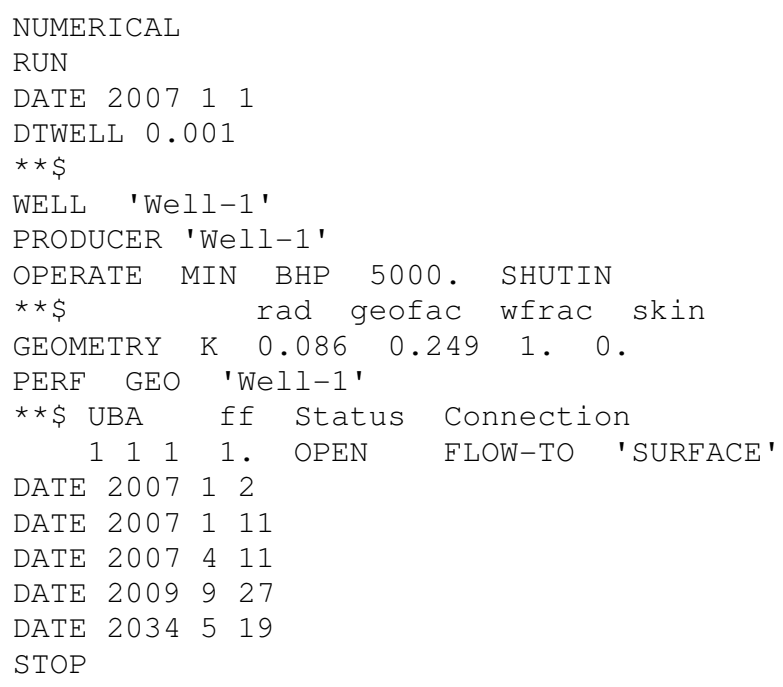

\section{Results and Discussion}

Aqueous saturation: As per the problem description saturated conditions are maintained in the first half of the domain and unsaturated conditions in the other. As the simulation proceeds due to mass transfer water flows from one part to the other. The aqueous saturation curves match well with other hydrate codes in this problem. By the thousandth day, mechanical equilibrium is seen in the reservoir. Profiles of aqueous saturation are plotted at different time steps shown in Figure 3-4.

Relative permeability: Relative permeability is a function of aqueous saturation. At a high aqueous saturation, even a small change in the saturation brings a huge variation in the relative permeability curves. This can be seen in Figure 3-6. 
Temperature: Initially the temperature at $x=0$ is $20^{\circ} \mathrm{C}$ and at $x=20 \mathrm{~m}$ it is $40^{\circ} \mathrm{C}$. Due to heat transfer, thermal equilibrium is reached by ten thousandth day. This scenario is in excellent agreement with all codes. It is given in Figure 3-5.

Aqueous $\mathrm{CH}_{4}$ Mass Fraction: In the grid, the pressure and temperature are different at different locations. The solubility of methane in water is dependent on temperature and pressure. Initially, there is varying amount of dissolved methane at different coordinates in the grid. As the simulation proceeds, the pressure and temperature come to equilibrium and hence the dissolved methane is the same everywhere in the grid. This is given in Figure 3-7

Aqueous Pressure: The aqueous phase pressure at $x=0$ is $5 \mathrm{MPa}$ and at $x=20 \mathrm{~m}$ it is 4.6 MPa. Equilibrium is reached at 100 days. This is plotted in Figure 3-8. 

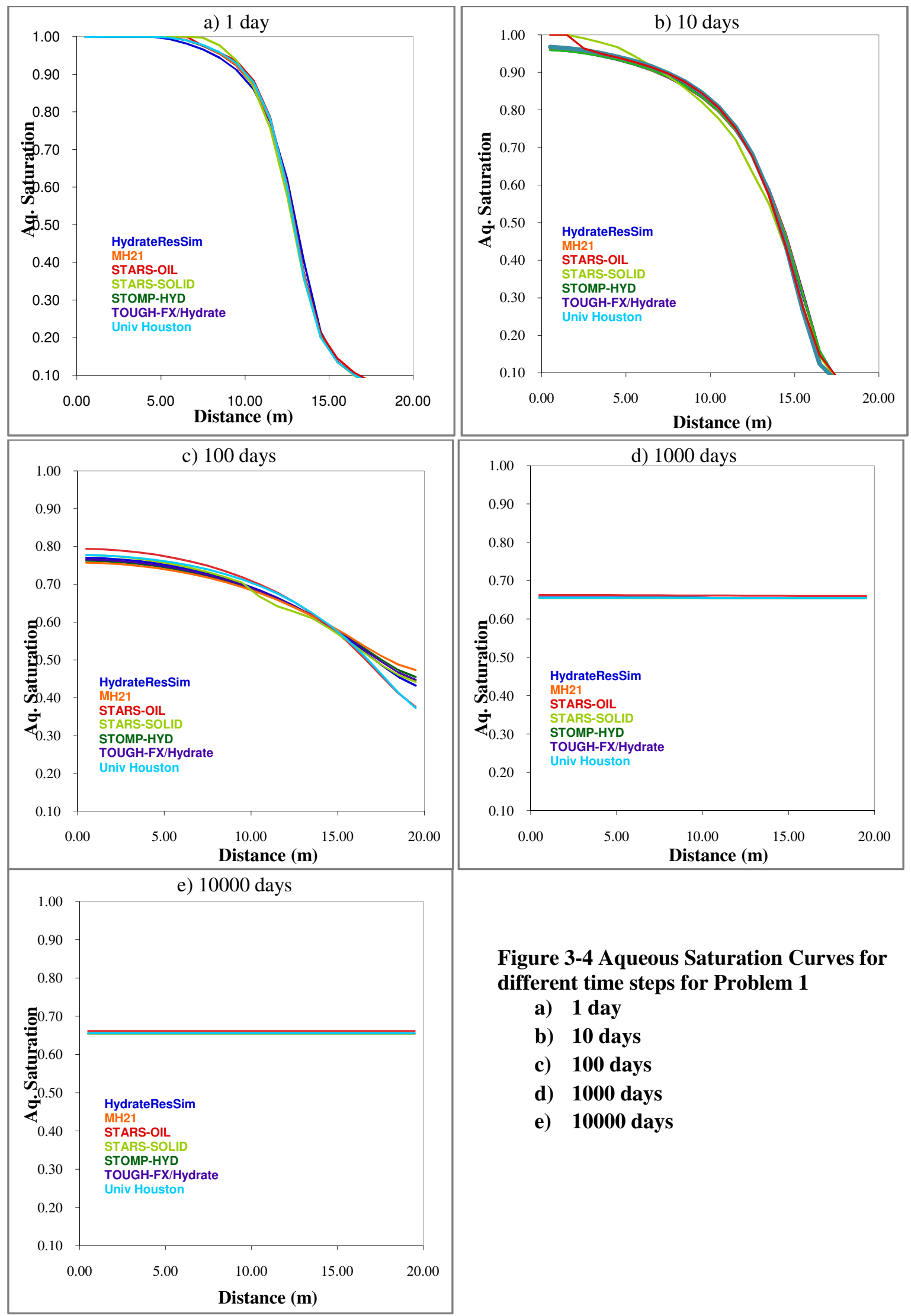

Figure 3-4 Aqueous Saturation Curves for different time steps for Problem 1
a) 1 day
b) 10 days
c) 100 days
d) 1000 days
e) 10000 days 

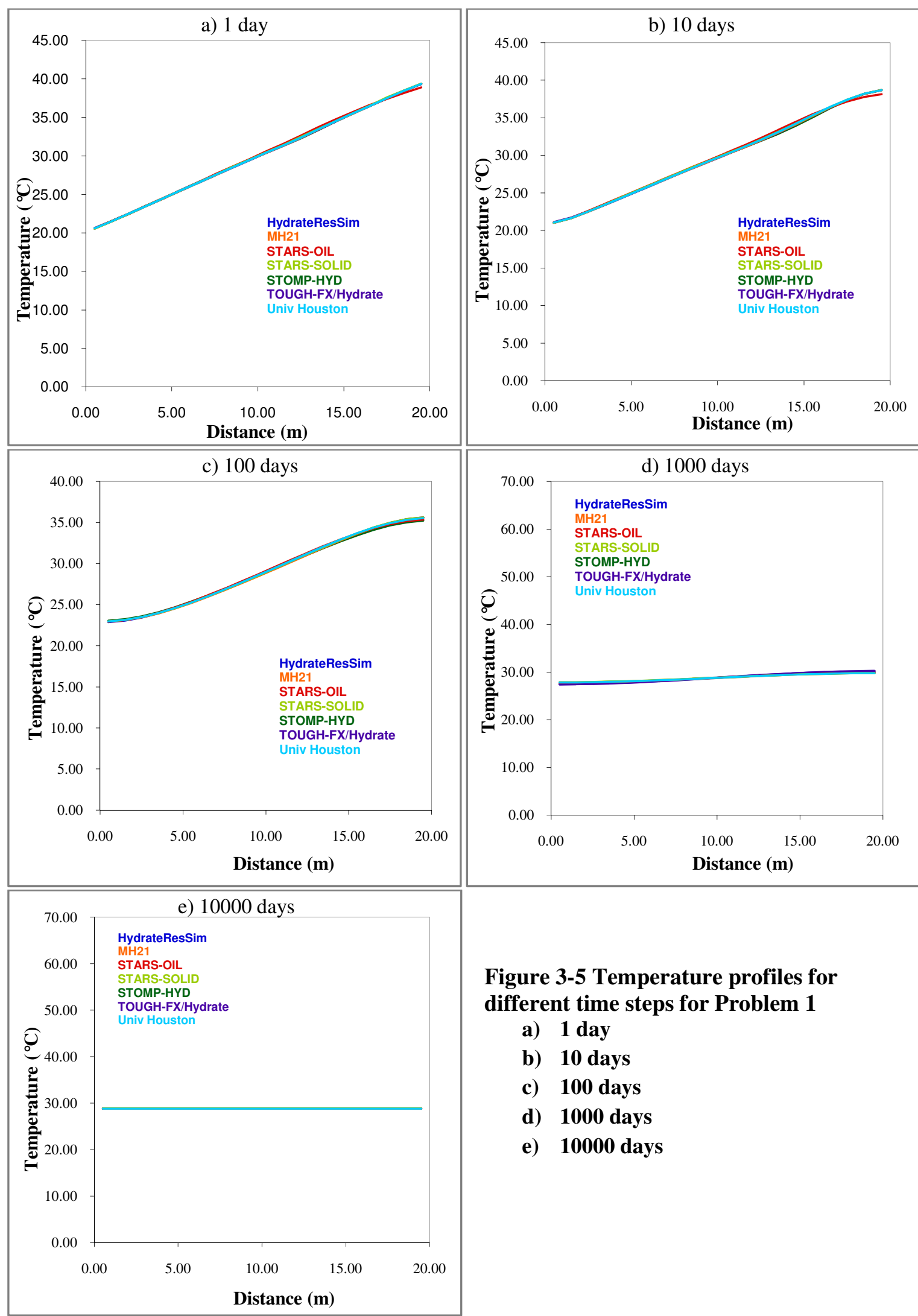

Figure 3-5 Temperature profiles for different time steps for Problem 1
a) 1 day
b) 10 days
c) 100 days
d) 1000 days
e) 10000 days 

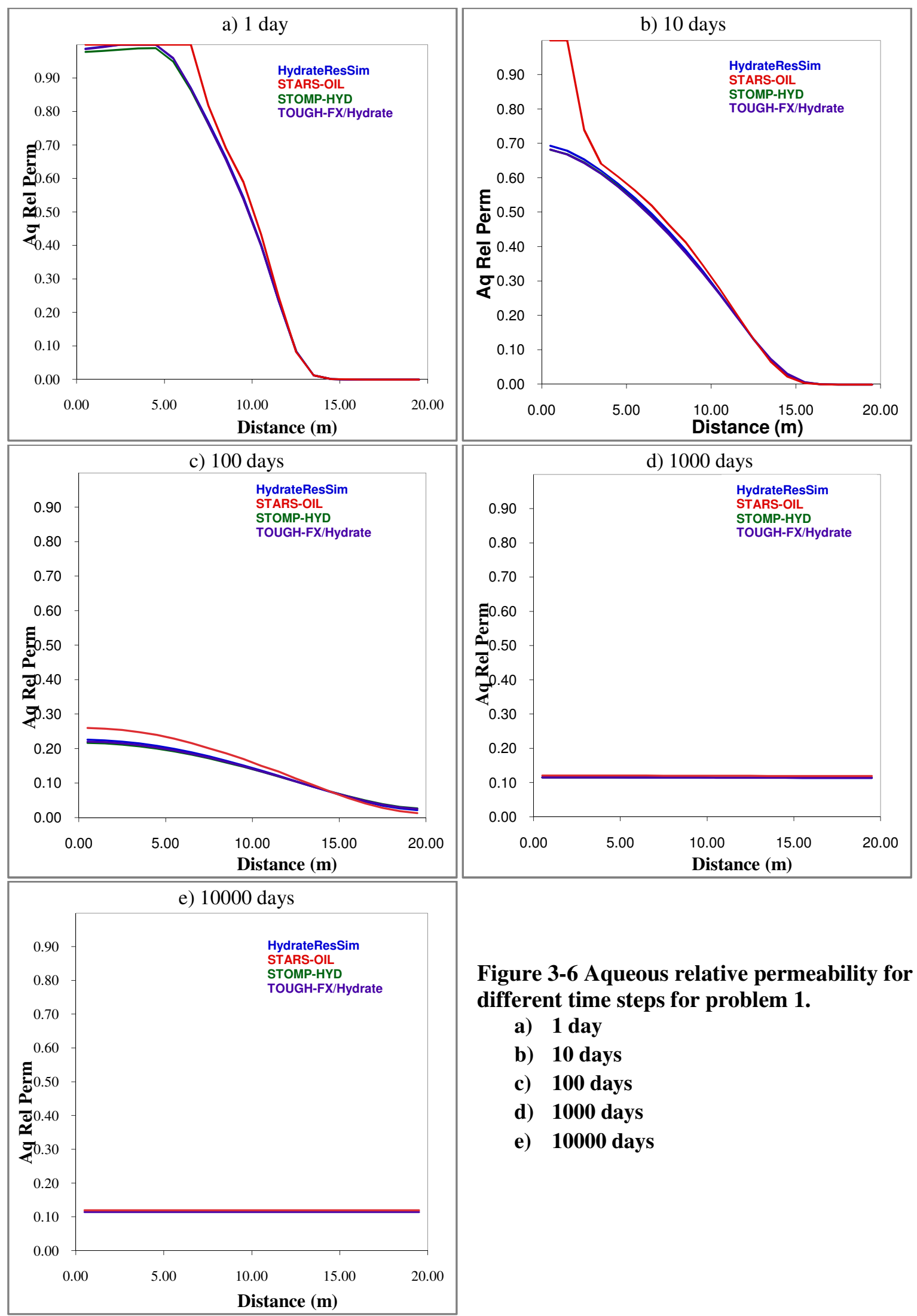

Figure 3-6 Aqueous relative permeability for different time steps for problem 1.
a) 1 day
b) 10 days
c) 100 days
d) 1000 days
e) 10000 days 

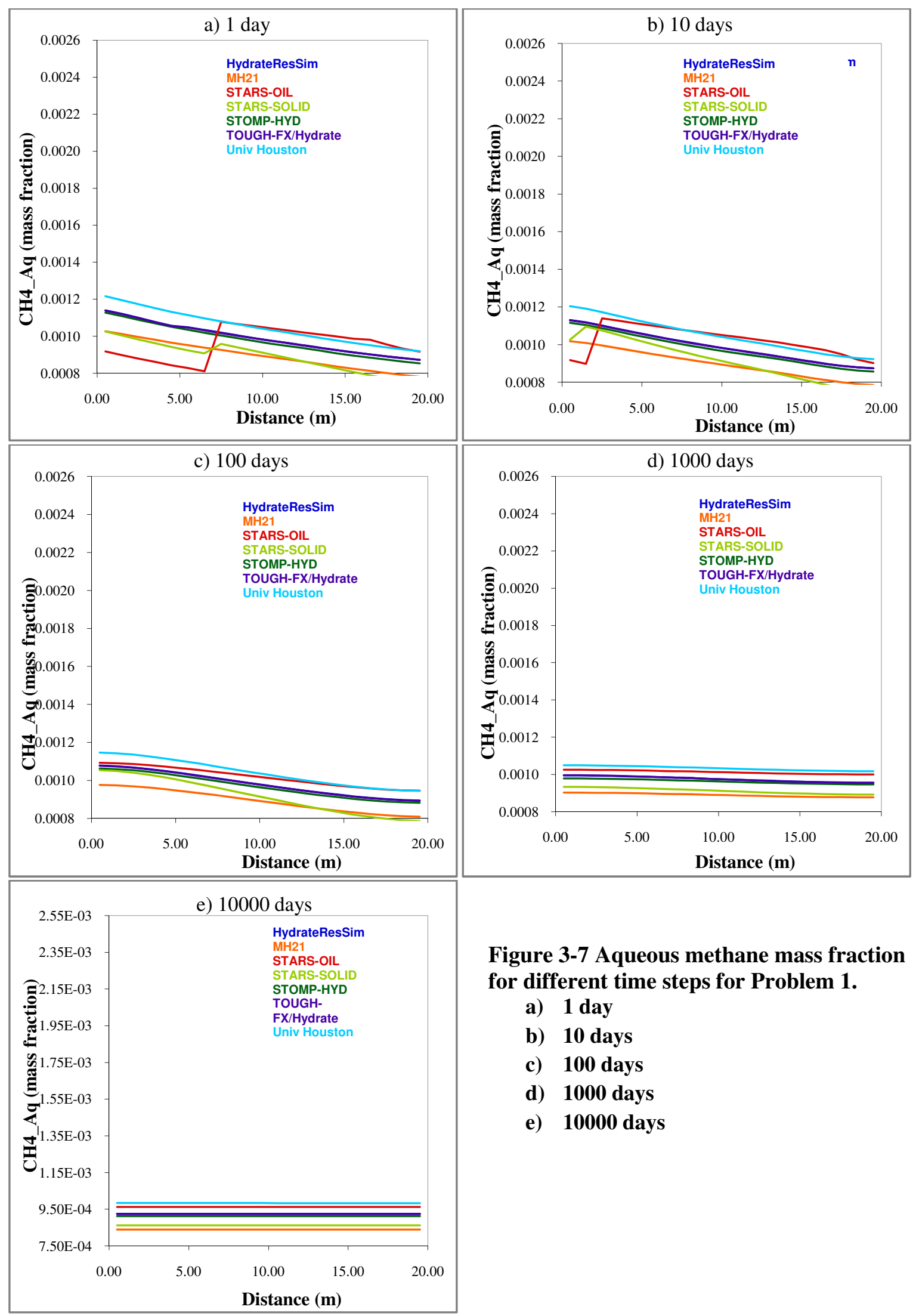

Figure 3-7 Aqueous methane mass fraction for different time steps for Problem 1.
a) 1 day
b) 10 days
c) 100 days
d) 1000 days
e) 10000 days 

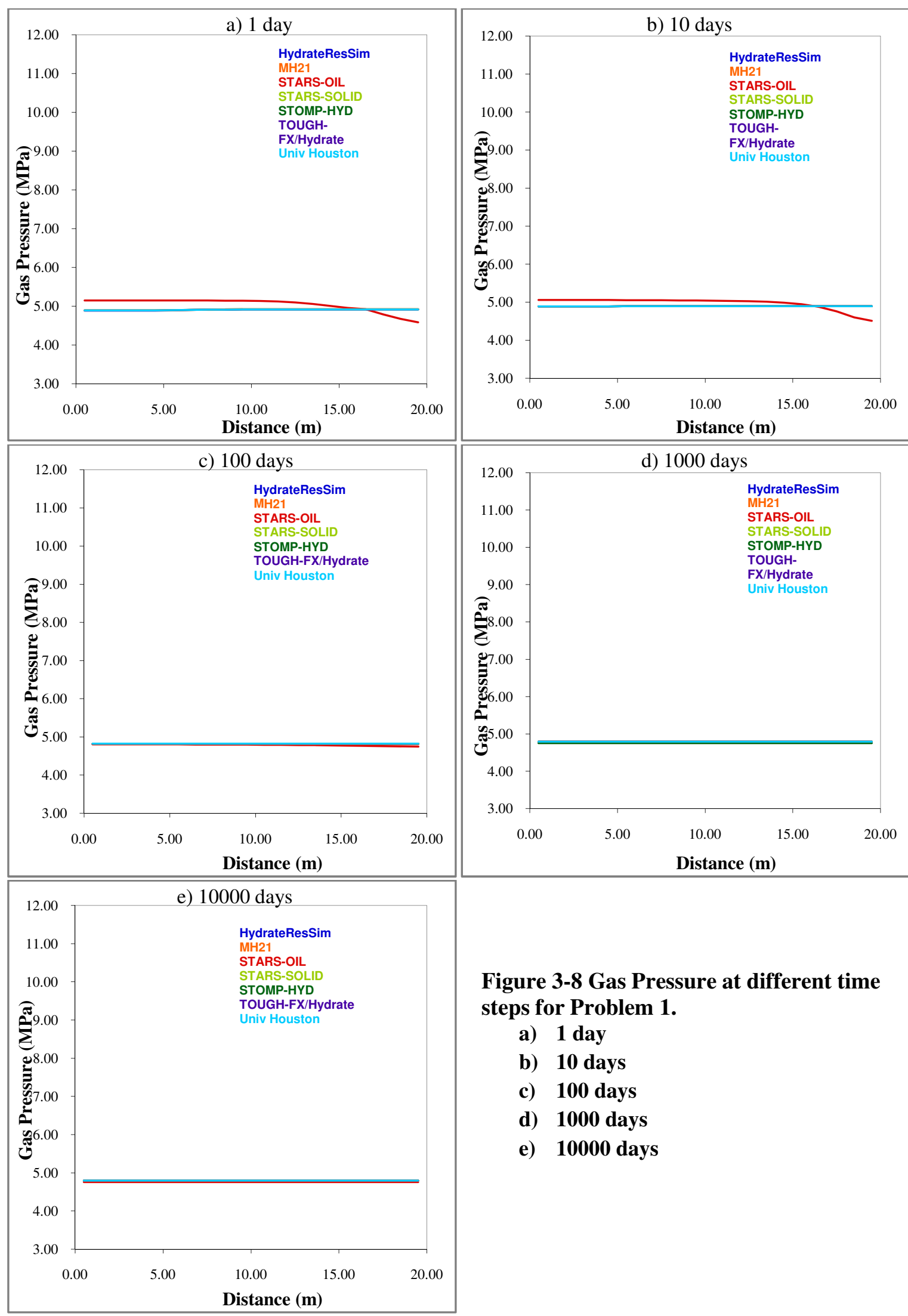

Figure 3-8 Gas Pressure at different time steps for Problem 1.
a) 1 day
b) 10 days
c) 100 days
d) 1000 days
e) 10000 days 


\subsection{Problem 2}

This problem of the code comparison study uses the same grid as suggested in problem 1. The difference between these two problems is that there is a hydrate phase in the first half of the domain. Hydrate dissociates due to the thermal conditions prevailing in the second half of the domain. The hydrate dissociation and formation process is simulated using a kinetic model. The simulation proceeds to equilibrium conditions leading to complete hydrate dissociation.

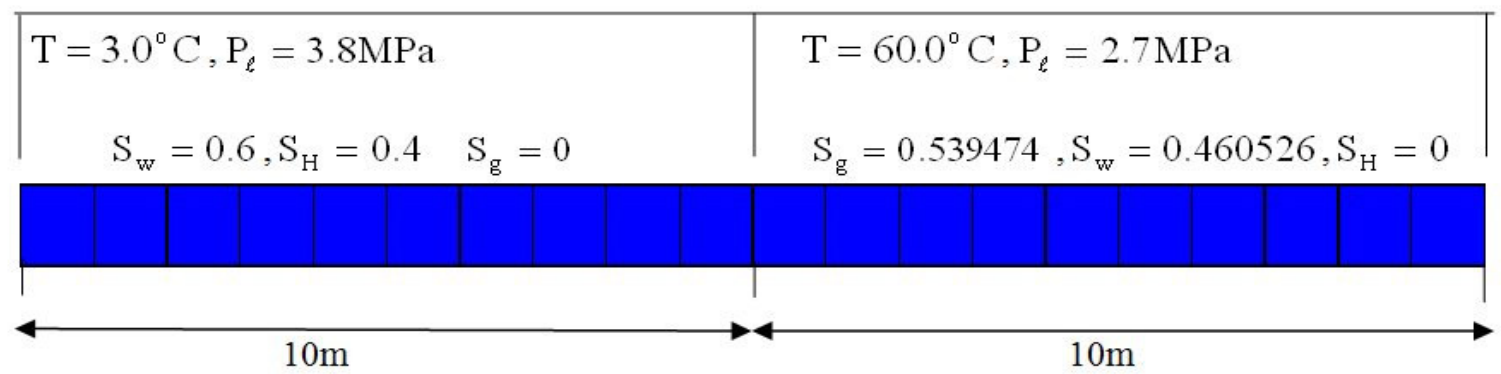

Figure 3-9 Schematic view of problem 2

Processes simulated in this problem

- Multi-fluid flow for a water- $\mathrm{CH}_{4}$-hydrate system in a porous media subject to relative permeability, capillarity and phase transitions.

- Hydrate dissociation due to thermal stimulation

- Heat transfer across the porous media with phase advection

- Change in thermodynamic and transport properties with pressure and temperature

- Solubility changes of methane in water with pressure and temperature 
Hydrate Equilibrium pressure, hydration number, densities of liquid gas and hydrate, methane composition in liquid and solid phases are specified in Table 3-2.

Table 3-2 Input Parameters for Problem 2
\begin{tabular}{|c|c|}
\hline$P_{h}^{e q}=3.420 \mathrm{MPa}$ & $P_{g}=2.8 \mathrm{MPa}$ \\
$N_{h}^{w}=6.176$ & $\rho_{l}=983.889 \mathrm{~kg} / \mathrm{m3}$ \\
$y_{l c}^{C H 4}=0.9650$ & $\mu_{l}=4.6642 \times 10^{-4}$ \\
$y_{s c}^{C H 4}=0.8392$ & $\rho_{g}=16.7376 \mathrm{~kg} / \mathrm{m}^{3}$ \\
$\rho_{h}=911.04 \mathrm{~kg} / \mathrm{m}^{3}$ & $\mu_{g}=1.2198 \times 10^{-5} \mathrm{~Pa} \mathrm{~s}$ \\
\hline & \\
\hline
\end{tabular}

Different input parameters like porosity, specific heat, thermal conductivity and pore compressibility are same as in Problem 1 and are specified in Table 3-1. Capillary pressure model and Relative permeability model used in this problem are same as in Problem 1.

\section{Data and sampling frequency}

Profiles of water saturation, hydrate saturation, gas saturation, temperature, pressure, aqueous methane mass fraction, cumulative methane release, and rate of methane release are studied for different time steps ( 0,1 day, 10 days, 100 days, 1000 days, 10,000 days). 


\subsubsection{Solution to Problem 2}

Problem 2 has the same grid dimensions as that of Problem 1. It is a 20m-length horizontal domain divided into 20 cells each of length $1 \mathrm{~m}$. Porosity and permeability for the entire grid are 0.3 and $100 \mathrm{mD}$ respectively. Medium properties and thermal properties are same as that of Problem 1.

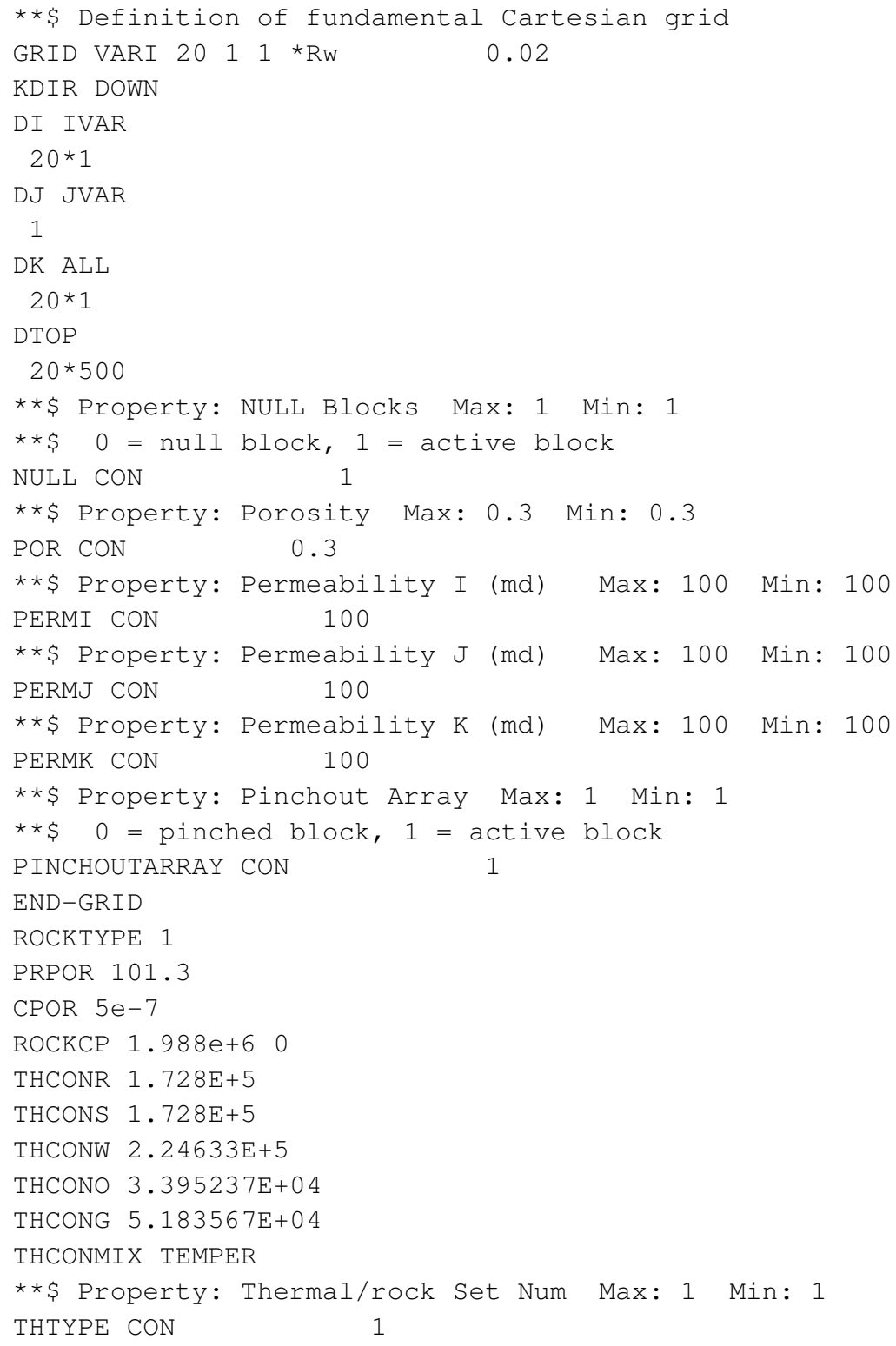

The difference between Problem 2 and Problem 1 is that there is an extra component hydrate in the first half of the domain. The system defined in this problem is water- $\mathrm{CH}_{4}$-hydrate. It is 
a 3- component, 3-phase system. Hydrate can be defined as either the oil phase with very high viscosity or as a solid phase. Each method has its own advantages and disadvantages.

\section{Hydrate modeled as an oil}

Hydrate saturation when expressed as an oil phase represents liquid saturation. Relative permeability and Capillary pressure curves are a function of water saturation. In CMG STARS, gas relative permeability and capillary pressure have to be entered as a function of liquid saturation $\left(S_{l}=S_{w}+S_{H=o i l}\right)$. This small variation in the relative permeability and capillary pressure curves makes it difficult to match the results of STARS to other codes. The dependence of permeability on porosity cannot be modeled in this method. The hydrate (oil), water and gas are specified in the pores of the medium according to following equations.

$S_{l}+S_{g}=1$

$S_{l}=S_{w}+S_{H=o i l}$

\section{Hydrate modeled as a solid}

In CMG STARS, water and gas saturations are measured on a scale that does not include hydrate. The assumption is that hydrate is a solid and it is not related to/contained in the pore spaces. The equation used to calculate water and gas saturation is $S_{w}+S_{g}=1$. Relative permeabilities depend on water saturation and hence these results are difficult to match with other codes.

Hydrate properties like molecular weight, critical temperature, critical pressure are specified in the data file. Due to wide range of pressure and temperature values in the entire grid, gasliquid $K$ values for water and methane are calculated using the following correlation.

$$
K=\left(\frac{K V 1}{P}+K V 2 * P+K V 3\right) * E X P\left(\frac{K V 4}{T-K V 5}\right)
$$


CPL2

$0.0 \mathrm{E}+0 \quad 0.0 \mathrm{E}+0 \quad 0.0 \mathrm{E}+0$

CPL3

$0.0 \mathrm{E}+0 \quad 0.0 \mathrm{E}+0 \quad 0.0 \mathrm{E}+0$

CPL 4

$0.0 \mathrm{E}+0 \quad 0.0 \mathrm{E}+0 \quad 0.0 \mathrm{E}+0$

MOLDEN

$55501.5 \quad 18723 \quad 7696.23$

CP

5. $0 \mathrm{E}-7 \quad 0.0 \quad 5.0 \mathrm{E}-7$

CT1

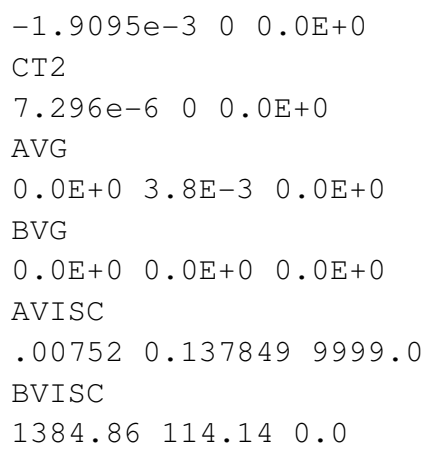

Hydrate formation and dissociation reactions are specified by Equilibrium kinetics. Hydrate dissociation is an endothermic first order reaction with an enthalpy of $-51857.9364 \mathrm{~J} / \mathrm{gmol}$ and activation energy of $150218.3525 \mathrm{~J} / \mathrm{gmol}$.

\section{Hydrate $\rightleftharpoons 6.1$ water $+\mathrm{CH}_{4}$}

Equilibrium $\mathrm{K}$ value for forward and backward reaction is given by the correlation.

$$
K(P, T)=\left(\frac{r x k 1}{P}+r x k 2 \times P+r x k 3\right) \times \exp \left(\frac{r x k 4}{T-r x k 5}\right)
$$

$r x k 1, r x k 2, r x k 3, r x k 4$ and $r x k 5$ are the correlation coefficients.

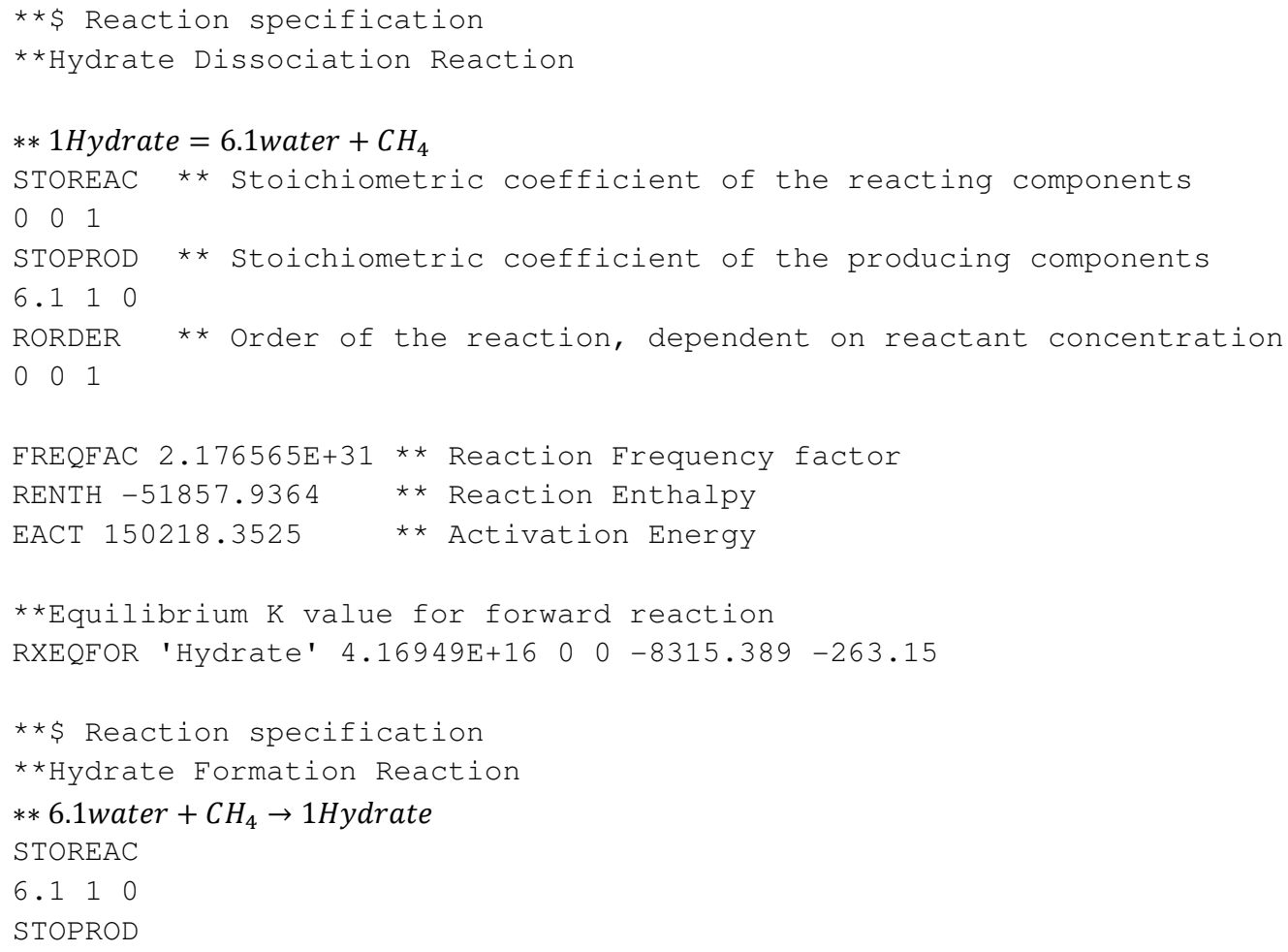


$\begin{array}{lll}0 & 0 & 1\end{array}$

RORDER

$\begin{array}{lll}0 & 0 & 1\end{array}$

FREQFAC $1.0 \mathrm{e} 28$

RENTH 51857.9364

EACT 150218.3525

RXEQFOR 'Hydrate' $4.16949 \mathrm{E}+16 \quad 0 \quad 0 \quad-8315.389-263.15$

\section{Rock Fluid Properties are same as in problem 1}

\begin{tabular}{|c|c|c|c|c|}
\hline \multicolumn{5}{|l|}{ SWT } \\
\hline \multirow[t]{22}{*}{$\star \star \$$} & Sw & $\mathrm{krw}$ & kron & $\mathrm{PcOW}$ \\
\hline & 0 & $0.00 \mathrm{E}+00$ & \multicolumn{2}{|c|}{0.00000007} \\
\hline & 0.05 & $8.75 E-06$ & \multicolumn{2}{|c|}{0.000000} \\
\hline & 0.1 & $1.07 \mathrm{E}-04$ & \multicolumn{2}{|c|}{0.000000} \\
\hline & 0.15 & $4.62 \mathrm{E}-04$ & \multicolumn{2}{|c|}{0.000000} \\
\hline & 0.2 & $1.32 \mathrm{E}-03$ & \multicolumn{2}{|c|}{0.000000} \\
\hline & 0.25 & $2.97 E-03$ & \multicolumn{2}{|c|}{0.000000} \\
\hline & 0.3 & $5.82 \mathrm{E}-03$ & \multicolumn{2}{|c|}{0.000000} \\
\hline & 0.35 & $1.03 E-02$ & \multicolumn{2}{|c|}{0.000000} \\
\hline & 0.4 & 1. $70 \mathrm{E}-02$ & \multicolumn{2}{|c|}{0.000000} \\
\hline & 0.45 & $2.65 \mathrm{E}-02$ & \multicolumn{2}{|c|}{0.000000} \\
\hline & 0.5 & $3.96 \mathrm{E}-02$ & \multicolumn{2}{|c|}{0.000000} \\
\hline & 0.55 & $5.74 \mathrm{E}-02$ & \multicolumn{2}{|c|}{0.000000} \\
\hline & 0.6 & $8.08 E-02$ & \multicolumn{2}{|c|}{0.000000} \\
\hline & 0.65 & $1.11 \mathrm{E}-01$ & \multicolumn{2}{|c|}{0.000000} \\
\hline & 0.7 & $1.51 \mathrm{E}-01$ & \multicolumn{2}{|c|}{0.000000} \\
\hline & 0.75 & $2.02 \mathrm{E}-01$ & \multicolumn{2}{|c|}{0.000000} \\
\hline & 0.8 & $2.69 \mathrm{E}-01$ & \multicolumn{2}{|c|}{0.000000} \\
\hline & 0.85 & $3.56 \mathrm{E}-01$ & \multicolumn{2}{|c|}{0.000000} \\
\hline & 0.9 & $4.72 E-01$ & \multicolumn{2}{|c|}{0.000000} \\
\hline & 0.95 & $6.40 \mathrm{E}-01$ & \multicolumn{2}{|c|}{0.000000} \\
\hline & 1 & $1.00 \mathrm{E}+00$ & \multicolumn{2}{|c|}{0.000000} \\
\hline \multicolumn{5}{|c|}{$\mathrm{SLT}$} \\
\hline$\star \star \$$ & $\mathrm{Sl}$ & $\mathrm{krg}$ & krog & Pcog \\
\hline & 0.01 & 1.000 & 0 & 928.16 \\
\hline & 0.100 & 0.914 & 0 & 259.870 \\
\hline & 0.200 & 0.800 & 0 & 174.086 \\
\hline & 0.250 & 0.738 & 0 & 151.975 \\
\hline & 0.300 & 0.673 & 0 & 135.379 \\
\hline & 0.341 & 0.620 & 0 & 124.462 \\
\hline & 0.381 & 0.566 & 0 & 115.139 \\
\hline & 0.422 & 0.513 & 0 & 106.990 \\
\hline & 0.463 & 0.460 & 0 & 99.727 \\
\hline & 0.503 & 0.408 & 0 & 93.143 \\
\hline & 0.544 & 0.357 & 0 & 87.081 \\
\hline & 0.584 & 0.308 & 0 & 81.419 \\
\hline & 0.625 & 0.261 & 0 & 76.056 \\
\hline & 0.666 & 0.217 & 0 & 70.902 \\
\hline & 0.706 & 0.175 & 0 & 65.875 \\
\hline & 0.747 & 0.136 & 0 & 60.889 \\
\hline
\end{tabular}




$\begin{array}{lccr}0.788 & 0.101 & 0 & 55.846 \\ 0.828 & 0.070 & 0 & 50.617 \\ 0.869 & 0.044 & 0 & 45.007 \\ 0.909 & 0.023 & 0 & 38.659 \\ 0.950 & 0.008 & 0 & 30.700 \\ 1.000 & 0.000 & 7.0000 \mathrm{E}-08 & 0.000\end{array}$

Initial conditions like pressure, temperature, saturations, aqueous and gas mole fractions are initially specified a constant and are then modified by using 'MOD' keyword.

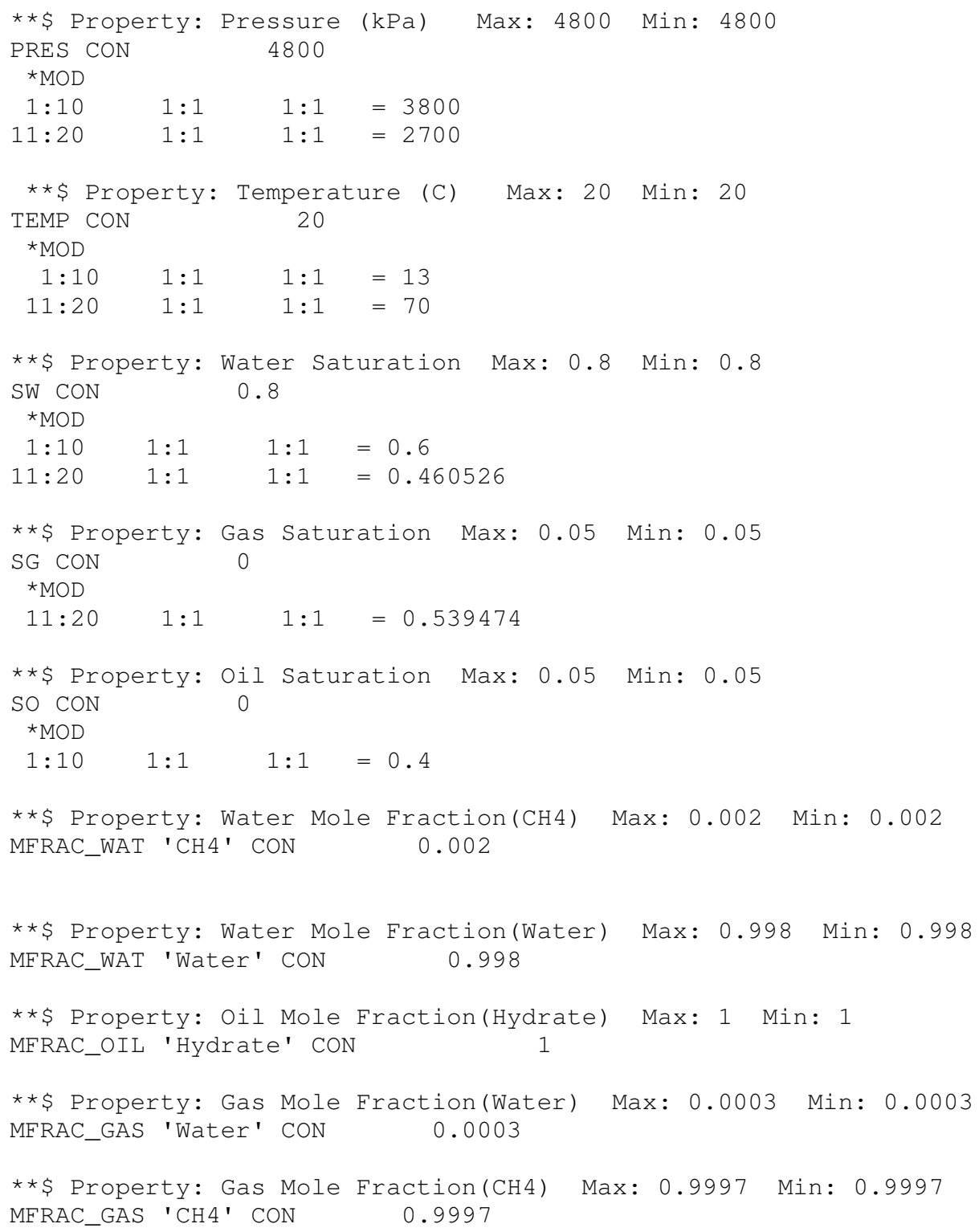

Well Conditions and the time interval chosen to run the simulation is same as in Problem 1

NUMERICAL

RUN 


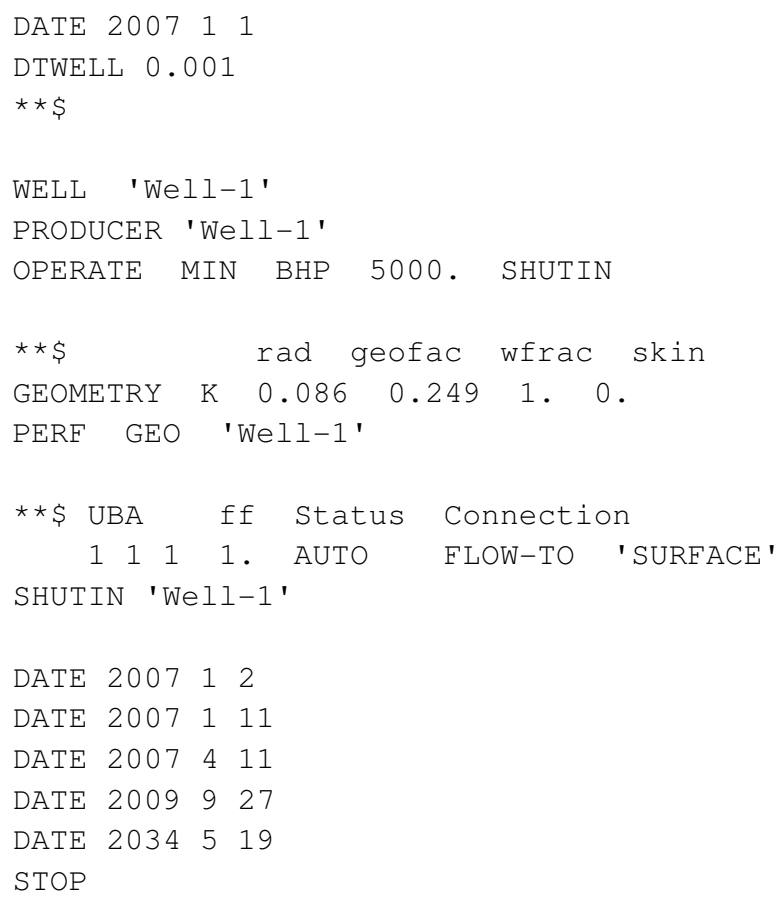

\section{Results}

Thermal stimulation as well as depressurization cause hydrates dissociation initially. As, the simulation time proceeds, dissociation is principally due to thermal stimulation as a result of the propagation of a thermal wave from the second half of the domain. Initially hydrate dissociation occurs without hydrate formation. After 10 days, hydrate formation is observed along with dissociation due to the migration of released methane gas from the other half of the reservoir as shown in Figure 3-12. Equilibrium is reached in the reservoir. All the reservoir properties at different time steps are in perfect agreement with other simulators participating in the study which is shown in Figures 3-10 to Figure 3-16. 

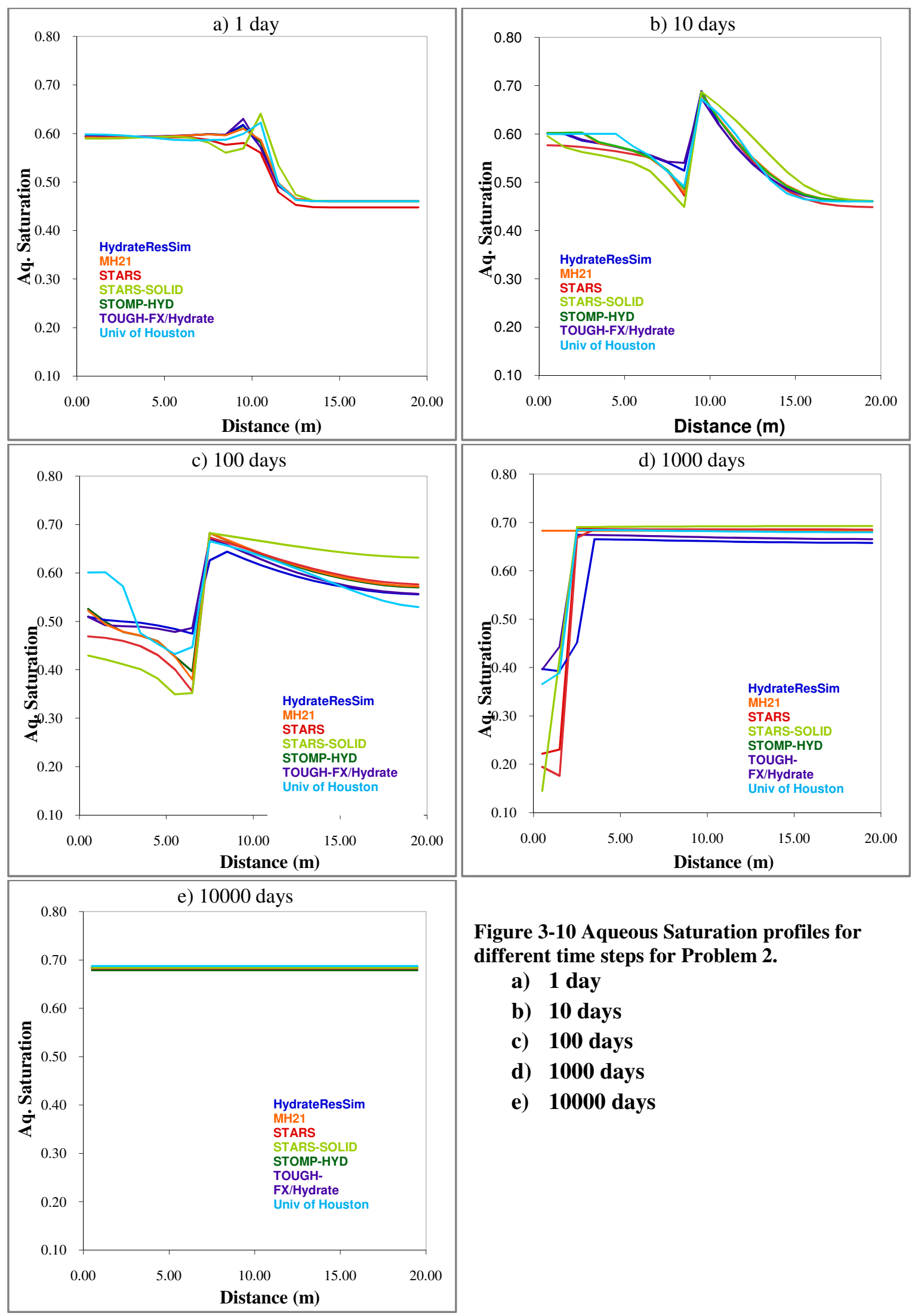

Figure 3-10 Aqueous Saturation profiles for different time steps for Problem 2.
a) 1 day
b) 10 days
c) 100 days
d) 1000 days
e) 10000 days 

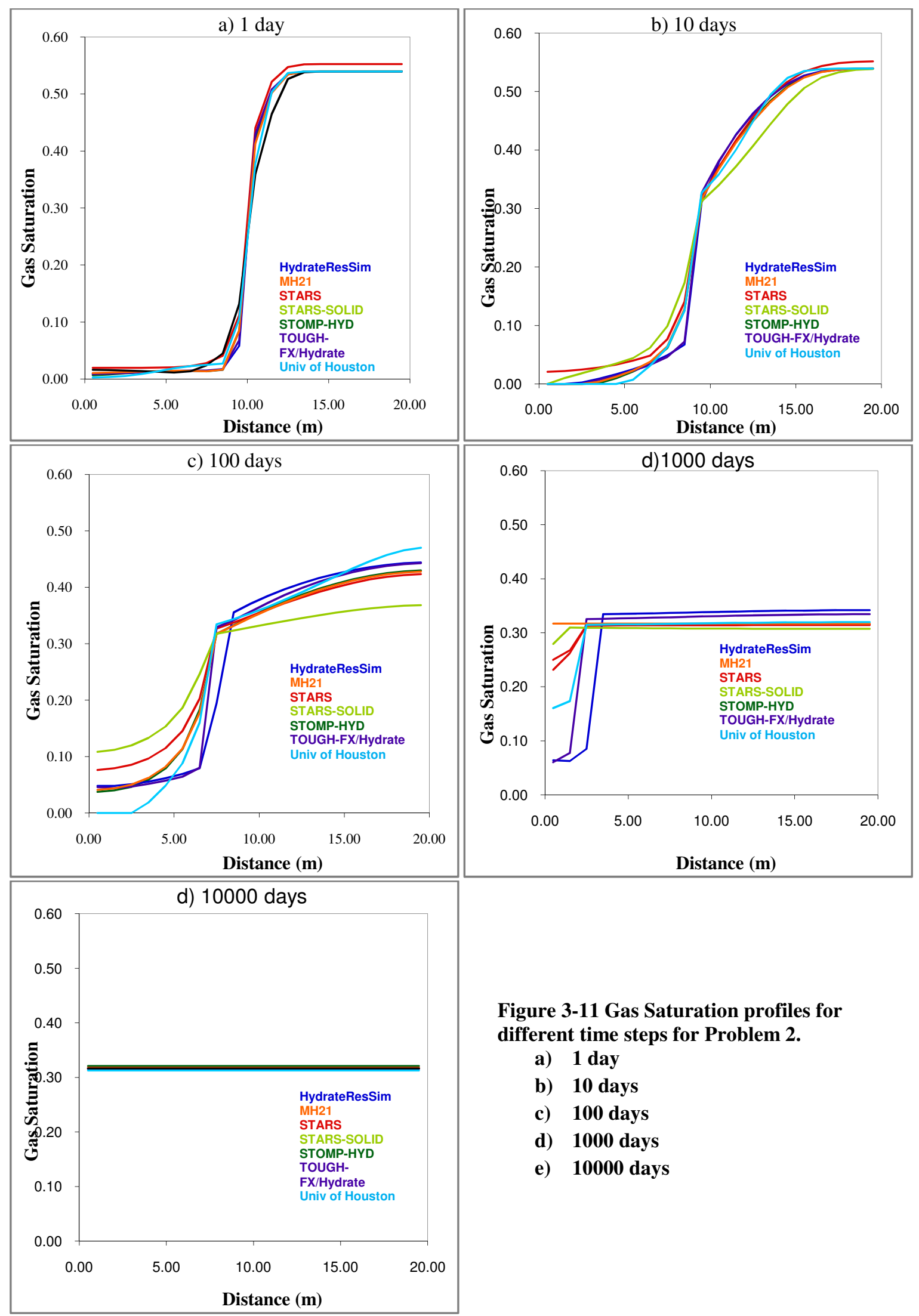

Figure 3-11 Gas Saturation profiles for different time steps for Problem 2.
a) 1 day
b) 10 days
c) 100 days
d) 1000 days
e) 10000 days 

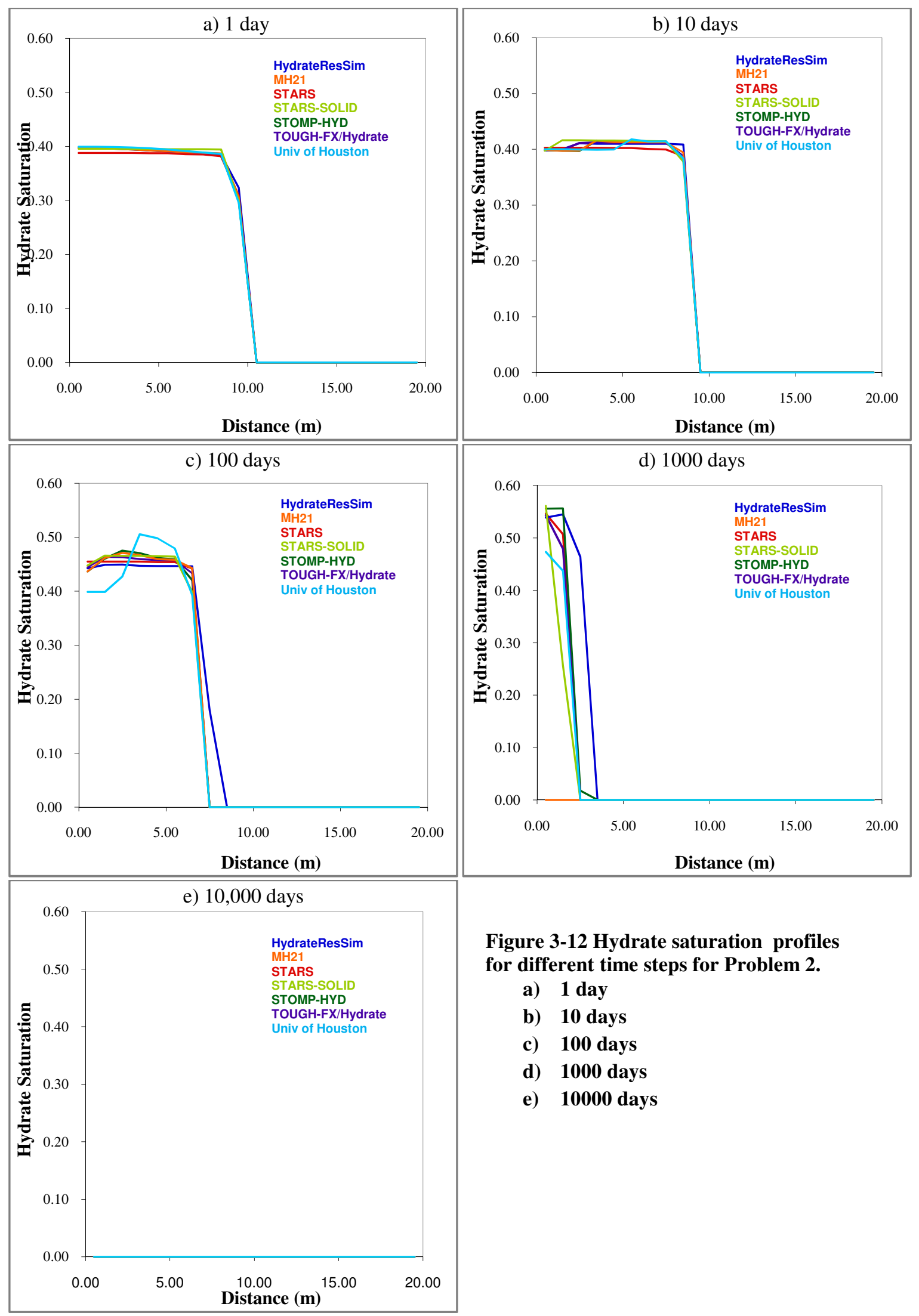

Figure 3-12 Hydrate saturation profiles for different time steps for Problem 2.
a) 1 day
b) 10 days
c) 100 days
d) 1000 days
e) 10000 days 

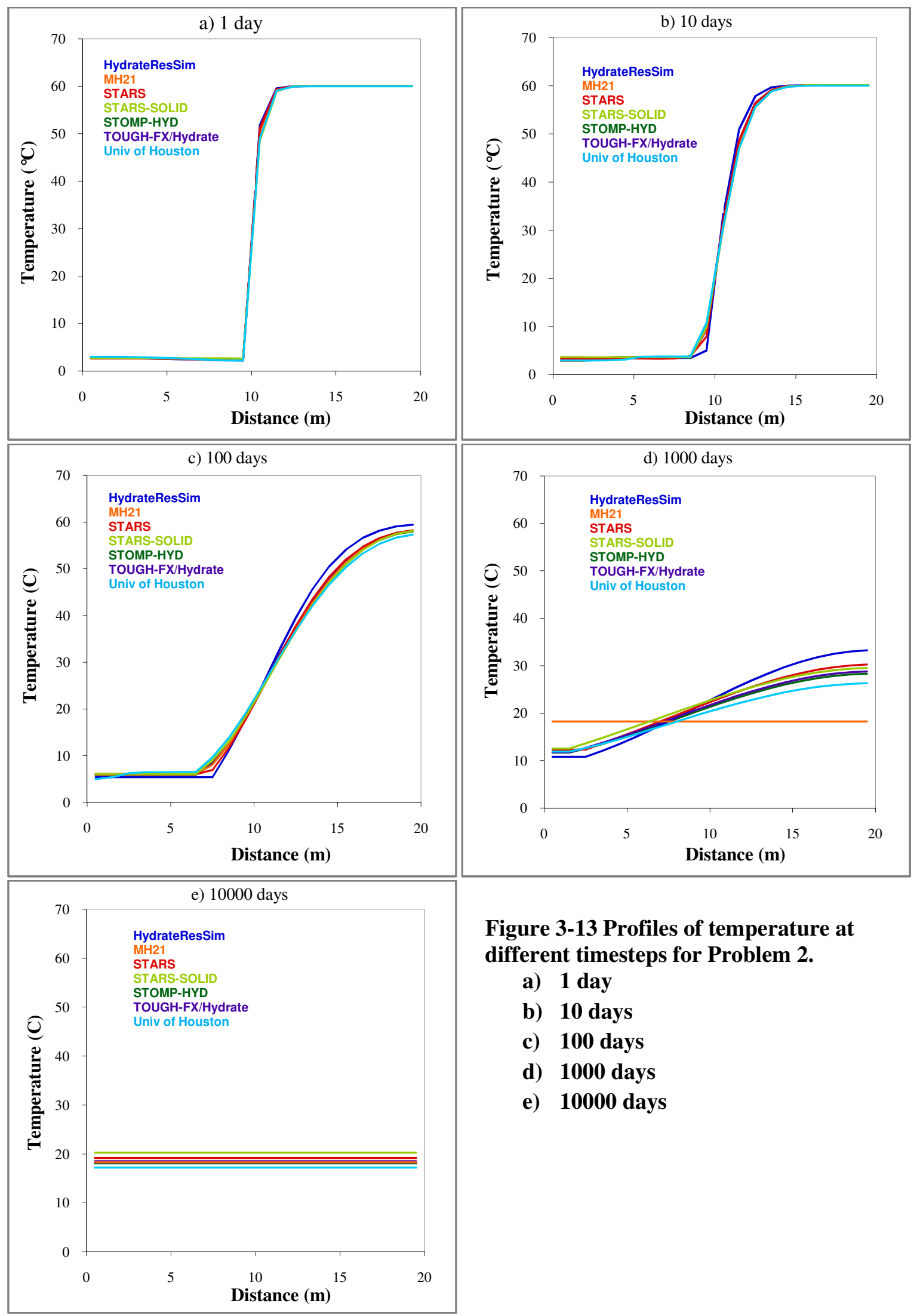

Figure 3-13 Profiles of temperature at different timesteps for Problem 2.
a) 1 day
b) 10 days
c) 100 days
d) 1000 days
e) 10000 days 

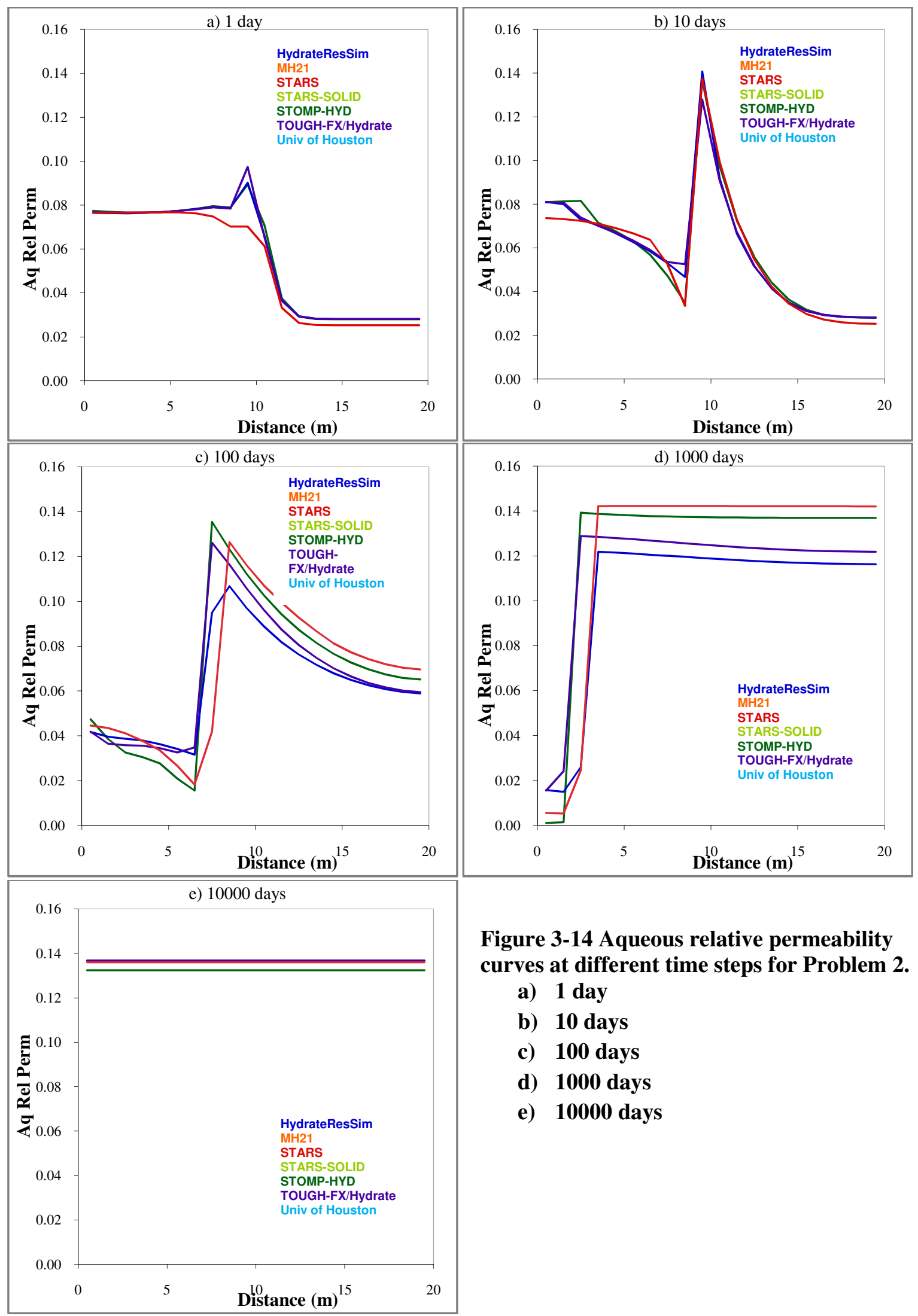

Figure 3-14 Aqueous relative permeability curves at different time steps for Problem 2.
a) 1 day
b) 10 days
c) 100 days
d) 1000 days
e) 10000 days 

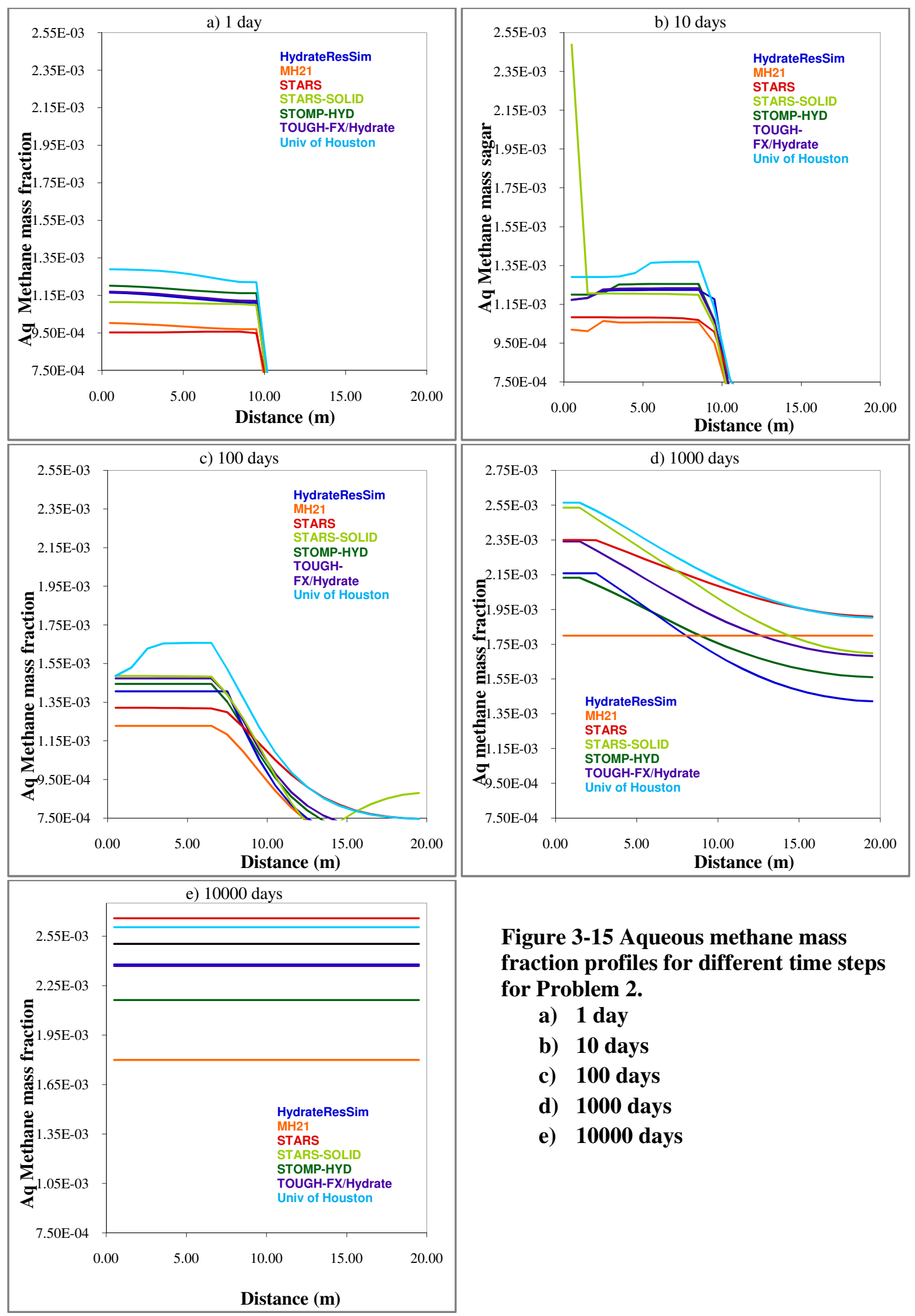

Figure 3-15 Aqueous methane mass fraction profiles for different time steps for Problem 2.
a) 1 day
b) 10 days
c) 100 days
d) 1000 days
e) 10000 days 

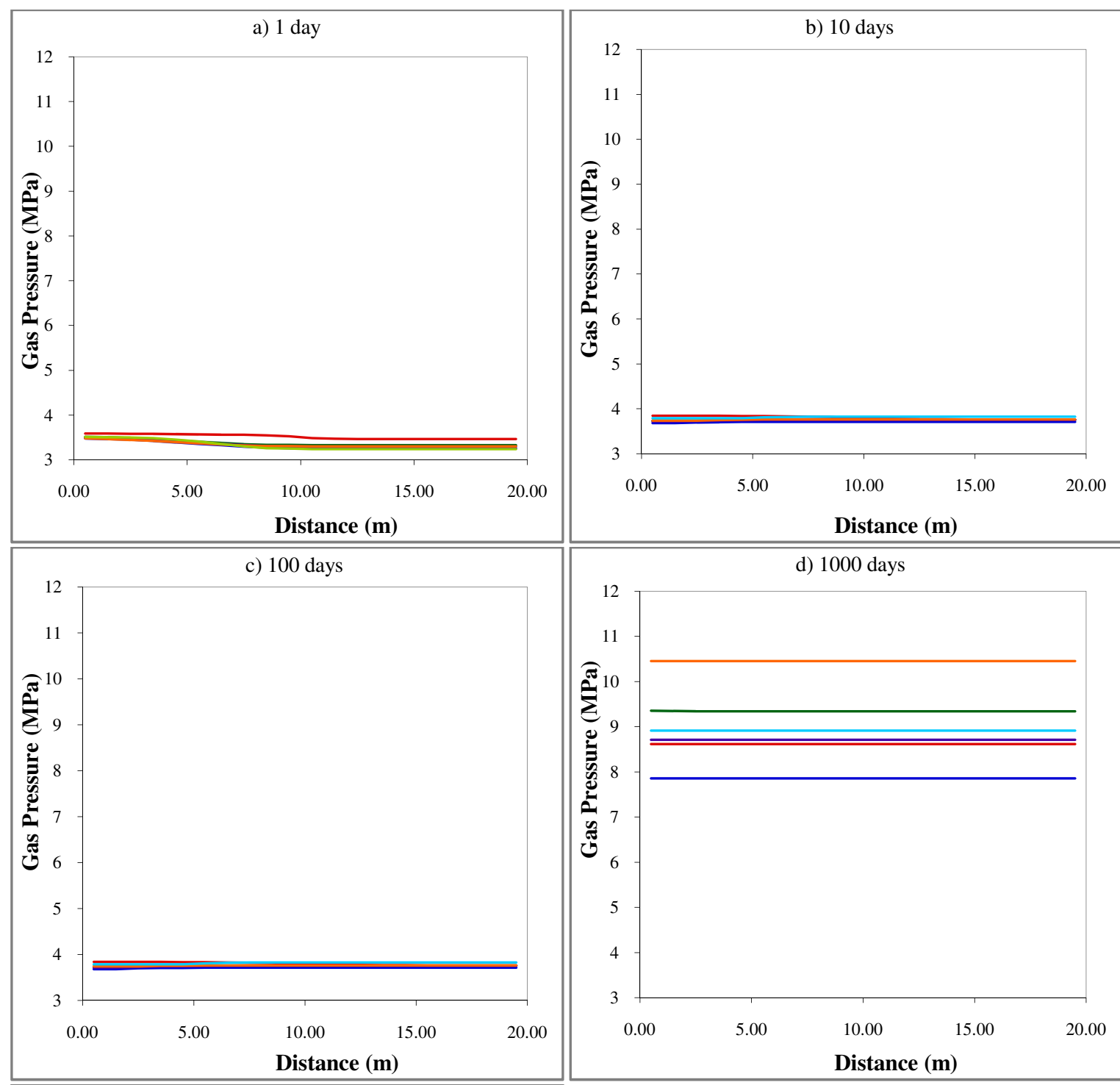

d) 1000 days
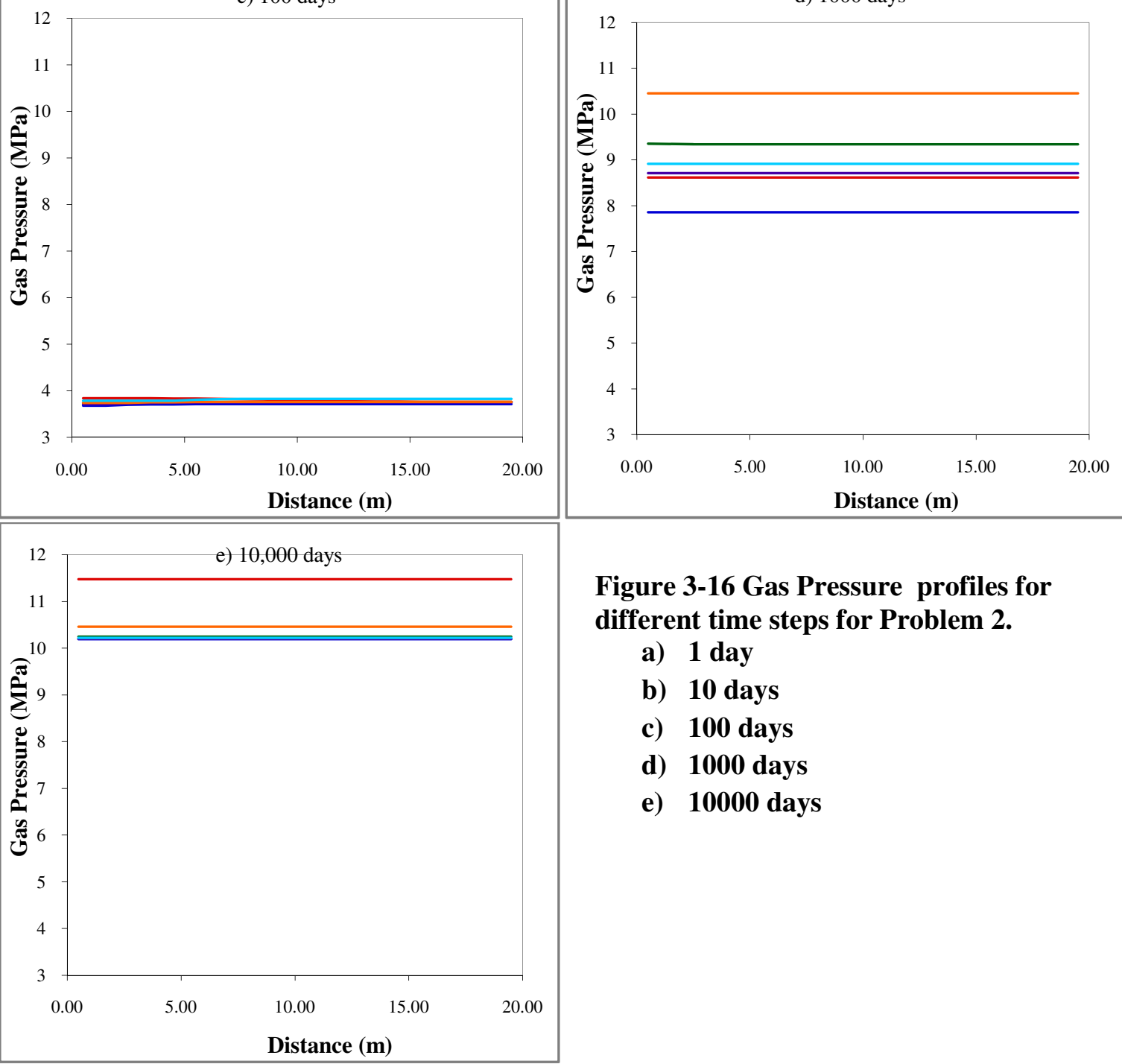

Figure 3-16 Gas Pressure profiles for different time steps for Problem 2.
a) 1 day
b) 10 days
c) 100 days
d) 1000 days
e) 10000 days 


\subsection{Problem 3}

This problem is defined to explore the basic differences between the simulators when a hydrate reservoir is subjected to different production techniques (depressurization and thermal stimulation). In problem 2 there is a heat transfer from one part of the domain to other part leading to hydrate dissociation. In this problem heat is supplied to the system to trigger hydrate dissociation. Hydrate dissociation is an endothermic reaction. During dissociation, formation of ice and secondary hydrate are more likely to occur. Three cases are defined in this problem to closely observe hydrate dissociation and ice formation.

Case 1: Hydrate dissociation due to thermal stimulation

Case 2: Depressurization to a pressure above the Quadruple point (no ice formation)

Case3: Depressurization to a pressure below the Quadruple point leading to ice formation.

\section{Domain Description}

A closed horizontal one dimensional domain is chosen for this problem.

1-D Cartesian system, $\mathrm{L} \times \mathrm{W} \times \mathrm{H}=1.5 \mathrm{~m} \times 1.0 \mathrm{~m} \times 1.0 \mathrm{~m}$.

The entire length is uniformly discretized into 30 cells each of length $0.05 \mathrm{~m}$.

So $\quad \Delta \mathrm{x}=0.05 \mathrm{~m}, \Delta \mathrm{y}=\Delta \mathrm{z}=1 \mathrm{~m}$ 


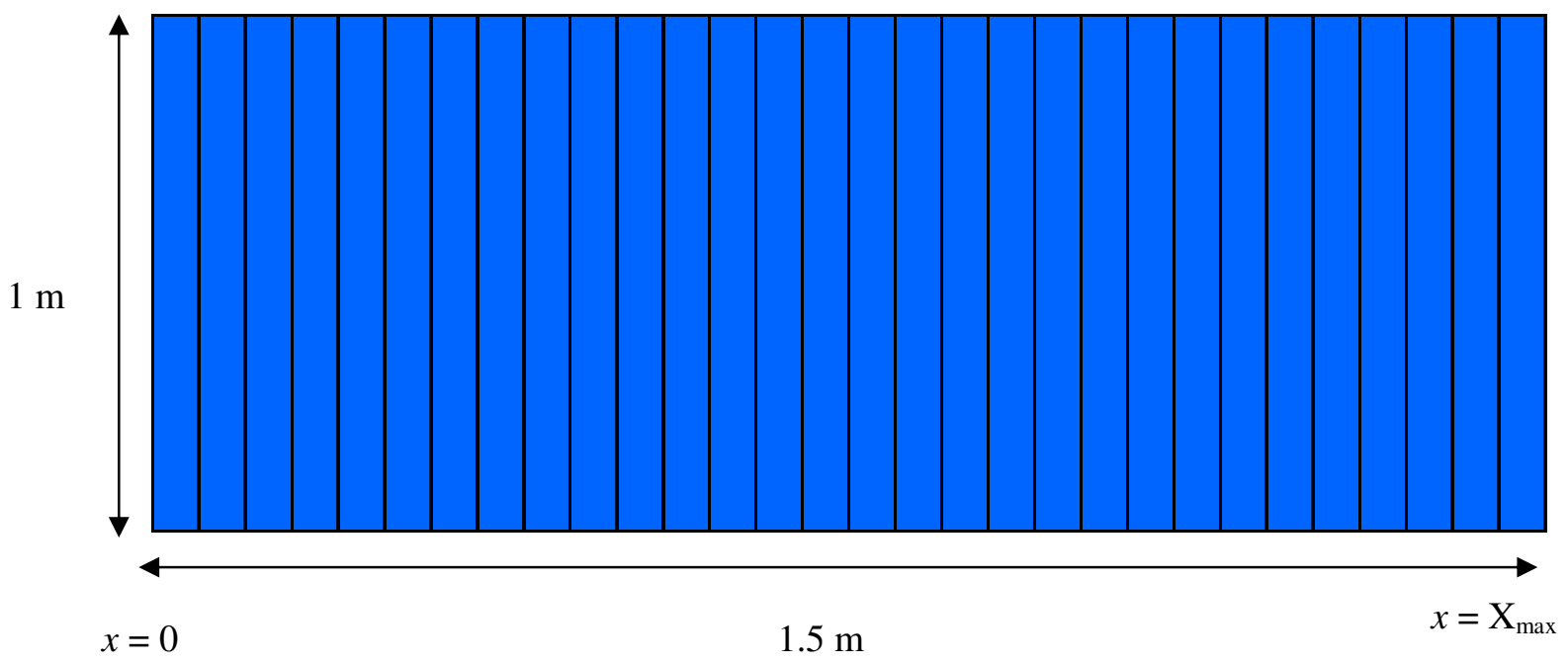

Figure 3- 17 Schematic representation of grid for Problem 3

\section{Case 1: Thermal stimulation}

Pressure and temperature of the entire reservoir are $8 \mathrm{MPa}$ and $2^{\circ} \mathrm{C}$. A constant heat supply is maintained in the first block for the hydrate to dissociate. Initial and Boundary conditions for the entire reservoir are

\section{Initial Conditions}

Pressure: $\quad P_{i}=8 \mathrm{MPa}$

Temperature: $T_{i}=2^{\circ} \mathrm{C}$

Saturations: $\quad S_{H}=0.5, S_{W}=0.5, S_{G}=0.0$

\section{Boundary Conditions}

At $x=X_{\max }$ : No mass or heat flow

At $\quad x=0: \quad S_{W}=1.0$

$$
P_{0}=8 \mathrm{MPa}
$$

$T_{0}=45^{0} \mathrm{C}$ 


\section{Case 2: Depressurization to a pressure above the Quadruple point}

There is no ice formation in this case. The entire reservoir is at an initial pressure of $8 \mathrm{MPa}$ and is depressurized to $2.8 \mathrm{MPa}$. A constant water saturation of $100 \%$ is maintained in the first block.

\section{Initial Conditions}

Pressure: $\quad P_{i}=8 \mathrm{MPa}$

Temperature: $T_{i}=6^{\circ} \mathrm{C}$

Saturations: $\quad S_{H}=0.5, S_{W}=0.5, S_{G}=0.0$

\section{Boundary Conditions}

At $x=X_{\text {max }}$ : No mass or heat flow

At $\quad x=0: \quad S_{W}=1.0$

$$
\begin{aligned}
P_{0} & =2.8 \mathrm{MPa} \\
T_{0} & =6^{0} \mathrm{C}
\end{aligned}
$$

\section{Case 3: Depressurization below the Quadruple point leading to ice formation}

In this case pressure is depressurized up to $0.5 \mathrm{MPa}$ to allow ice to form. The remaining boundary conditions are same as in case 1

Initial Conditions:

Pressure: $\quad P_{i}=8 \mathrm{MPa}$

Temperature: $T_{i}=6^{\circ} \mathrm{C}$

Saturations: $\quad S_{H}=0.5, S_{W}=0.5, S_{G}=0.0$

\section{Boundary Conditions:}

At $x=X_{\max }$ : No mass or heat flow

At $x=0: \quad S_{W}=1.0$

$$
\begin{aligned}
P_{0} & =0.5 \mathrm{MPa} \\
T_{0} & =6^{0} \mathrm{C}
\end{aligned}
$$

The following properties and models used are same for all the cases. 


\section{Medium properties:}

Hydraulic and thermal properties play an important role in the production of gas from gas hydrates. These properties are constant in the entire reservoir.

\section{Thermal properties}

Grain specific heat $\mathrm{C}=1000 \mathrm{~J} / \mathrm{kg} / \mathrm{K}$

Dry Thermal Conductivity $\mathrm{k}_{\Theta \mathrm{D}}=2 \mathrm{~W} / \mathrm{m} / \mathrm{K}$

Wet Thermal Conductivity $\mathrm{k}_{\Theta \mathrm{w}}=2 \mathrm{~W} / \mathrm{m} / \mathrm{K}$

\section{Hydraulic properties}

Intrinsic Permeability: $\quad \mathrm{k}=3.0 \times 10^{-13} \mathrm{~m}^{2}$ (0.3 Darcys)

Porosity: $\quad \phi=0.3$

Pore compressibility: $\quad \beta=5.0 \times 10^{-9} \mathrm{~Pa}^{-1}$

Grain Density: $\quad \rho_{\mathrm{R}}=2600 \mathrm{~kg} / \mathrm{m}^{3}$

\section{Relative permeability model}

The relative permeability model used in this problem is developed by Stone ${ }^{36}$ and Aziz ${ }^{37}$.

$$
\begin{aligned}
& k_{r G}=\left(S_{G}^{*}\right)^{n}, \quad S_{G}^{*}=\left(S_{G}-S_{i r G}\right) /\left(1-S_{i r A}\right) \\
& k_{r A}=\left(S_{A}^{*}\right)^{n}, S_{A}^{*}=\left(S_{A}-S_{i r A}\right) /\left(1-S_{i r A}\right)
\end{aligned}
$$

Where $S_{i r G}, S_{i r A}$ represents irreducible gas and aqueous saturation.

In this problem $S_{i r G}=0.02, S_{i r A}=0.12$ and $\mathrm{n}=3.0$.

A plot of relative permeability vs. water saturation is shown in Figure 3-18. 


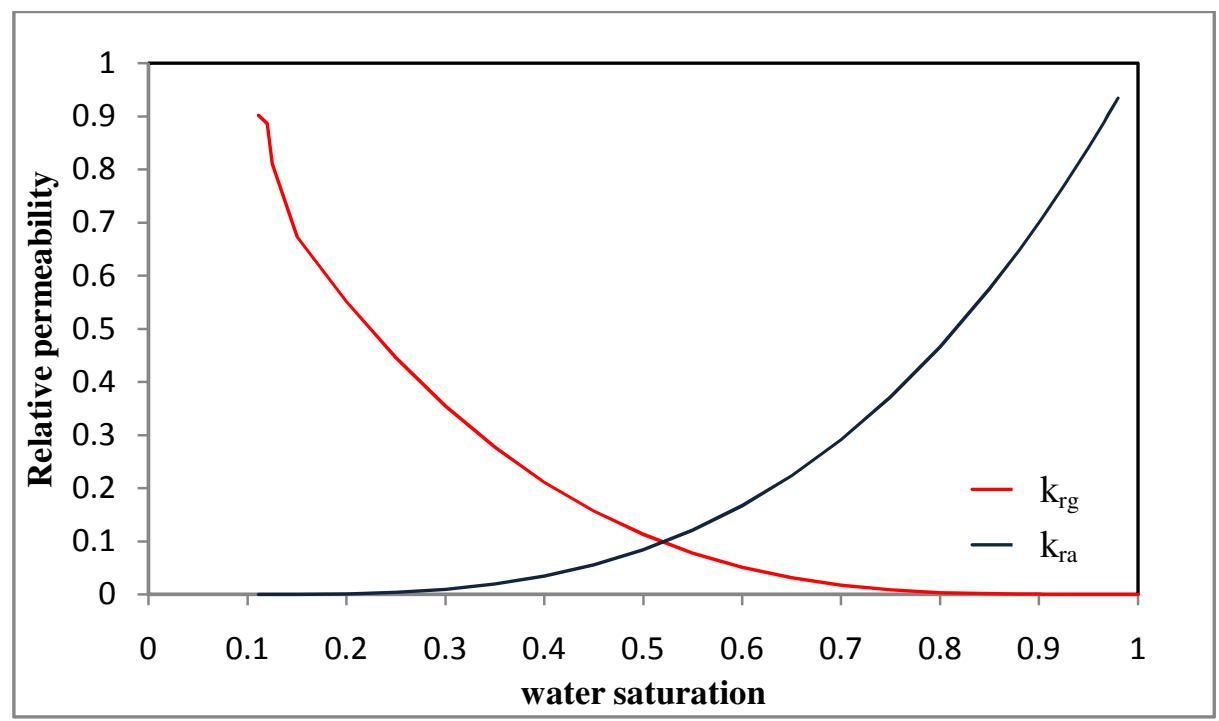

Figure 3- 18 Aqueous and Gas Relative permeability curves as a function of Water Saturation

\section{Capillary pressure Model}

Capillary pressure model used is same as in the above problems. A plot of capillary pressures vs. water saturation is shown in Figure 3-19. Different parameters used in this model are specified in Table 3-3.

$P_{\text {cap }}=-P_{0}\left[\left(S^{*}\right)^{-1 / \lambda}-1\right]^{\lambda}, S^{*}=\frac{\left(S_{A}-S_{i r A}\right)}{\left(S_{m \times A}-S_{i r A}\right)}$

Where $-P_{\max } \leq P_{c a p} \leq 0$

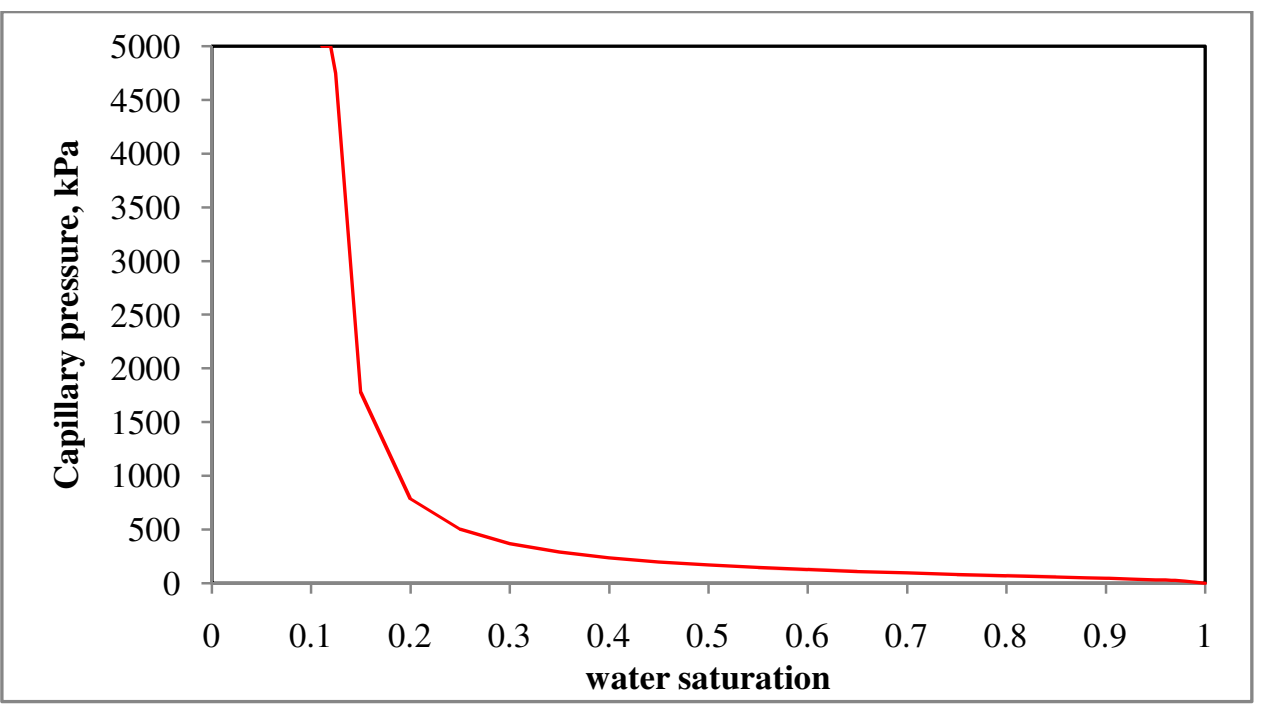

Figure 3-19 Capillary Pressure vs. Water Saturation 


\section{Data and sampling frequency}

Profiles of water saturation, temperature, pressure, aqueous relative permeability, and aqueous methane mass fraction and capillary pressure, gas rate, cumulative gas rate are compared for different time steps. The time steps considered here are different for each case.

\section{Case 1: Thermal stimulation}

Data recorded at 1 hr, 3 hrs, 6 hrs, 12 hrs, 1 day, 2 days, 3 days, and 5 days

\section{Case 2: Depressurization to a pressure above the $Q$ point}

Results reported at $2 \mathrm{~min}, 5 \mathrm{~min}, 20 \mathrm{~min}, 1 \mathrm{hr}, 1.5 \mathrm{hrs}, 12 \mathrm{hrs}, 1 \mathrm{day}, 2$ days, and 3 days

\section{Case 3: Depressurization to a pressure below $Q$ point}

Results reported at 2min, 5min, 10min, 20min, $30 \mathrm{~min}, 45 \mathrm{~min}, 1 \mathrm{hr}, 1$ day, 5 days. 


\subsubsection{Solution to Problem 3}

The grid in problem 1 is a 1-D domain of length $1.5 \mathrm{~m}$. The entire length is uniformly discretized into 30 cells each of length $0.05 \mathrm{~m}$. The same grid is used for all the cases. The grid is modified to meet the boundary conditions of the problem. The difficulty in this problem lies in maintaining the boundary conditions applied for each case throughout the run. All the cases have a boundary condition that water saturation at $x=0$ is always $100 \%$ throughout the simulation. In STARS, it is not practical to maintain a constant boundary in a block. The boundary conditions are achieved and have to be maintained so by making some other changes in the system. Other simulators can treat the block as a single entity and assign fixed properties. STARS have an inbuilt well bore model. Once a well is defined, it is not a block anymore. For each block a water saturation of $100 \%$ is difficult is attain and even if it is specified, the saturation later changes due to mass transfer and the boundary condition is abandoned. This was a major difficulty in solving this problem.

For each $\mathrm{s}_{\mathrm{w}}=1$ boundary condition is difficult to attain.

To overcome this problem a bigger block was incorporated but even then water saturation did not match with other codes. To match the results with other codes and to fix the boundary condition problem, two extra blocks were defined. Water is injected at high rate of $50,000 \mathrm{~m}^{3} /$ day in the first block and then produced at the same rate. The permeability's of the two blocks are set very high so that these two blocks do not affect the properties like pressure temperature and saturations of the rest of the blocks. Temperature of the water that is injected is set according to the boundary condition required for each case.

The modified grid is of length $2.5 \mathrm{~m}$. The first two cells are each of length $0.5 \mathrm{~m}$. The next 30 cells are of $0.05 \mathrm{~m}$ in length as per the problem description. A constant porosity of 0.3 is used. Permeability for the first two cells is constant and is $1 \mathrm{e} 6 \mathrm{mD}$. Other 30 cells have a constant permeability of $300 \mathrm{mD}$.

Grid description, component properties, Hydrate dissociation formation reactions and rock-fluid properties are same for all the cases $(1,2 \& 3)$ and are specified below in the input data file. 


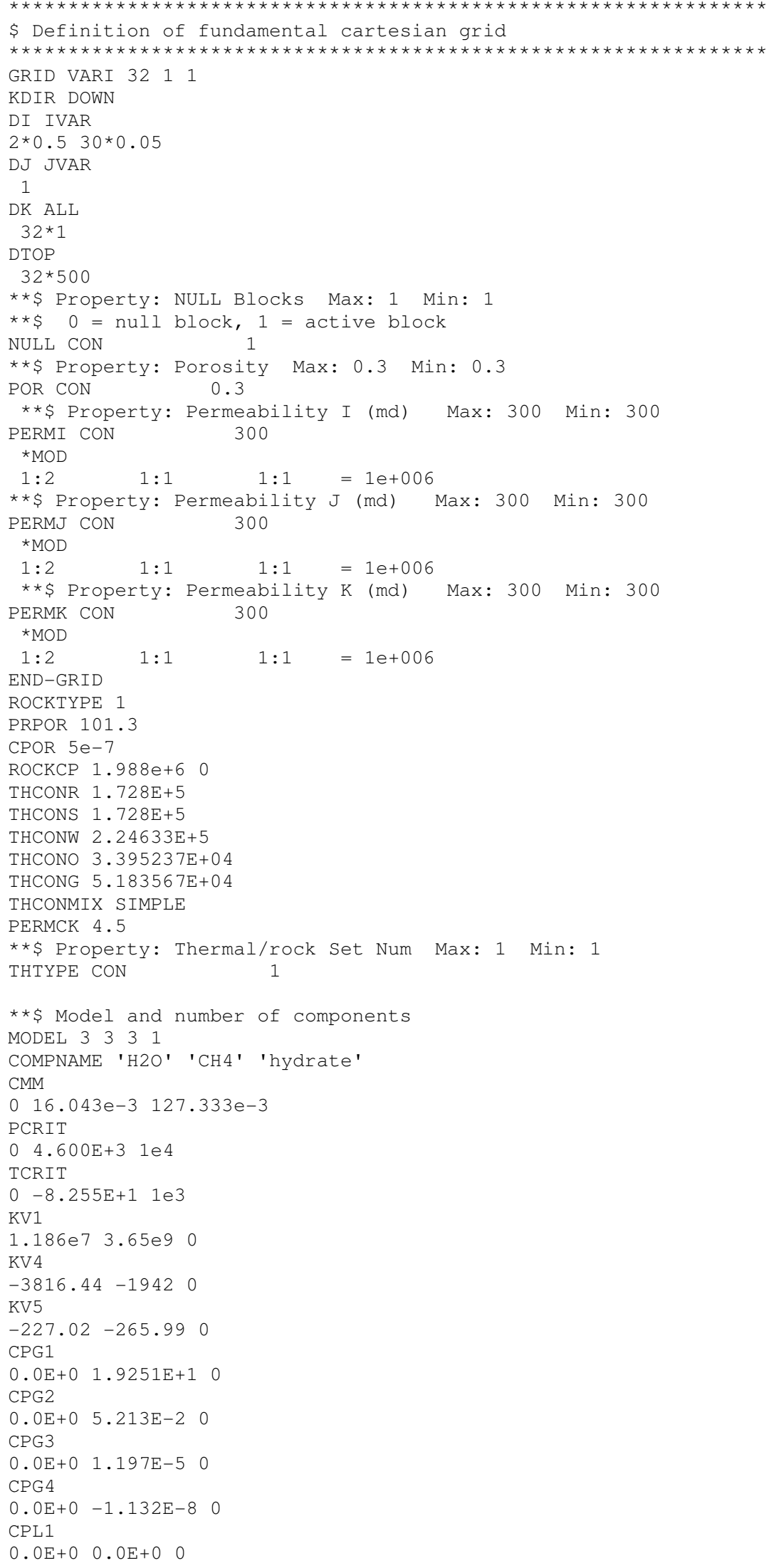




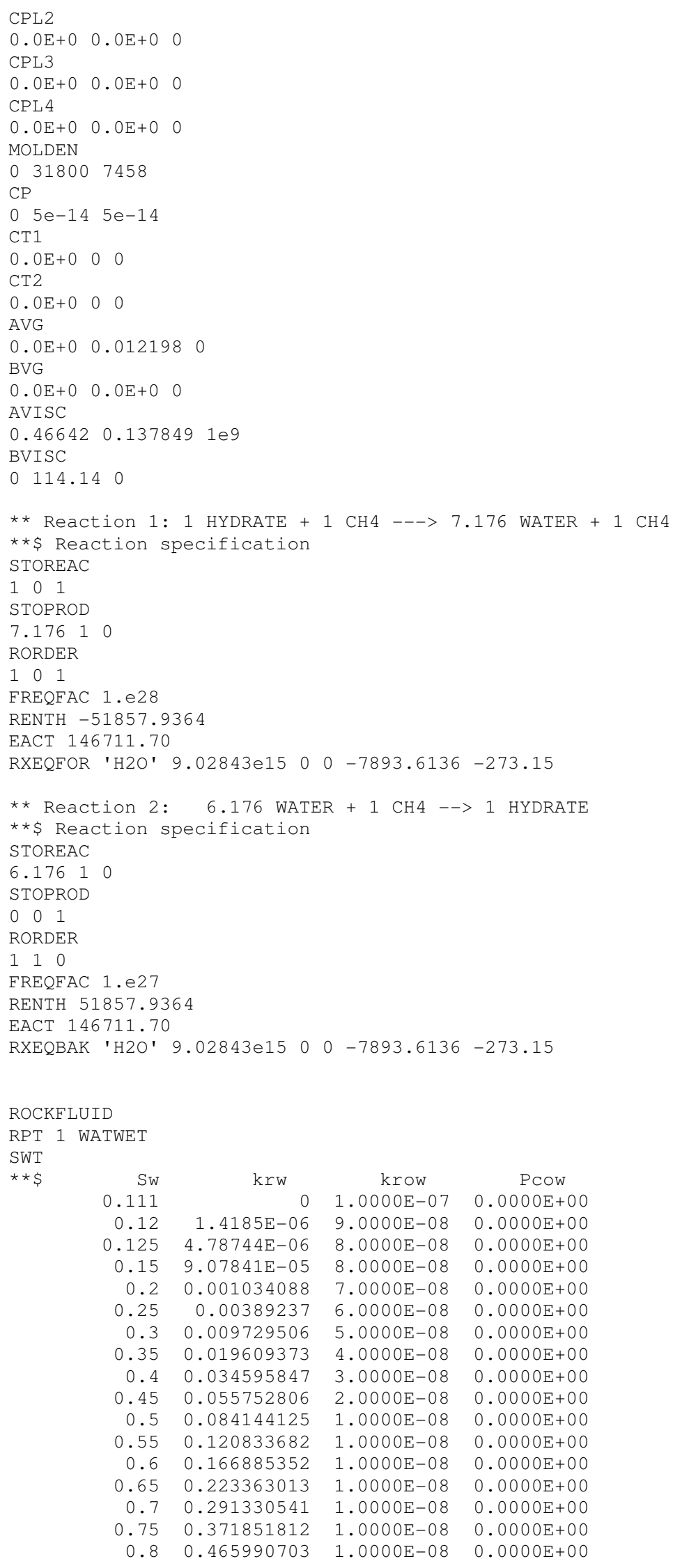




$\begin{array}{rrrr}0.85 & 0.574811091 & 1.0000 \mathrm{E}-08 & 0.0000 \mathrm{E}+00 \\ 0.88 & 0.647593015 & 1.0000 \mathrm{E}-08 & 0.0000 \mathrm{E}+00 \\ 0.9 & 0.699376852 & 1.0000 \mathrm{E}-08 & 0.0000 \mathrm{E}+00 \\ 0.903 & 0.707374731 & 1.0000 \mathrm{E}-08 & 0.0000 \mathrm{E}+00 \\ 0.925 & 0.767896709 & 1.0000 \mathrm{E}-08 & 0.0000 \mathrm{E}+00 \\ 0.95 & 0.840751863 & 1.0000 \mathrm{E}-08 & 0.0000 \mathrm{E}+00 \\ 0.958 & 0.865002847 & 1.0000 \mathrm{E}-08 & 0.0000 \mathrm{E}+00 \\ 0.96 & 0.871137596 & 1.0000 \mathrm{E}-08 & 0.0000 \mathrm{E}+00 \\ 0.966 & 0.889715741 & 1.0000 \mathrm{E}-08 & 0.0000 \mathrm{E}+00 \\ 0.97 & 0.902246765 & 1.0000 \mathrm{E}-08 & 0.0000 \mathrm{E}+00 \\ 0.98 & 0.934087882 & 0 & 0.0000 \mathrm{E}+00\end{array}$

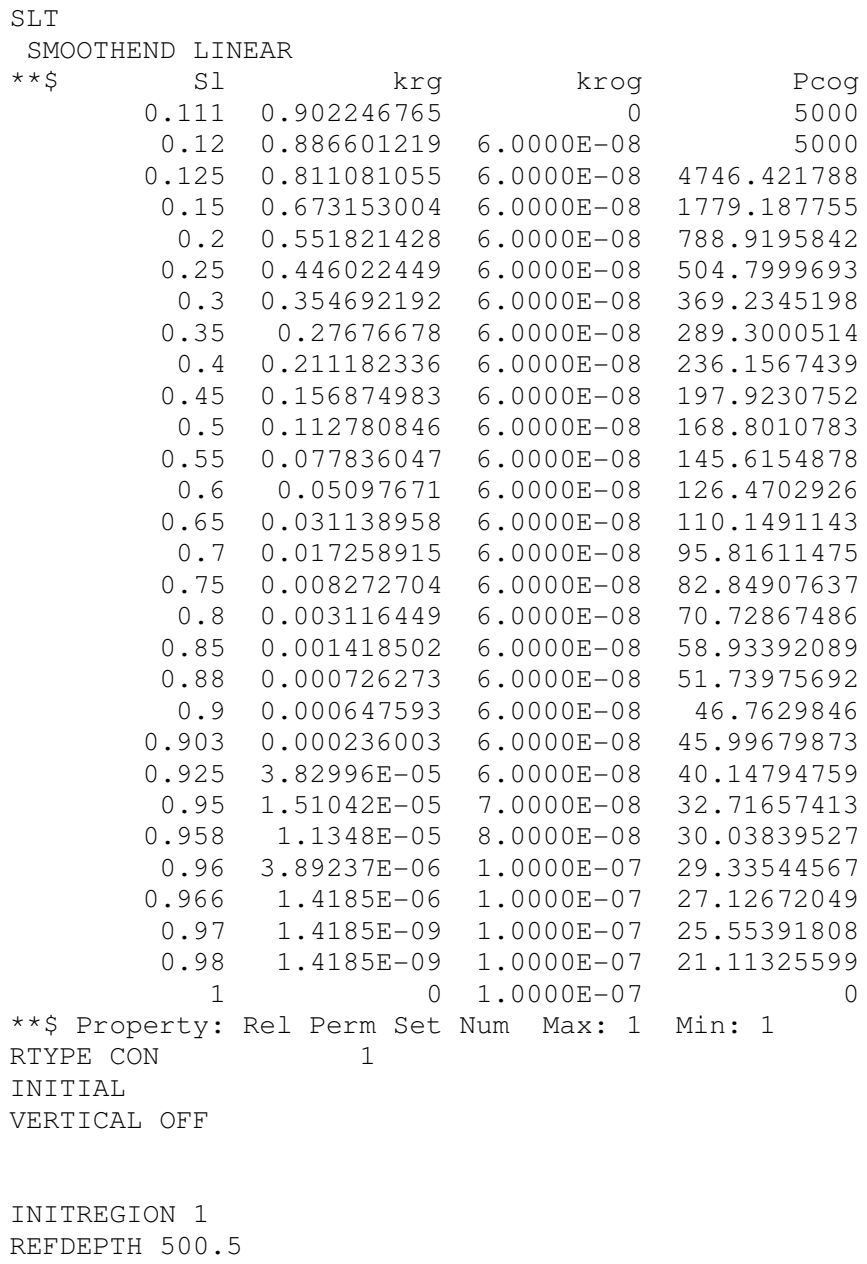

Pressure, temperature, saturations of the grid blocks are different for each case and are specified according to the problem description. Well constraints are different in all the cases and are specified in the input data file for each case.

\section{Case 1}


Pressure of the reservoir is $8 \mathrm{MPa}$ and temperature of the reservoir is $2^{\circ} \mathrm{C}$. The temperature of the first three blocks is maintained at a constant temperature of $45^{\circ} \mathrm{C}$. Water is injected in the first block through an injector well (well 1) at rate of $50,000 \mathrm{~m}^{3} /$ day. A producer well is introduced in the second block and water is produced at the same rate of $50,000 \mathrm{~m}^{3} /$ day. The temperature of the injected stream (water) is $45^{\circ} \mathrm{C}$. Initially there is no gas in the reservoir. Hydrate saturation is $50 \%$ in the entire reservoir. The time steps at which the simulations are carried out are different for each case and are specified according to the problem description.

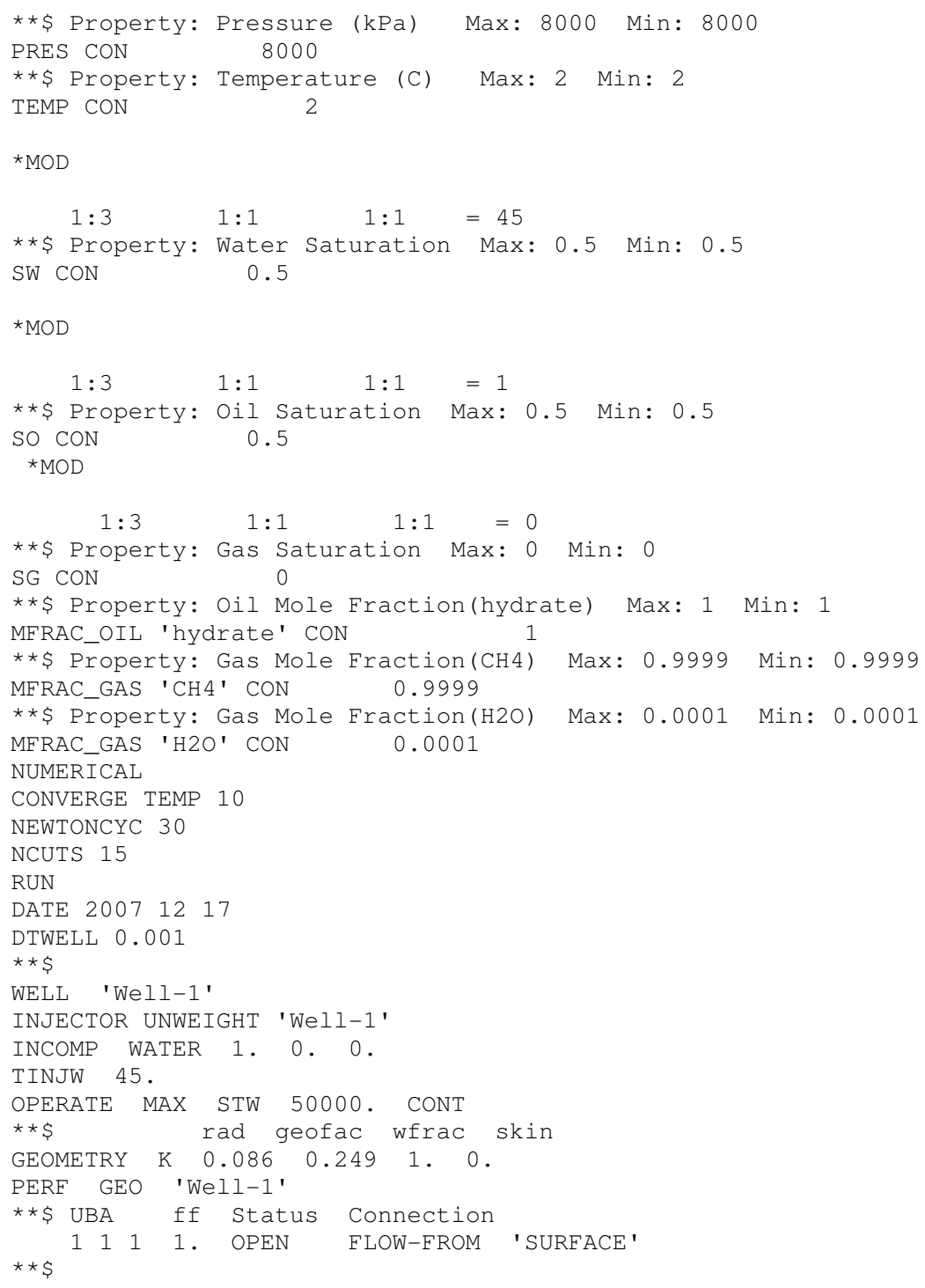




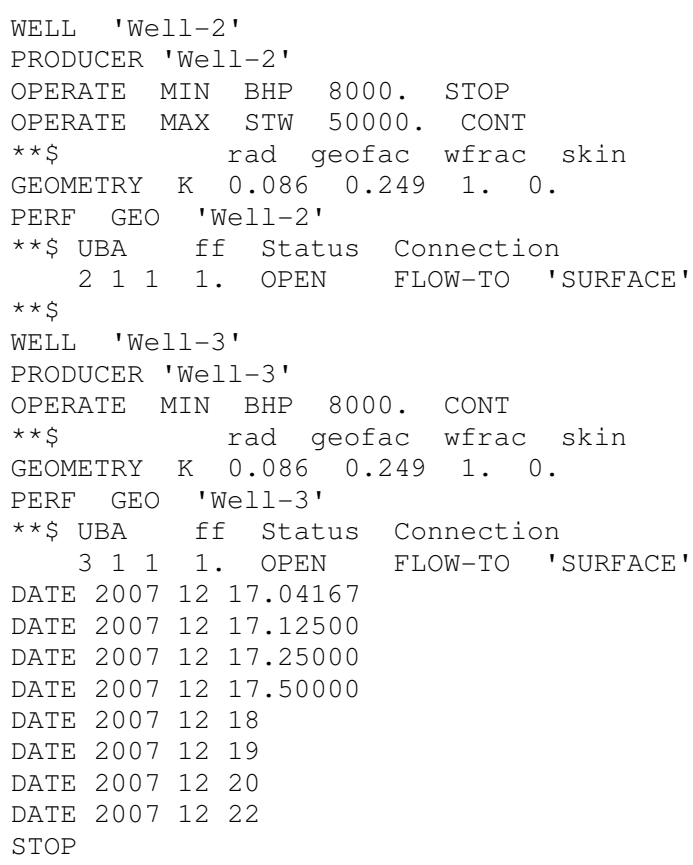

\section{Case 2}

The reservoir in this case is depressurized to a Bottom-hole pressure of $2.8 \mathrm{MPa}$ leading to hydrate dissociation. Pressure and temperature for the entire reservoir are $8 \mathrm{MPa}$ and $6^{\circ} \mathrm{C}$. Three wells are defined in the first three blocks as in the previous case. Water is injected at a rate of $10,000 \mathrm{~m}^{3} /$ day in the first block and produced at the same rate in the second block by a producer well. The temperature of the injected stream (water) is $6^{\circ} \mathrm{C}$. This flow rate gave better match of results of CMG STARS with other hydrate codes. The part of data file different from the previous case is given below.

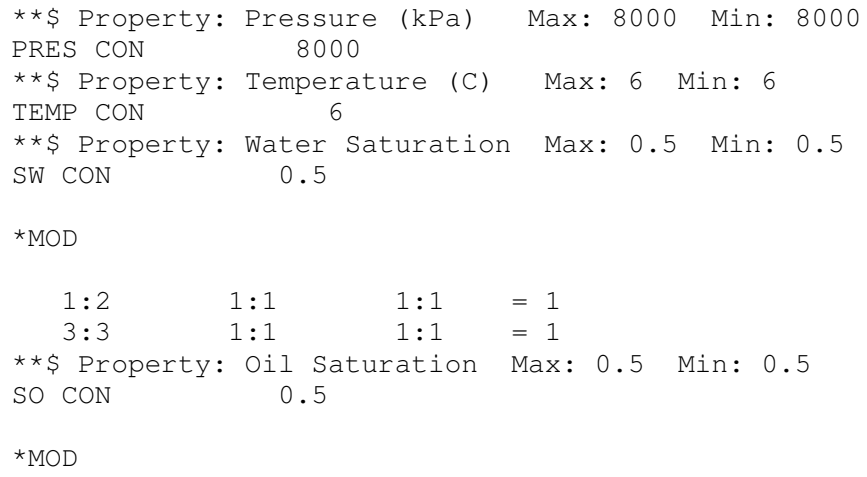




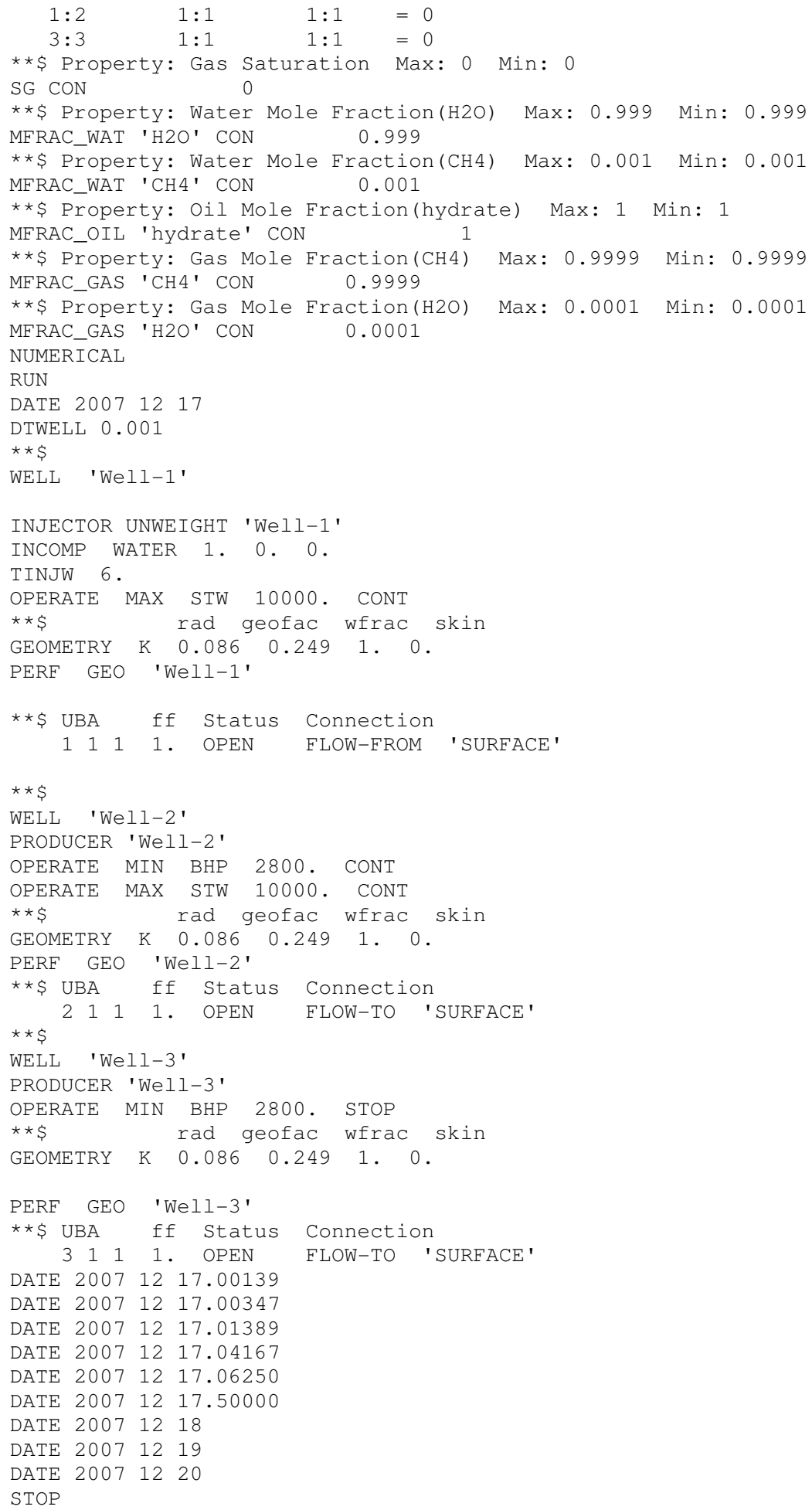




\section{Case 3}

In this case the reservoir is depressurized to a lower pressure of $500 \mathrm{kPa}$. Ice formation is included in the system by adding "*ICE" keyword in the component property section in the input data file. Three wells are defined as in the previous case to ensure that the water saturation in the first block is always one and the bottom-hole pressure applied is $500 \mathrm{kPa}$.

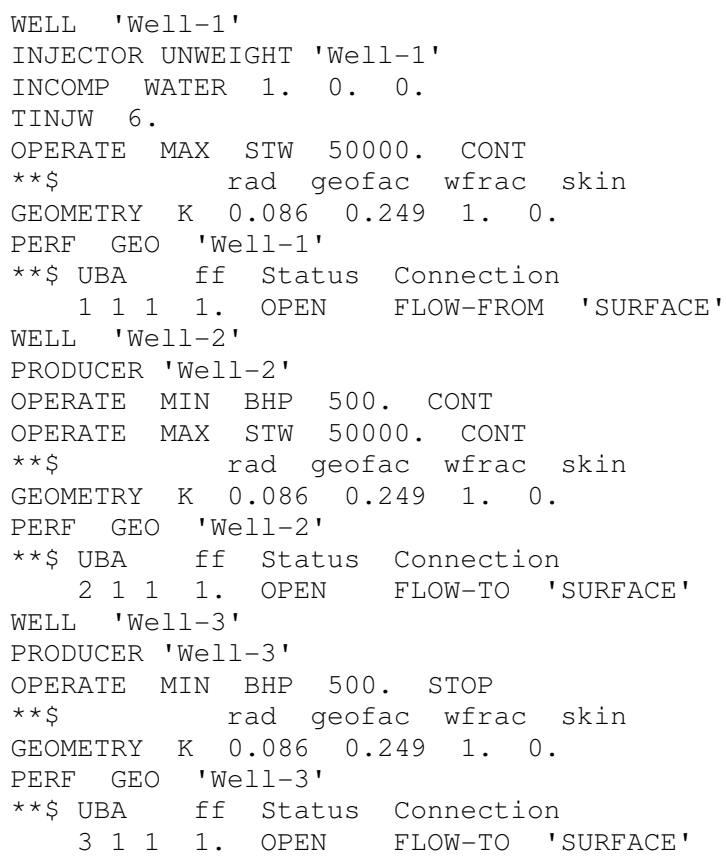

\section{Results}

\section{CASE 1}

Profiles of aqueous saturation for CMG STARS are in good agreement with other codes. Initially water saturation is 0.5 for the entire reservoir. It is subject to a boundary condition $S_{w}=1.0$ at $x=0$. In STARS the boundary condition is obtained by continuous injection and production of water from the first and second blocks. Unlike other codes STARS took a little longer time to maintain this boundary condition. It can be seen from Figure 3-20 that aqueous saturation for the first half of the domain is highly affected by the boundary 
condition. There is a drop in the aqueous saturation values due to secondary hydrate formation. Figure 3-20 shows profiles of aqueous saturation for selected time steps $(1 \mathrm{hr}, 3$ hrs, 6 hrs, 12 hrs, 1 day, 2 days, 3 days, 5 days).

Initially there is no gas in the reservoir. Hydrate dissociates due to the heat given to the system in the form of boundary condition at $x=0, \mathrm{~T}_{\mathrm{o}}=45^{\circ} \mathrm{C}$. Gas saturation at $\mathrm{x}=0$, is not zero initially because the water saturation at this point is not 1 . Higher saturations are observed near the well bore for different time steps given in Figure 3-21. Results of CMG STARS are in good agreement with other codes.

Hydrate saturation is 0.5 initially for the entire reservoir. Due to thermal stimulation hydrate which is near to the well bore quickly dissociates. Hydrate formation is also observed in this case. All the simulators captured the movement of dissociation front in the same way. As the simulation proceeds hydrate dissociates slowly which indicates the slow movement of the thermal wave in the reservoir as shown in Figure 3-22. At the end of the simulation which is at 5 days hydrate in the first half of the domain dissociates completely.

This is a thermal stimulation case so it is very important to match temperature profiles. CMG STARS are in excellent agreement with other codes as seen from Figure 3-23. Small peaks in the profiles of temperature show the movement of dissociation front.

Aqueous relative permeability is a function of aqueous saturation. As the simulation proceeds and boundary condition of water saturation equal to $100 \%$ is attained in the first block there is a complete match of the permeability curves. Figure 3-24 shows the aqueous permeability curves at different time steps. Due to the injector and the producer wells in the system the 
pressure of the reservoir is shifted to a higher value. This is shown in Figure 3-26. Due to higher pressure values aqueous mass fraction is also shifted as shown in Figure 3-25. Capillary pressure is expressed as a function of liquid saturation in STARS. However the profiles of capillary pressure look similar to other codes as in Figure 3-27 

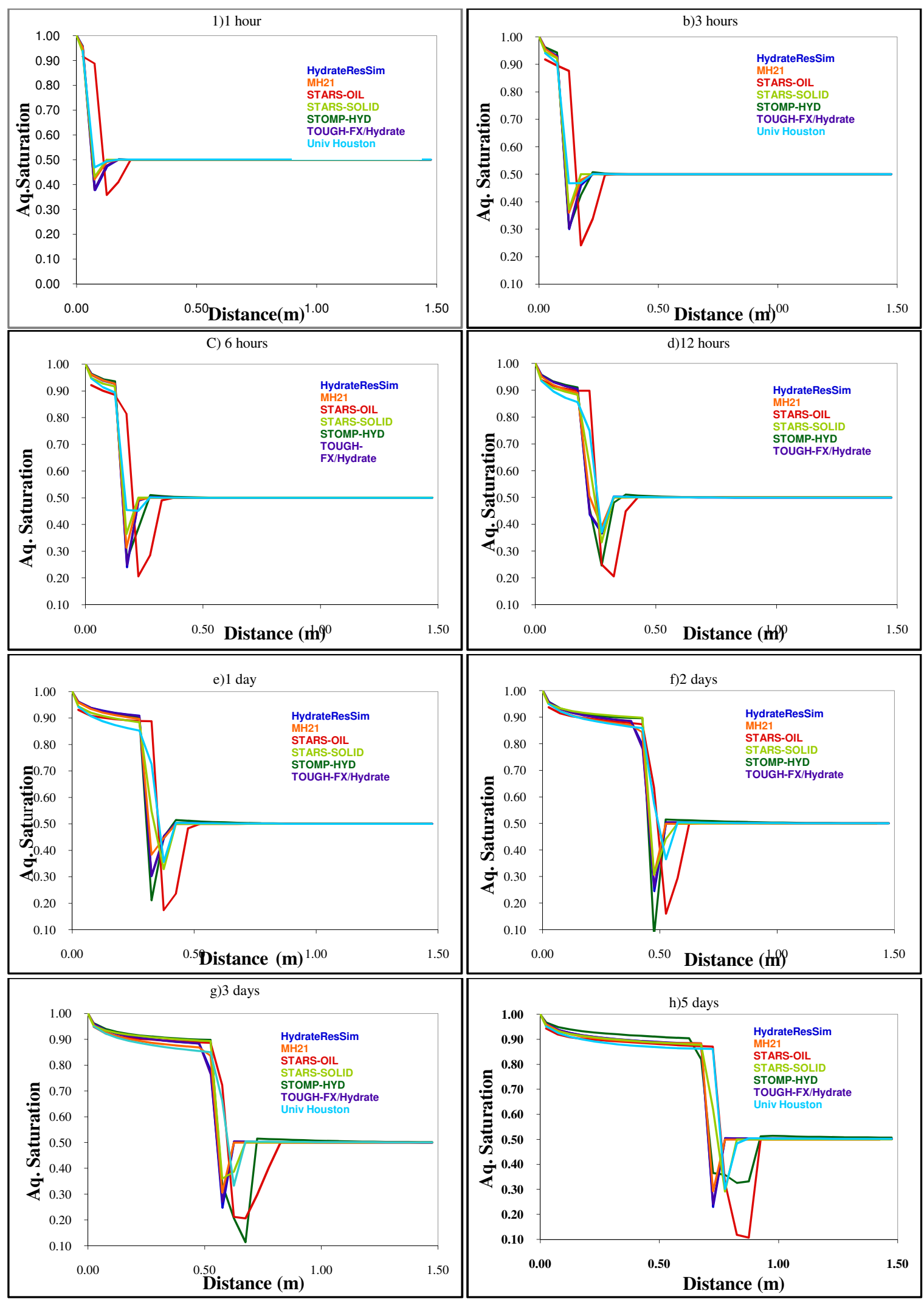

Figure 3- 20 Profiles of Aqueous saturation at different times for problem 3 Case 1 

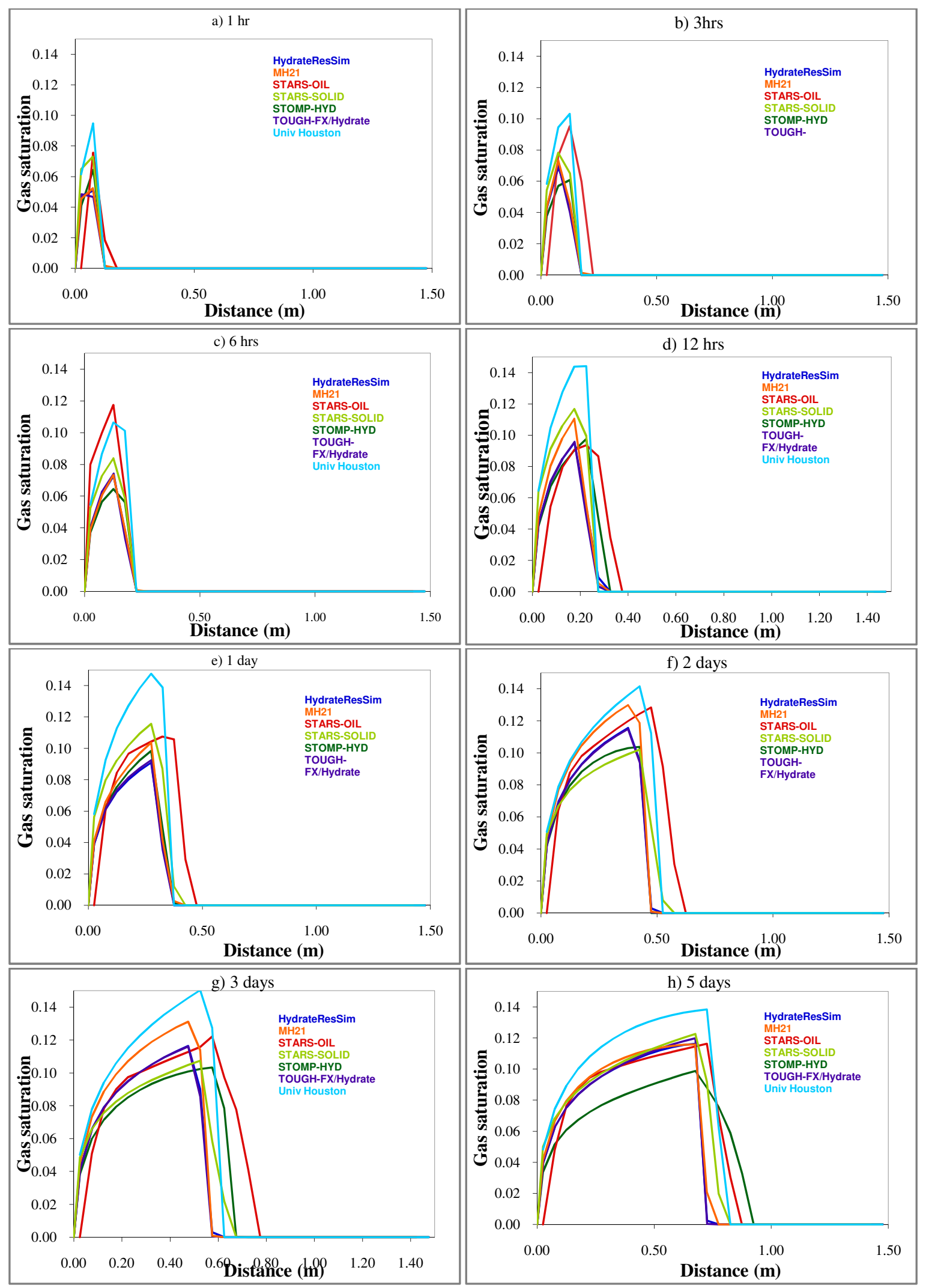

Figure 3- 21 Profiles of gas saturation at different time steps for Problem 3 Case 1 

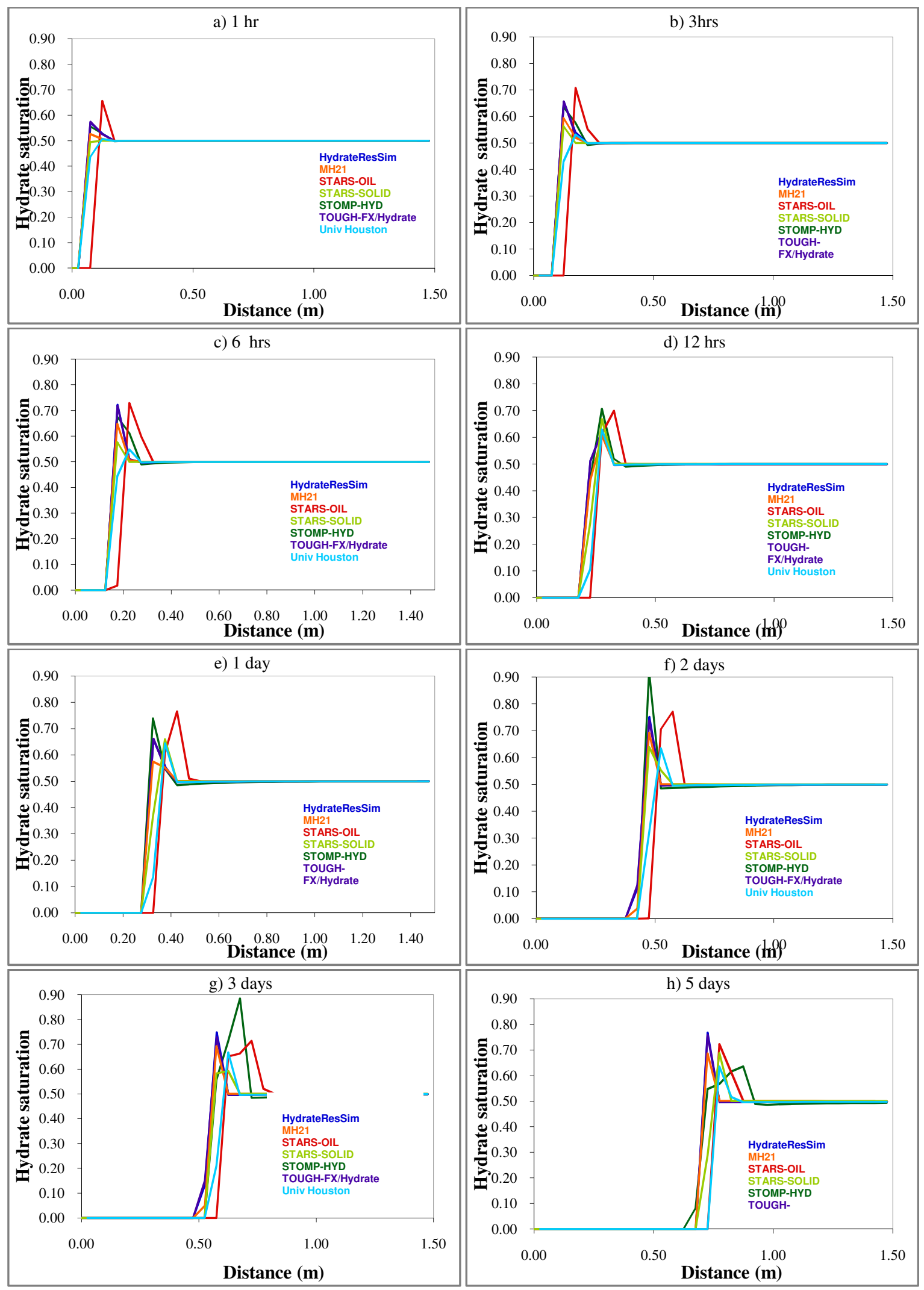

Figure 3- 22 Profiles of hydrate saturation at different times for Problem 3 Case 1 

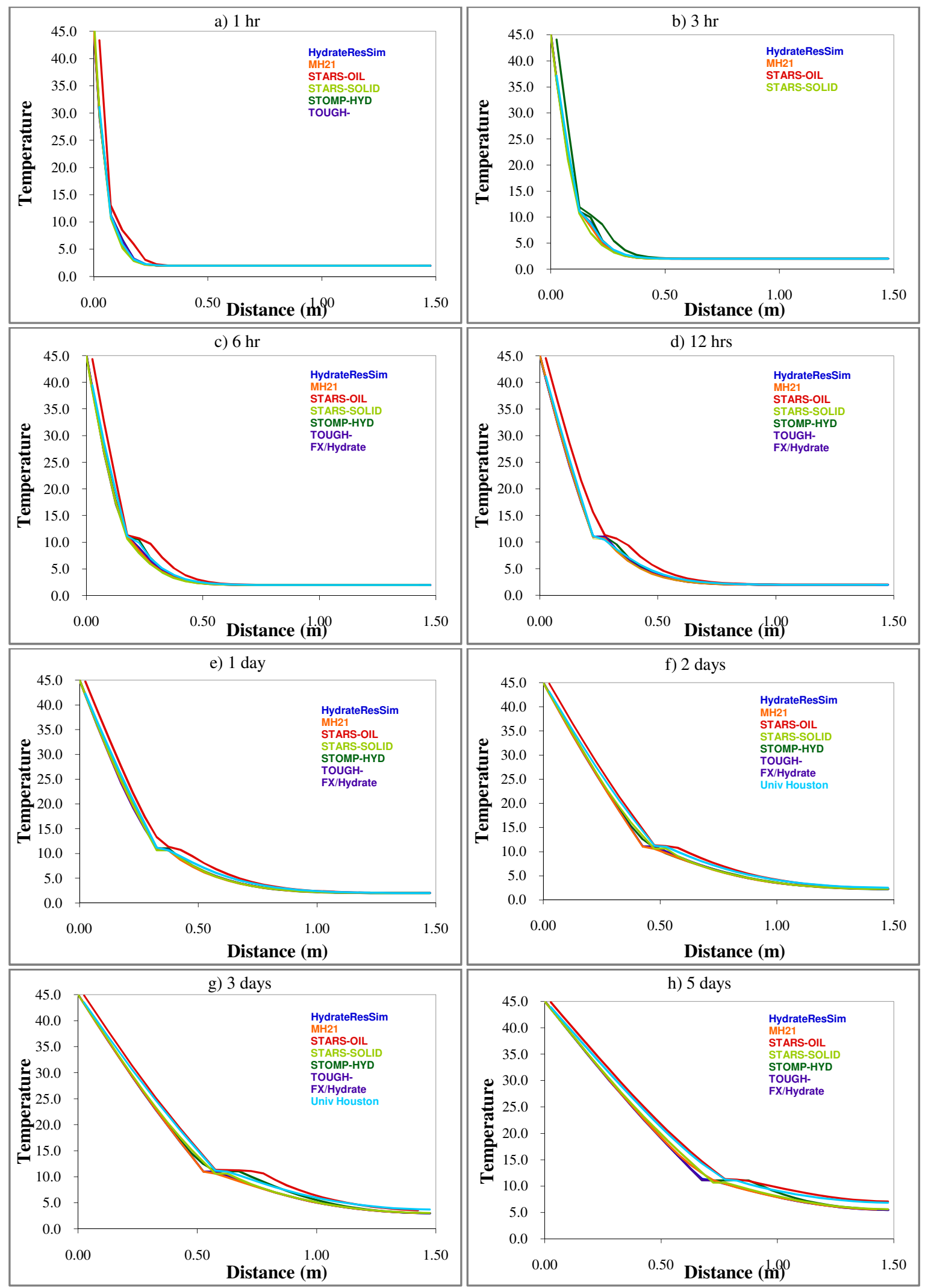

Figure 3- 23 Profiles of temperature at different times for Problem 3 Case 1 

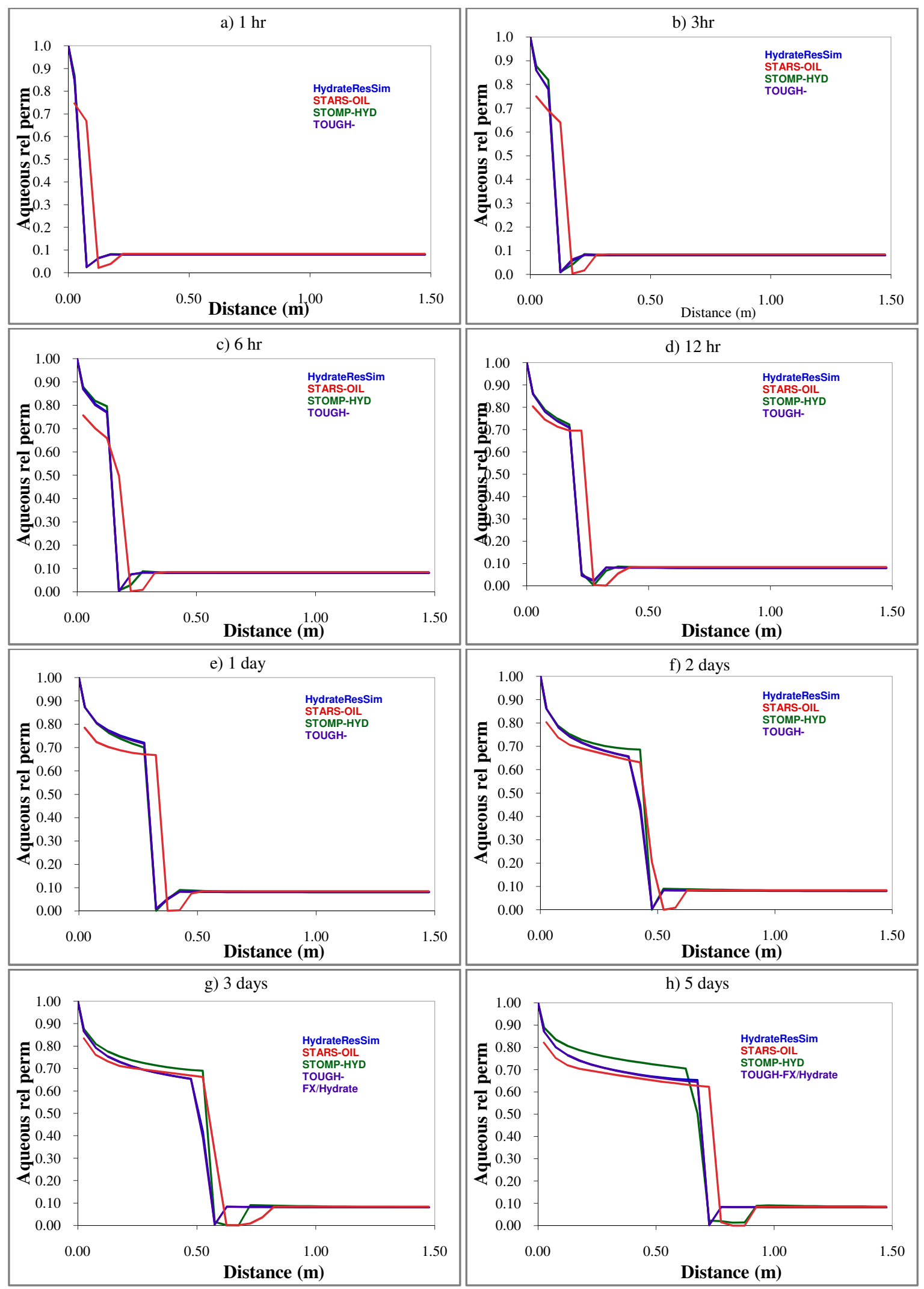

Figure 3- 24 Profiles of Aqueous relative permeability at different times for Problem 3 Case 1 

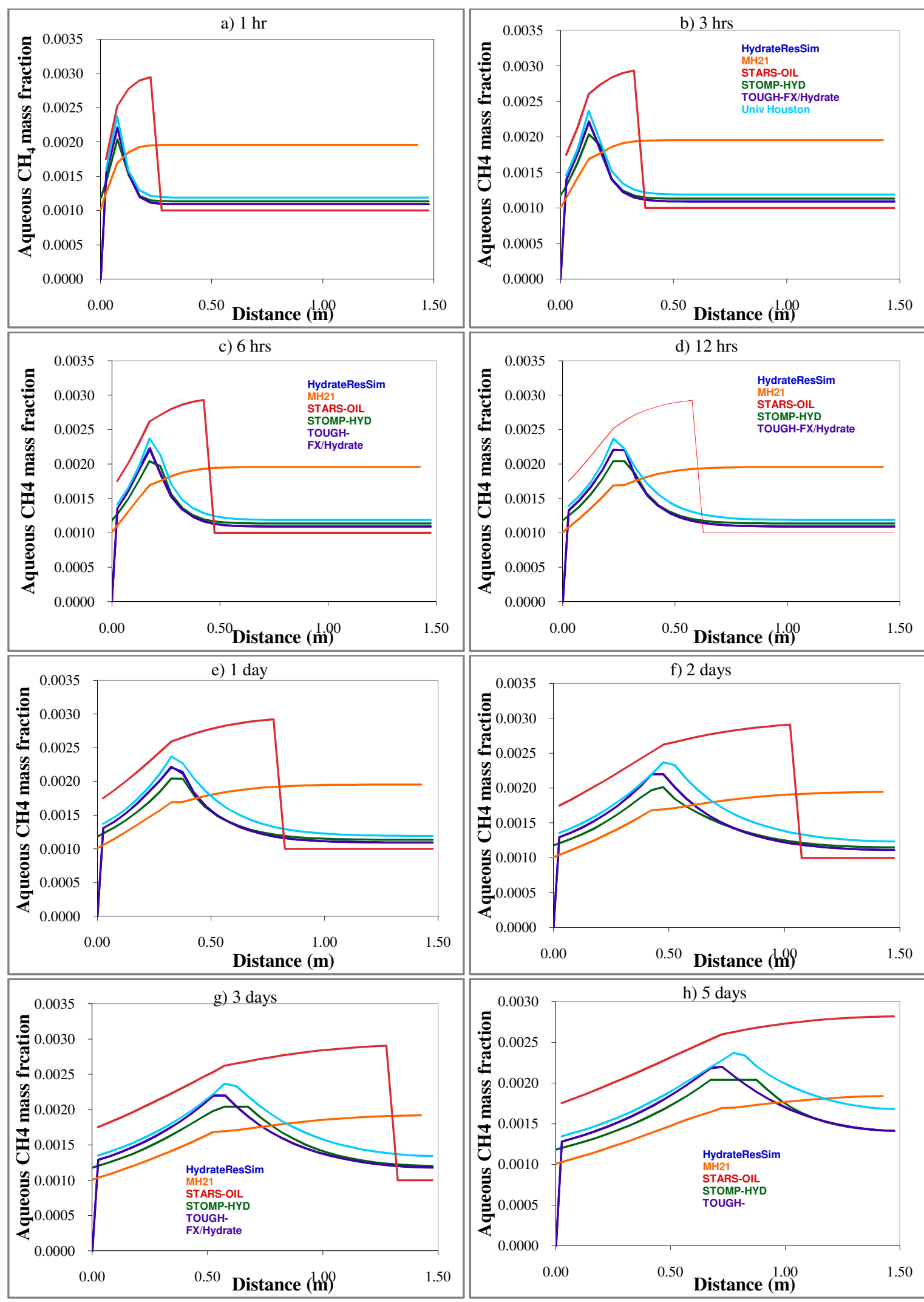

Figure 3- 25 Profiles of Aqueous methane mass fraction at different times for Problem 3 Case 1 

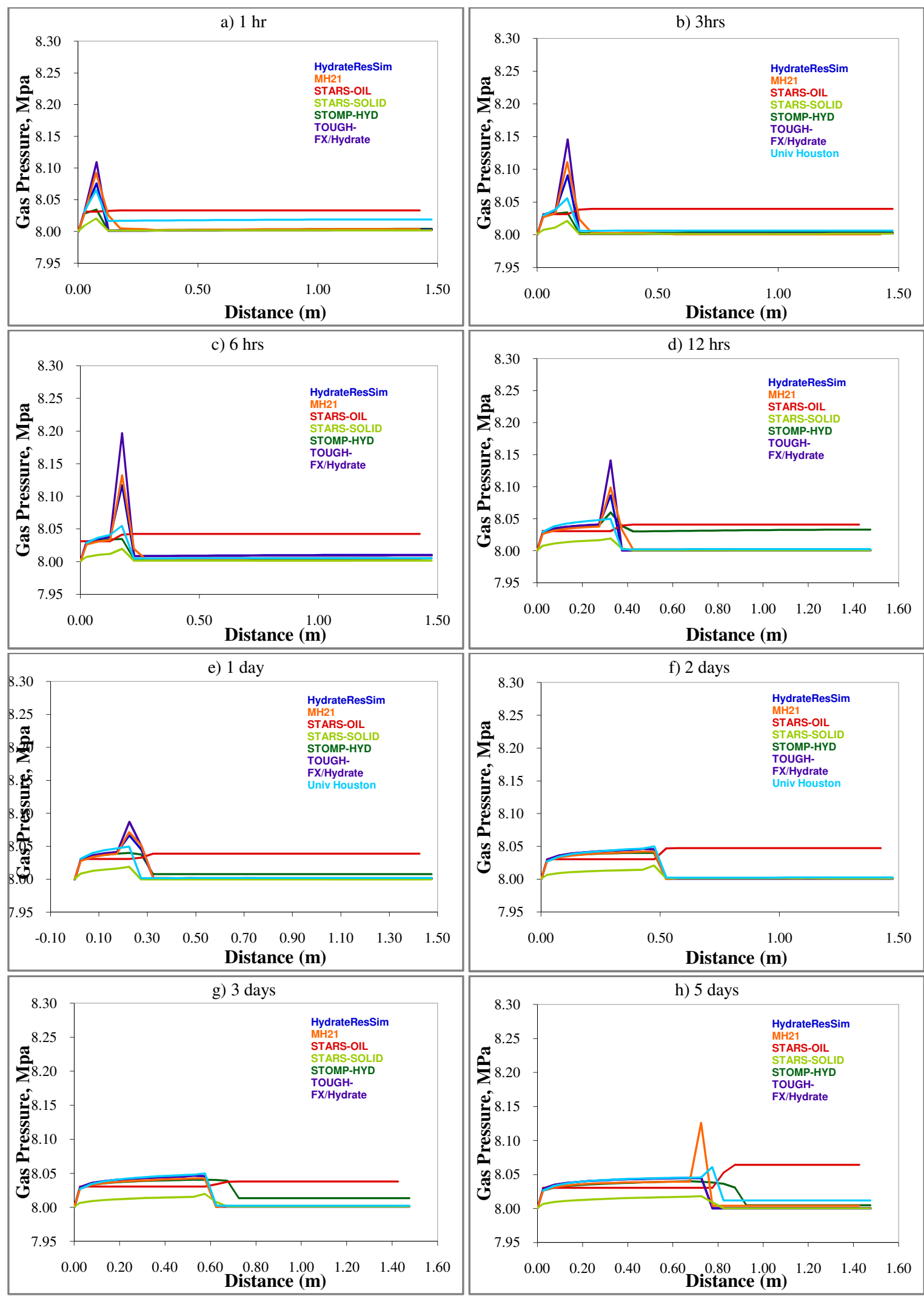

Figure 3- 26 Profiles of Pressure at different times for Problem 3 Case 1 

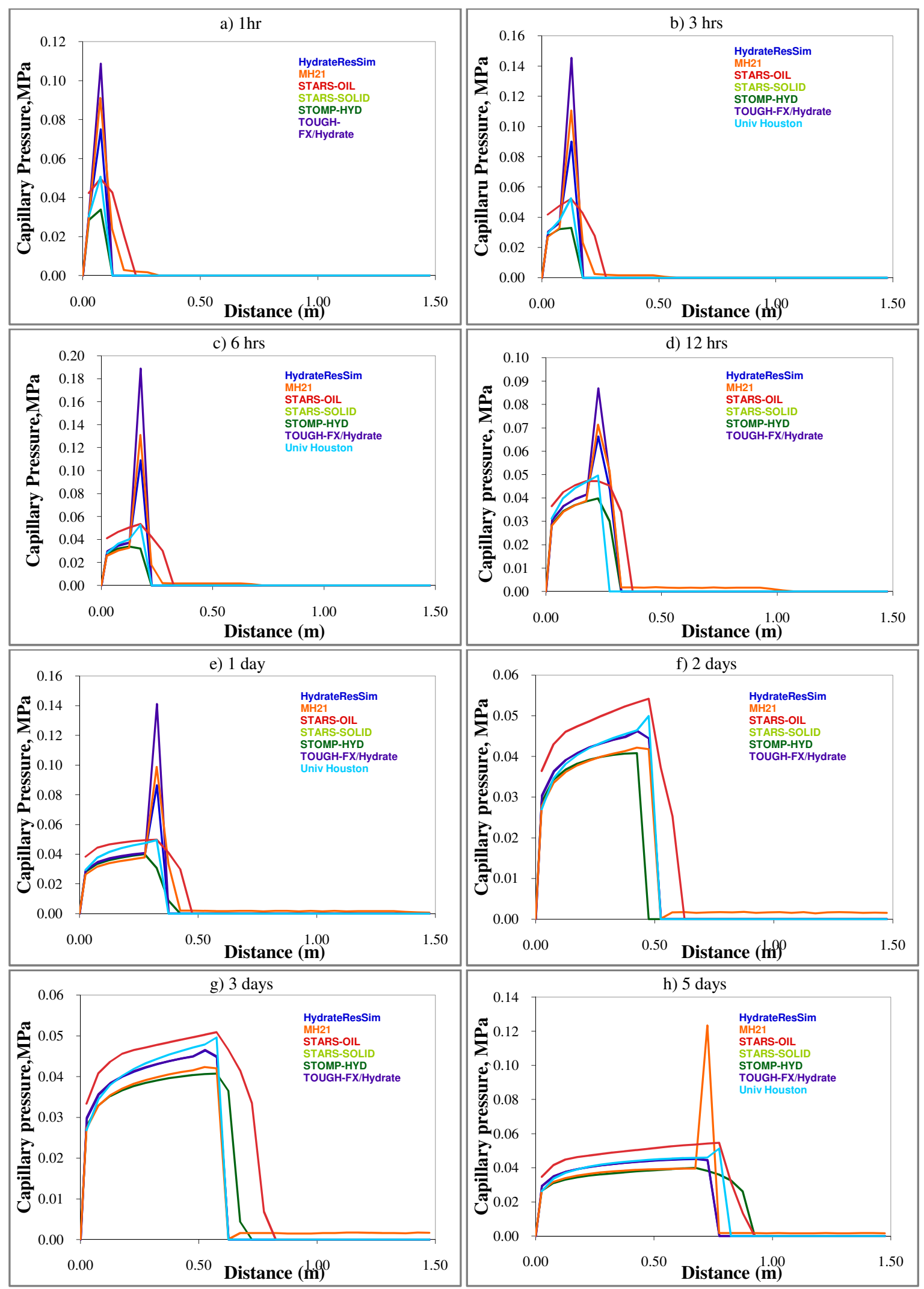

Figure 3- 27 Profiles of capillary pressure at different times for Problem 3 Case 1 


\section{CASE 2}

As in the previous discussion the boundary condition $\left(x=0, S_{\mathrm{w}}=1.0\right)$ is not maintained initially but after some time as the simulation proceeds this difficulty is also achieved. Figure 3-29 shows profiles of aqueous saturation in good agreement with other codes

Initially there is no gas in the reservoir. Hydrate dissociates due to depressurization of the well. Figure 3-30 shows the profiles of gas saturation. Profiles of hydrate saturation, temperature and aqueous methane mass fraction are in good agreement with other codes as shown in Figure 3-31, Figure3-32 and Figure 3-34.

Aqueous relative permeability curves are affected initially due to the boundary condition problem as shown in Figure 3-33. As the time proceeds good match of permeability curves with other codes for CMG STARS is obtained. Profiles of gas pressure as in Figure 3-35 shows the propagation of the pressure wave when the reservoir is depressurized. Initially the reservoir pressure is at $8 \mathrm{MPa}$ and is depressurized to 2.8 MPa. Capillary pressure is expressed as a function of liquid saturation (water + hydrate) in STARS. However the profiles of capillary pressure look similar to other codes as shown in Figure 3-36. Figure 3.28 shows cumulative and gas rates for CMG STARS.

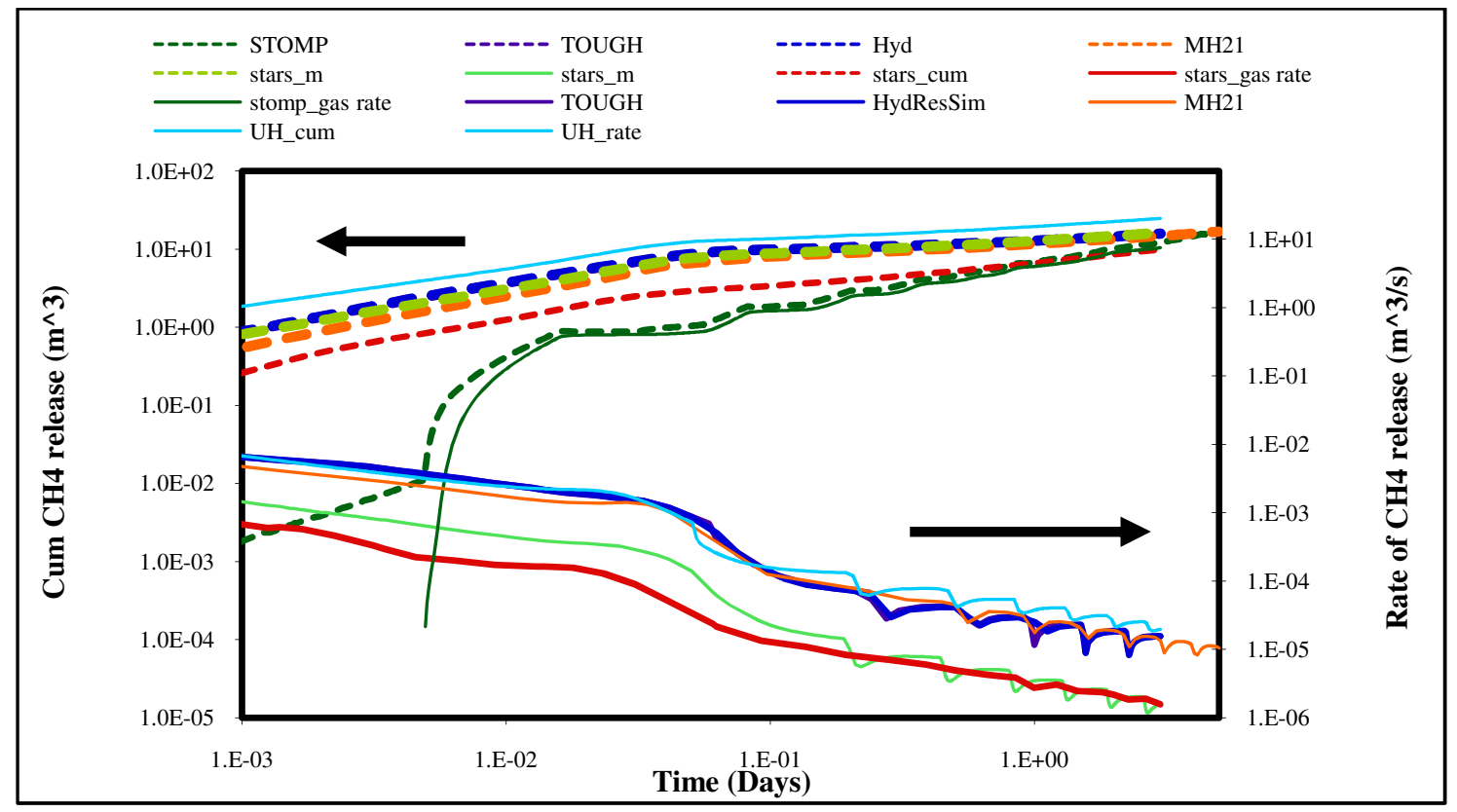

Figure 3- 28 Production rates for problem 3, Case 2 


\section{Aqueous Saturation}
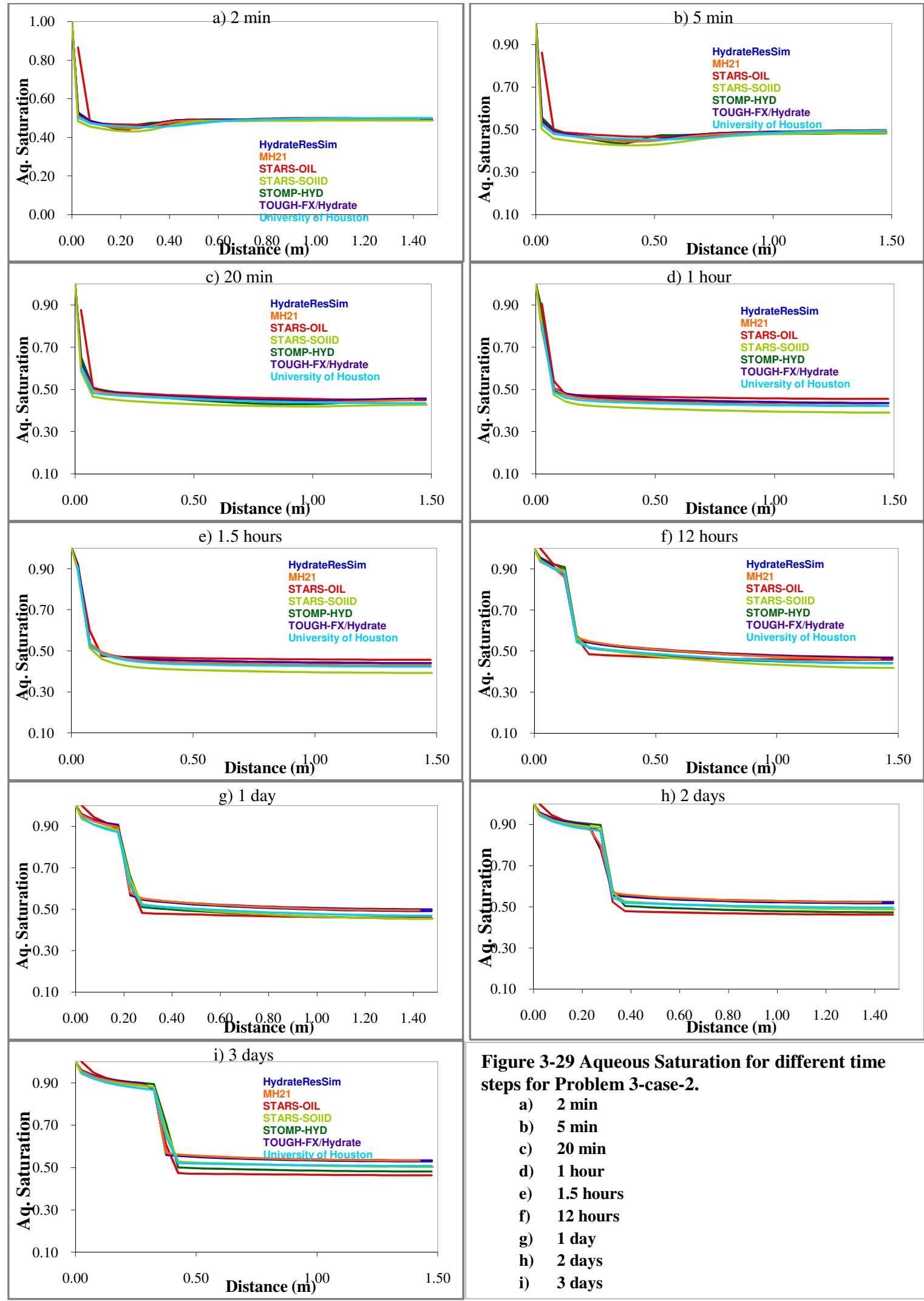

Figure 3-29 Aqueous Saturation for different time steps for Problem 3-case-2.
a) $2 \mathrm{~min}$
b) $5 \mathrm{~min}$
c) $20 \mathrm{~min}$
d) 1 hour
e) 1.5 hours
f) 12 hours
g) 1 day
h) 2 days
i) 3 days 
Gas Saturation
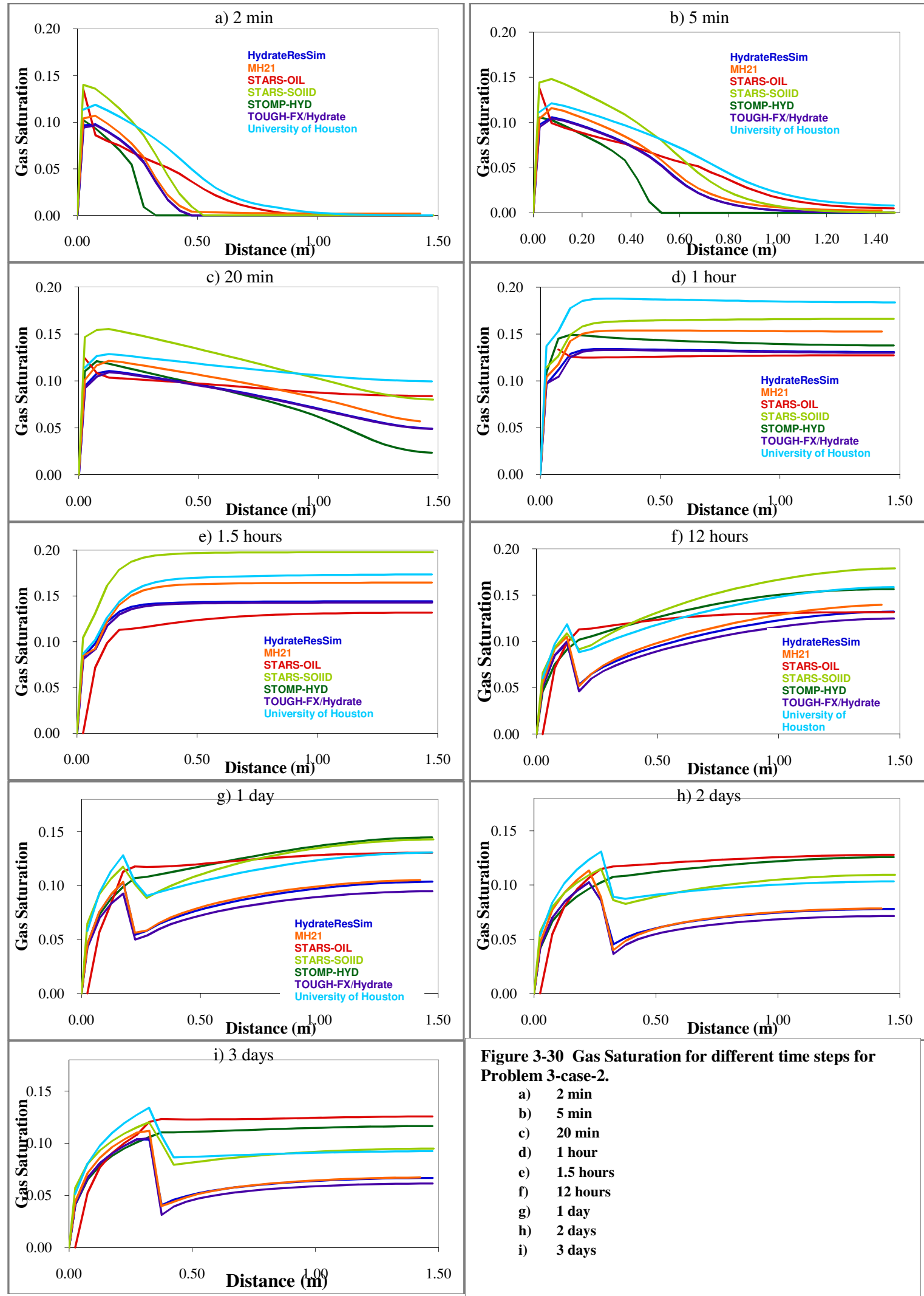

Figure 3-30 Gas Saturation for different time steps for

Problem 3-case-2.
a) $2 \mathrm{~min}$
b) $5 \mathrm{~min}$
c) $20 \mathrm{~min}$
d) 1 hour
e) 1.5 hours
f) 12 hours
g) 1 day
h) 2 days
i) 3 days 


\section{Hydrate Saturation}
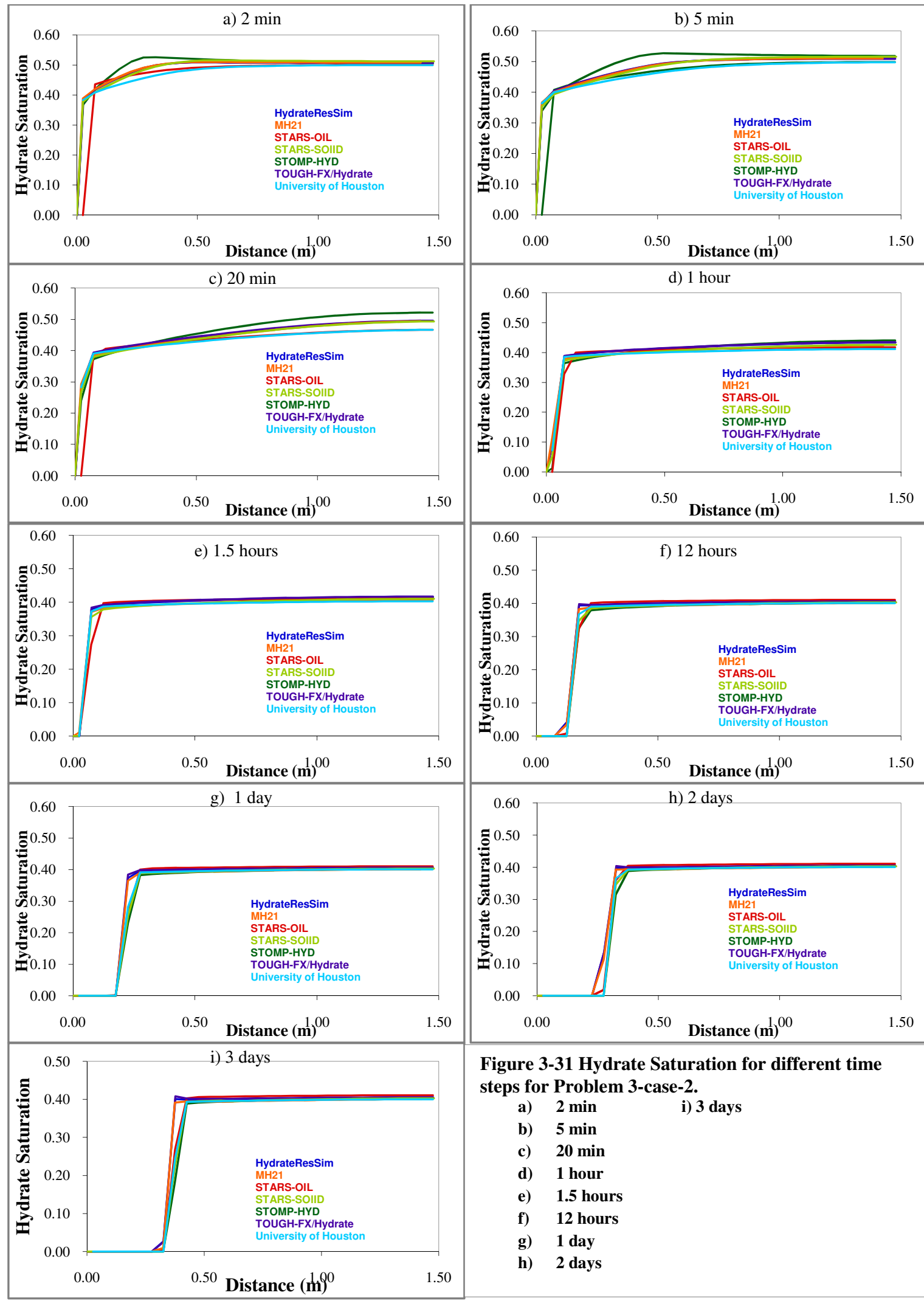

Figure 3-31 Hydrate Saturation for different time steps for Problem 3-case-2.
a) $2 \mathrm{~min}$
i) 3 days
b) 5 min
c) $20 \mathrm{~min}$
d) 1 hour
e) 1.5 hours
f) 12 hours
g) 1 day
h) 2 days 


\section{Temperature}
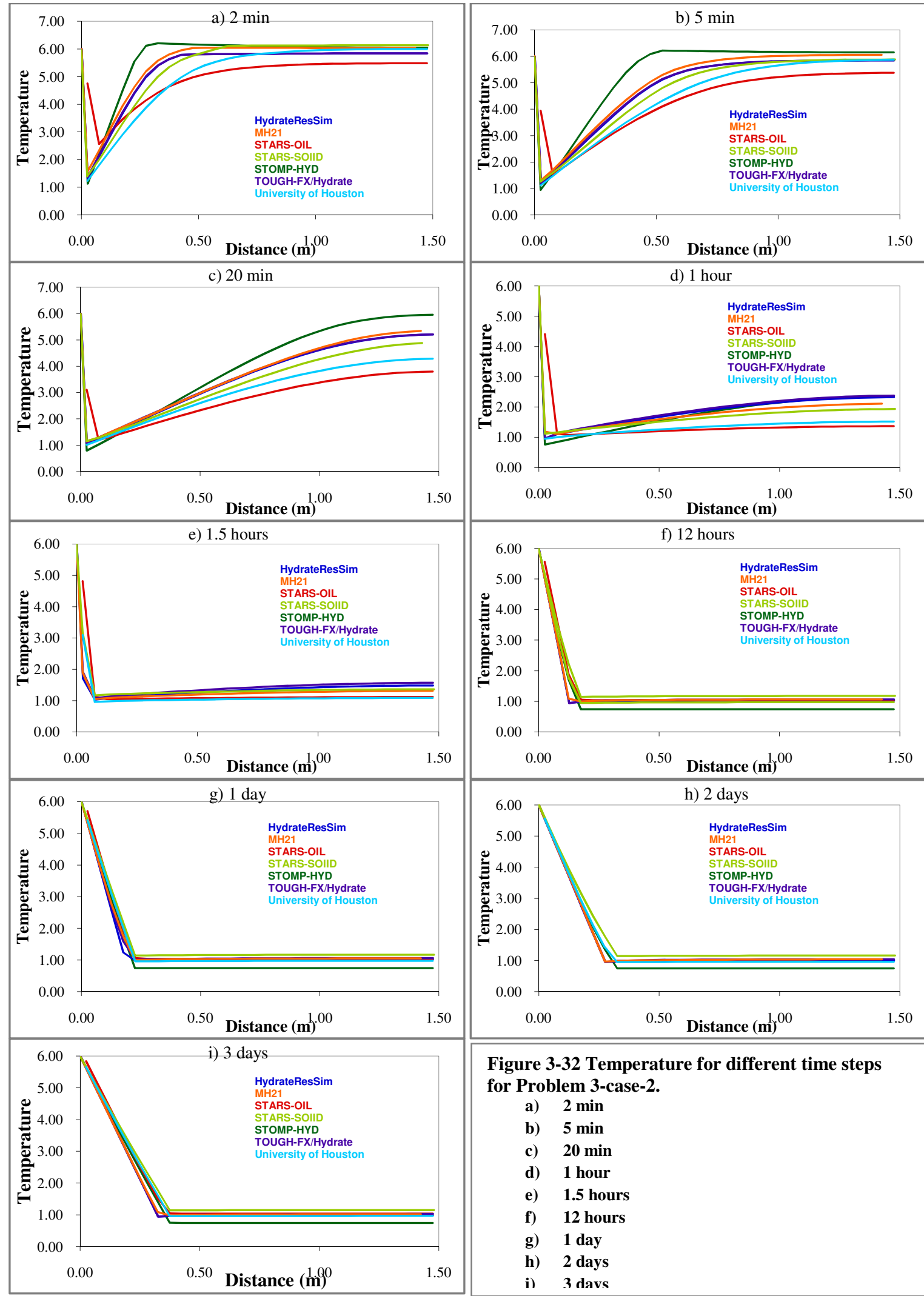

Figure 3-32 Temperature for different time steps for Problem 3-case-2.
a) $2 \mathrm{~min}$
b) $5 \mathrm{~min}$
c) $20 \mathrm{~min}$
d) 1 hour
e) 1.5 hours
f) 12 hours
g) 1 day
h) 2 days
i) 3 davs 


\section{Aqueous phase relative permeability}
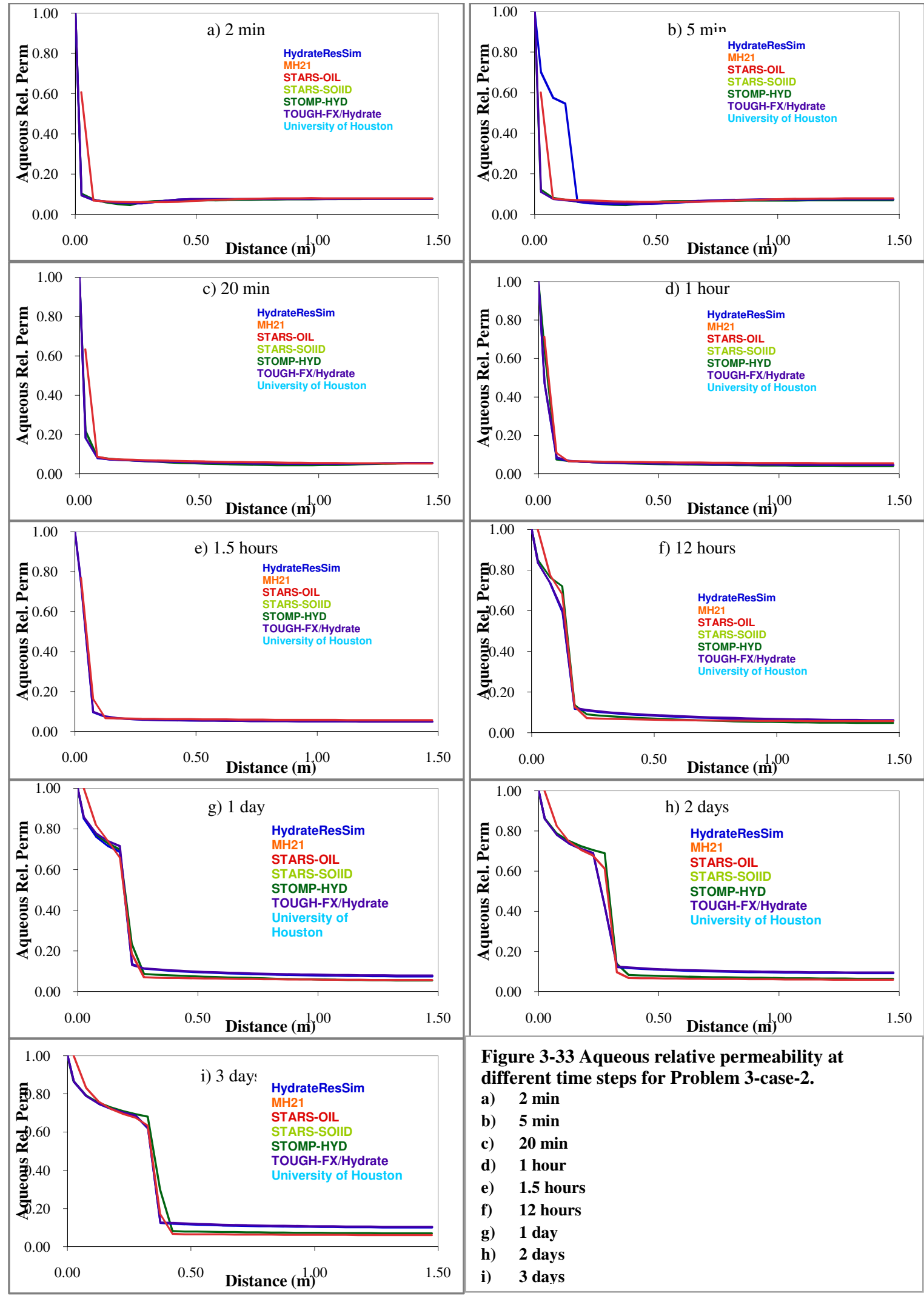

Figure 3-33 Aqueous relative permeability at different time steps for Problem 3-case-2.
a) 2 min
b) $5 \mathrm{~min}$
c) $20 \mathrm{~min}$
d) 1 hour
e) 1.5 hours
f) 12 hours
g) 1 day
h) 2 days
i) 3 days 


\section{Aqueous phase methane mass fraction}
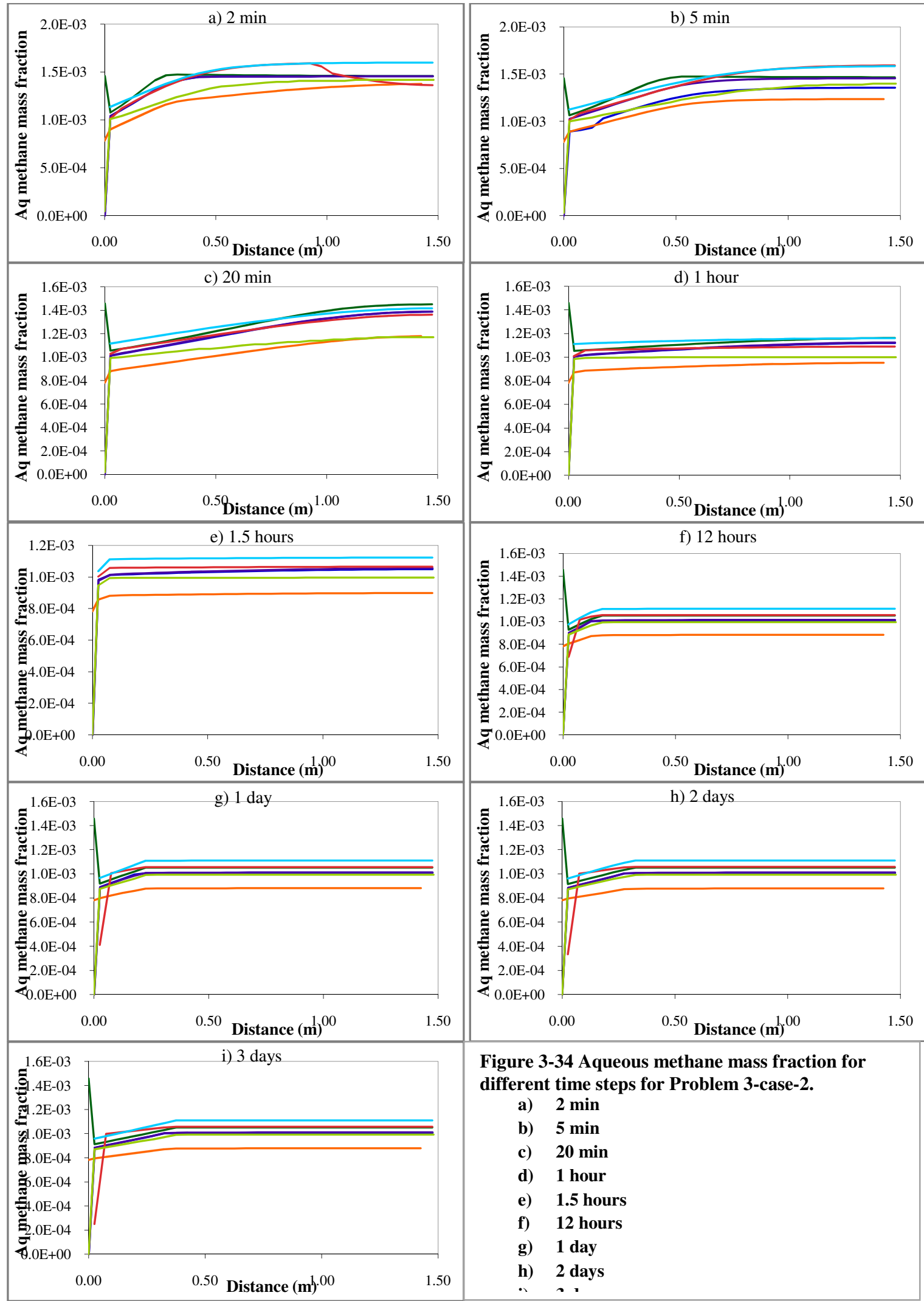

Figure 3-34 Aqueous methane mass fraction for different time steps for Problem 3-case-2.
a) 2 min
b) 5 min
c) $20 \mathrm{~min}$
d) 1 hour
e) 1.5 hours
f) 12 hours
g) 1 day
h) 2 days 


\section{Gas pressure}
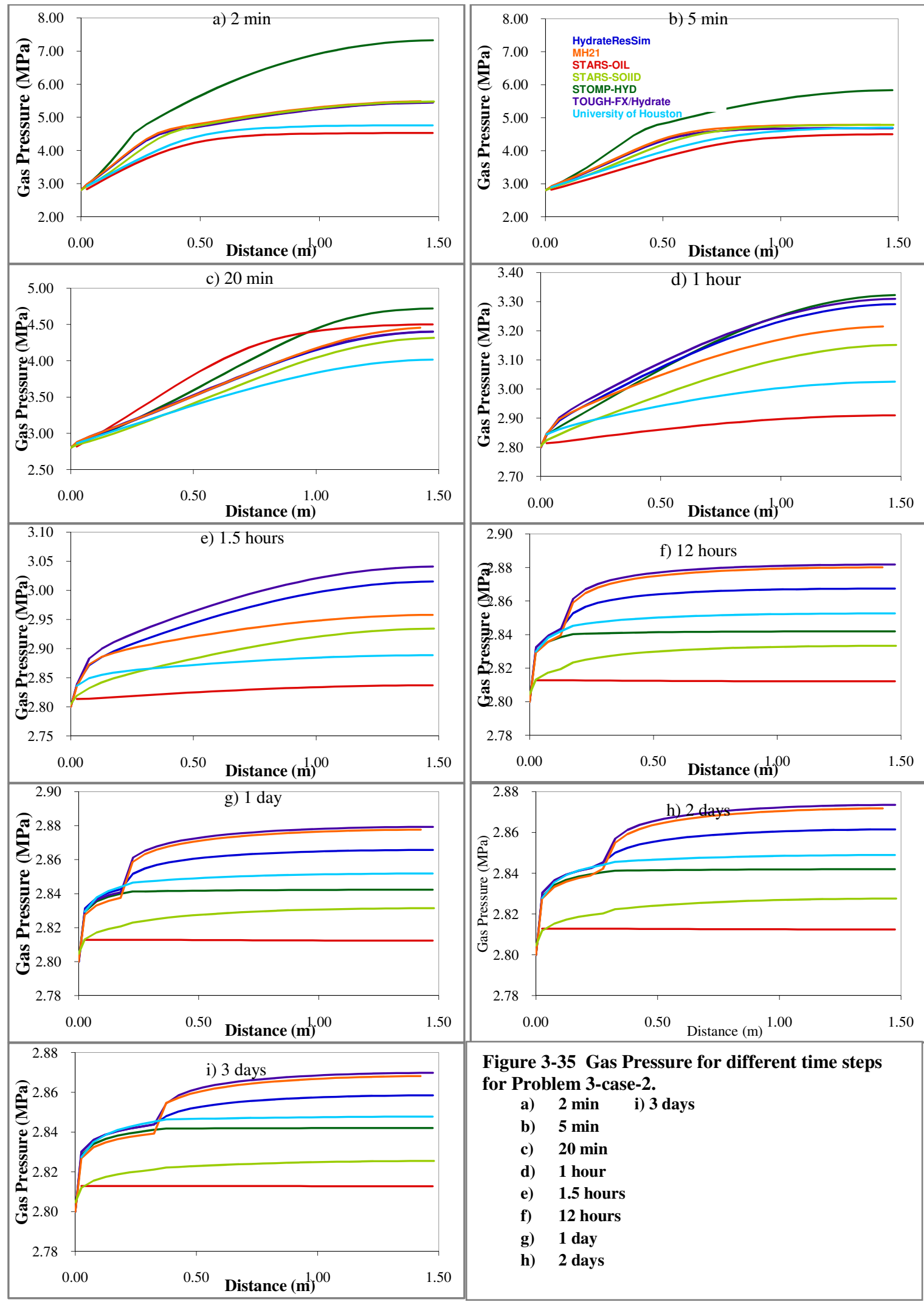

Figure 3-35 Gas Pressure for different time steps for Problem 3-case-2.
a) 2 min $\quad$ i) 3 days
b) 5 min
c) $20 \mathrm{~min}$
d) 1 hour
e) 1.5 hours
f) 12 hours
g) 1 day
h) 2 days 
Gas water capillary pressure
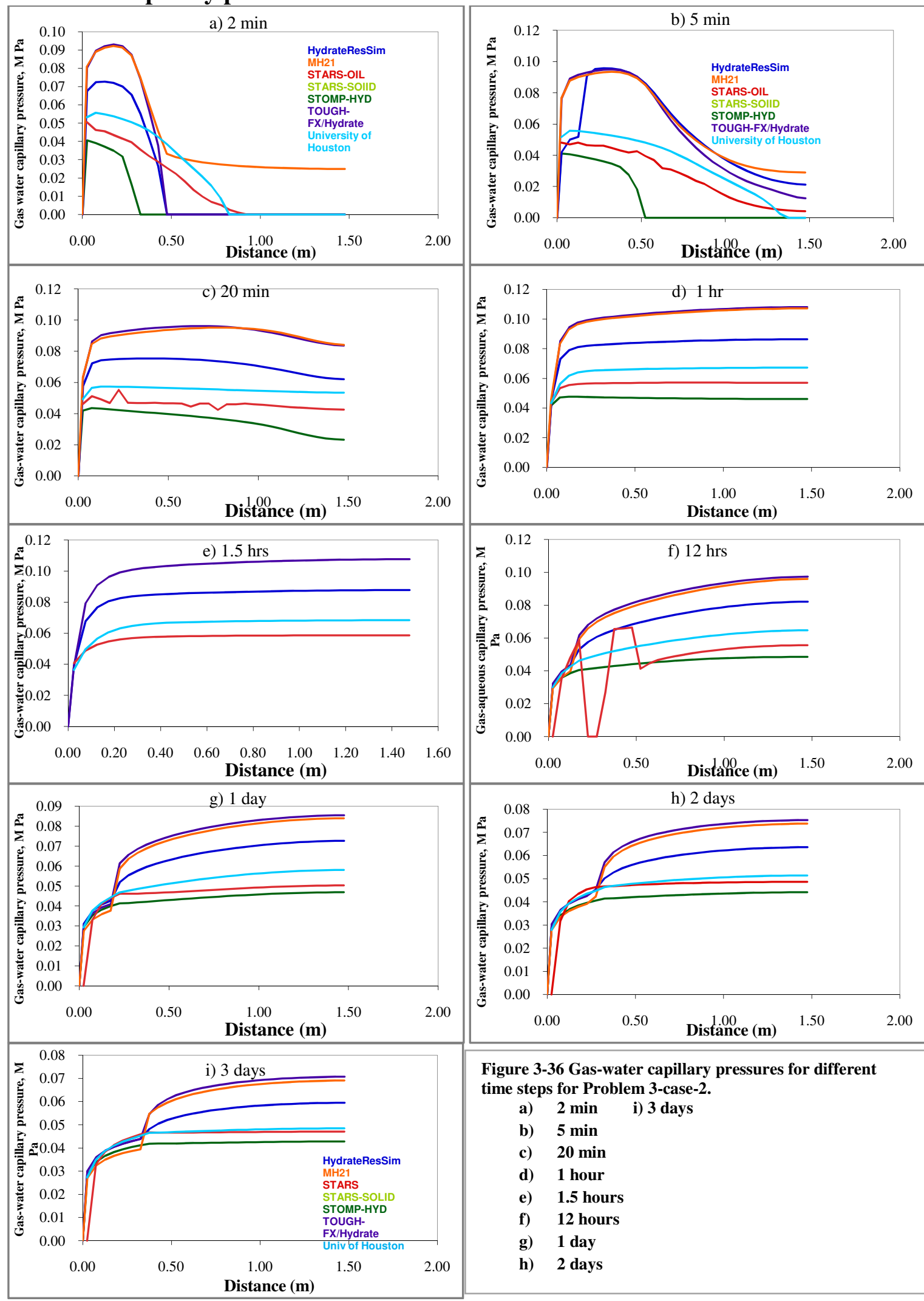

Figure 3-36 Gas-water capillary pressures for different time steps for Problem 3-case-2.
$\begin{array}{ll}\text { a) } 2 \text { min } & \text { i) } 3 \text { days }\end{array}$
b) 5 min
c) $20 \mathrm{~min}$
d) 1 hour
e) 1.5 hours
f) 12 hours
g) 1 day
h) 2 days 


\section{Case 3}

In this case, the reservoir is depressurized to a pressure below the Quadruple point leading to ice formation. Differences in the results of various simulators are obtained due to ice formation in the system. The observed differences are due to the way each simulator calculates the ice formation phenomena. There are two ways in which ice can be specified in the input data file of CMG STARS. Ice can be specified by adding the keyword *ICE in the component property section of the input data file. When this is used, temperatures down to $100^{\circ} \mathrm{C}$ can be tolerated in the reservoir. The other way is not using this default, but to specify ice as a component and include its reactions (melting \& formation). In this method, the minimum temperature allowed is $0.85^{\circ}$ and so the entire reservoir and its reactions are scaled up to a higher temperature during the simulation and reset again in the results. Both methods were used to run the simulations for matching results with the other codes. The results that will be presented in this document will be of those obtained from *ICE method of specifying the ice component.

Initially hydrate and aqueous saturation are 0.5 each. As the simulation proceeds, hydrate dissociates giving gas and water molecules. In this problem hydrate dissociation occurs at different points for different simulators. Figure 3-37 shows the movement of dissociation front for CMG STARS at different time steps. Profiles of aqueous saturation, aqueous phase relative permeability and temperature for CMG STARS are shown in Figure 3-38, 3-39 and 3-40 respectively. They are found to be in good agreement with other codes.

More ice formation is seen in STARS simulations at the beginning of the run itself (shown in Figure 3-41). Due to this extra ice in the first few blocks of the grid, there is no void space 
for the dissociated methane to escape in the gas phase and as a result increase in the aqueous phase methane mass fraction is observed as in Figure 3-43. There is no much increase in the gas pressure (shown in Figure 3-44) initially, which shows there is something wrong in the whole calculation process of CMG. This also explains the high irregularity in the gas saturation curves as shown in Figure 3-42. 

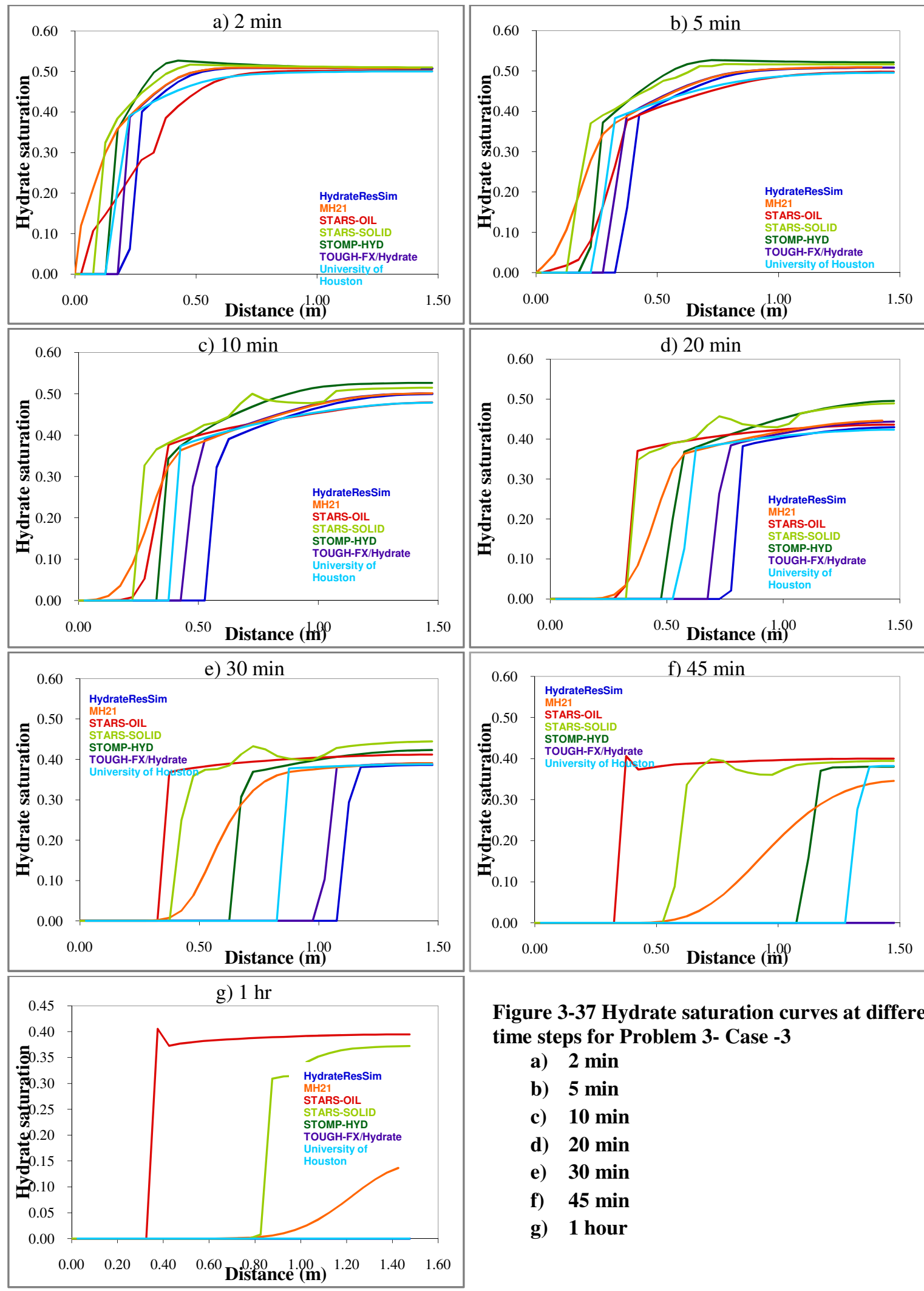

Figure 3-37 Hydrate saturation curves at different time steps for Problem 3- Case -3
a) 2 min
b) $5 \mathrm{~min}$
c) $10 \mathrm{~min}$
d) $20 \mathrm{~min}$
e) $30 \mathrm{~min}$
f) $45 \mathrm{~min}$
g) 1 hour 

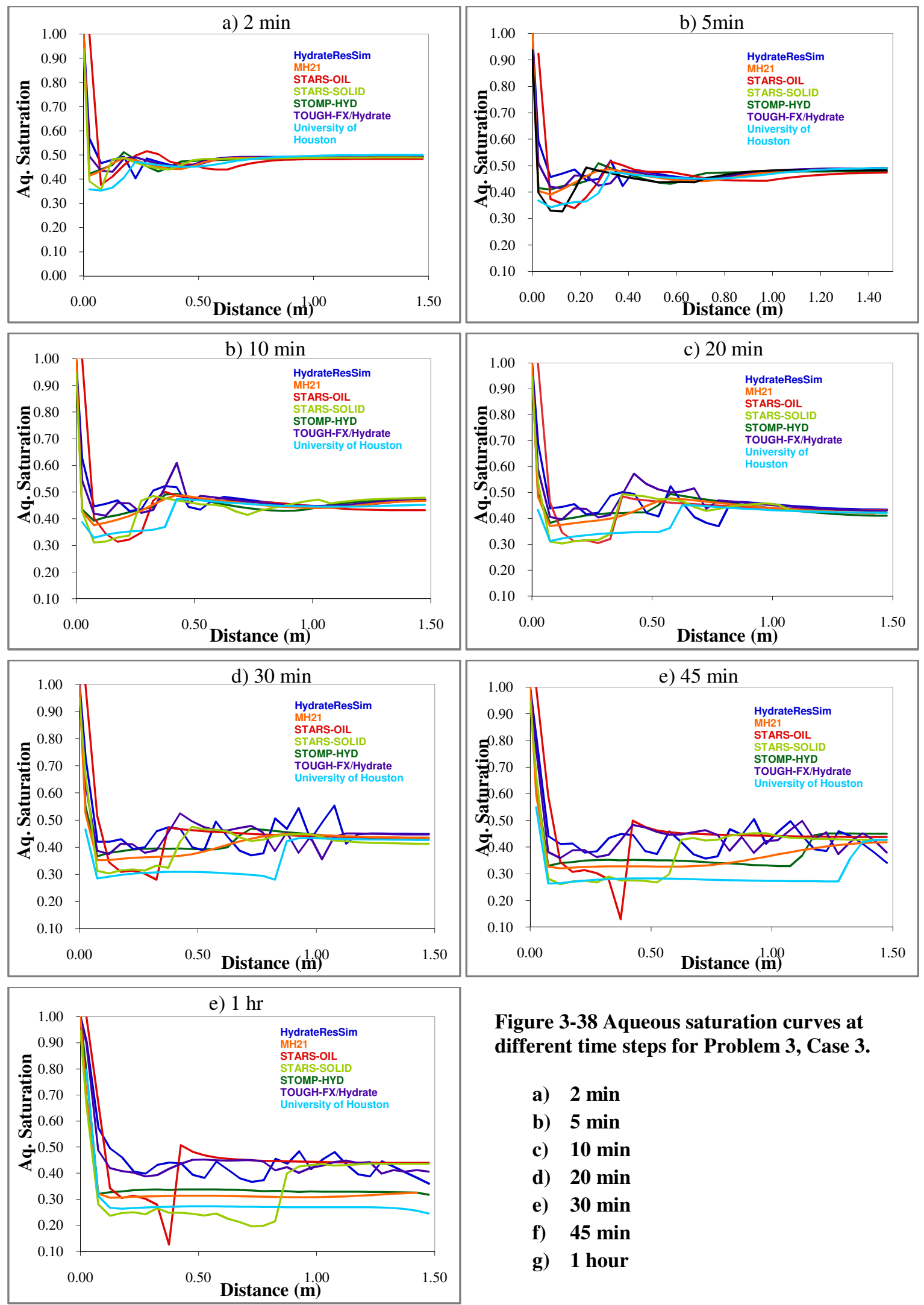

Figure 3-38 Aqueous saturation curves at different time steps for Problem 3, Case 3.
a) 2 min
b) $5 \mathrm{~min}$
c) $10 \mathrm{~min}$
d) $20 \mathrm{~min}$
e) $30 \mathrm{~min}$
f) $45 \mathrm{~min}$
g) 1 hour 

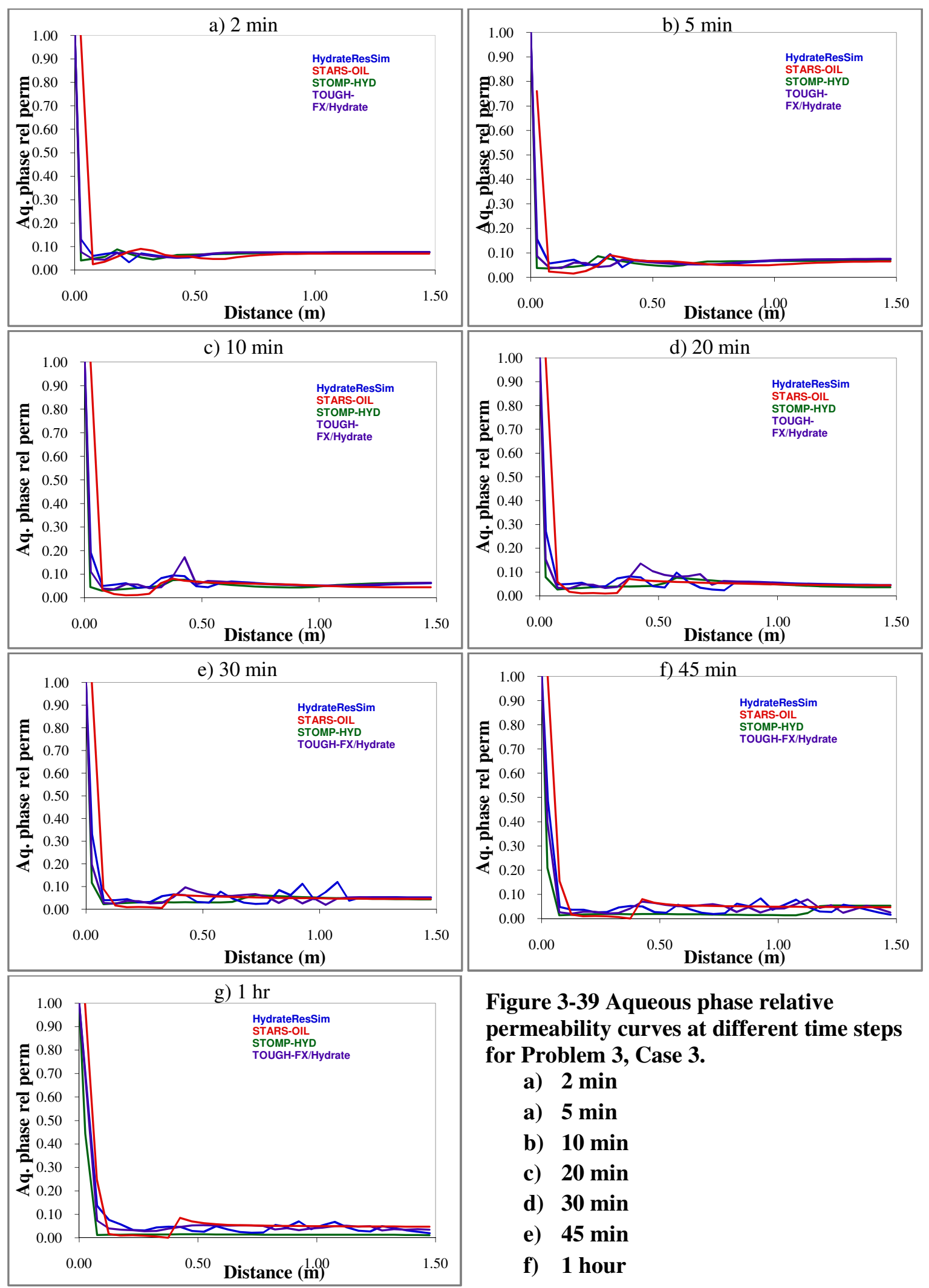

Figure 3-39 Aqueous phase relative permeability curves at different time steps for Problem 3, Case 3.
a) 2 min
a) $5 \mathrm{~min}$
b) $10 \mathrm{~min}$
c) $20 \mathrm{~min}$
d) $30 \mathrm{~min}$
e) $45 \mathrm{~min}$
f) 1 hour 

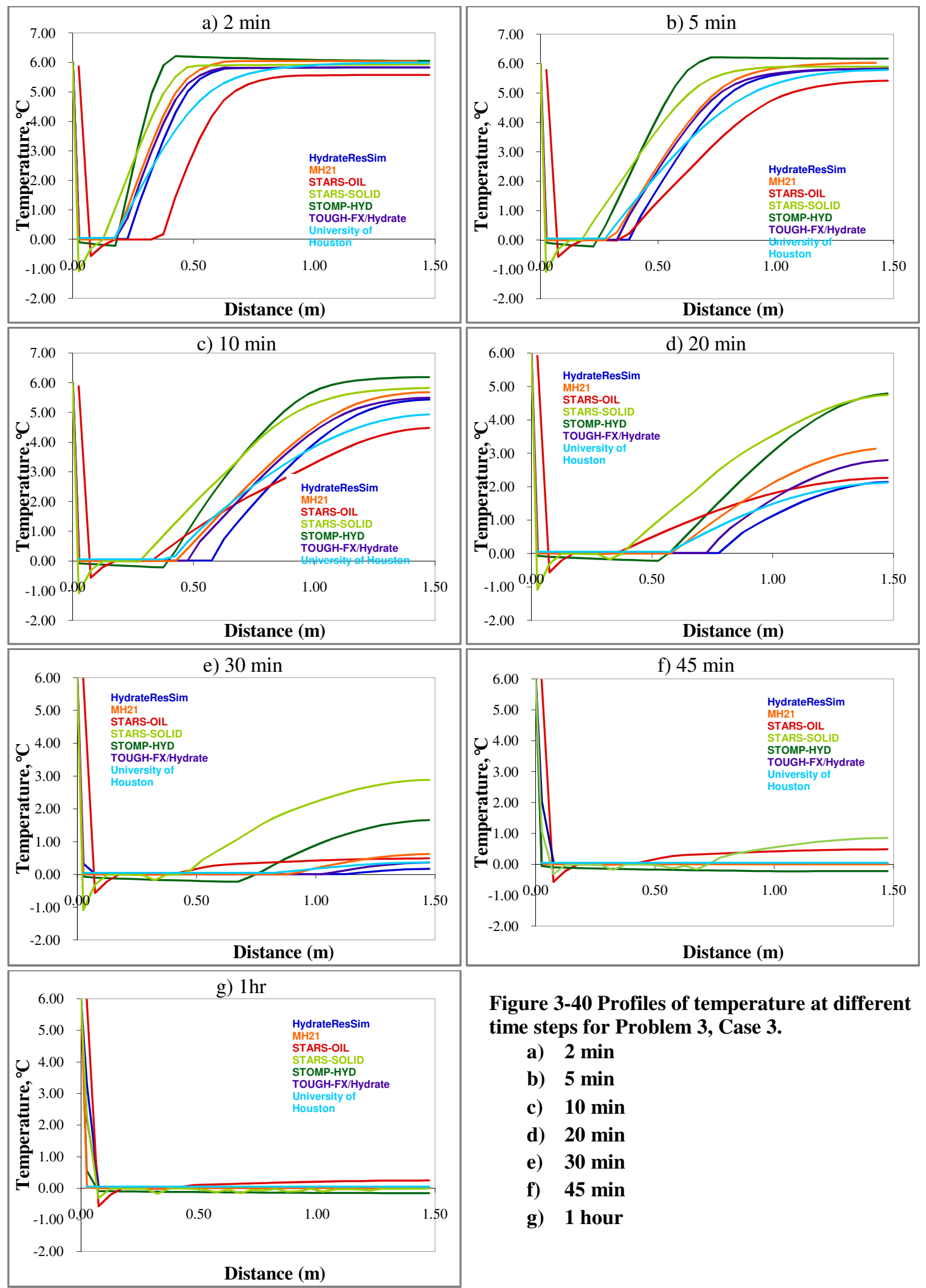

Figure 3-40 Profiles of temperature at different time steps for Problem 3, Case 3.
a) $2 \mathrm{~min}$
b) $5 \mathrm{~min}$
c) $10 \mathrm{~min}$
d) $20 \mathrm{~min}$
e) $30 \mathrm{~min}$
f) $45 \mathrm{~min}$
g) 1 hour 

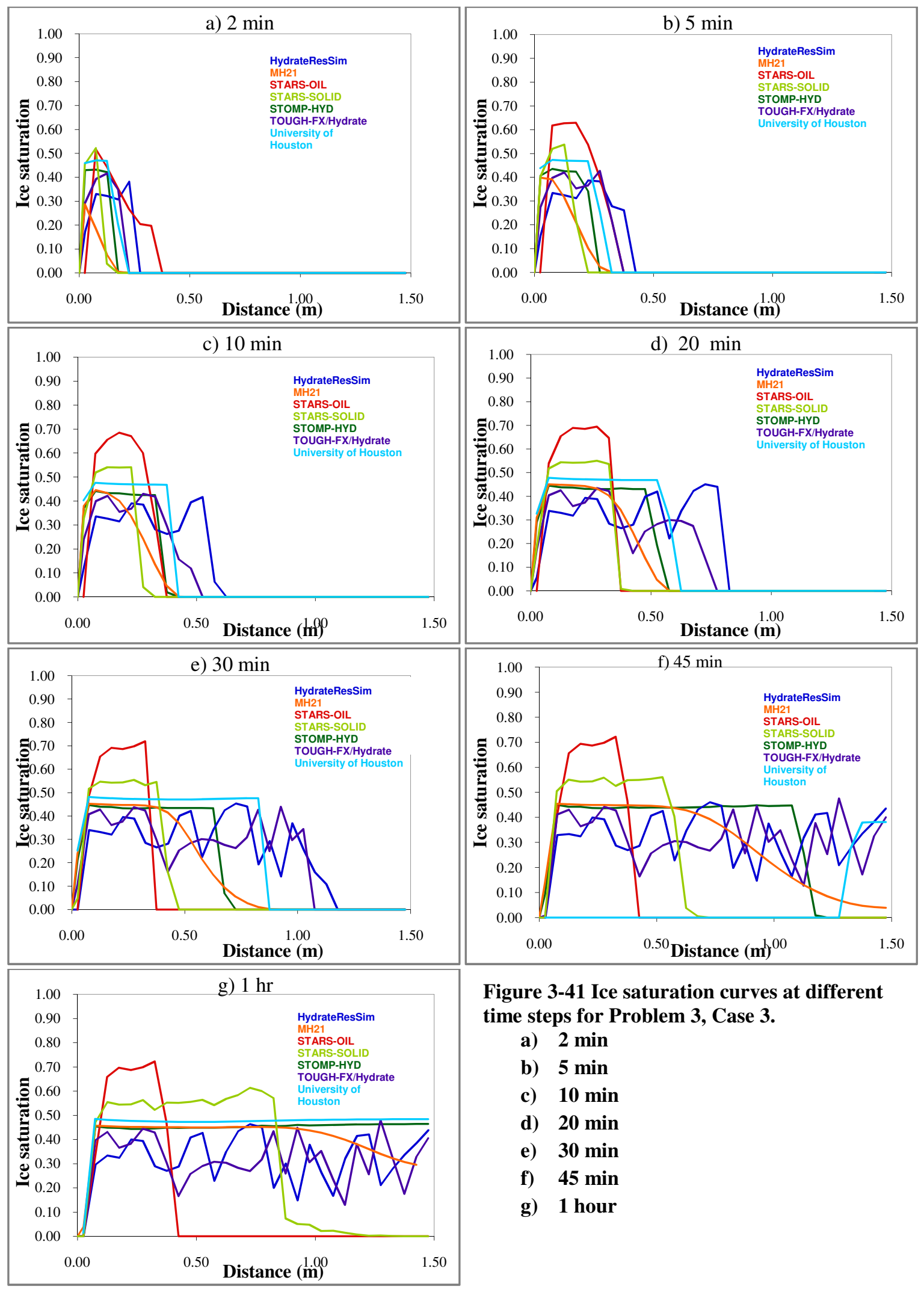

Figure 3-41 Ice saturation curves at different time steps for Problem 3, Case 3.
a) $2 \mathrm{~min}$
b) $5 \mathrm{~min}$
c) $10 \mathrm{~min}$
d) $20 \mathrm{~min}$
e) $30 \mathrm{~min}$
f) $45 \mathrm{~min}$
g) 1 hour 

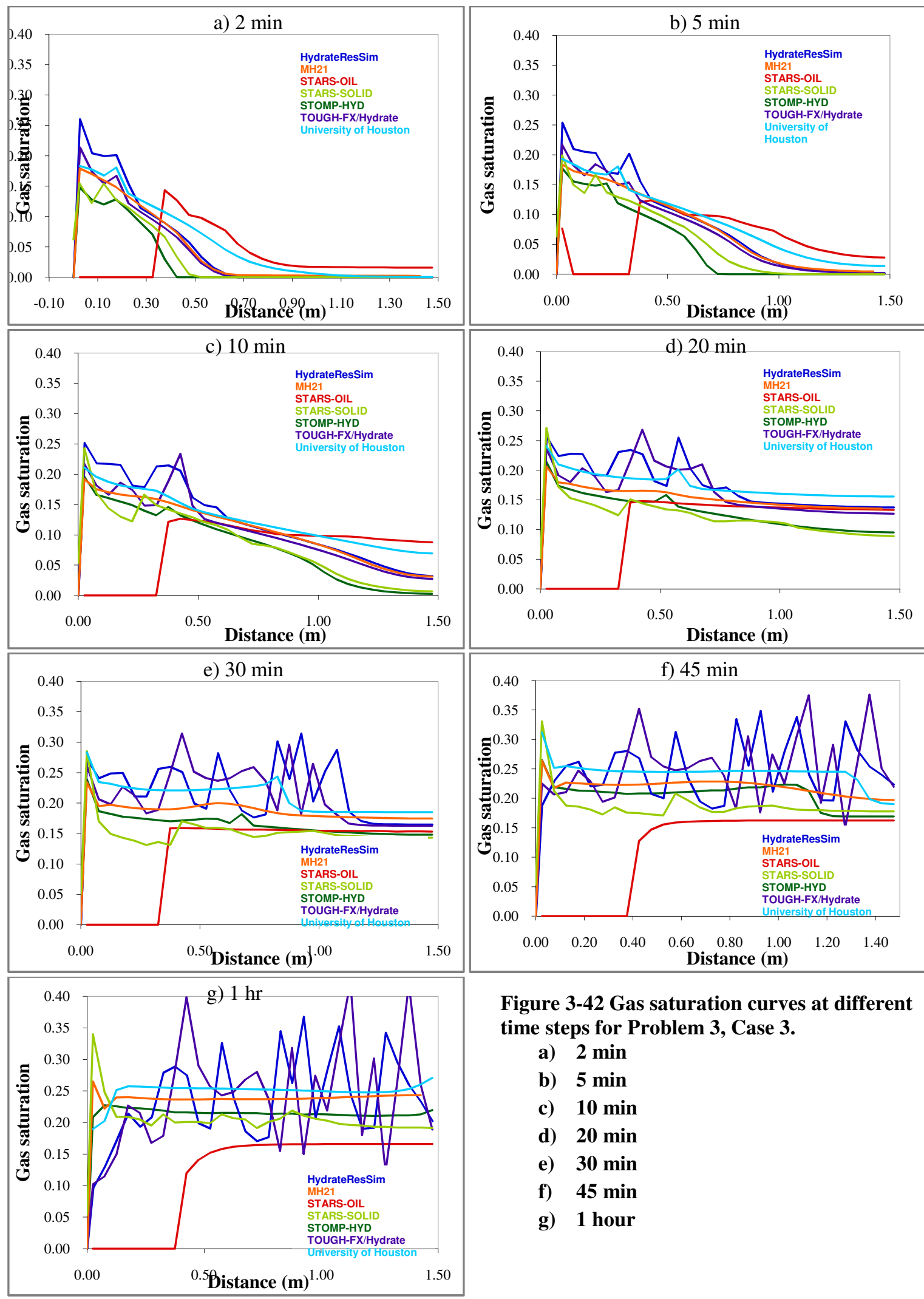

Figure 3-42 Gas saturation curves at different time steps for Problem 3, Case 3.
a) $2 \mathrm{~min}$
b) $5 \mathrm{~min}$
c) $10 \mathrm{~min}$
d) $20 \mathrm{~min}$
e) $30 \mathrm{~min}$
f) $45 \mathrm{~min}$
g) 1 hour 

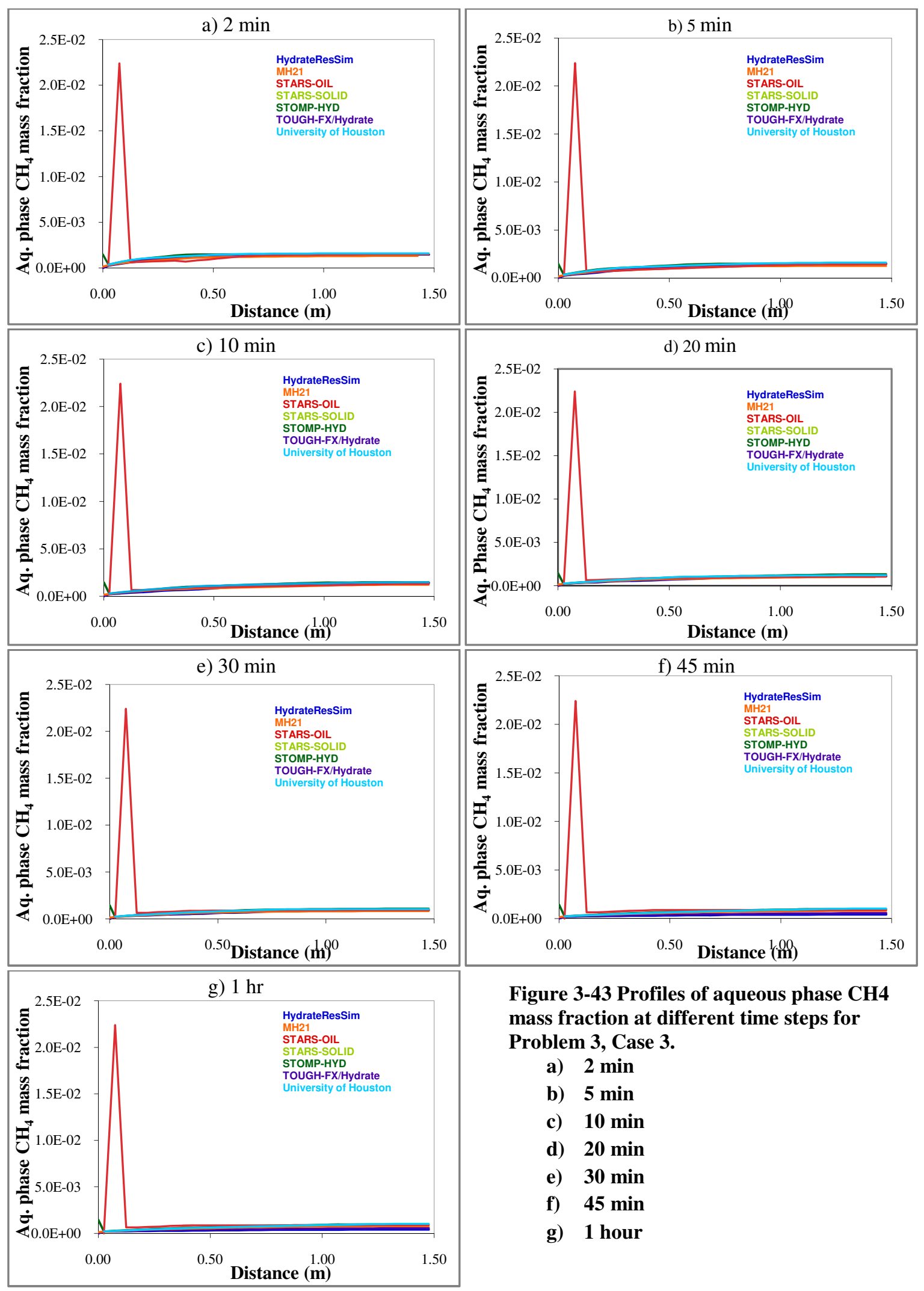

Figure 3-43 Profiles of aqueous phase CH4 mass fraction at different time steps for Problem 3, Case 3.
a) 2 min
b) $5 \mathrm{~min}$
c) $10 \mathrm{~min}$
d) $20 \mathrm{~min}$
e) $30 \mathrm{~min}$
f) $45 \mathrm{~min}$
g) 1 hour 

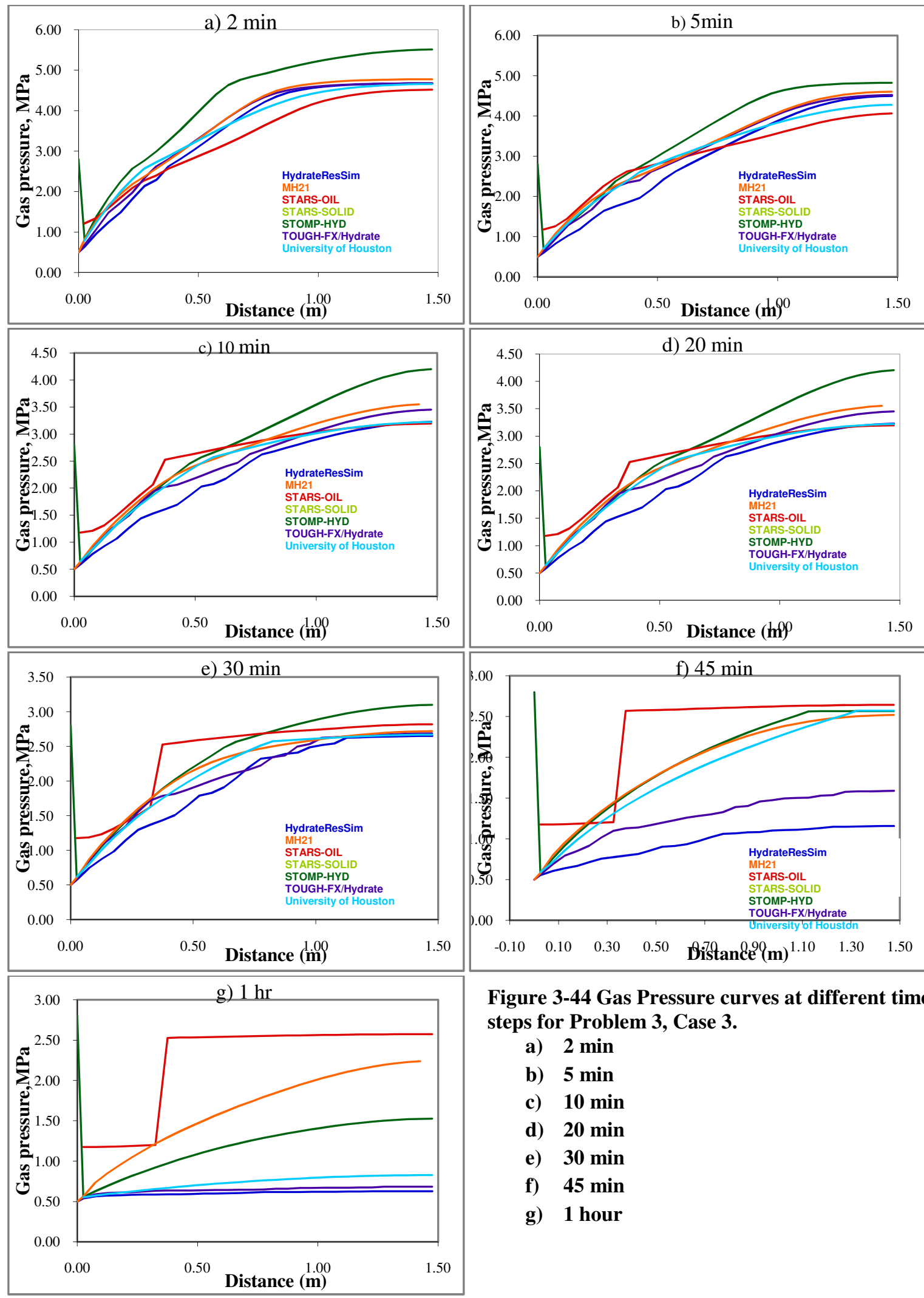

Figure 3-44 Gas Pressure curves at different time steps for Problem 3, Case 3.
a) $2 \mathrm{~min}$
b) $5 \mathrm{~min}$
c) $10 \mathrm{~min}$
d) $20 \mathrm{~min}$
e) $30 \mathrm{~min}$
f) $45 \mathrm{~min}$
g) 1 hour 


\section{1-D and 2-D radial systems: Problems and Solutions}

In Problem 4, a radial cylindrical grid is defined. There are two cases in this problem; they arise from different methods of hydrate dissociation too, Thermal Stimulation and Depressurization.

Problem 5 shows a typical example of a Class 2 Hydrate Deposit in which the hydrate layer is bound by two water saturated shale zones. Eight different cases have been modeled in this problem. The effect of hydrate saturation and finite discretization of the grid is also studied in this problem. 


\subsection{Problem 4}

A cylindrical domain is considered in this problem. A fine discretization is used to capture the dissociation front and to understand the transport properties in a radial domain. This problem is defined to introduce similarity solutions to hydrate dissociation processes. Two different cases are defined to study the thermal stimulation and depressurization process in a radial domain.

\section{Grid Description}

A one dimensional radial domain of $1000 \mathrm{~m} \times 1.0 \mathrm{~m}(r \times z)$ is considered. It is further discretized into 1500 cells, 1000 radial cells with a $\Delta r=0.02 m$ followed by 500 radial cells logarithmically distributed from $r=20 \mathrm{~m}$ to $r=1000 \mathrm{~m}$.

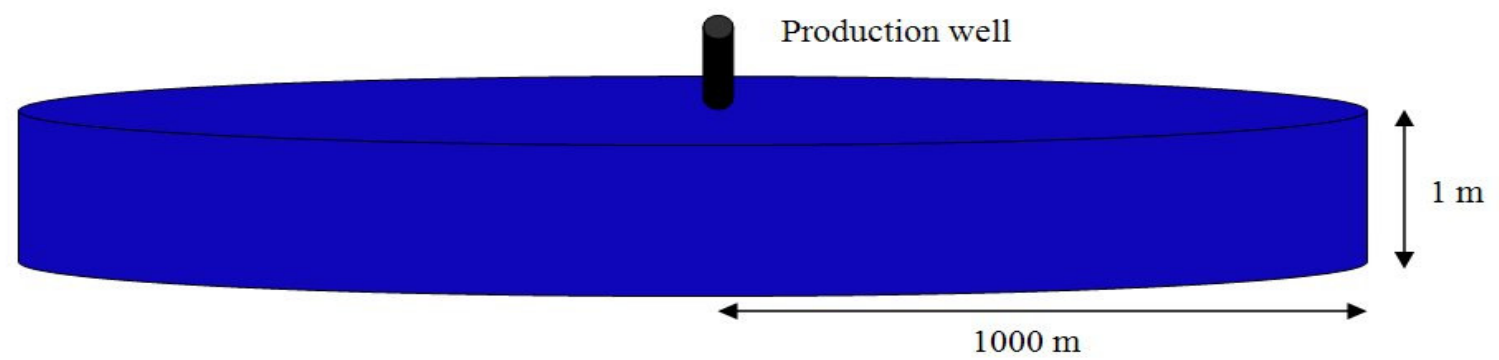

Figure 4-1 Schematic view of the grid for problem 4.

\section{Case 1: Thermal Stimulation}

\section{Initial conditions}

Pressure: $\quad P_{i}=4.6 \mathrm{MPa}$

Temperature: $T_{i}=3^{\circ} \mathrm{C}$

Saturations: $\quad S_{H}=0.5, S_{W}=0.5, S_{G}=0.0$

\section{Boundary Conditions:}

At $r=R_{\max }: \quad$ constant thermodynamic conditions

At $r=0: \quad Q_{H}=150 \mathrm{~W}$ 


\section{Case 2: Depressurization to a pressure below $Q$ point}

\section{Initial conditions:}

Pressure: $\quad P_{i}=9.5 \mathrm{MPa}$

Temperature: $T_{i}=3^{\circ} \mathrm{C}$

Saturations: $\quad S_{H}=0.4, S_{W}=0.6, S_{G}=0.0$

\section{Boundary Conditions:}

At $r=R_{\max }: \quad$ constant thermodynamic conditions

At $r=0: \quad Q=0.1 \mathrm{~kg} / \mathrm{s}$; Fluid rate

\section{Medium properties:}

Hydraulic and thermal properties are specified in Table 4.1

Table 4-1 Input Parameters and Specifications

\begin{tabular}{|c|c|}
\hline Parameter & Value \\
\hline Porosity & 0.3 \\
\hline Permeability & $1000 \mathrm{mD}$ \\
\hline Bulk Density & $1855 \mathrm{~kg} / \mathrm{m} 3$ \\
\hline Grain Density & $2600 \mathrm{~kg} / \mathrm{m} 3$ \\
\hline Grain Specific Heat & $750 \mathrm{~J} / \mathrm{kg} \mathrm{K}$ \\
\hline Bulk Specific cheat & $525 \mathrm{~J} / \mathrm{kg} \mathrm{K}$ \\
\hline Dry Thermal Conductivity & $2.0 \mathrm{~W} / \mathrm{m} \mathrm{K}$ \\
\hline Water-Saturated Thermal Conductivity & $2.18 \mathrm{~W} / \mathrm{m} \mathrm{K}$ \\
\hline Pore Compressibility & $5.0 \times 10-10 \mathrm{~Pa}^{-1}$ \\
\hline composite thermal conductivity Model & linear \\
\hline Capillary Pressure Model & Van-Genuchten Equation $^{34}$ \\
\hline$\lambda$ parameter & $0.132 \mathrm{~m}-1$ \\
\hline$S_{i r A}$ parameter & 2.823 \\
\hline $1 / P_{o}$ parameter & 1 \\
\hline$P_{\max }$ parameter & $5.0 \times 106 \mathrm{~Pa}$ \\
\hline$S_{\mathrm{mxA}}$ parameter & 1 \\
\hline Aqueous Relative Permeability Model & Stone $^{36}+$ Aziz $^{37}$ \\
\hline$S_{\text {irA }}$ parameter & 0.12 \\
\hline$n$ parameter & 3 \\
\hline Gas Relative Permeability Model & Stone $^{36}+$ Aziz $^{37}$ \\
\hline$S_{\text {irG }}$ parameter & 0.02 \\
\hline
\end{tabular}




\section{Relative Permeability Model}

The relative permeability model used in this problem is same as in problem 3 and is developed by Stone and Aziz.

$k_{r G}=\left(S_{G}^{*}\right)^{n}, S_{G}^{*}=\left(S_{G}-S_{i r G}\right) /\left(1-S_{i r A}\right)$

$k_{r A}=\left(S_{A}^{*}\right)^{n}, S_{A}^{*}=\left(S_{A}-S_{i r A}\right) /\left(1-S_{i r A}\right)$

Where, $S_{i r G}, \mathrm{~S}_{\mathrm{irA}}$ represents irreducible gas and aqueous saturation.

In this problem $S_{i r G}=0.02, S_{i r A}=0.12$ and $n=3.0$.

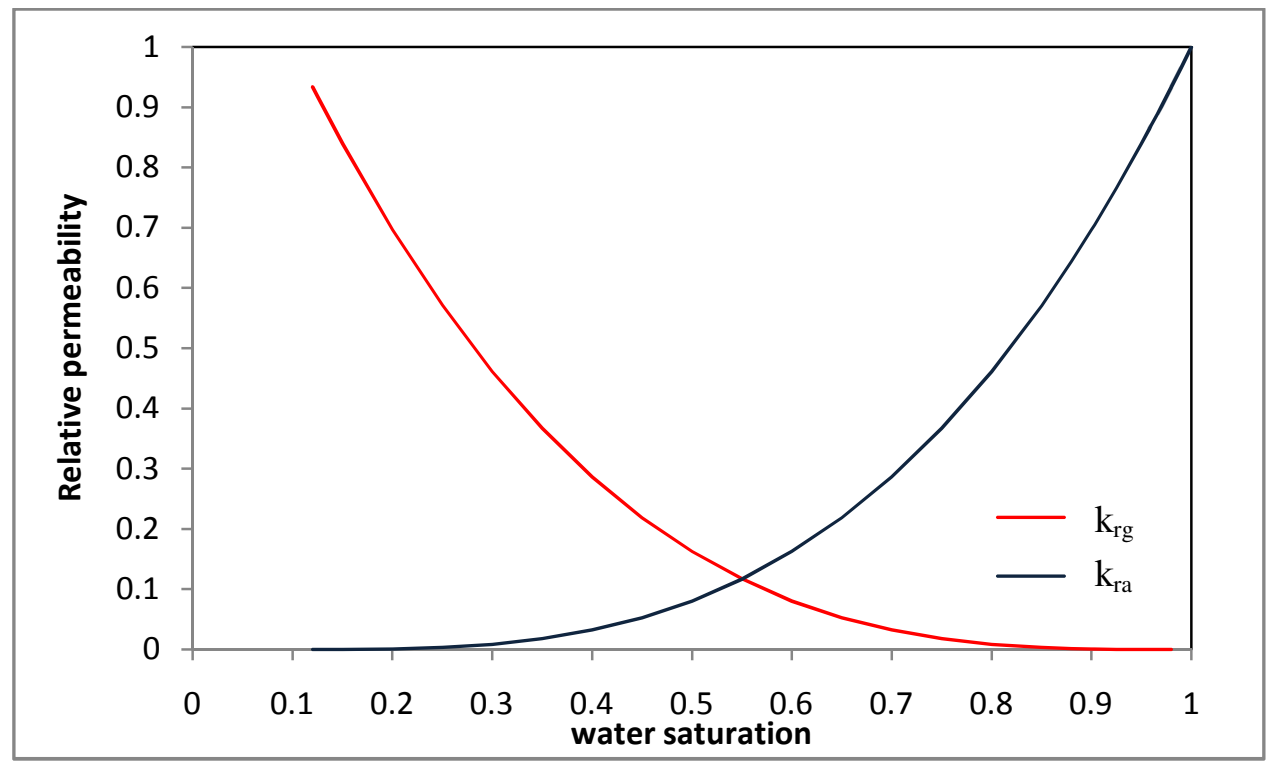

Figure 4- 2 Aqueous and gas relative permeability curves as a function of water saturation for Problem 4

\section{Capillary pressure model:}

To avoid complexities, capillary pressure is not considered for the thermal case (case 1). For the depressurization case (Case-2) capillary pressure used is the same as in problem3.

$P_{c a p}=-P_{0}\left[\left(S^{*}\right)^{-1 / \lambda}-1\right]^{\lambda}, S^{*}=\frac{\left(S_{A}-S_{i r A}\right)}{\left(S_{m x A}-S_{i r A}\right)}$ where $-\mathrm{P}_{\max } \leq \mathrm{P}_{\text {cap }} \leq 0$

Different parameters in this model are specified in Table 4-1 


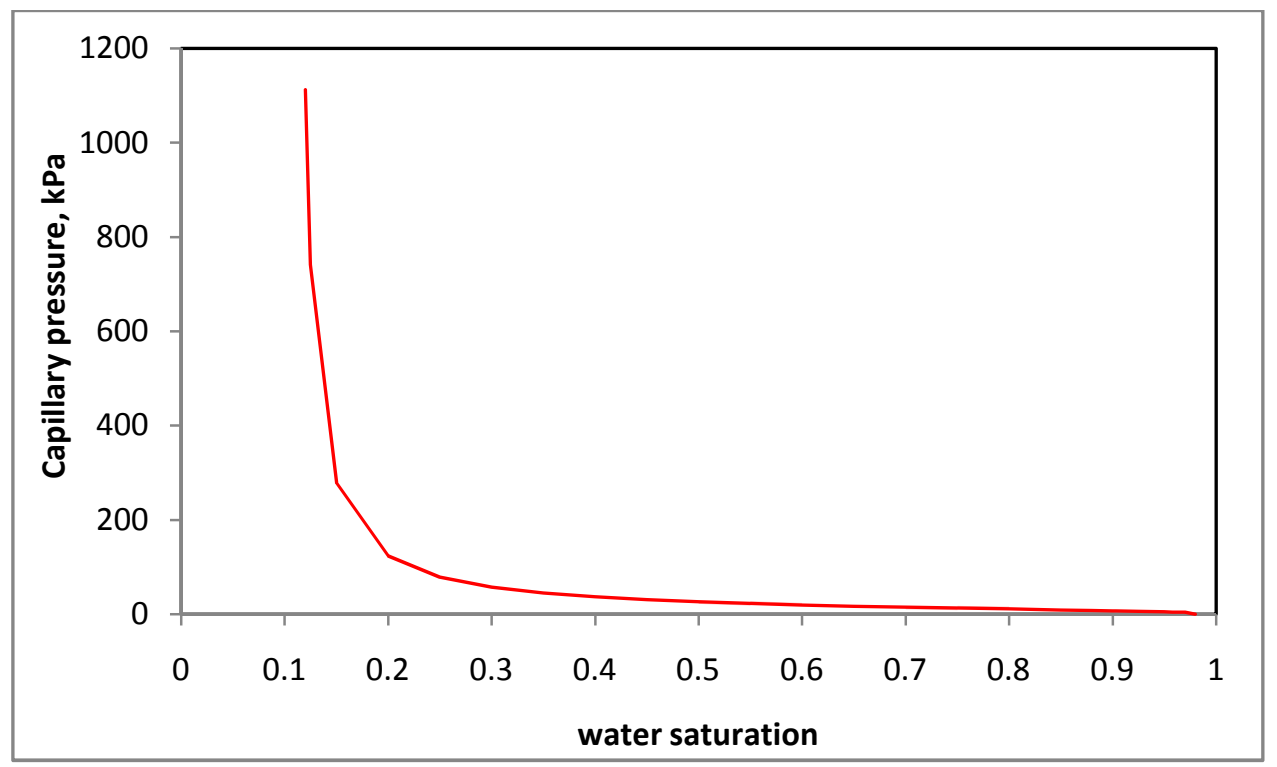

Figure 4-3 Capillary Pressure vs. Water Saturation for Problem 4.

\section{Data and sampling frequency}

Profiles of water saturation, temperature, pressure, aqueous relative permeability, and aqueous methane mass fraction and capillary pressure, gas rate, cumulative gas rate are compared for different time steps. The time steps considered here are different for each case.

\section{Case 1: Thermal Stimulation}

Data is recorded at 2 days, 5 days, 10 days, 15 days, 20 days, 30 days, 45 days and 60 days.

\section{Case 2: Depressurization to a pressure above $Q$ point}

Data is recorded at 2 days, 5 days, 10 days, 15 days, 20 days, 30 days and 45 days. 


\subsubsection{Solution to Problem 4}

The cylindrical grid is very finely discretized into 1500 cells in the radial direction. Two cases are defined based on the method of hydrate dissociation chosen. Grid description, medium and rock-fluid properties are same for both the cases. To avoid complexities, capillary pressure is not considered for the thermal case. As given in the problem description the only difference between case $1 \& 2$ is their initial and boundary conditions. Porosity and permeability are 0.3 and $300 \mathrm{mD}$. The input data file used in this problem is specified below.

\begin{tabular}{|c|c|c|c|c|c|}
\hline \multicolumn{6}{|l|}{$\begin{array}{l}\text { GRID RADIAL } \\
\text { KDIR DOWN } \\
\text { DI IVAR }\end{array}$} \\
\hline $\begin{array}{c}* * 1000 \mathrm{rad}= \\
0.02\end{array}$ & $\begin{array}{c}\text { al cells of } \\
0.0202594\end{array}$ & $r=0.02 \mathrm{~m}$ & & & \\
\hline 0.0205222 & 0.0207883 & 0.0210579 & 0.021331 & 0.0216077 & 0.0218879 \\
\hline 0.0221718 & 0.0224594 & 0.0227507 & 0.0230458 & 0.0233446 & 0.0236474 \\
\hline 0.0239541 & 0.0242648 & 0.0245795 & 0.0248983 & 0.0252212 & 0.0255483 \\
\hline 0.0258797 & 0.0262153 & 0.0265553 & 0.0268997 & 0.0272486 & 0.027602 \\
\hline 0.02796 & 0.0283226 & 0.02869 & 0.0290621 & 0.029439 & 0.0298208 \\
\hline 0.0302076 & 0.0305994 & 0.0309962 & 0.0313982 & 0.0318055 & 0.032218 \\
\hline 0.0326358 & 0.0330591 & 0.0334879 & 0.0339222 & 0.0343622 & 0.0348078 \\
\hline 0.0352593 & 0.0357166 & 0.0361798 & 0.036649 & 0.0371244 & 0.0376059 \\
\hline 0.0380936 & 0.0385877 & 0.0390881 & 0.0395951 & 0.0401086 & 0.0406288 \\
\hline 0.0411558 & 0.0416895 & 0.0422302 & 0.042778 & 0.0433328 & 0.0438948 \\
\hline 0.0444641 & 0.0450408 & 0.0456249 & 0.0462167 & 0.0468161 & 0.0474233 \\
\hline 0.0480383 & 0.0486614 & 0.0492925 & 0.0499318 & 0.0505794 & 0.0512354 \\
\hline 0.0518999 & 0.052573 & 0.0532549 & 0.0539456 & 0.0546452 & 0.055354 \\
\hline 0.0560719 & 0.0567991 & 0.0575358 & 0.058282 & 0.0590379 & 0.0598036 \\
\hline 0.0605792 & 0.0613649 & 0.0621608 & 0.062967 & 0.0637837 & 0.0646109 \\
\hline 0.0654489 & 0.0662978 & 0.0671576 & 0.0680286 & 0.068911 & 0.0698047 \\
\hline 0.07071 & 0.0716271 & 0.0725561 & 0.0734971 & 0.0744504 & 0.075416 \\
\hline 0.0763941 & 0.0773849 & 0.0783886 & 0.0794052 & 0.0804351 & 0.0814783 \\
\hline 0.0825351 & 0.0836055 & 0.0846898 & 0.0857882 & 0.0869009 & 0.088028 \\
\hline 0.0891696 & 0.0903261 & 0.0914977 & 0.0926843 & 0.0938864 & 0.0951041 \\
\hline 0.0963376 & 0.097587 & 0.0988527 & 0.100135 & 0.101434 & 0.102749 \\
\hline 0.104082 & 0.105432 & 0.106799 & 0.108184 & 0.109587 & 0.111009 \\
\hline 0.112448 & 0.113907 & 0.115384 & 0.116881 & 0.118396 & 0.119932 \\
\hline 0.121488 & 0.123063 & 0.124659 & 0.126276 & 0.127914 & 0.129573 \\
\hline 0.131253 & 0.132956 & 0.13468 & 0.136427 & 0.138196 & 0.139989 \\
\hline 0.141804 & 0.143643 & 0.145506 & 0.147393 & 0.149305 & 0.151242 \\
\hline 0.153203 & 0.15519 & 0.157203 & 0.159242 & 0.161307 & 0.163399 \\
\hline 0.165518 & 0.167665 & 0.16984 & 0.172042 & 0.174274 & 0.176534 \\
\hline 0.178824 & 0.181143 & 0.183492 & 0.185872 & 0.188283 & 0.190725 \\
\hline 0.193198 & 0.195704 & 0.198242 & 0.200813 & 0.203418 & 0.206056 \\
\hline 0.208729 & 0.211436 & 0.214178 & 0.216956 & 0.21977 & 0.22262 \\
\hline 0.225507 & 0.228432 & 0.231395 & 0.234396 & 0.237436 & 0.240515 \\
\hline 0.243635 & 0.246795 & 0.249996 & 0.253238 & 0.256522 & 0.259849 \\
\hline 0.263219 & 0.266633 & 0.270092 & 0.273594 & 0.277143 & 0.280737 \\
\hline 0.284378 & 0.288067 & 0.291803 & 0.295587 & 0.299421 & 0.303305 \\
\hline 0.307238 & 0.311223 & 0.31526 & 0.319348 & 0.32349 & 0.327686 \\
\hline 0.331936 & 0.336241 & 0.340602 & 0.345019 & 0.349494 & 0.354027 \\
\hline 0.358618 & 0.36327 & 0.367981 & 0.372754 & 0.377588 & 0.382485 \\
\hline 0.387446 & 0.392471 & 0.397561 & 0.402718 & 0.407941 & 0.413232 \\
\hline 0.418591 & 0.42402 & 0.429519 & 0.43509 & 0.440733 & 0.446449 \\
\hline 0.45224 & 0.458105 & 0.464046 & 0.470065 & 0.476162 & 0.482337 \\
\hline
\end{tabular}




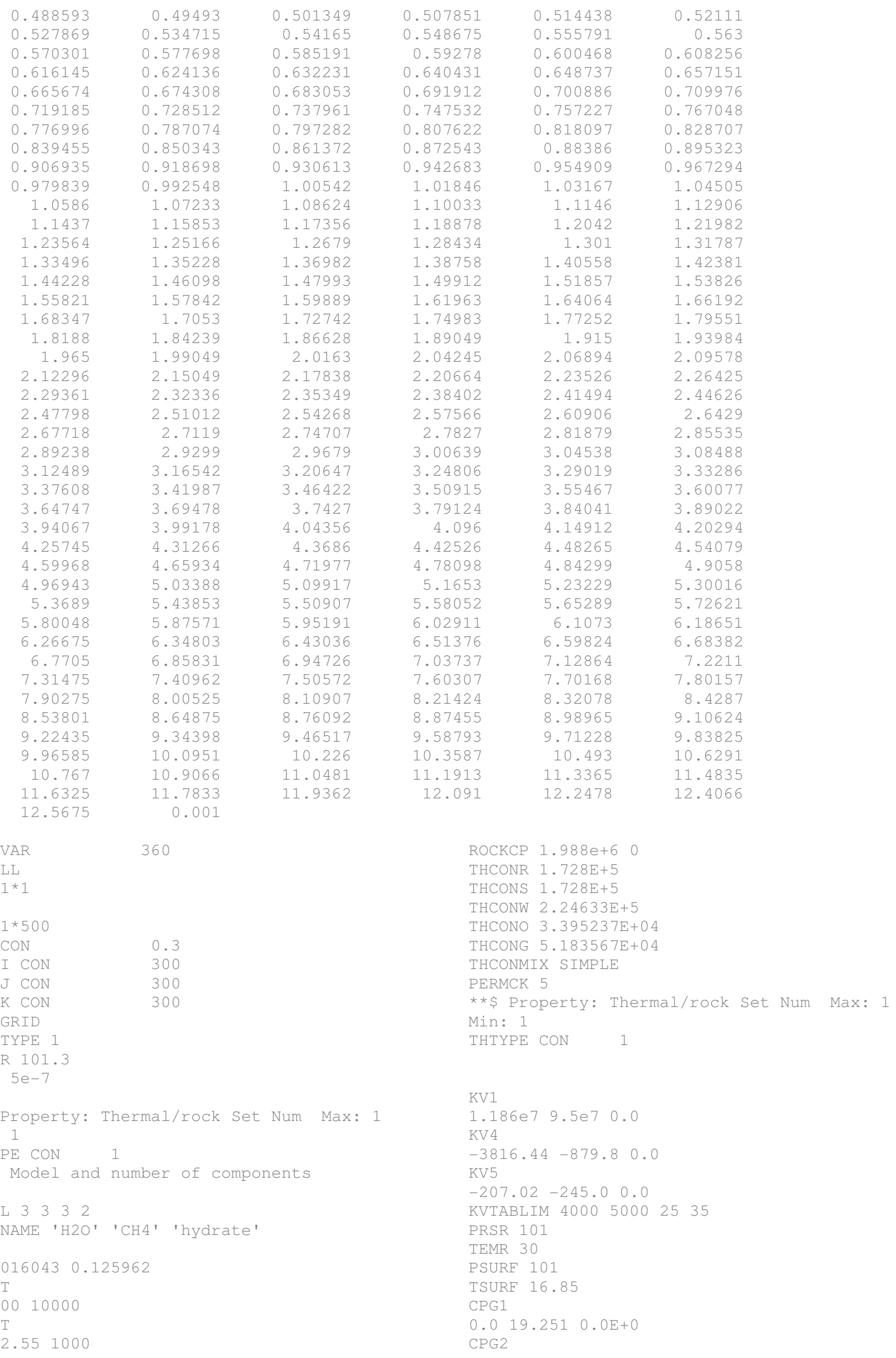




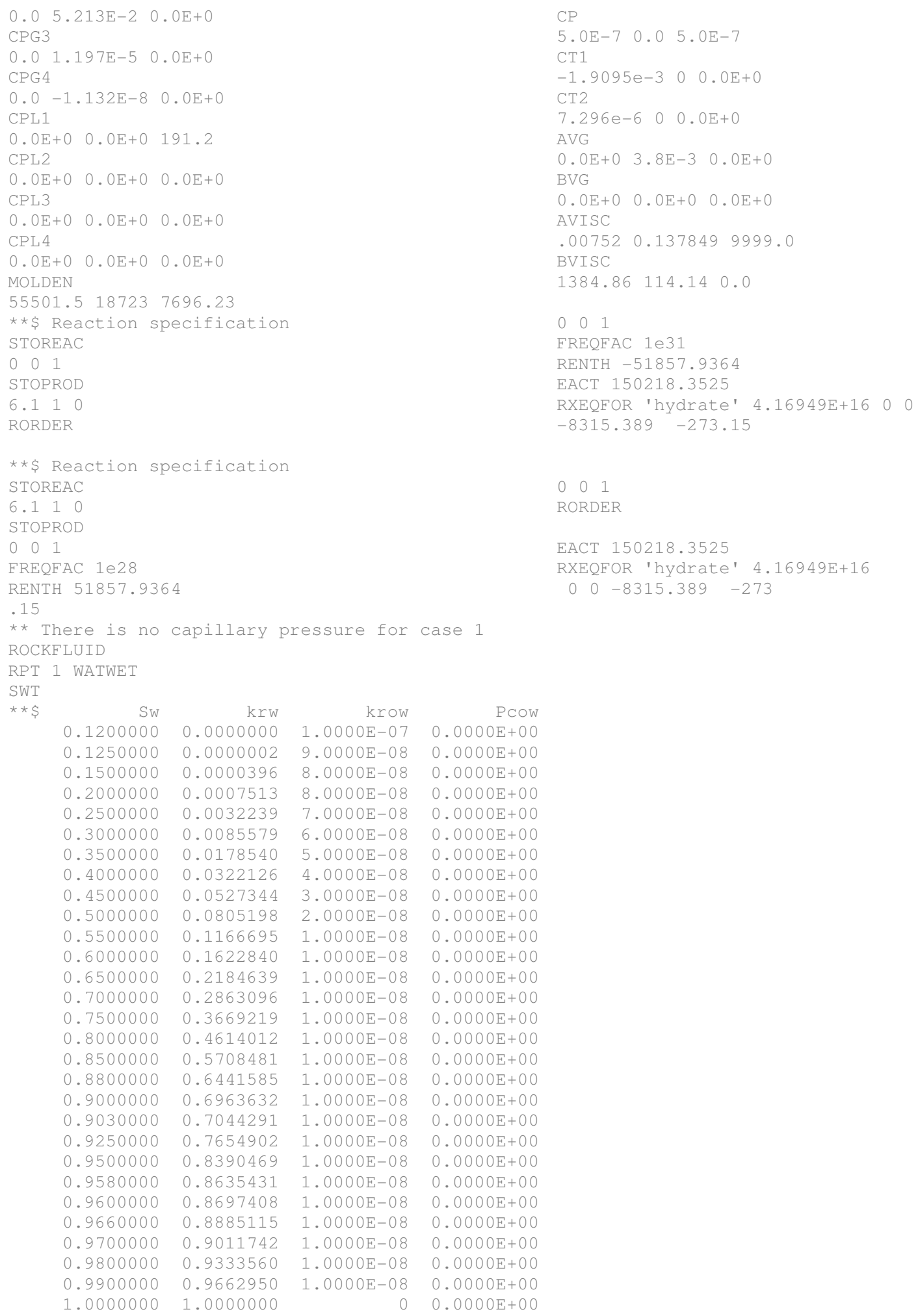

$\mathrm{CP}$

$5.0 \mathrm{E}-7 \quad 0.0 \quad 5.0 \mathrm{E}-7$

CT1

$-1.9095 e-3 \quad 0 \quad 0.0 \mathrm{E}+0$

CT2

$7.296 e-6 \quad 0 \quad 0.0 E+0$

AVG

$0.0 \mathrm{E}+0 \quad 3.8 \mathrm{E}-3 \quad 0.0 \mathrm{E}+0$

BVG

$0.0 \mathrm{E}+0 \quad 0.0 \mathrm{E}+0 \quad 0.0 \mathrm{E}+0$

AVISC

.007520 .1378499999 .0

BVISC

$1384.86114 .14 \quad 0.0$

$\begin{array}{lll}0 & 0 & 1\end{array}$

FREQFAC 1 e 31

RENTH -51857.9364

EACT 150218.3525

RXEQFOR 'hydrate' 4.16949E+16 00

$-8315.389-273.15$

$\begin{array}{lll}0 & 0 & 1\end{array}$

RORDER

EACT 150218.3525

RXEOFOR 'hydrate' $4.16949 \mathrm{E}+16$

$\begin{array}{llll}0 & 0 & -8315.389 & -273\end{array}$ 


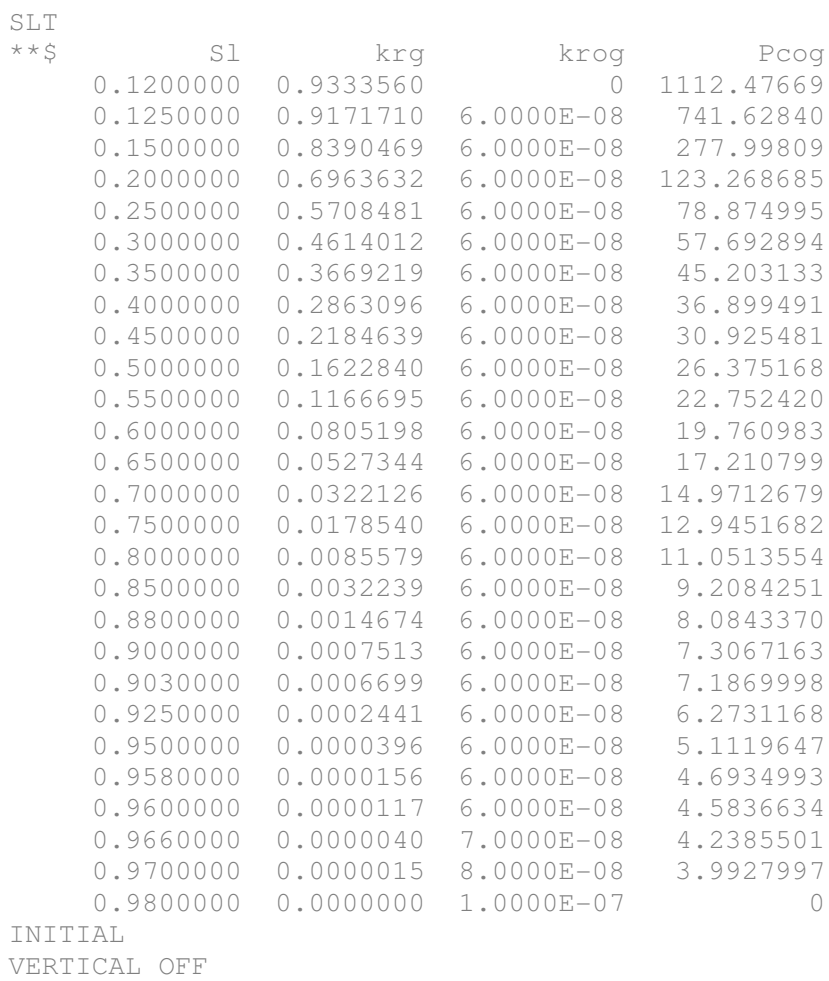

\section{Case 1 Thermal Stimulation}

Reservoir pressure and temperature are at 4.6 $\mathrm{MPa}$ and $3^{\circ} \mathrm{C}$. A constant heat supply of 1.296 $\mathrm{x} 10^{7} \mathrm{~J} /$ day at $r=0$ is specified by keyword 'HEATR CON'. Hydrate saturation is 0.5 in the entire reservoir. A extra constraint of bottom hole pressure of $4607 \mathrm{kPa}$ is added in the well to ensure that all hydrate that is dissociated is due to thermal stimulation.

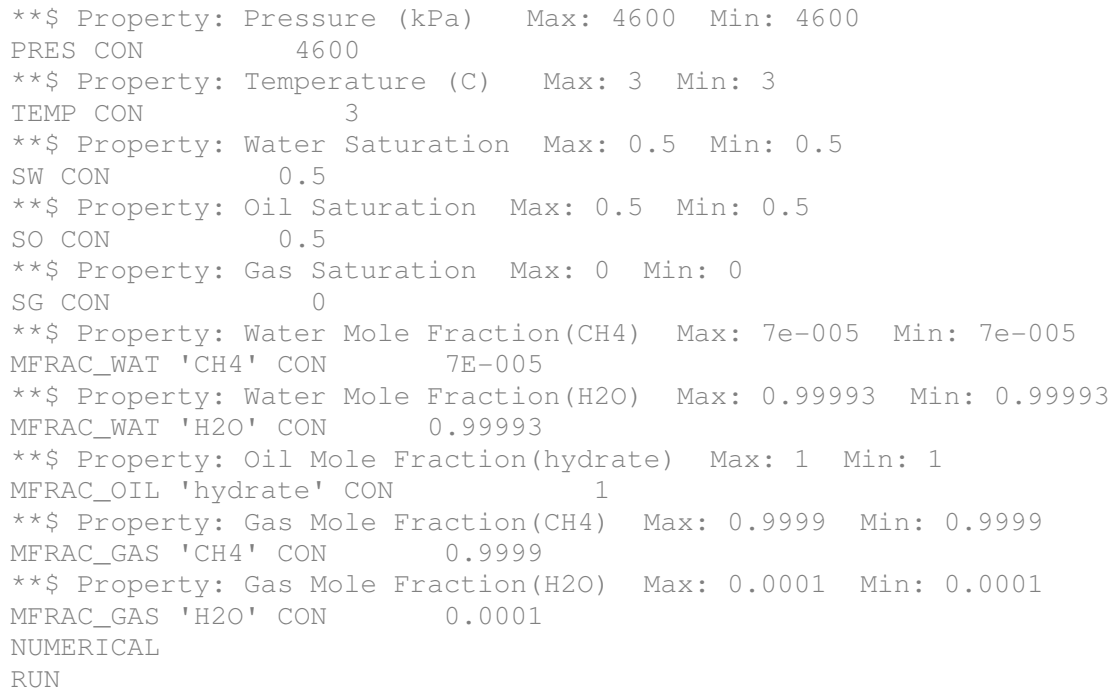




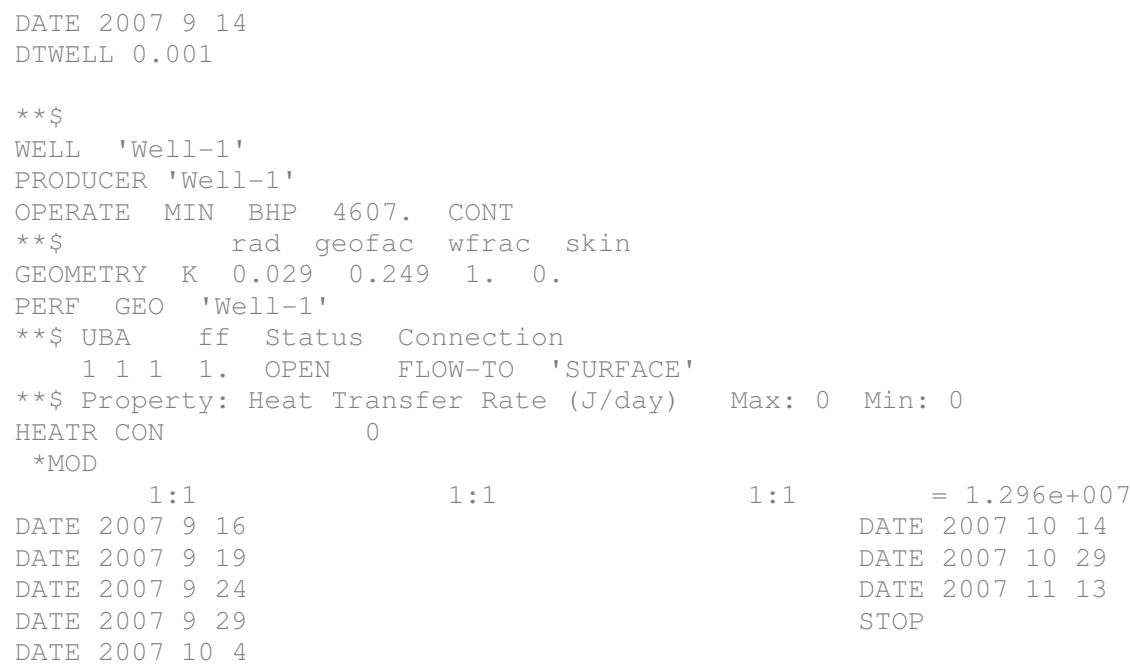

\section{Case 2 Depressurization}

Initial and boundary conditions are different from the previous case. Reservoir pressure is $9500 \mathrm{kPa}$ and is depressurized by taking out fluid through a well at a constant rate of 0.1 $\mathrm{kg} / \mathrm{sec}$. Hydrate saturation is 0.4 in the entire reservoir as specified in the problem description.

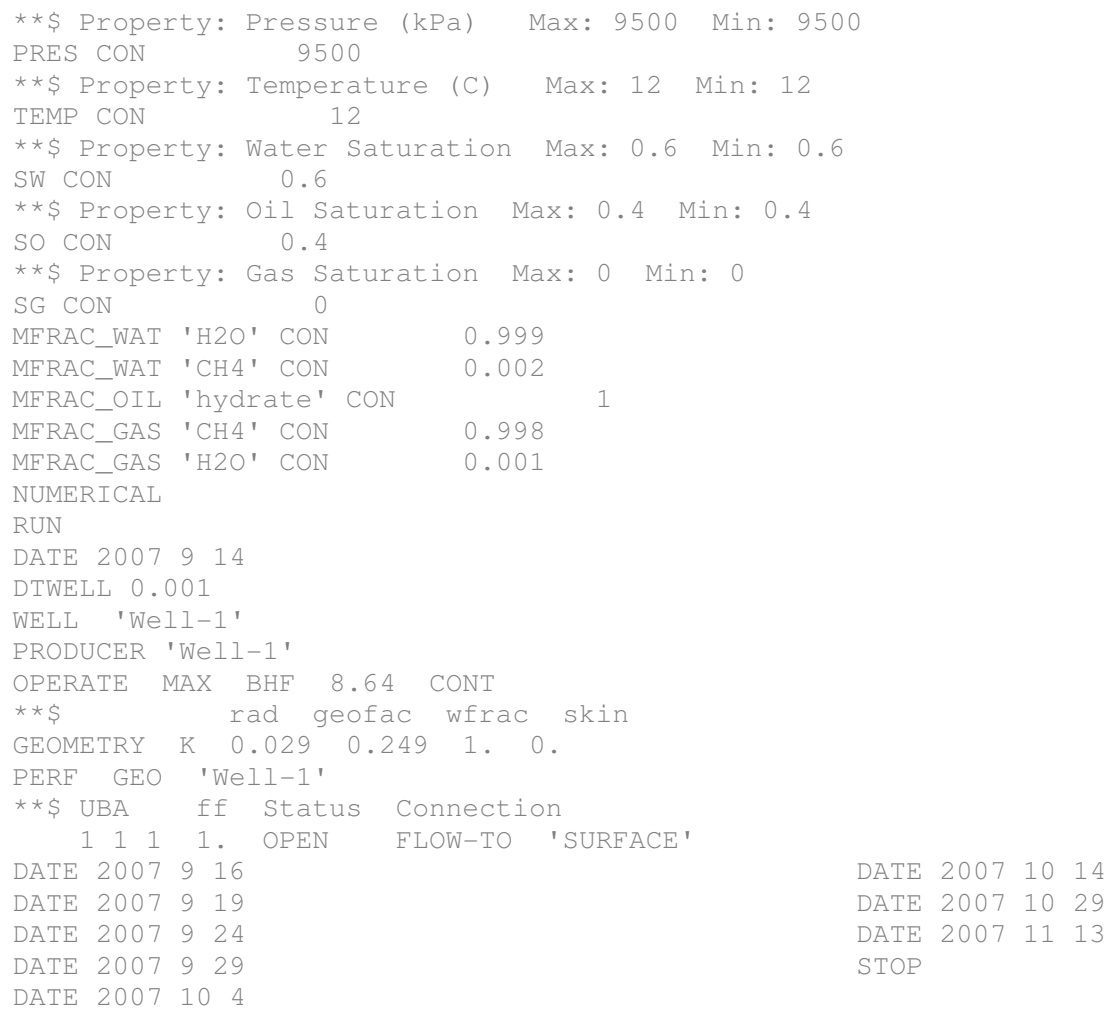




\subsubsection{Results of similarity solution study of hydrate dissociation in radial domain.}

Similarity solution can provide a simple and robust tool to evaluate the production potential of hydrate accumulations. If a problem has a similarity solution, there is no need to conduct long term simulations; Short term simulation results can be used to predict long term results. Results at any time are sufficient to describe system behavior and performance at any time. Different properties like pressure, temperature, saturations, aqueous phase relative permeability are plotted against $\mathrm{r}^{2} / \mathrm{t}$ and the results showed that the curves are invariant confirming that this problem has a similarity solution. Similarity solutions were found for both the cases of problem 4 in all the reservoir simulators.

\section{Case I: Thermal Stimulation}

Temperature: In this case, hydrate dissociates due to constant heat supply of $1.29 \times 10^{7} \mathrm{~J} / \mathrm{day}$ in the well bore. To validate the results of CMG STARS with other codes, it is first important to match the temperature profiles. Figure 4-4 shows temperature profiles for CMG STARS and TOUGH/Fx-Hydrate in good agreement.
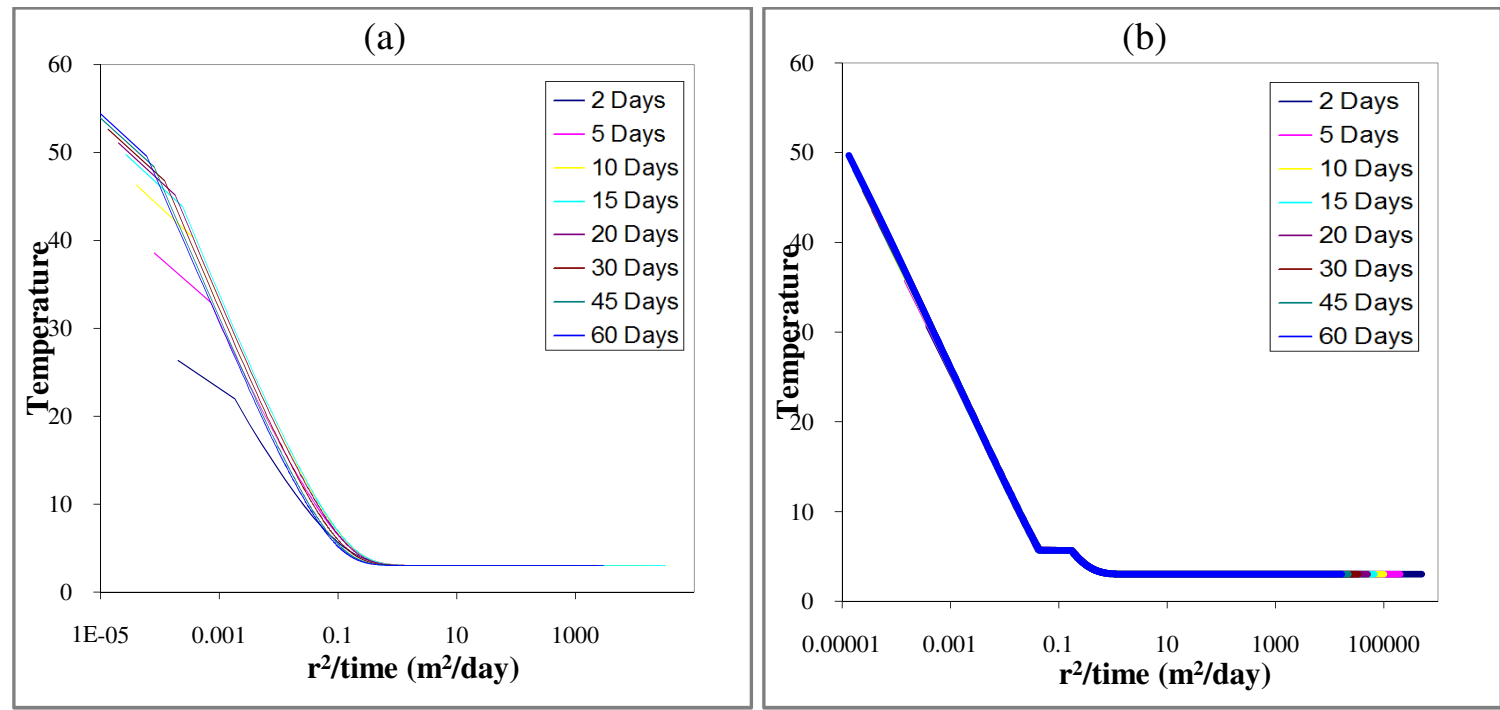

Figure 4- 4 Profiles of Temperature of Problem 4 case 1 for (a) CMG STARS (b) TOUGH-Fx/HYDRATE. 
Saturations: The hydrate, gas and water saturation distributions for all other simulators except STARS (when used hydrate as oil phase) indicates a very sharp dissociation front. In CMG STARS unlike in other codes, a property change applied to a block affects the neighboring blocks also. When heat is added to the system from the block at $r=0$, hydrate in the neighboring blocks also feels that heat and as a result, there is no sharp dissociation front and hence no secondary hydrate formation. Figure 4-5 to Figure 4-7 shows saturation curves for STARS and TOUGH/Fx-Hydrate.
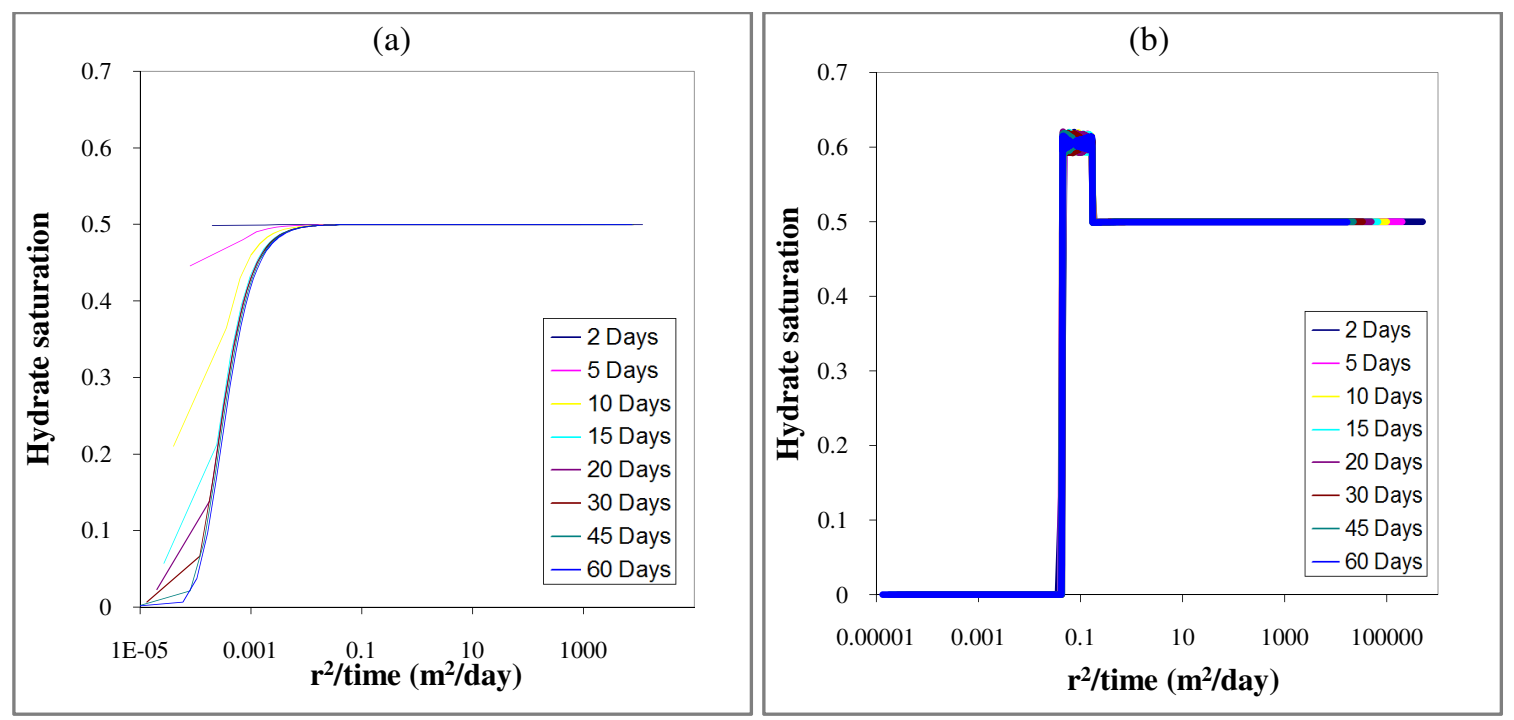

Figure 4- 5 Profiles of Hydrate saturation of Problem 4 case 1 for (a) CMG STARS (b) TOUGH-Fx/HYDRATE. 

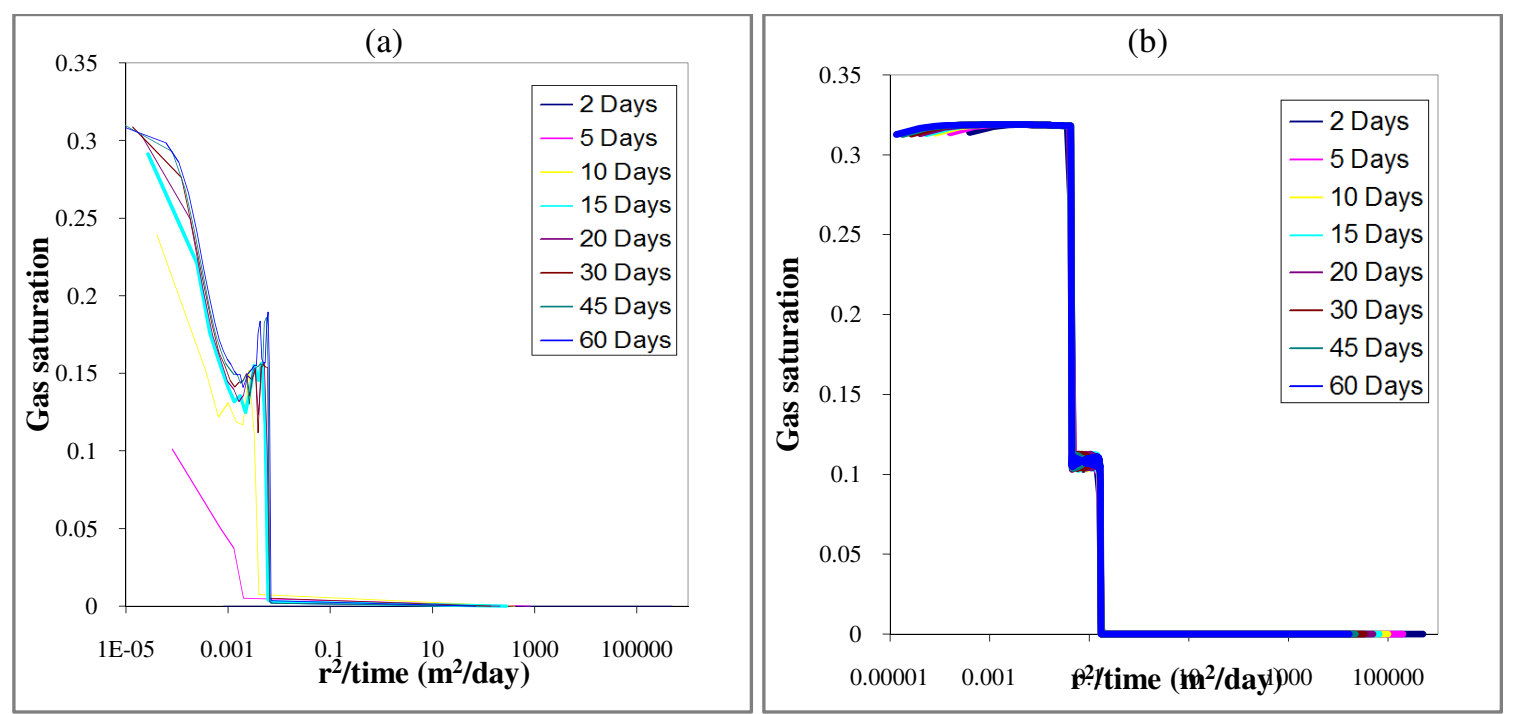

Figure 4- 6 Profiles of Gas saturation of Problem 4 case 1 for (a) CMG STARS (b) TOUGH-Fx/HYDRATE.
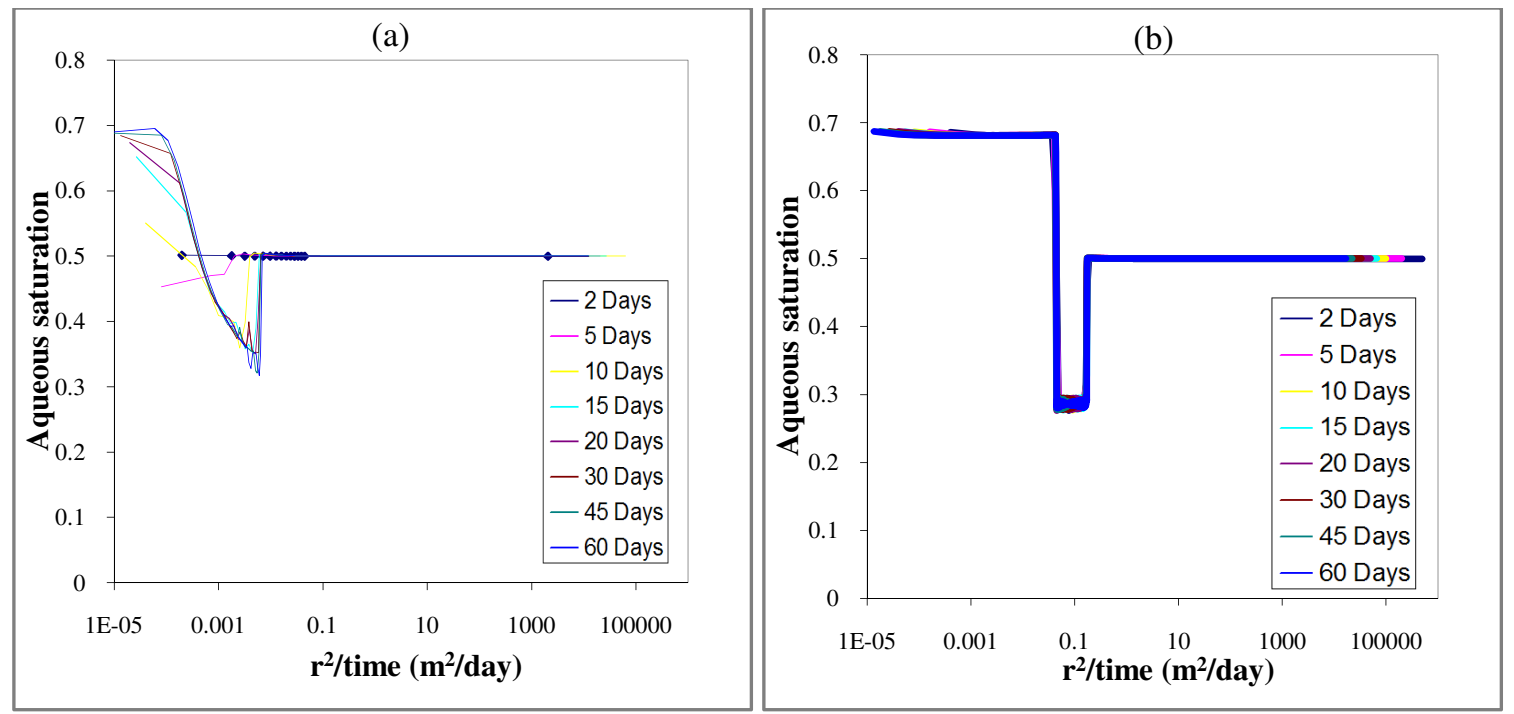

Figure 4- 7 Profiles of Aqueous saturation of Problem 4 case 1 for (a) CMG STARS (b) TOUGH-Fx/HYDRATE.

Aqueous phase relative permeability: Relative permeability is a function of water saturation. Aqueous phase relative permeability is calculated based on water saturation at every time step. So, same kind of behavior is seen for this property also as shown in Figure 4-8. 

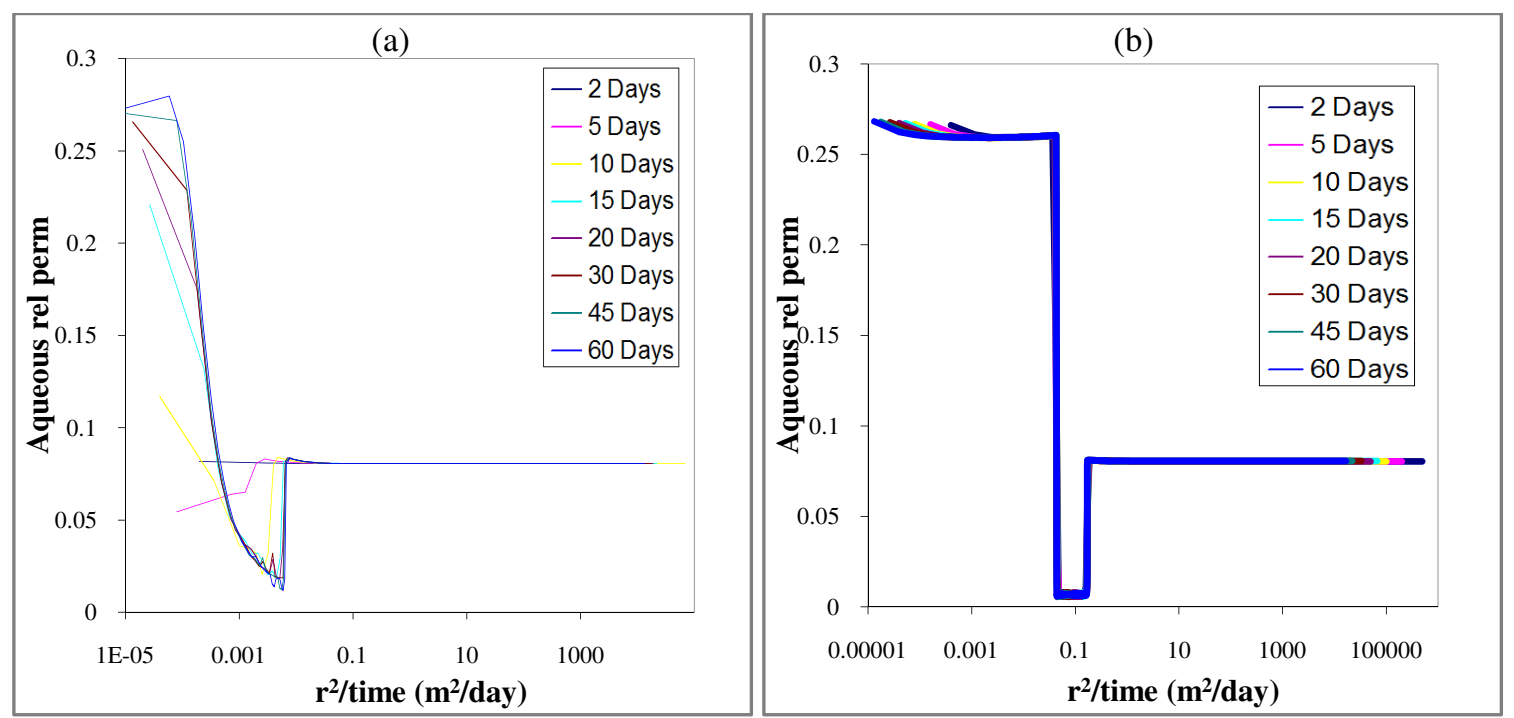

Figure 4- 8 Profiles of Aqueous saturation of Problem 4 case 1 for (a) CMG STARS (b) TOUGH-Fx/HYDRATE.

A Bottom-hole pressure of $4600 \mathrm{kPa}$ is added as an extra boundary condition to ensure that hydrate is dissociated only through thermal stimulation and not by depressurization. Figure 4-9 shows the small differences in the profiles of gas pressure for STARS and TOUGH-

\section{FX/HYDRATE.}
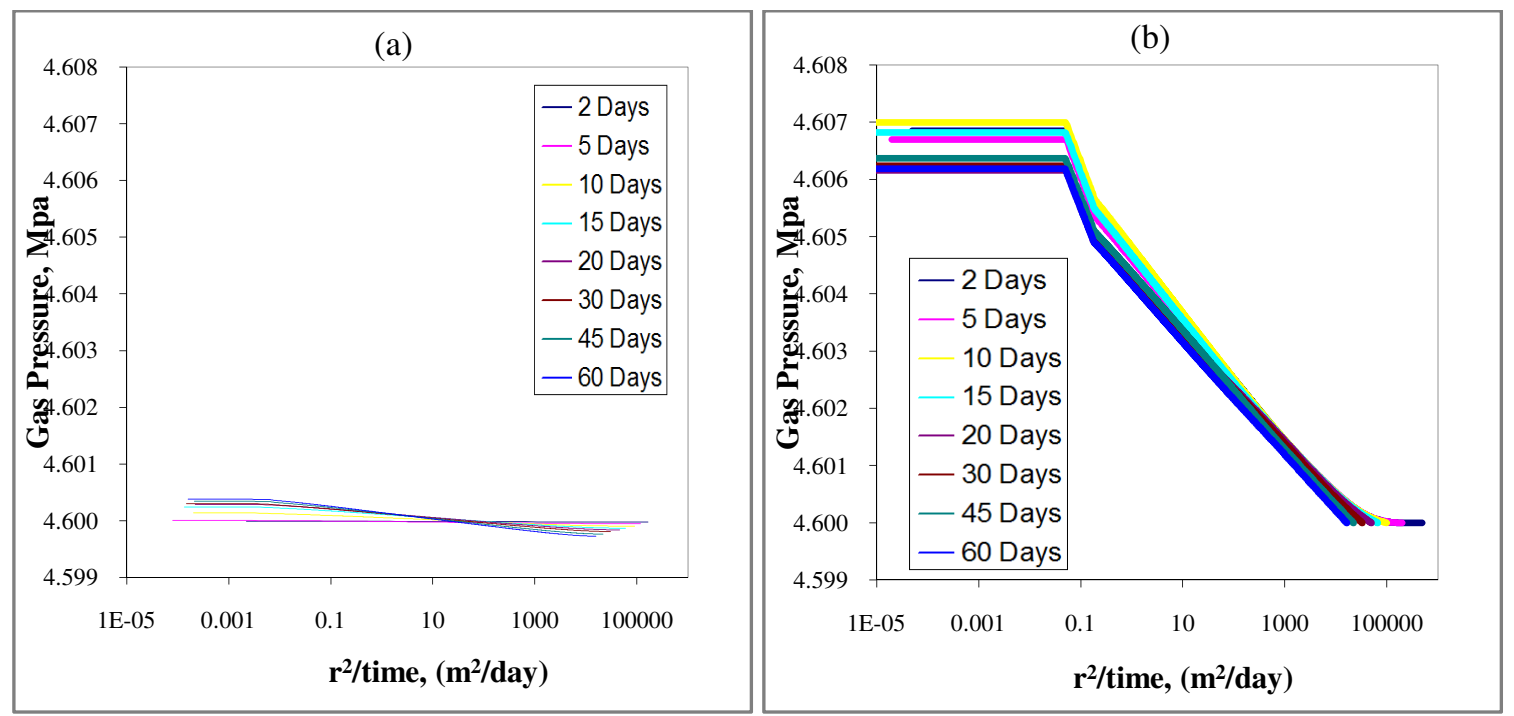

Figure 4- 9 Profiles of Gas pressure of Problem 4 case 1 for (a) CMG STARS (b) TOUGH-Fx/HYDRATE. 


\section{Case II: Depressurization to a Pressure below $Q$ point}

In this case of depressurization, fluids are removed through a well at a constant rate of 0.1 $\mathrm{kg} / \mathrm{s}$ causing depressurization. There is no restriction in the fluid distribution in the production stream. Pressure, temperature, saturations, aqueous phase relative permeability and mass fraction of $\mathrm{CH}_{4}$ in the aqueous phase are plotted vs $r^{2} / t$ and the results for CMG STARS confirm the presence of similarity solution to this problem. Profiles of all these properties are in excellent agreement with other codes. There is no sharp hydrate dissociation front in this case. Results also confirmed that depressurization yields higher production rates. Hydrate dissociation reaction is an endothermic reaction, so it cools the reservoir resulting in the drop of temperatures which may even sometimes lead to secondary hydrate formation. In this case there is no secondary hydrate formation due to higher temperatures in the reservoir. Profiles of pressure and temperature for STARS and TOUGH-Fx/HYDRATE are shown in Figure 4-10 and Figure 4-11.

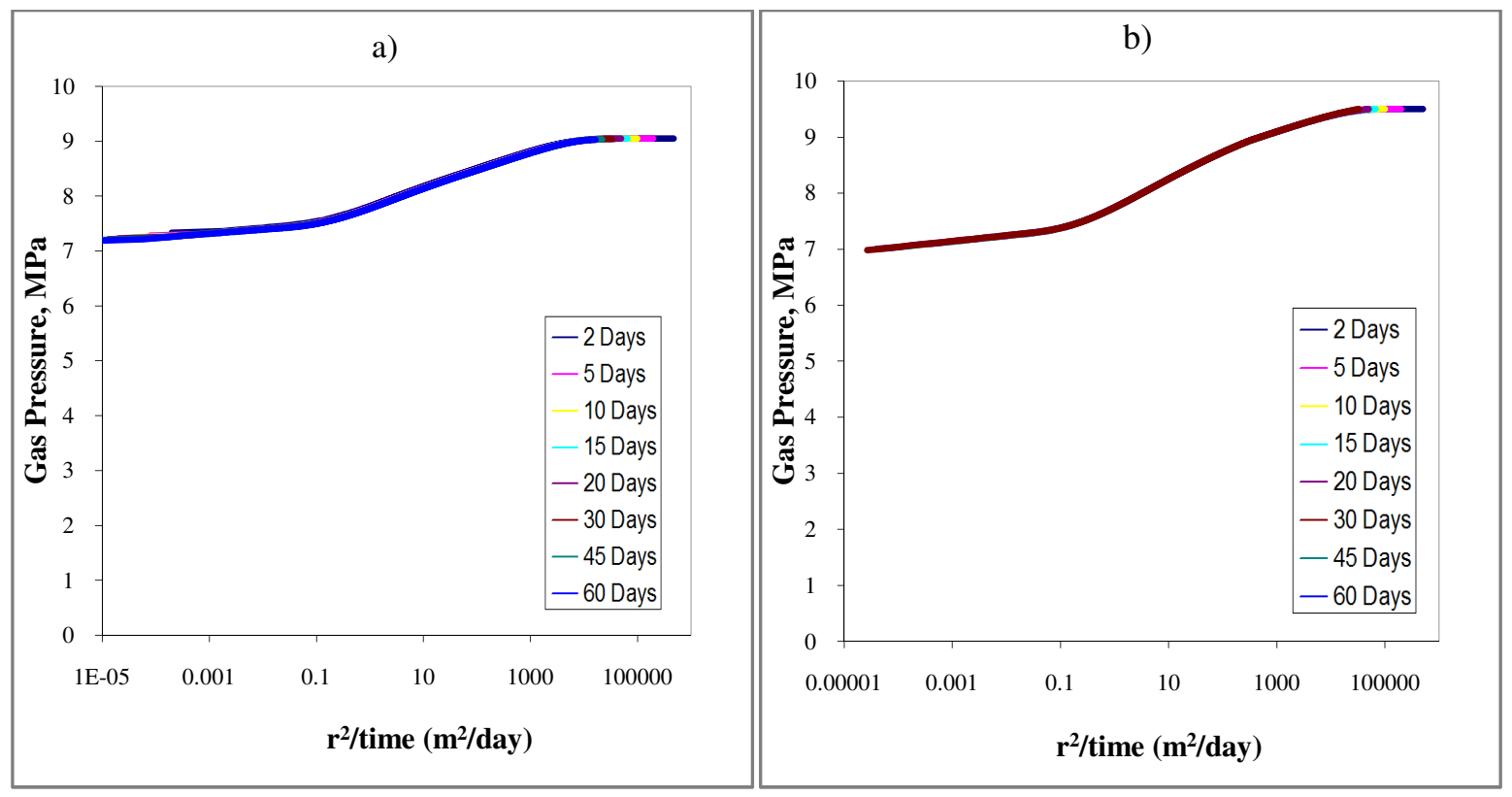

Figure 4-10 Profiles of Gas pressure of Problem 4 case 2 for (a) CMG STARS (b) TOUGH-Fx/HYDRATE. 

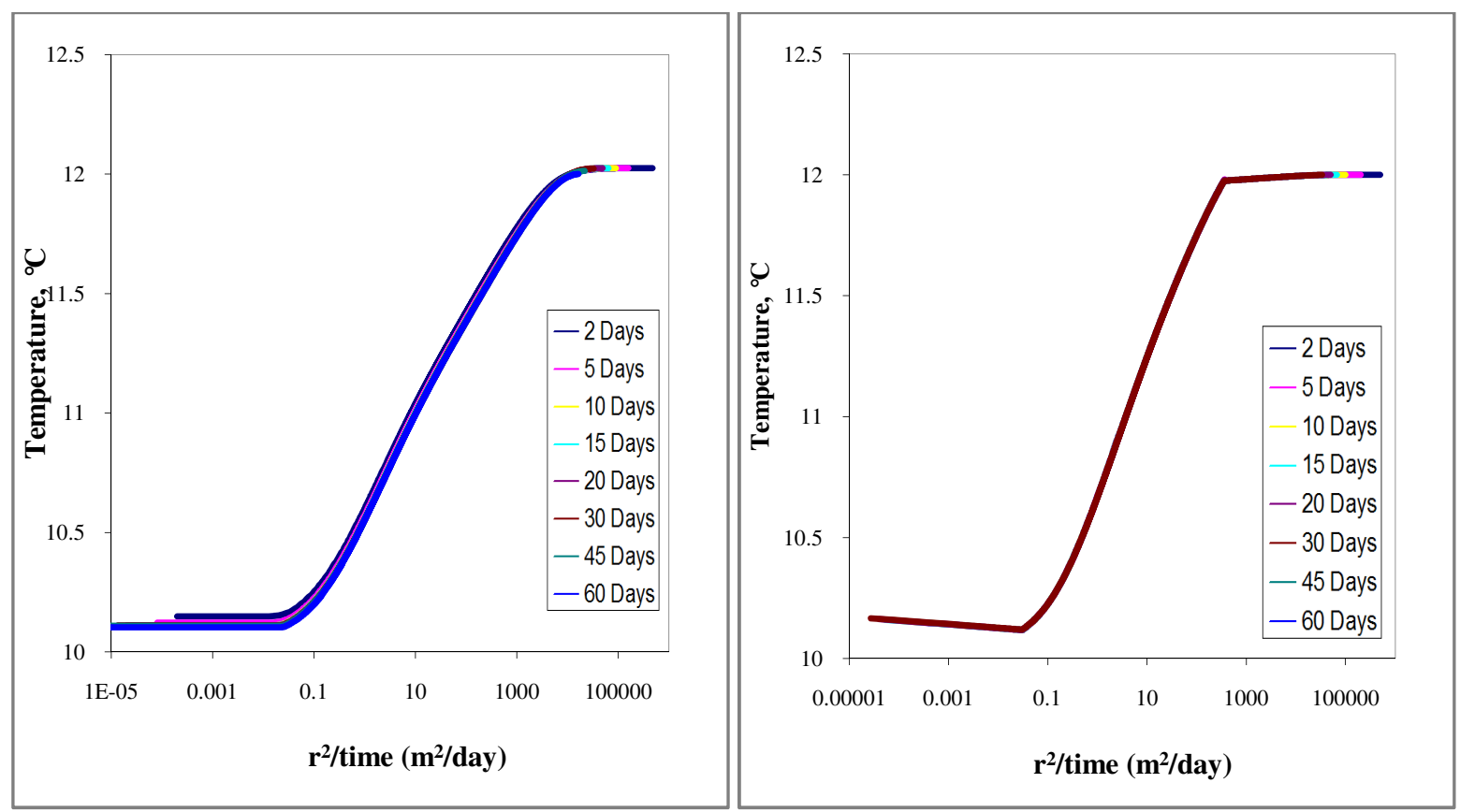

Figure 4- 11 Profiles of Temperature of Problem 4 case 2 for (a) CMG STARS (b) TOUGH-Fx/HYDRATE.

Profiles of hydrate saturation, aqueous saturation and gas saturation are given in Figures 4-11 to Figure 4-13. They are in excellent agreement with other code results. Small fluctuation about the mean is observed in the results for STARS due to numerical difficulties caused by fine discretization of the grid. Aqueous relative permeability for STARS and TOUGH are given in Figure 4-14. Differences in the profile for aqueous CH4 mass fraction for STARS and TOUGH are observed as shown in Figure 4-15. Luckily gas-water capillary pressure for STARS also showed good agreement with TOUGH as shown in Figure 4-16. 


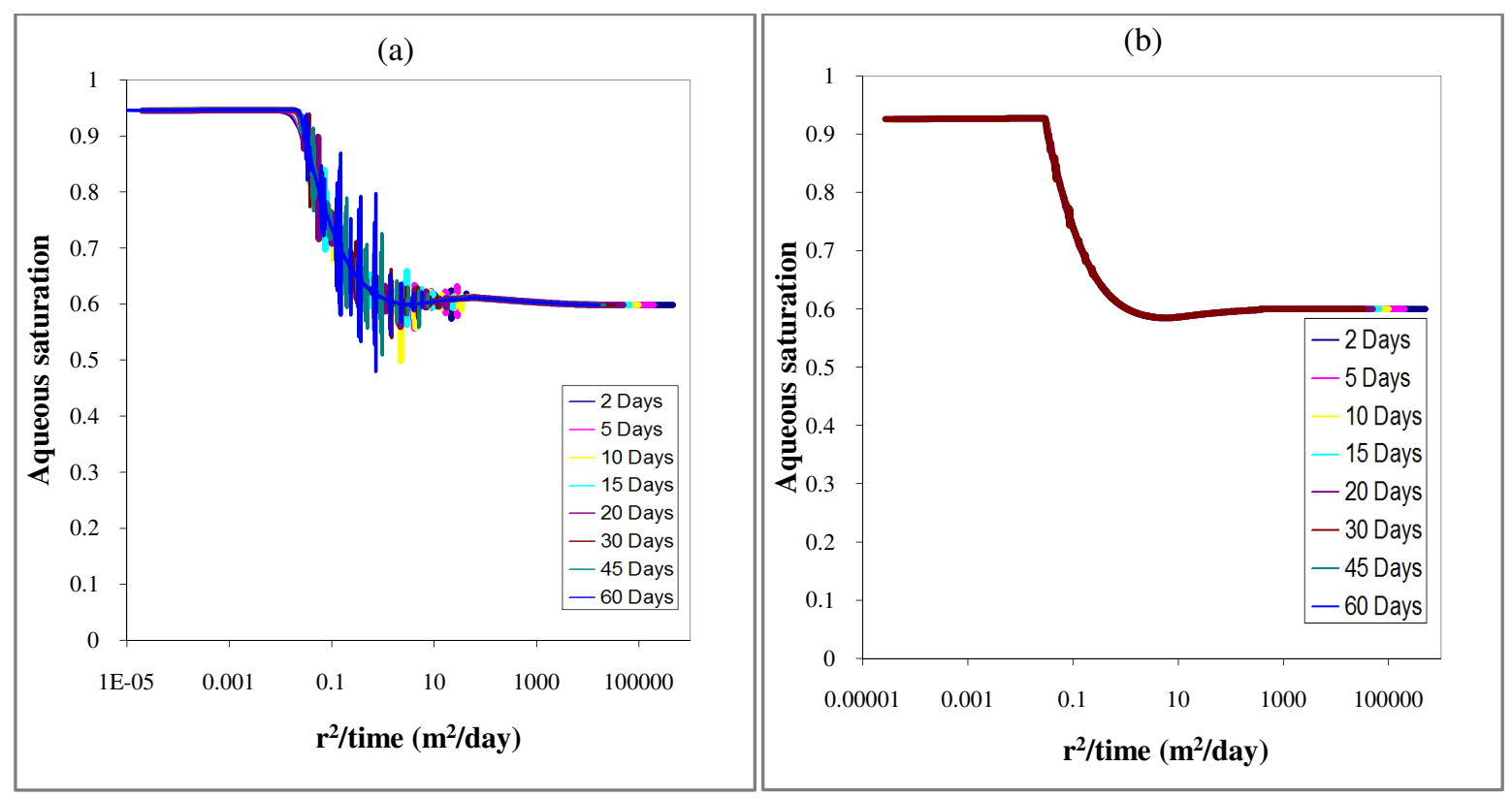

Figure 4- 10 Profiles of aqueous saturation of Problem 4 case 2 for (a) CMG STARS (b) TOUGH-Fx/HYDRATE.
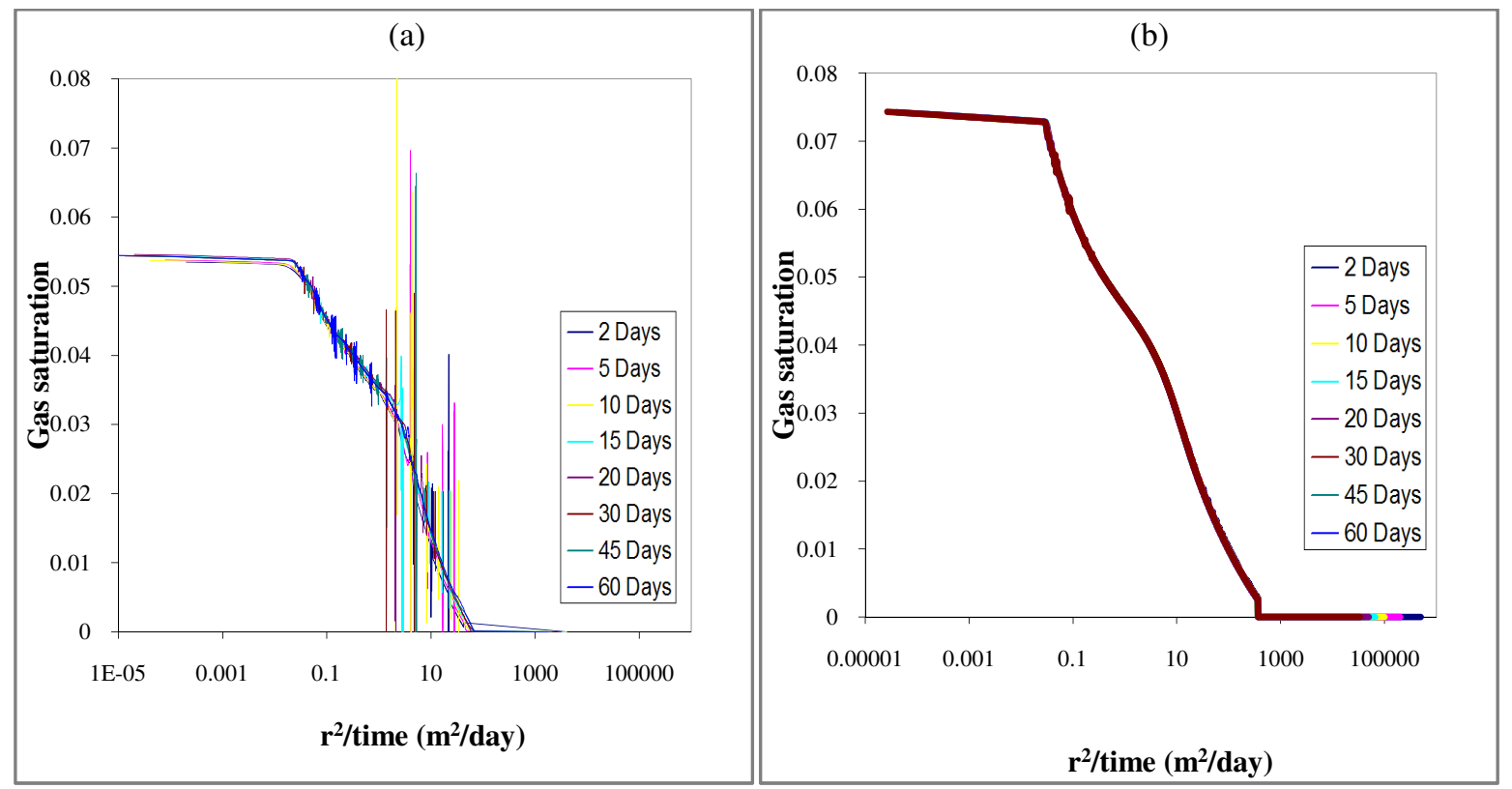

Figure 4- 113 Profiles of gas saturation of Problem 4 case 2 for (a) CMG STARS (b) TOUGH-Fx/HYDRATE. 


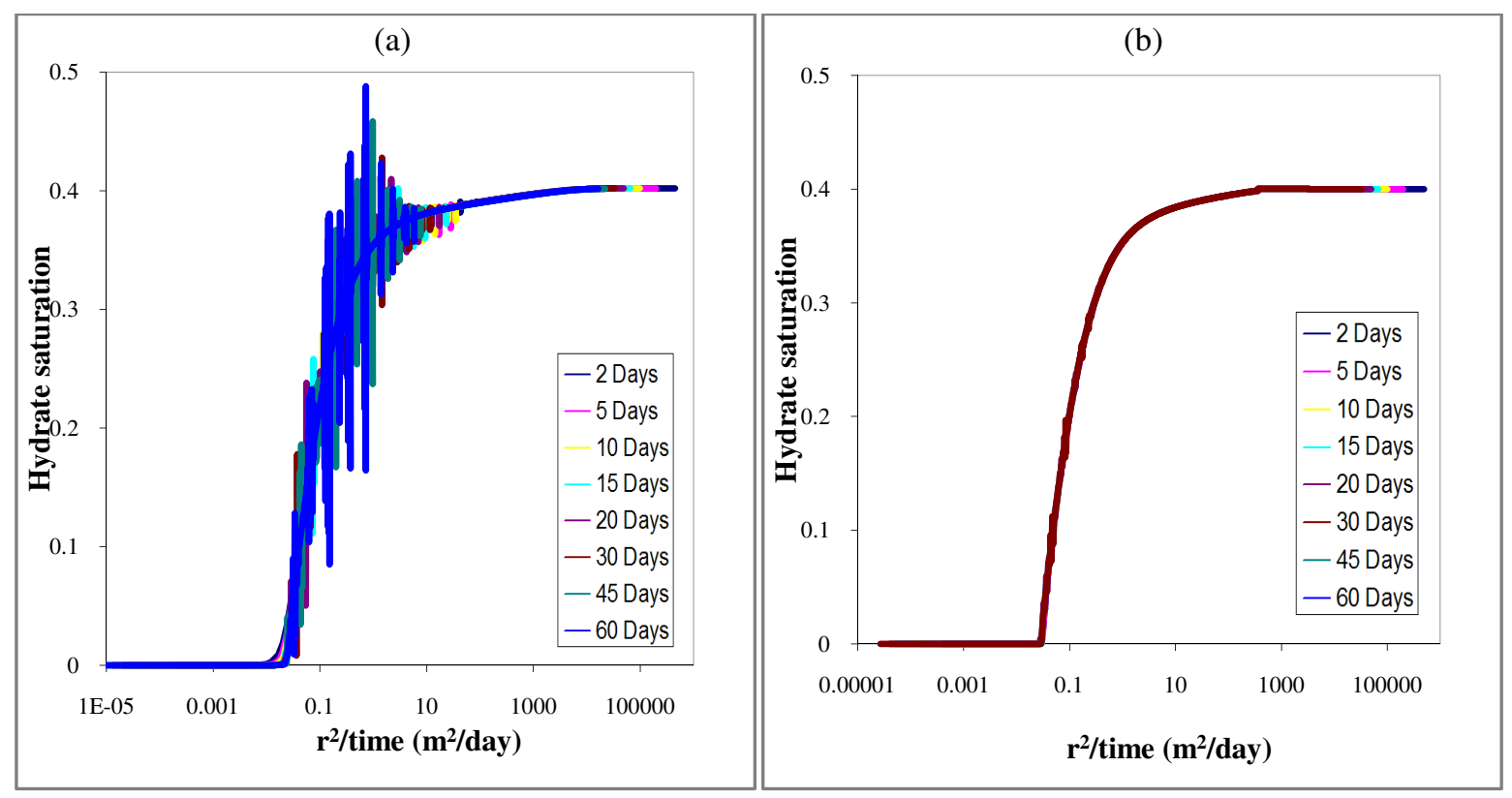

Figure 4- 14 Profiles of hydrate saturation of Problem 4 case 2 for (a) CMG STARS (b) TOUGH-Fx/HYDRATE.
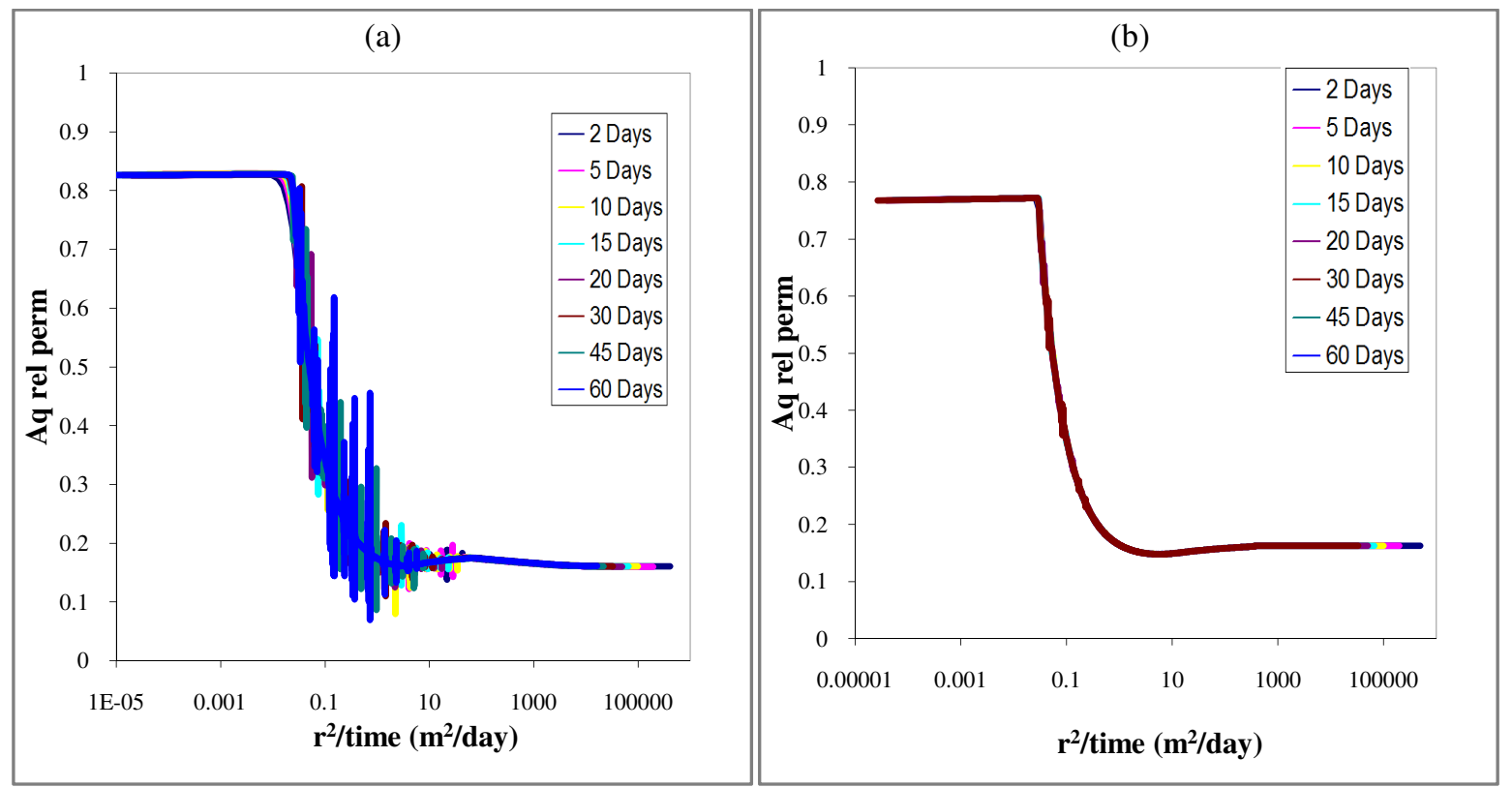

Figure 4- 15 Profiles of aqueous relative permeability of Problem 4 case 2 for (a) CMG STARS (b) TOUGHFX/HYDRATE. 


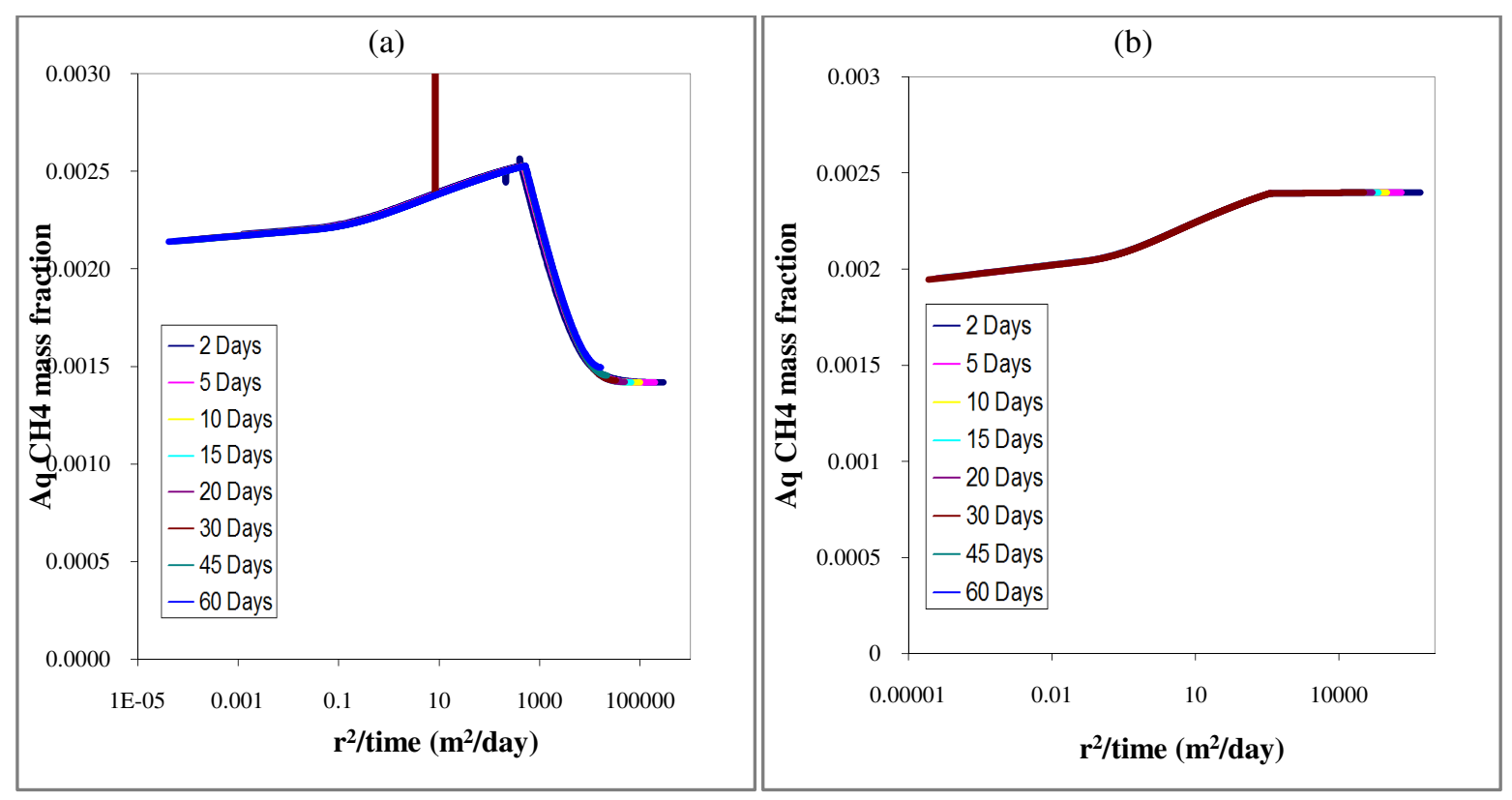

Figure 4- 16 Profiles of aqueous CH4 mass fraction of Problem 4 case 2 for (a) CMG STARS (b) TOUGHFX/HYDRATE.

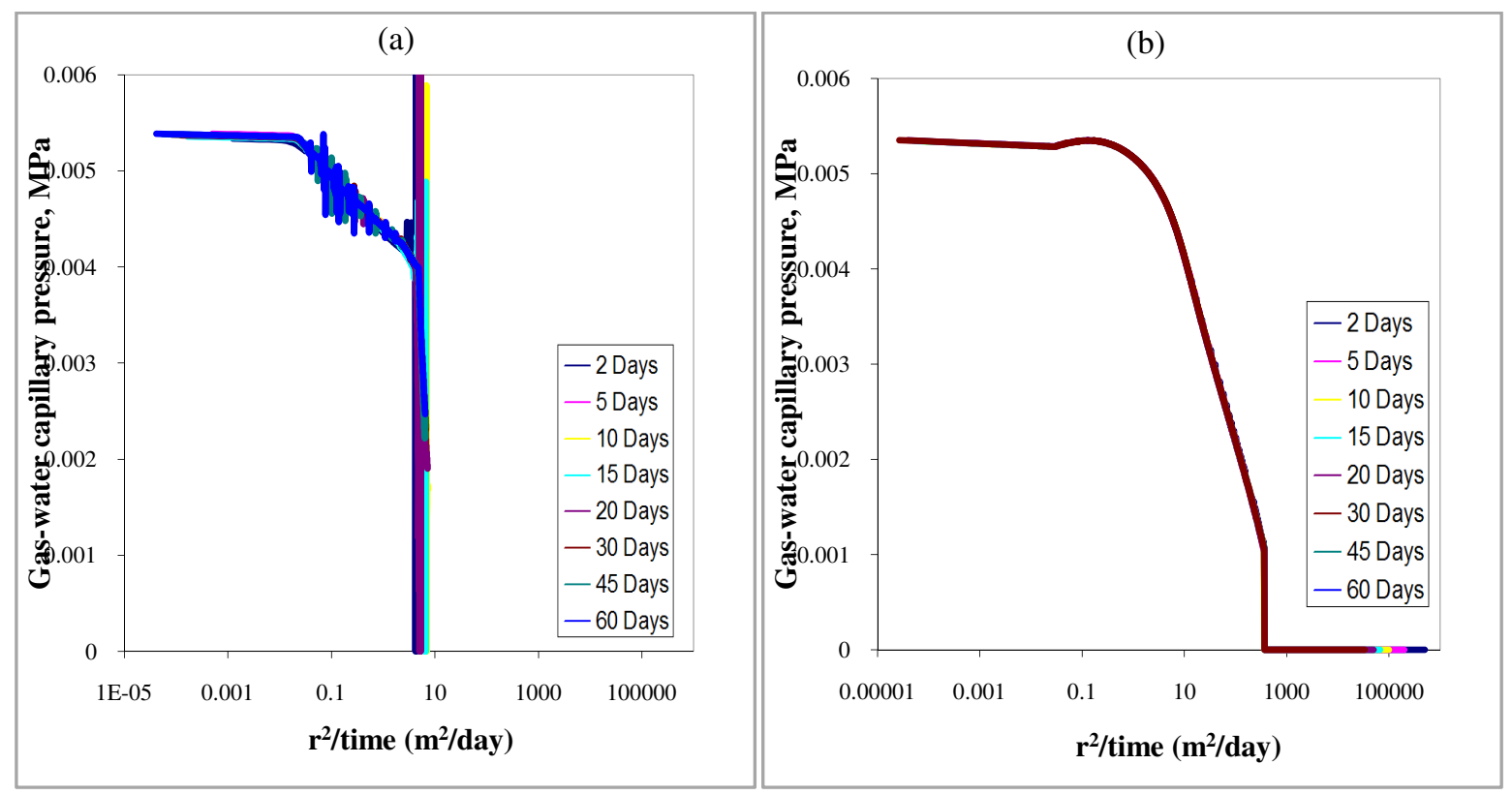

Figure 4- 17 Profiles of gas-water capillary pressure of Problem 4 case 2 for (a) CMG STARS (b) TOUGHFX/HYDRATE. 


\subsection{Problem 5}

This problem is a typical example of Class 2 hydrate deposits in which hydrate layer is bounded by saturated water zone. This problem models gas hydrate dissociation behavior in a two dimensional radial domain. The grid consists of a hydrate zone which is bounded at the top and bottom by two shale zones. The thickness of the hydrate layer is $10 \mathrm{~m}$ and the corresponding shale zones are $25 \mathrm{~m}$. Two different cases, cases A and B are defined to evaluate the effect of hydrate saturation on the production rates. The problem is set up to verify the effect of discretization on the responses. For the same case four different models are developed to understand the effect of discretization.

\section{Grid Description:}

The length and height of the 2-D radial grid system is $1000 \mathrm{~m} \times 60 \mathrm{~m}$. The schematic of the radial grid is shown in Figure 4-18

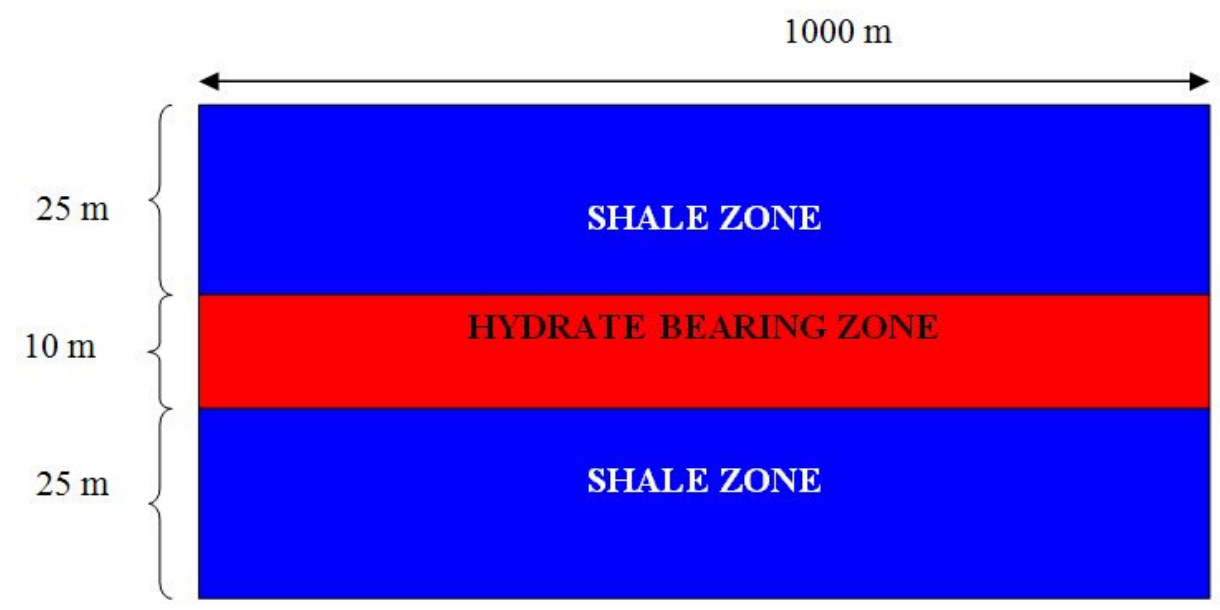

Figure 4-18 Geometry of the cylindrical grid for Problem 5.

The method for hydrate dissociation is chosen as depressurization. The bottom-hole pressure for the depressurization is chosen in such a way that there is no ice formation, i.e. the 
pressure is maintained above the quadruple point. There is no mass or heat flow to the surroundings.

\section{Discretization of the grid:}

The entire reservoir is discretized in four different ways. However, for all four discretizations the grid is logarithmically distributed in the $r$-direction. The innermost grid have a $\Delta r$ of $0.02 \mathrm{~m}$. The logarithmic distribution is calculated by the following formula

$\Delta r_{n+1}=f * \Delta r_{n}$, where $\mathrm{f}$ is a constant which is fixed for every model.

\section{Model $1(200 \times 30)$}

$r$ direction : 200 cells logarithmically distributed from $r_{\mathrm{w}}=0.10795 \mathrm{~m}$ to $r_{200}=1000 \mathrm{~m}$, $z$ direction : 30 cells $(5 \times 5 \mathrm{~m}, 20 \times 0.5 \mathrm{~m}, 5 \times 5 \mathrm{~m}), \Delta r_{1}=0.02$ and $f=1.03856$

\section{Model $2(200 \times 11)$}

$r$ direction : 200 cells logarithmically distributed from $r_{\mathrm{w}}=0.10795 \mathrm{~m}$ to $r_{200}=1000 \mathrm{~m}$ $z$ direction : 11 cells $(5 \times 5 \mathrm{~m}, 1 \times 10.0 \mathrm{~m}, 5 \times 5 \mathrm{~m}), \Delta r_{1}=0.02$ and $f=1.03856$

\section{Model $3(50$ x 30)}

$r$ direction : 50 cells logarithmically distributed from $r_{\mathrm{w}}=0.10795 \mathrm{~m}$ to $r_{50}=1000 \mathrm{~m}$

$z$ direction : 30 cells $(5 \times 5 \mathrm{~m}, 20 \times 0.5 \mathrm{~m}, 5 \times 5 \mathrm{~m}), \Delta r_{1}=0.02$ and $f=1.20257$

\section{Model 4 (50 x 11)}

$r$ direction : 50 cells logarithmically distributed from $r_{\mathrm{w}}=0.10795 \mathrm{~m}$ to $r_{50}=1000 \mathrm{~m}$ $z$ direction : 11 cells $(5 \times 5 \mathrm{~m}, 1 \times 10.0 \mathrm{~m}, 5 \times 5 \mathrm{~m}), \Delta r_{1}=0.02$ and $f=1.20257$

\section{Case Description}

Considering the four different discretizations used for this problem, the introduction of two cases, A and B means that eight different cases are modeled in this problem. The hydrate 
saturation for case A and case B are 0.8 and 0.75 . Different cases and their parameters are given in Table 4-2.

Table 4-2 Case Description of Problem 5

\begin{tabular}{|l|c|c|c|c|}
\hline Case & Discretization & $\mathrm{S}_{\mathrm{H}}$ & $\mathrm{S}_{\mathrm{W}}$ & Pressure \& Temperature \\
\hline Case A-1 & Model 1 & 0.8 & 0.2 & Table 4-3 \\
Case A-2 & Model 2 & 0.8 & 0.2 & Table 4-4 \\
Case A-3 & Model 3 & 0.8 & 0.2 & Table 4-3 \\
Case A-4 & Model 4 & 0.8 & 0.2 & Table 4-4 \\
Case B-1 & Model 1 & 0.75 & 0.25 & Table 4-3 \\
Case B-2 & Model 2 & 0.75 & 0.25 & Table 4-4 \\
Case B-3 & Model 3 & 0.75 & 0.25 & Table 4-3 \\
Case B-4 & Model 4 & 0.75 & 0.25 & Table 4-4 \\
\hline
\end{tabular}

\section{Initial Conditions}

Pressure and temperature for different layers are specified in Table 4-3 and Table 4-4.

\section{Pressure \& Temperature:}

Model 1 \& Model 3

Table 4-3 Pressures and Temperatures for Models $1 \& 3$

\begin{tabular}{|l|l|l|l|l|l|}
\hline \multirow{2}{*}{ Layer } & Pressure & Temperature & Layer & Pressure & Temperature \\
& & & & & \\
& $(\mathrm{MPa})$ & $(\mathrm{K})$ & & $(\mathrm{MPa})$ & $(\mathrm{K})$ \\
\hline 2 & 10.382 & 285.676 & 16 & 10.654 & 286.507 \\
\hline 3 & 10.431 & 285.827 & 17 & 10.658 & 286.521 \\
\hline 4 & 10.48 & 285.979 & 18 & 10.663 & 286.536 \\
\hline 5 & 10.529 & 286.13 & 19 & 10.668 & 286.55 \\
\hline 6 & 10.578 & 286.281 & 20 & 10.673 & 286.564 \\
\hline 7 & 10.604 & 286.364 & 21 & 10.678 & 286.579 \\
\hline 8 & 10.609 & 286.379 & 22 & 10.683 & 286.593 \\
\hline 9 & 10.614 & 286.393 & 23 & 10.688 & 286.607 \\
\hline 10 & 10.619 & 286.407 & 24 & 10.693 & 286.622 \\
\hline 11 & 10.624 & 286.421 & 25 & 10.698 & 286.636 \\
\hline 12 & 10.634 & 286.436 & 26 & 10.724 & 286.719 \\
\hline 13 & 10.639 & 286.464 & 28 & 10.822 & 287.022 \\
\hline 14 & 10.644 & 286.479 & 29 & 10.871 & 287.173 \\
\hline 15 & 10.649 & 286.493 & 30 & 10.92 & 287.324 \\
\hline
\end{tabular}


Table 4- 4 Pressures and Temperatures for Models $2 \& 4$

\begin{tabular}{|l|l|l|}
\hline Layer & $\begin{array}{l}\text { Pressure } \\
(\mathrm{MPa})\end{array}$ & $\begin{array}{l}\text { Temperature } \\
(\mathrm{K})\end{array}$ \\
\hline 1 & 10.382 & 285.676 \\
2 & 10.431 & 285.827 \\
3 & 10.480 & 285.979 \\
4 & 10.529 & 286.130 \\
5 & 10.578 & 286.281 \\
6 & 10.651 & 286.500 \\
7 & 10.724 & 286.719 \\
8 & 10.773 & 286.870 \\
9 & 10.822 & 287.022 \\
10 & 10.871 & 287.173 \\
11 & 10.920 & 287.324 \\
\hline
\end{tabular}

\section{Hydrate Saturation \& Water Saturation:}

There is no gas in the entire reservoir. The hydrate and water saturations are distributed in the entire reservoir as shown in Table 4-5.

Table 4- 5 Hydrate and Water Saturation for different case studies

\begin{tabular}{|c|c|c|c|c|}
\hline Case & \multicolumn{2}{|c|}{ Hydrate Saturation $\left(\mathrm{S}_{\mathrm{H}}\right)$} & \multicolumn{2}{c|}{ Water saturation $\left(\mathrm{S}_{\mathrm{W}}\right)$} \\
\hline & Shale Zone & Hydrate zone & Shale Zone & Hydrate zone \\
\cline { 2 - 5 } Case A & 0 & 0.8 & 1 & 0.2 \\
Case B & 0 & 0.75 & 1 & 0.25 \\
\hline
\end{tabular}

\section{Boundary Conditions:}

There is no mass and heat flow outside the grid. The upper and lower boundary temperature are maintained a constant value of $285.6 \mathrm{~K}$ and $287.4 \mathrm{~K}$.

\section{Medium Properties:}

Hydraulic and thermal properties for this problem are specified in Table 4-6. 
Table 4-6 Hydraulic and Thermal Properties for Problem 5

\begin{tabular}{|c|c|}
\hline Parameter & Value \\
\hline Porosity & Shale zone (0.1), hydrate zone (0.4) \\
\hline Permeability & Shale zone (0.0), hydrate zone (1000 md) \\
\hline Rock Density & $2600 \mathrm{~kg} / \mathrm{m} 3$ \\
\hline Rock Specific cheat & $1000 \mathrm{~J} / \mathrm{kg} \mathrm{K}$ \\
\hline Dry Thermal Conductivity & $2.0 \mathrm{~W} / \mathrm{m} \mathrm{K}$ \\
\hline Pore Compressibility & $10^{-9} \mathrm{~Pa}^{-1}$ \\
\hline Composite Thermal Conductivity Model & linear \\
\hline Capillary Pressure Model & Van Genuchten Equation ${ }^{34}$ \\
\hline$\lambda$ parameter & 0.45 \\
\hline$S_{i r A}$ parameter & Case $\mathrm{A}(0.14)$, Case $\mathrm{B}(0.19)$ \\
\hline $1 / P_{o}$ parameter & $8 \times 10^{-5} \mathrm{~Pa}^{-1}$ \\
\hline$P_{\max }$ parameter & $5.0 \times 10^{6} \mathrm{~Pa}$ \\
\hline $\mathrm{S}_{\mathrm{mxA}}$ parameter & 1 \\
\hline Aqueous Relative Permeability Model & Stone $^{36}+$ Aziz $^{37}$ \\
\hline$S_{i r A}$ parameter & case $A(0.15)$, case $B(0.20)$ \\
\hline$n$ parameter & 3 \\
\hline Gas Relative Permeability Model & Stone $^{36}+\mathrm{Aziz}^{37}$ \\
\hline$S_{i r G}$ parameter & case $\mathrm{A}(0.02)$, case $\mathrm{B}(0.02)$ \\
\hline
\end{tabular}

\section{Relative permeability model}

Aqueous and gas relative permeability model used in this problem is same as that in problem

3. Irreducible water and gas saturation values for this problem are specified in Table 4-6.

$$
\begin{aligned}
& k_{r G}=\left(S_{G}{ }^{*}\right)^{n}, S_{G}{ }^{*}=\left(S_{G}-S_{i r G}\right) /\left(1-S_{i r A}\right) \\
& k_{r A}=\left(S_{A}{ }^{*}\right)^{n}, S_{A}{ }^{*}=\left(S_{A}-S_{i r A}\right) /\left(1-S_{i r A}\right)
\end{aligned}
$$

where $S_{i r G}, S_{i r A}$ represent irreducible gas and aqueous saturation. 


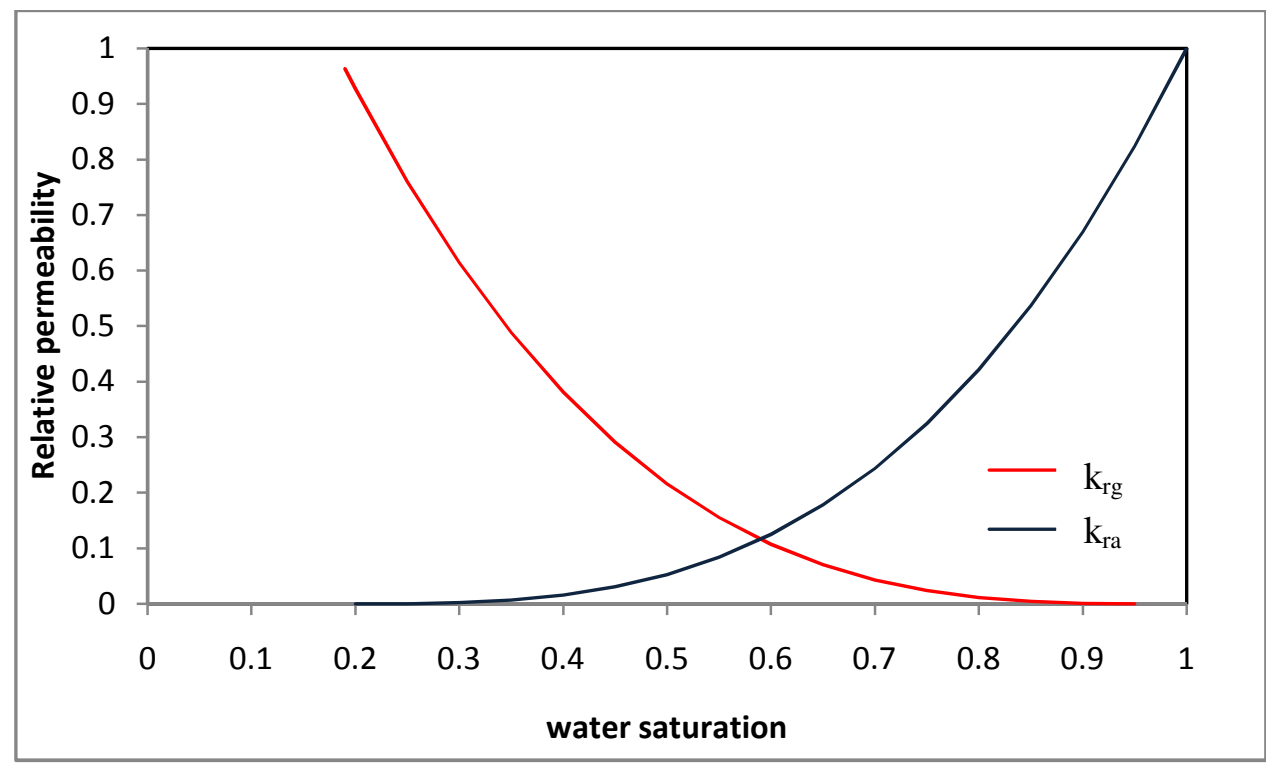

Figure 4-18 a Case A: Aqueous \& Gas Relative permeability curves

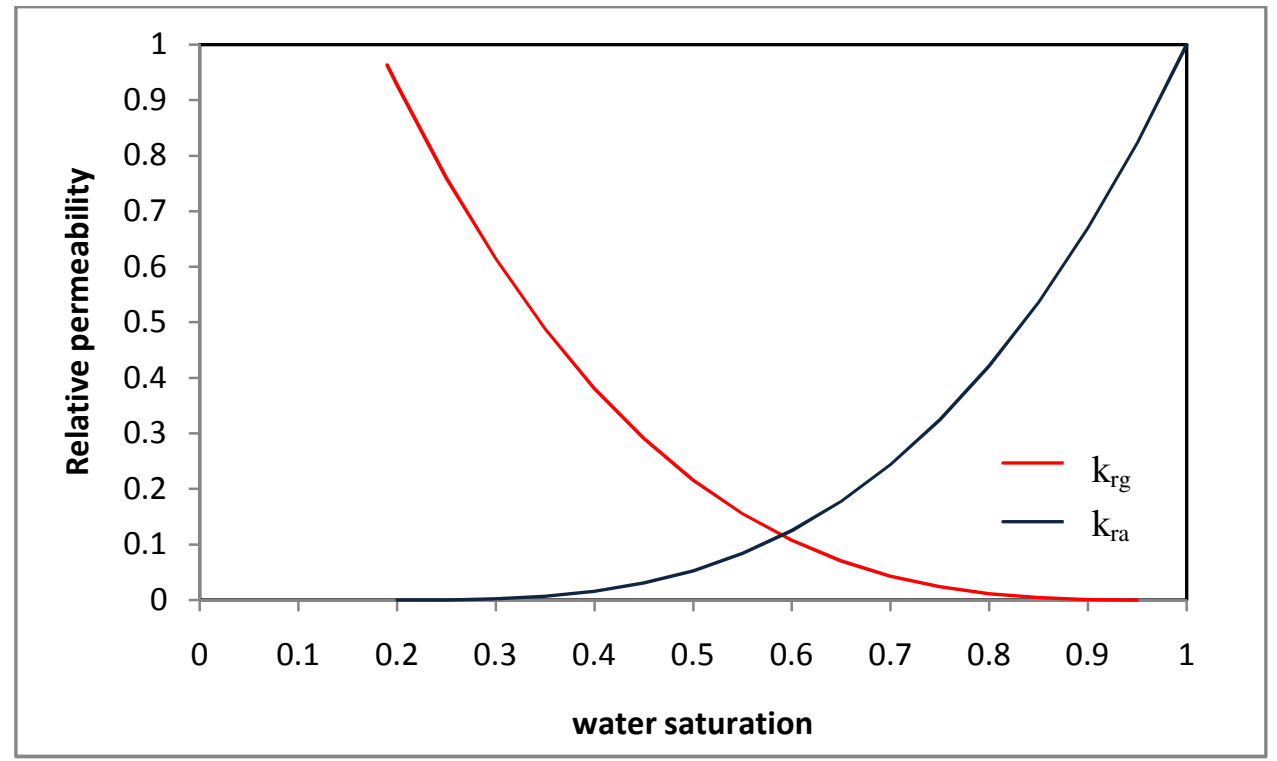

Figure 4-18 b Case B: Aqueous \& Gas Relative permeability curves 


\section{Capillary pressure model}

Capillary pressure model used in this problem is same as in problem 3. Different parameters and their specifications are given in Table 4-6. Plots of Capillary pressure for both cases are shown in Figure 4-19 (a) and (b)

$$
\begin{aligned}
& P_{c a p}=-P_{0}\left[\left(S^{*}\right)^{-1 / \lambda}-1\right]^{\lambda}, S^{*}=\frac{\left(S_{W}^{*}-S_{W i r}\right)}{1-S_{W i r}} \\
& S_{W}^{*}=\frac{S_{W}}{1-S_{H}-S_{I}}, \lambda=0.45
\end{aligned}
$$

Where $-\mathrm{P}_{\max } \leq \mathrm{P}_{\text {cap }} \leq 0$

$$
\mathrm{P}_{\max }=5000 \mathrm{kPa}
$$

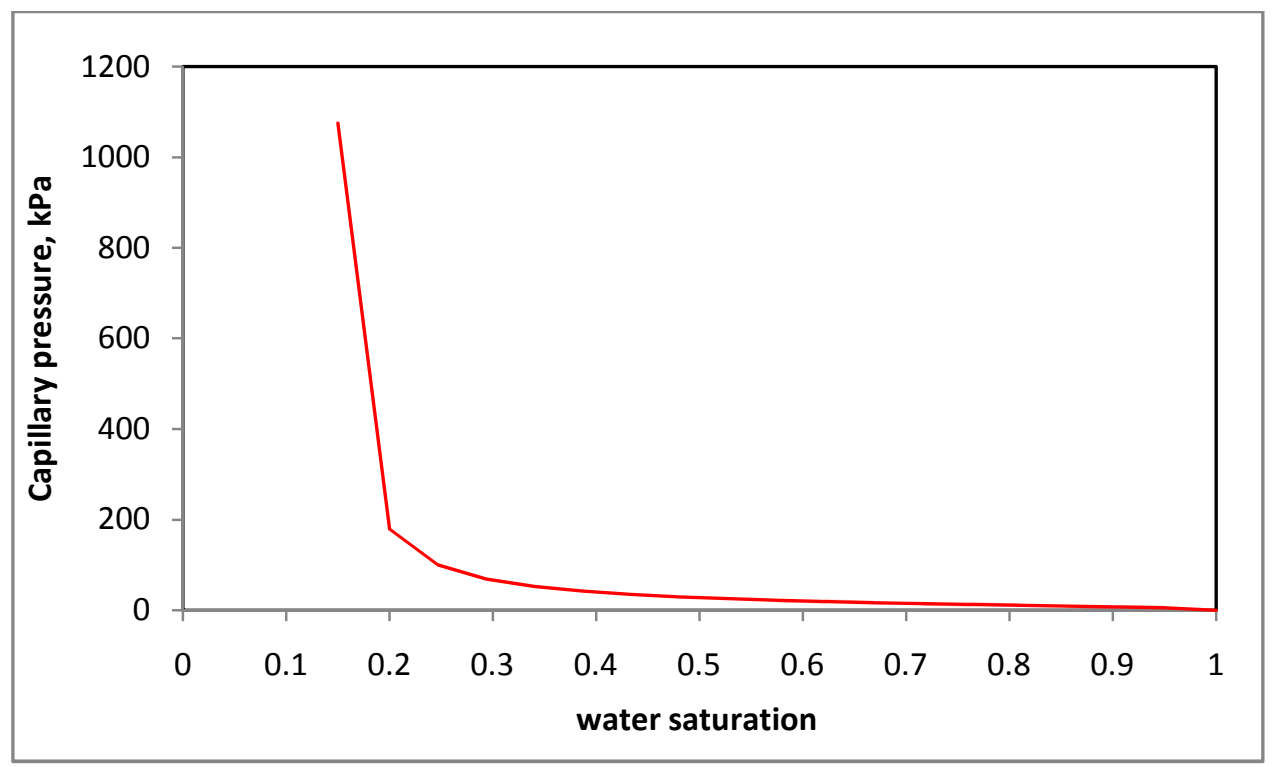

Figure 4-19 a Case A: Capillary pressure plotted against water saturation for Problem 5 


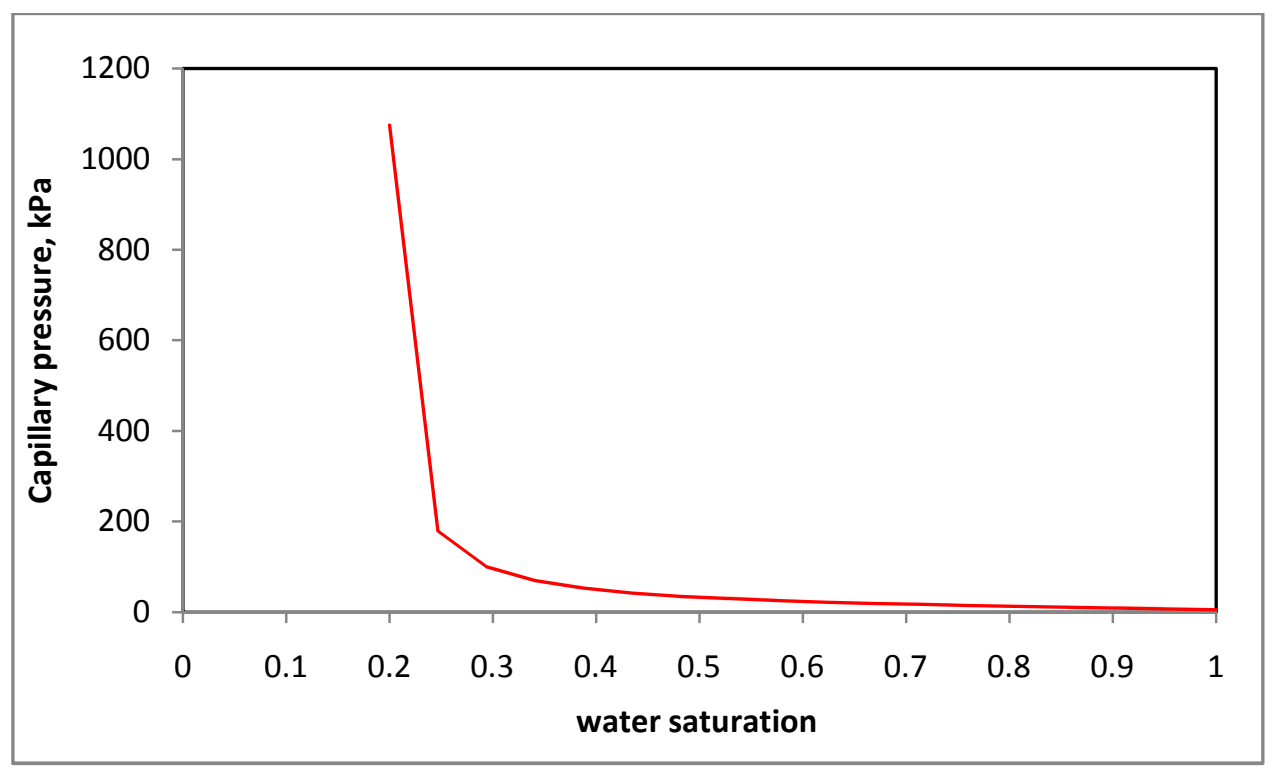

Figure 4-19 b Case B: Capillary pressure plotted against water Saturation for problem 5

\section{Well Details}

There is one vertical producer well at the center of the cylindrical grid of wellbore radius $0.10795 \mathrm{~m}$. The bottom hole flowing pressure is constant and is equal to $2.7 \mathrm{MPa}$ which is slightly above the $\mathrm{Q}$ point to avoid ice formation in the reservoir.

\section{Data and Sampling Frequency}

The simulations are carried out over a time period of 360 days. The production data is sampled every 10 days and the property distribution data is sampled every 90 days. The factors considered for data comparison are gas pressure, water pressure, methane hydrate saturation, water saturation, gas saturation, mass fraction of $\mathrm{CH}_{4}$ in the aqueous phase, gas

production rate, water production rate, cumulative gas production, and cumulative water production 


\subsubsection{Solution to Problem 5}

The length and height of this 2-D radial grid is $1000 \mathrm{~m} \mathrm{x} 60 \mathrm{~m}$. The grid is discredited in four different ways which are mentioned as models $(1,2,3 \& 4)$ and the discretization for each model are specified in the problem description. The input data file used for case 5-A-1 is specified below. Different data files are adapted based on this data file.

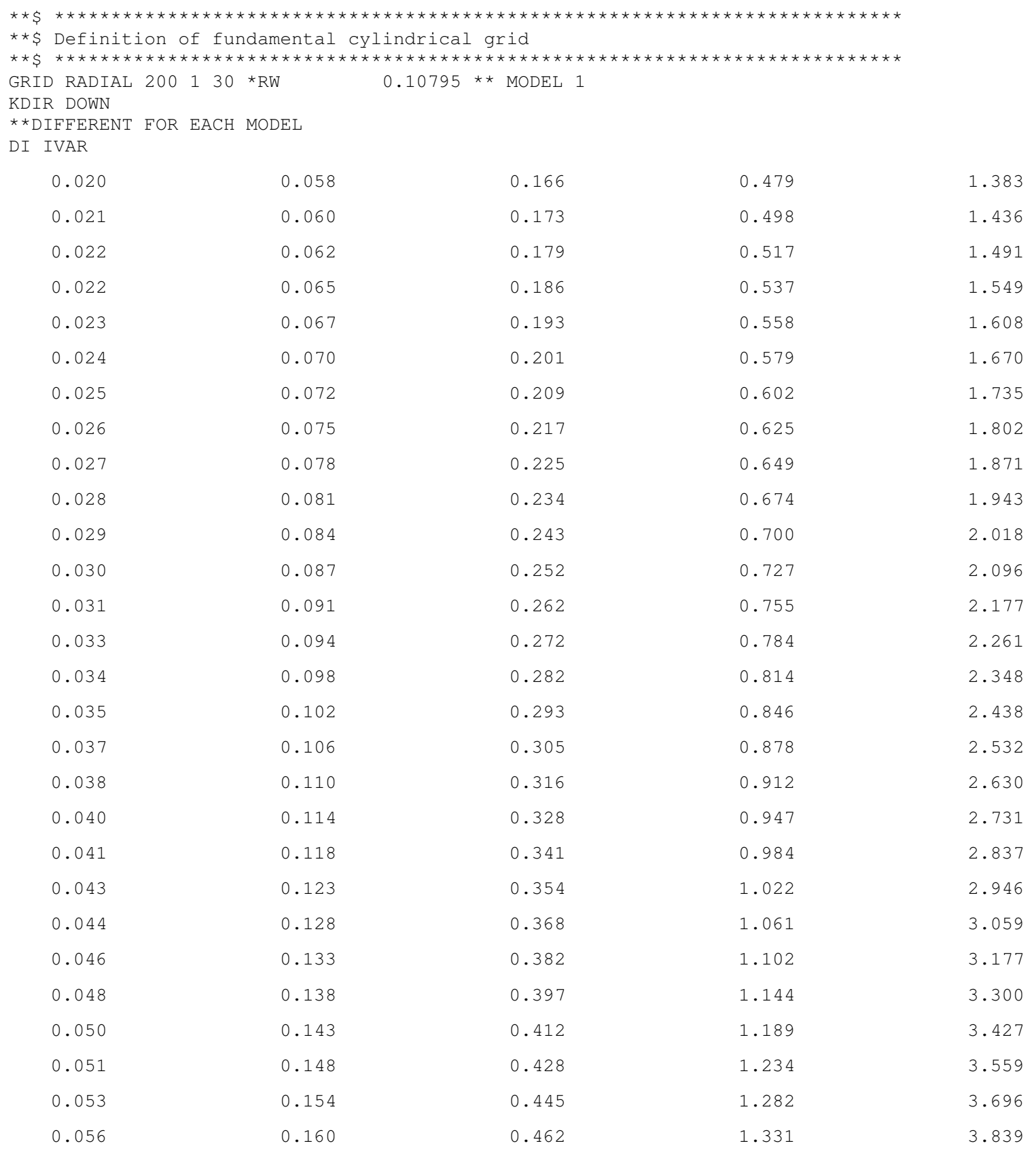




\begin{tabular}{|c|c|c|c|c|}
\hline 3.987 & 6.277 & 9.882 & 15.558 & 24.494 \\
\hline 4.140 & 6.519 & 10.263 & 16.157 & 25.438 \\
\hline 4.300 & 6.770 & 10.658 & 16.780 & 26.418 \\
\hline 4.466 & 7.031 & 11.069 & 17.427 & 27.437 \\
\hline 4.638 & 7.302 & 11.496 & 18.099 & 28.494 \\
\hline 4.817 & 7.583 & 11.939 & 18.796 & 29.592 \\
\hline 5.002 & 7.876 & 12.399 & 19.521 & 30.733 \\
\hline 5.195 & 8.179 & 12.877 & 20.273 & 31.918 \\
\hline 5.395 & 8.494 & 13.373 & 21.055 & 33.148 \\
\hline 5.603 & 8.822 & 13.889 & 21.866 & 34.426 \\
\hline 5.819 & 9.162 & 14.424 & 22.709 & 35.753 \\
\hline 6.044 & 9.515 & 14.980 & 23.585 & 37.131 \\
\hline
\end{tabular}

\begin{tabular}{|c|c|c|c|c|c|c|}
\hline \multicolumn{7}{|c|}{ DJ JVAR $\quad 360$} \\
\hline \multicolumn{7}{|c|}{ DK KVAR } \\
\hline 5 & 5 & 5 & 5 & 5 & & \\
\hline 0.5 & 0.5 & 0.5 & 0.5 & 0.5 & & \\
\hline 0.5 & 0.5 & 0.5 & 0.5 & 0.5 & & \\
\hline 0.5 & 0.5 & 0.5 & 0.5 & 0.5 & & \\
\hline 0.5 & 0.5 & 0.5 & 0.5 & 0.5 & & \\
\hline 5 & 5 & 5 & 5 & 5 & & \\
\hline \multicolumn{7}{|c|}{ DTOP } \\
\hline \multicolumn{7}{|c|}{ NULL CON 1} \\
\hline$\star \star \$$ & perty: & Porosity & $\operatorname{Max}$ & Min: & 0.1 & \\
\hline \multicolumn{7}{|c|}{ POR KVAR } \\
\hline & $20 * 0.4$ & $5 * 0.1$ & & & & \\
\hline \multicolumn{7}{|c|}{ PERMI KVAR } \\
\hline \multicolumn{7}{|c|}{$5 * 0.0001 \quad 20 * 1000 \quad 5 * 0.0001$} \\
\hline \multicolumn{7}{|c|}{ PERMJ KVAR } \\
\hline $5 * 0$ & $0120 * 1$ & $10005 * 0.06$ & 001 & & & \\
\hline \multicolumn{7}{|c|}{ PERMK KVAR } \\
\hline \multirow{2}{*}{\multicolumn{7}{|c|}{ END-GRID }} \\
\hline & & & & & & \\
\hline \multicolumn{7}{|c|}{ ROCKTYPE 1} \\
\hline \multirow{2}{*}{\multicolumn{7}{|c|}{$\begin{array}{l}* * \text { SAME AS IN THE PREVIOUS PROBLEM } \\
\star * \$ \text { Model and number of components }\end{array}$}} \\
\hline & & & & & & \\
\hline \multicolumn{7}{|c|}{ Same as previous problem } \\
\hline \multicolumn{7}{|c|}{ ROCKFLUID ** CASE A ONLY } \\
\hline \multicolumn{7}{|c|}{ RPT 1 WATWET } \\
\hline \multicolumn{7}{|c|}{ SWT } \\
\hline \multirow[t]{19}{*}{$\star \star \$$} & Sw & & $\mathrm{krw}$ & krow & & Pcow \\
\hline & 0.15 & & 0 & 0.00000009 & & 0 \\
\hline & 0.2 & 0.0002035 & 3542 & 0.00000008 & & 0 \\
\hline & 0.25 & 0.0016283 & 3333 & 0.00000008 & & 0 \\
\hline & 0.3 & 0.0054956 & 5624 & 0.00000007 & & 0 \\
\hline & 0.35 & 0.0130266 & 5664 & 0.00000006 & & 0 \\
\hline & 0.4 & $0.025442^{\circ}$ & 2703 & 0.00000005 & & 0 \\
\hline & 0.45 & 0.043964 & 4991 & 0.00000004 & & 0 \\
\hline & 0.5 & 0.069814 & 4777 & 0.00000003 & & 0 \\
\hline & 0.55 & 0.1042133 & 3312 & 0.00000002 & & 0 \\
\hline & 0.6 & 0.1483818 & 1844 & 0.00000001 & & 0 \\
\hline & 0.65 & 0.2035416 & 1624 & 0.00000001 & & 0 \\
\hline & 0.7 & 0.270913 & 3902 & 0.00000001 & & 0 \\
\hline & 0.75 & 0.351719 & 9927 & 0.00000001 & & 0 \\
\hline & 0.8 & 0.447180 & 9949 & 0.00000001 & & 0 \\
\hline & 0.85 & 0.5585182 & 3217 & 0.00000001 & & 0 \\
\hline & 0.9 & 0.6869525 & 2982 & 0.00000001 & & 0 \\
\hline & 0.95 & 0.833706 & 5493 & 0.00000001 & & 0 \\
\hline & 1 & & 1 & 0 & & 0 \\
\hline \multicolumn{7}{|l|}{ SLT } \\
\hline$\star \star \$$ & SI & & $\mathrm{krg}$ & krog & & $\mathrm{PCO}$ \\
\hline
\end{tabular}




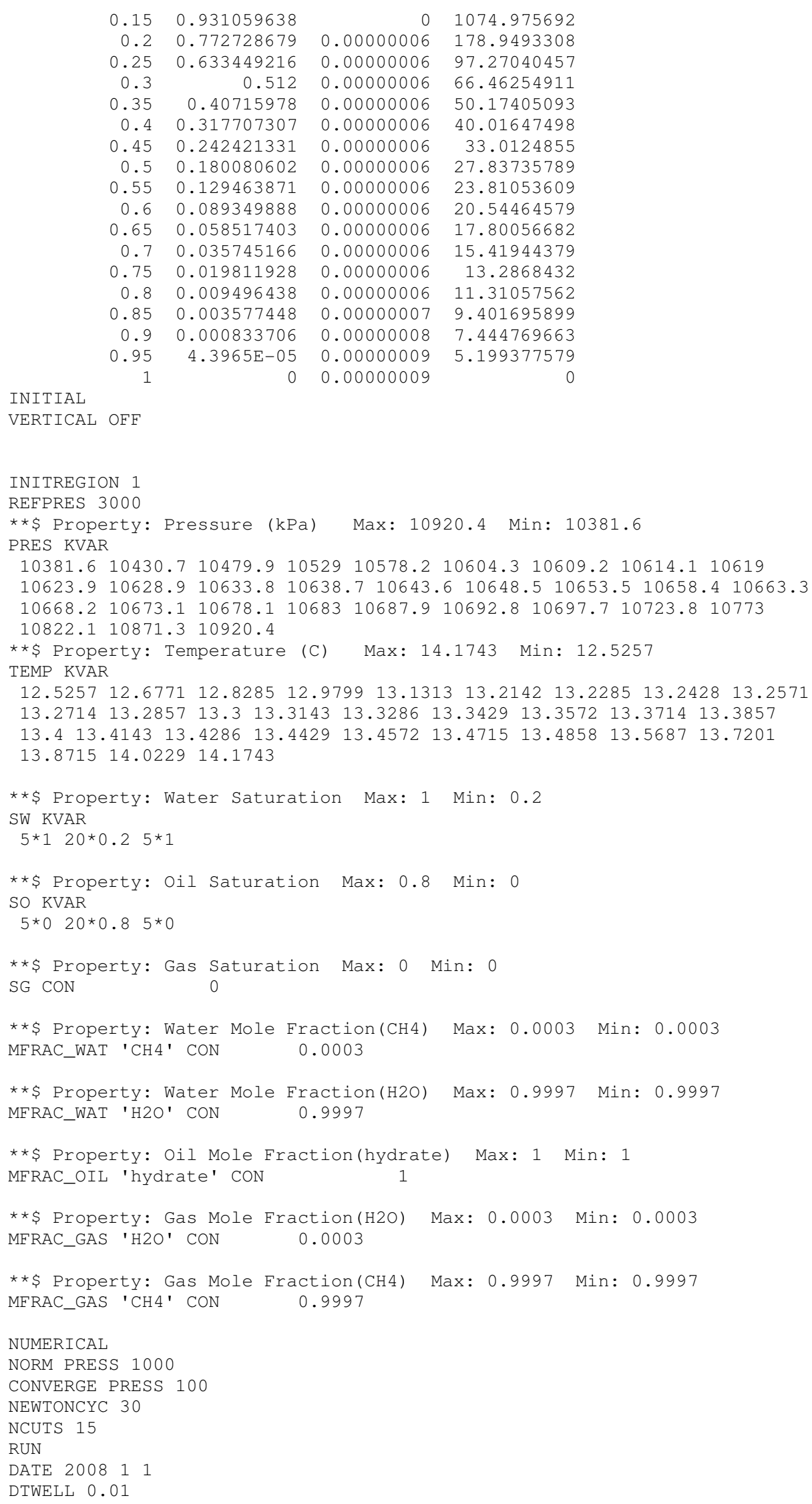




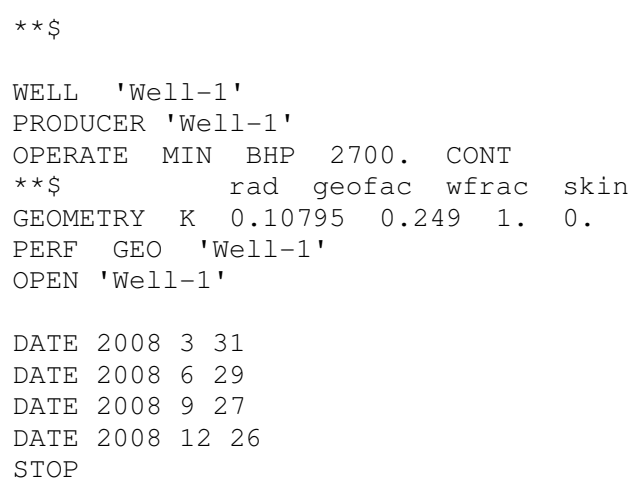

\section{Results}

\section{Effect of discretization on production rates}

Considering the four different discretizations used for this problem, the introduction of two cases A and B means that eight different cases are modeled. The hydrate saturation for Case A and Case B are 0.8 and 0.75 respectively. To study the effect of discretization on production rates profiles of case A-1 to A-4 and Case B-1 to B-4 are compared as given in Table 4-7.

Table 4-7 Effect of discretization on production rates for problem 5

\begin{tabular}{|l|l|c|c|c|}
\hline Case & Model & Discretization $(\boldsymbol{r} \boldsymbol{x} z)$ & $\begin{array}{l}\text { Avg Gas rates } \\
(\mathbf{3 6 0} \text { days }), \\
\mathbf{m}^{3} / \mathbf{d a y}\end{array}$ & $\begin{array}{l}\text { Avg water rates } \\
(\mathbf{3 6 0} \text { days }), \\
\mathbf{m}^{\mathbf{3}} / \mathbf{d a y}\end{array}$ \\
\hline case A-1 & Model 1 & $200 \times 30$ & 50,000 & 60 \\
case A-2 & Model 2 & $200 \times 11$ & 10,000 & 20 \\
case A-3 & Model 3 & $50 \times 30$ & 40,000 & 50 \\
case A-4 & Model 4 & $50 \times 11$ & 9,000 & 20 \\
case B-1 & Model 1 & $200 \times 30$ & 100,000 & 150 \\
case B-2 & Model 2 & $200 \times 11$ & 15,000 & 60 \\
case B-3 & Model 3 & $50 \times 30$ & 100,000 & 120 \\
case B-4 & Model 4 & $50 \times 11$ & 25,000 & 60 \\
\hline
\end{tabular}

Figures 4-21 to Figure 4-28 also show that the difference in the radial discretization of the grid did not affect production rates. Huge difference in the production rates is observed when discretization is changed in the $\mathrm{z}$ direction. In cases A-2, A-4, B-2 and B-4, the hydrate zone is treated as a single 
block due which lesser production rates are observed. Case (A-1, A-3) and Case (A-2, A-4) have similar production rates. The same is also found within Case B.

\section{Effect of hydrate saturation on production rates}

Hydrate saturation is varied for Case-A and Case B. Increase in the production rate is observed when hydrate saturation is varied from 0.8 to 0.75 . Table $4-8$ shows the difference in the average production rates in both Cases A\&B.

Table 4- 8 Effect of hydrate saturation on production rates for Problem 5

\begin{tabular}{|c|c|c|c|}
\hline Case & $\mathbf{S}_{\mathbf{H}}$ & $\begin{array}{c}\text { Avg Gas rates } \\
(\mathbf{3 6 0} \text { days }), \mathbf{m}^{\mathbf{3}} / \mathbf{d a y}\end{array}$ & $\begin{array}{c}\text { Avg water rates } \\
(\mathbf{3 6 0} \text { days }), \mathbf{~ m}^{\mathbf{3}} / \mathbf{d a y}\end{array}$ \\
\hline Case-A & 0.8 & 27,250 & 40 \\
Case B & 0.75 & 60,000 & 100 \\
\hline
\end{tabular}



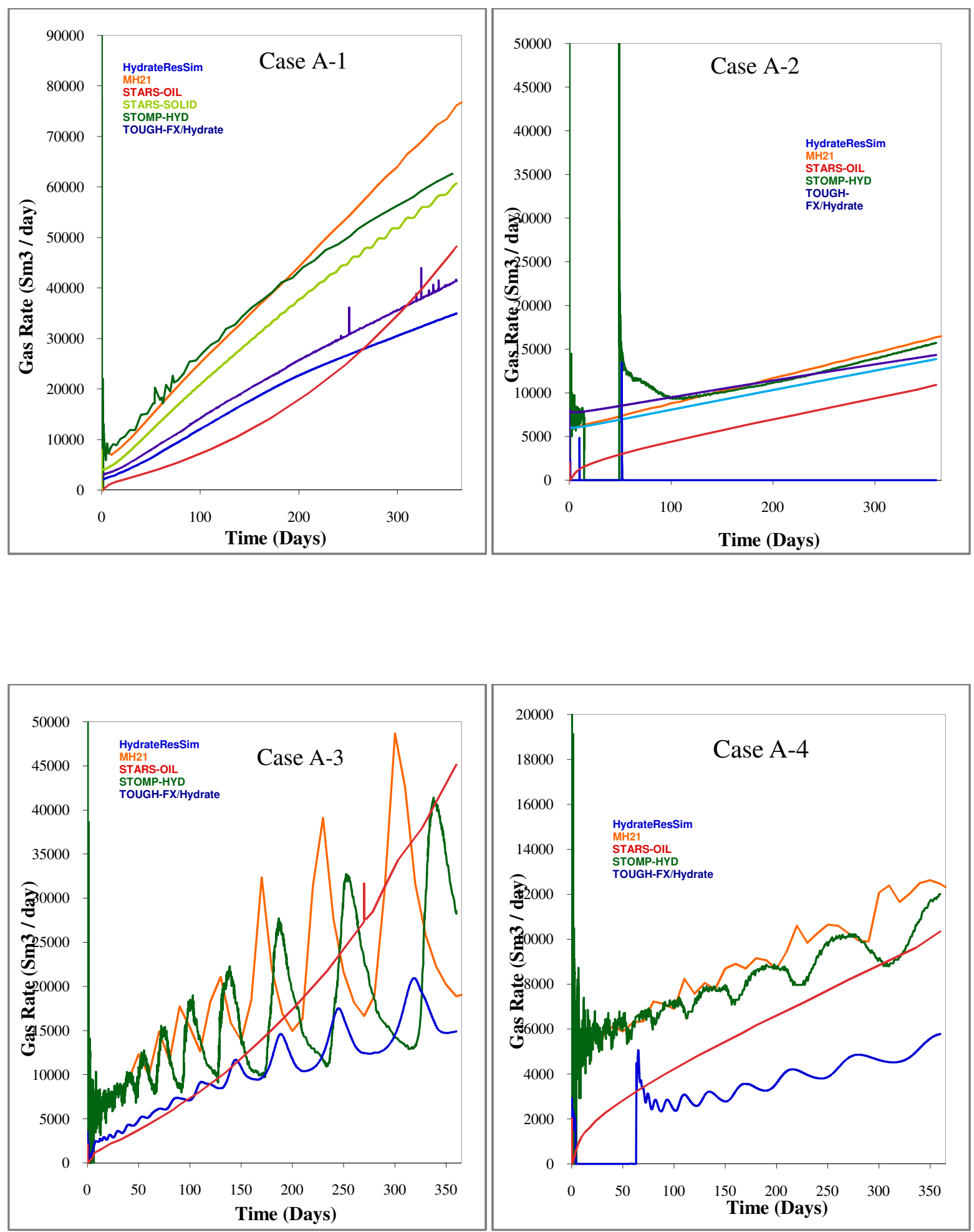

Figure 4-20 Gas Rates for problem 5 Cases A-1, A-2, A-3, A-4. 

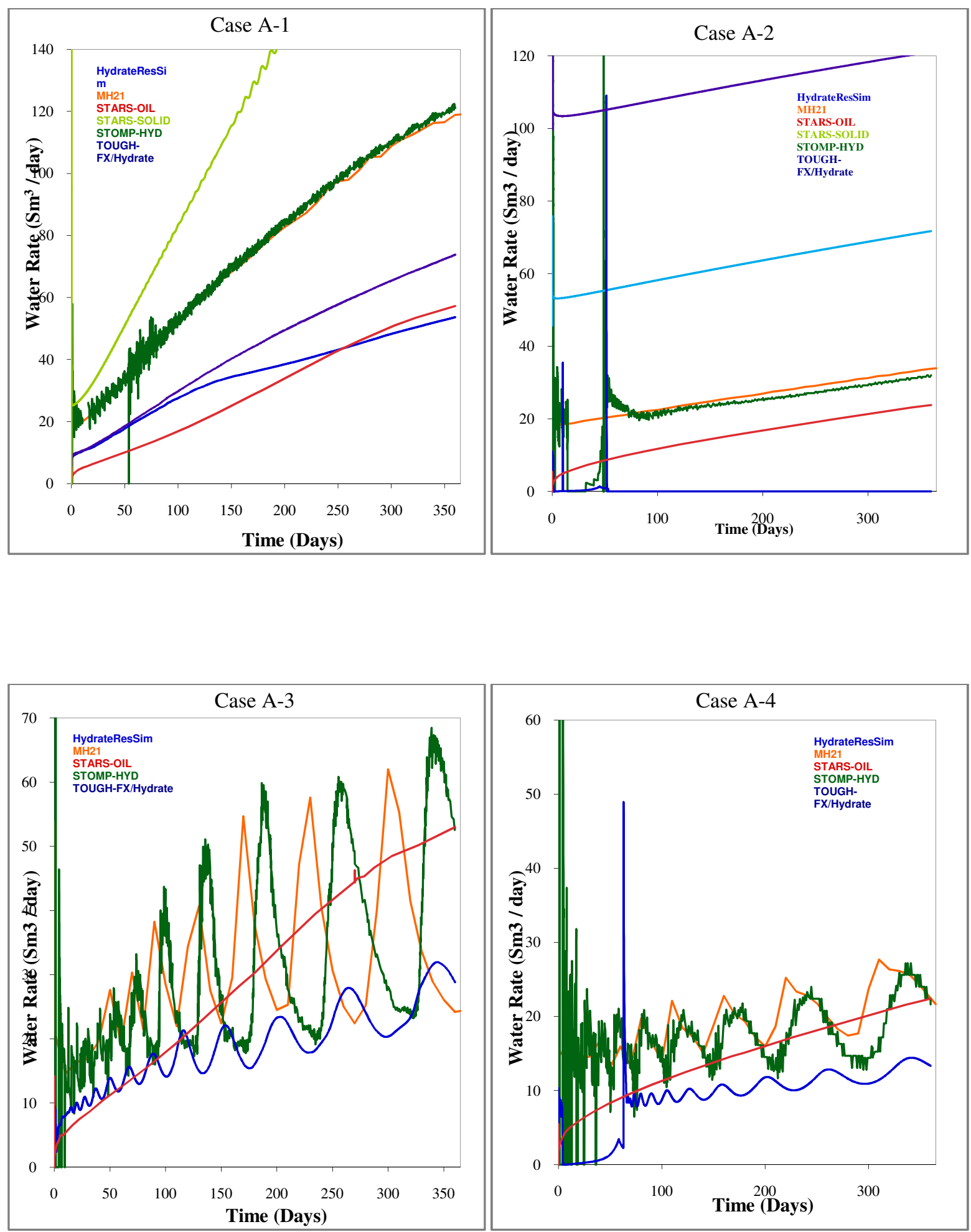

Figure 4-21 Gas Rates for problem 5 Cases A-1, A-2, A-3, A-4. 

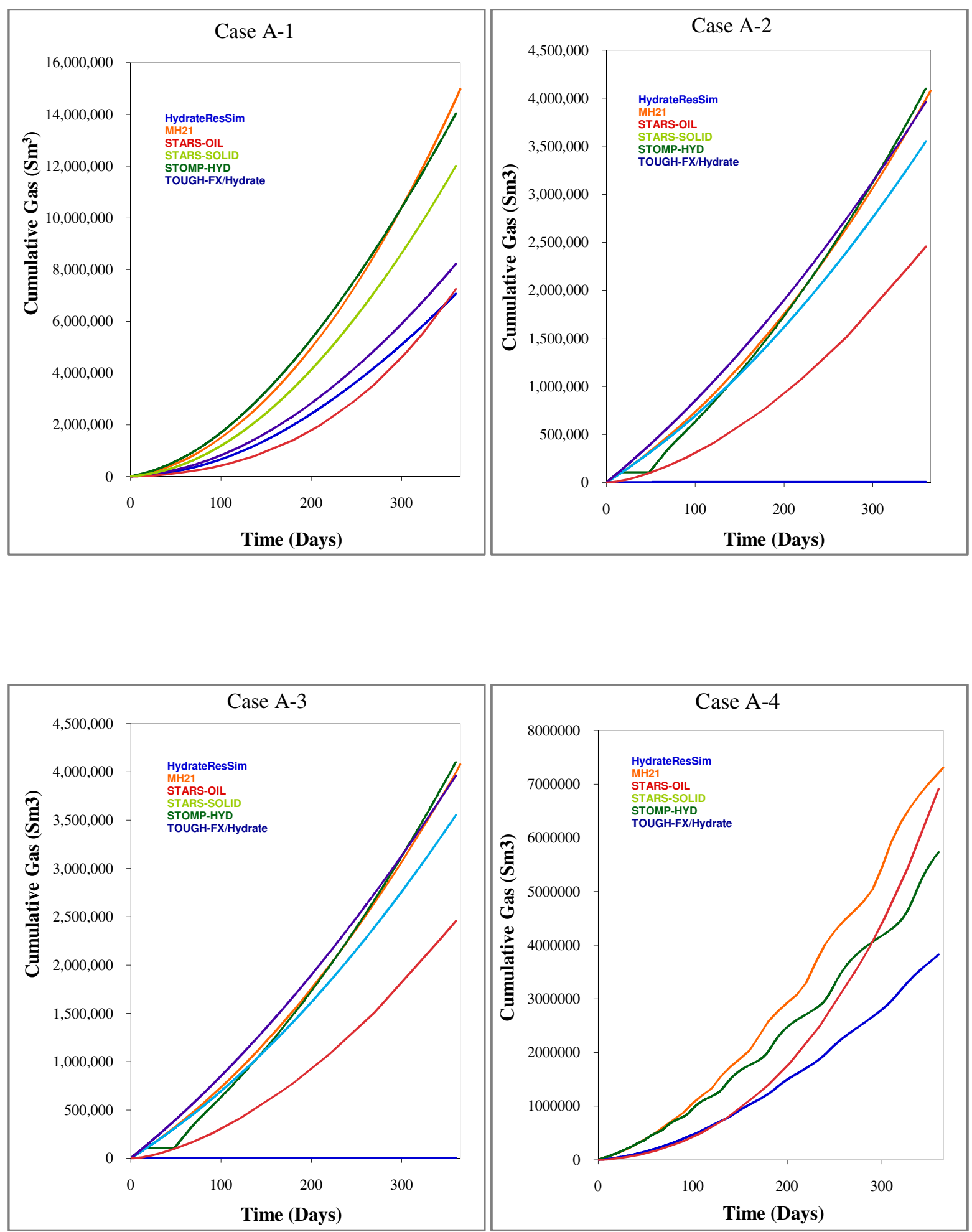

Figure 4-22 Cumulative gas production for problem 5 Cases A-1, A-2, A-3, A-4. 

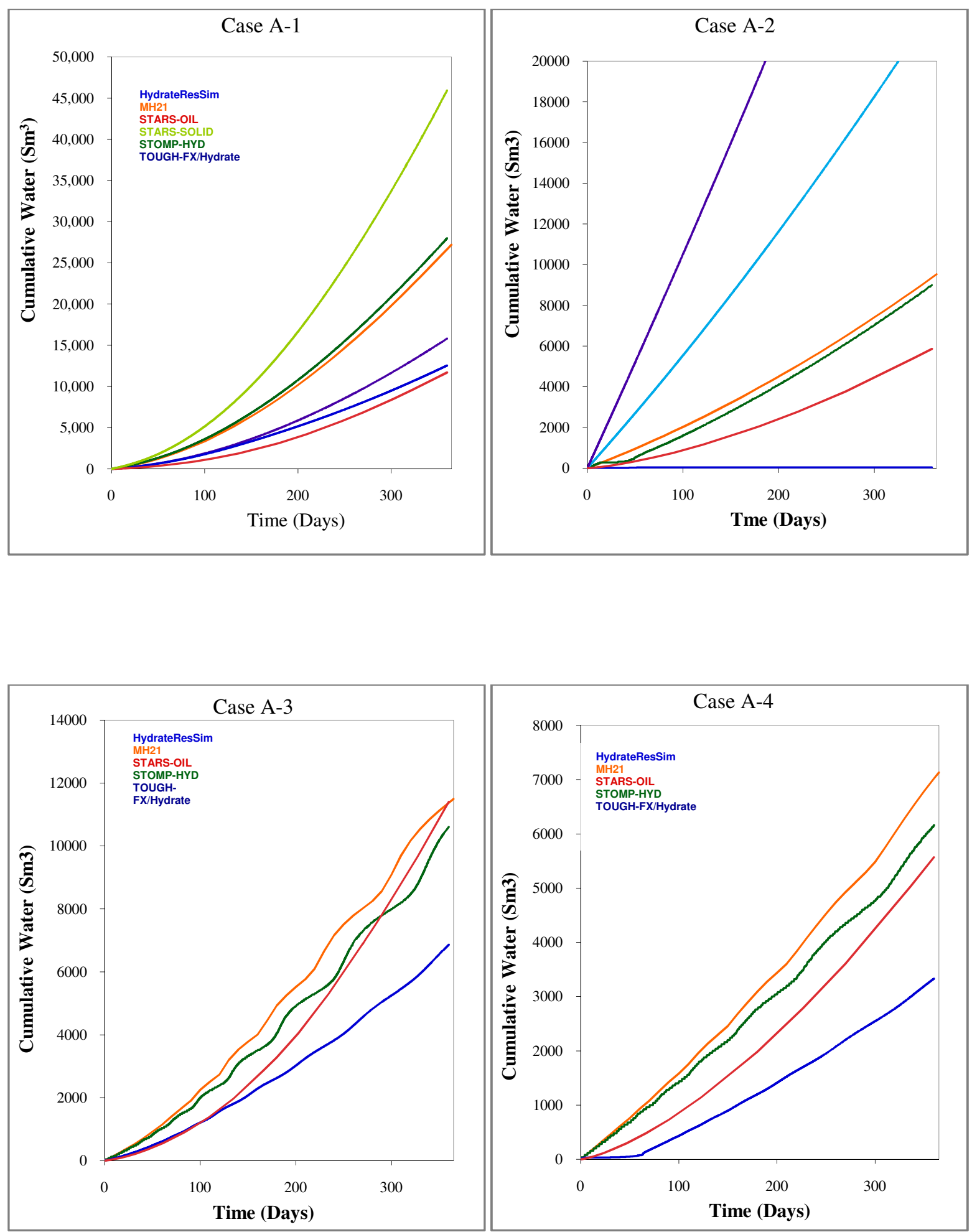

Figure 4-23 Cumulative water production for Problem 5 Cases A-1, A-2, A-3, A-4. 

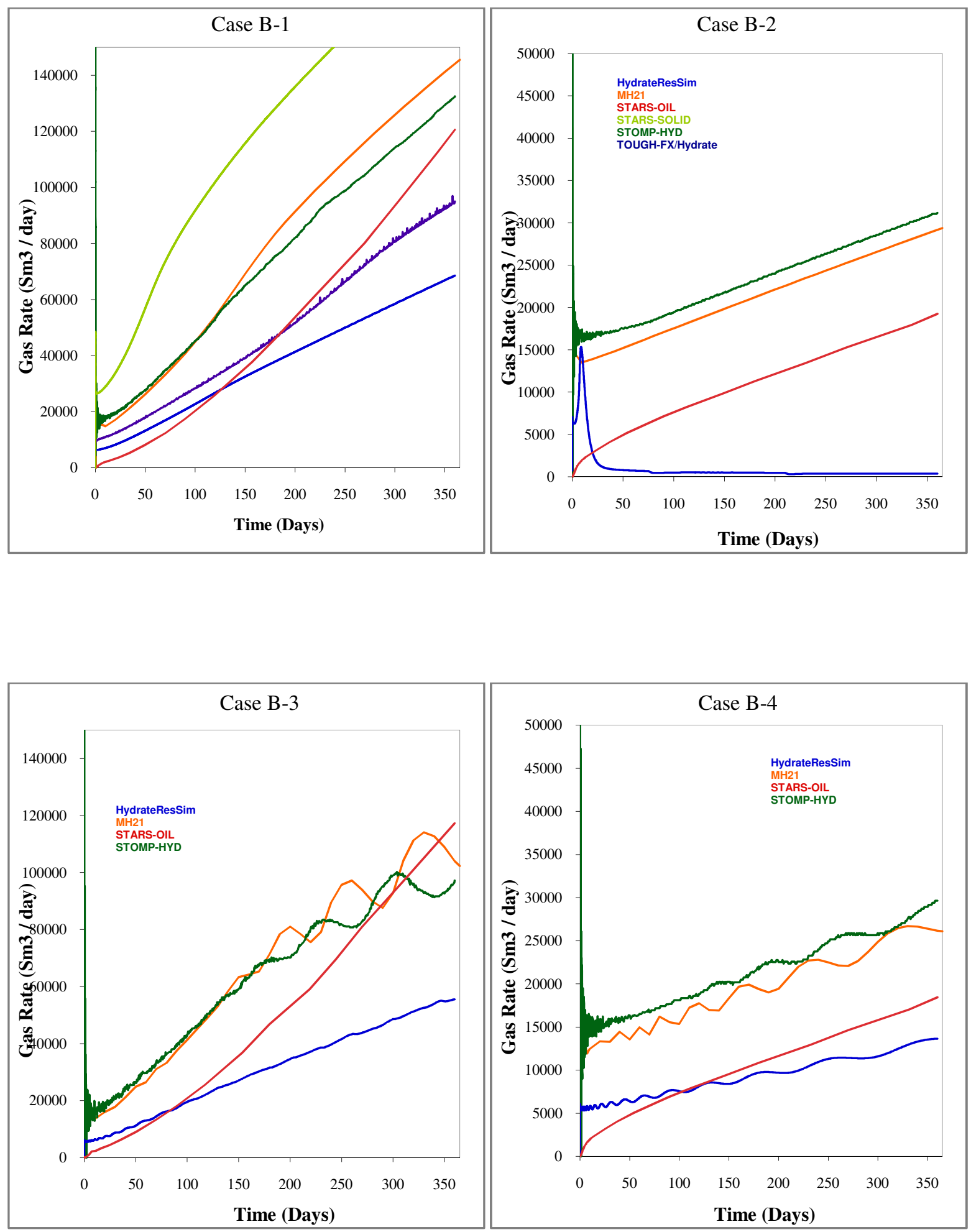

Figure 4-24 Gas rates for problem 5 Cases B-1, B-2, B-3, B-4. 

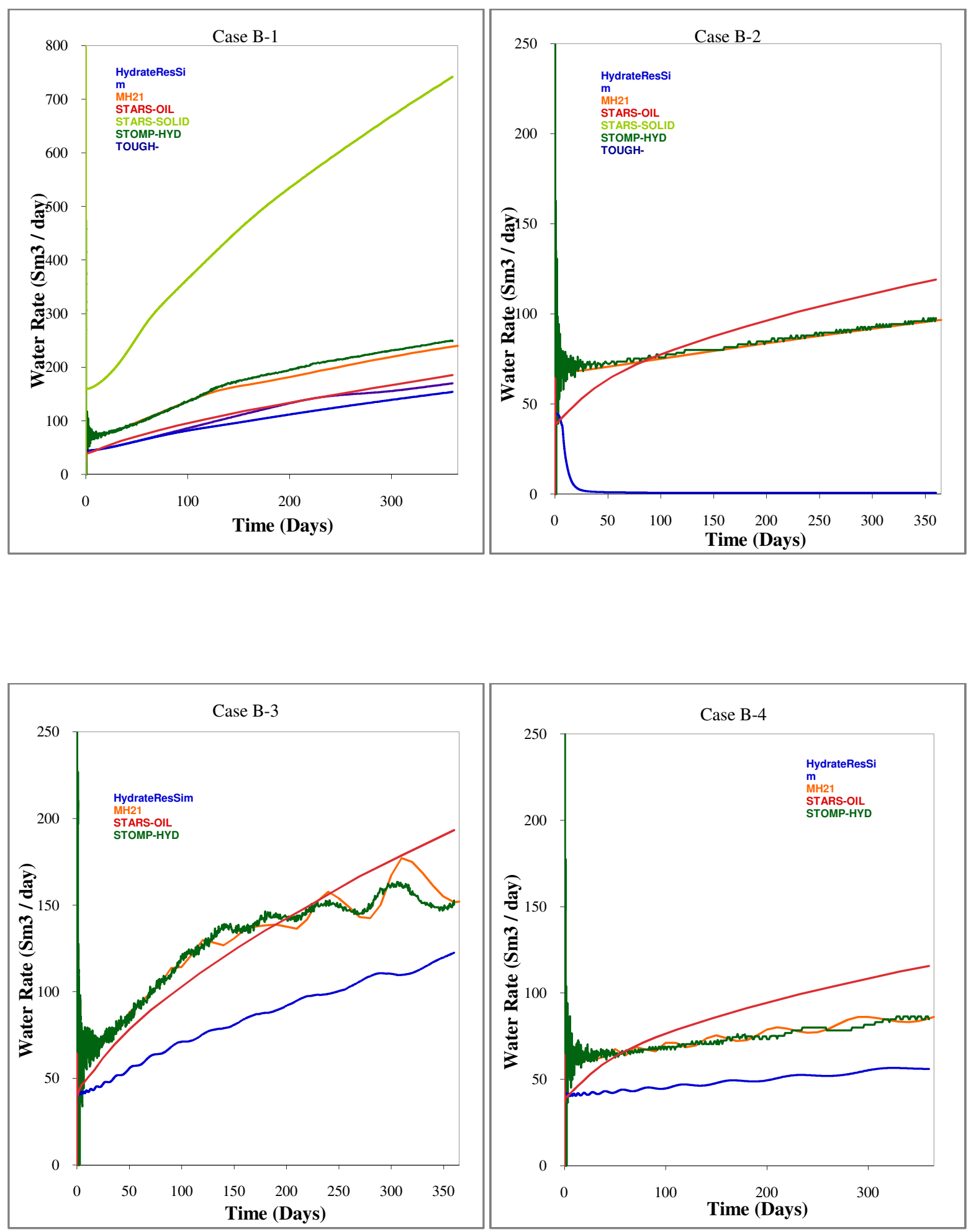

Figure 4-25 Water rates for problem 5 Cases B-1, B-2, B-3, B-4. 

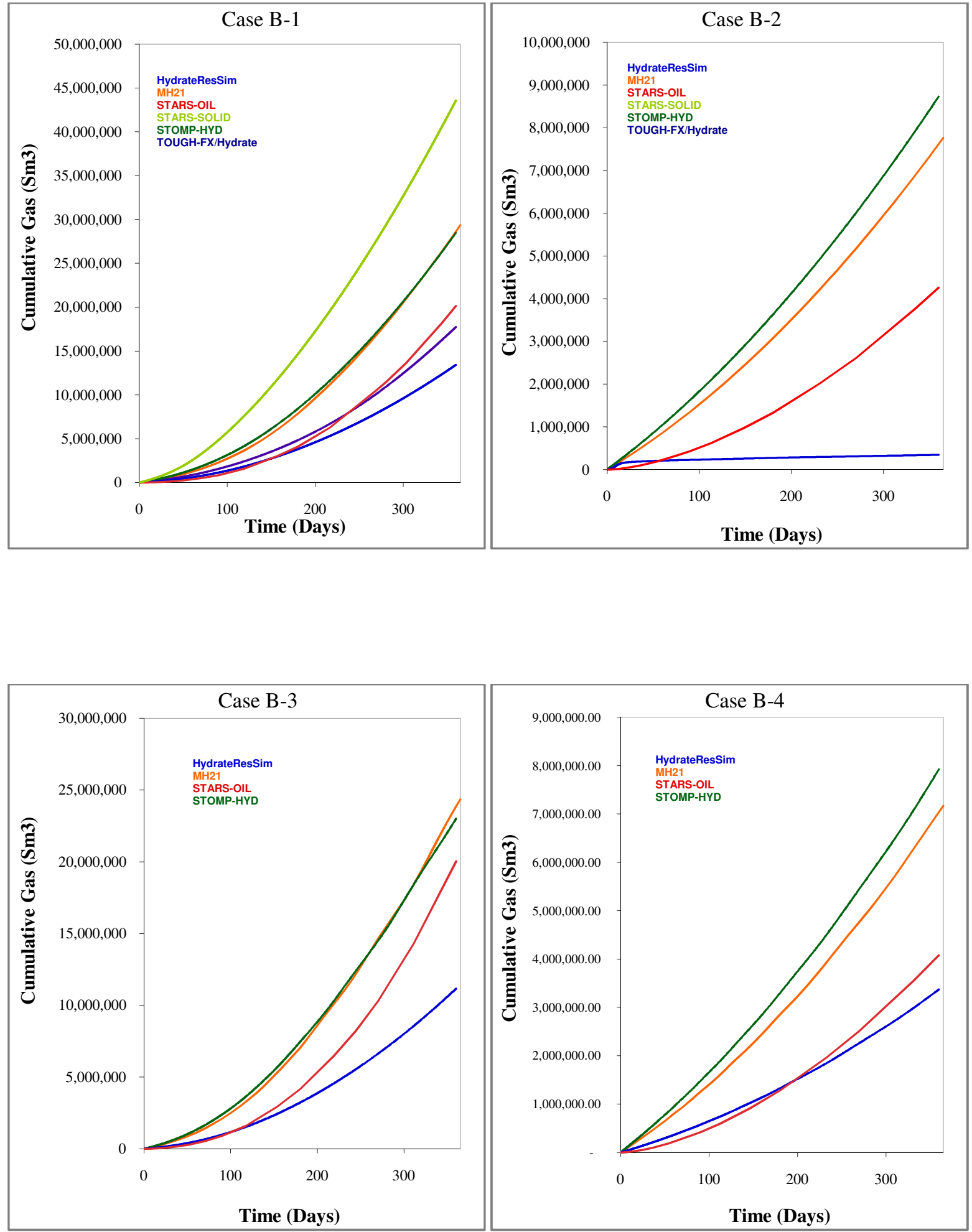

Figure 4-26 Cumulative gas production for problem 5 Cases B-1, B-2, B-3, B-4. 

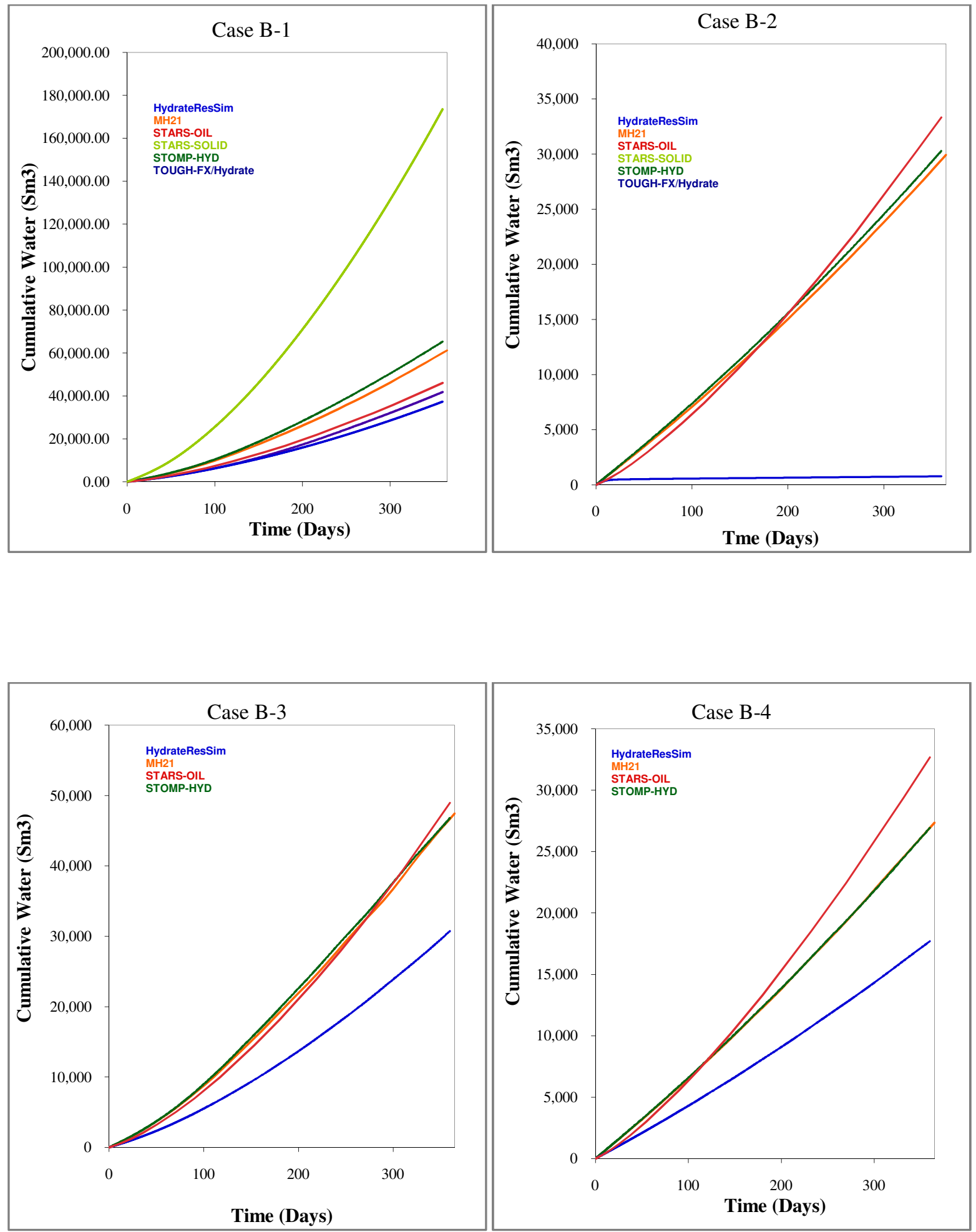

Figure 4-27 Cumulative water production for problem 5 Cases B-1, B-2, B-3, B-4. 


\section{Long term simulations on Prudhoe Bay and Mt. Elbert like sites}

The Majority of the permafrost gas hydrates of the United States are found in the Alaskan region because of the geologic conditions that are compatible to permafrost hydrate formation.

Three different sites are chosen the Mt. Elbert site at Milne Point, the Prudhoe Bay L-Pad deposit and a theoretical accumulation of Prudhoe Bay L-Pad site. These have been preferred since Mt. Elbert was the site of the BP/US DOE Modular Dynamics Testing in, February 2007 and has extensive well log data. Prudhoe Bay sites are deeper reservoirs.

For simplicity in this study, the anisotropy of the reservoirs has been replaced with the average of each of the reservoir parameters obtained from NMR well log data.

Problem 7a is based on the Mt. Elbert site. It is a cold reservoir and hydrate can be extremely stable making it difficult to produce gas from Mt. Elbert. It is solved using a radial cylindrical domain. The hydrate bearing layer is bound by two shale zones.

Problem $7 \mathrm{~b}$ originates from Prudhoe Bay L-Pad site. This reservoir consists of two hydrate bearing layers surrounded by shale zones. It is warmer than the reservoir specified in Problem 7a.

Problem $7 \mathrm{c}$ uses the same reservoir as that of Problem $7 \mathrm{~b}$; only difference being that is deeper, and thus warmer than the $7 \mathrm{~b}$ reservoir. 


\subsection{Problem 7a}

\section{Geometry of the grid:}

The whole structure of a grid is a cylinder with a vertical production well at the axis of the cylinder. There is distribution of cells in the grid in radial as well as vertical directions. The outer radius of the entire grid is $450 \mathrm{~m}$ and is $152.5 \mathrm{~m}$ deep. A schematic view of the grid is given in Figure 5-1.

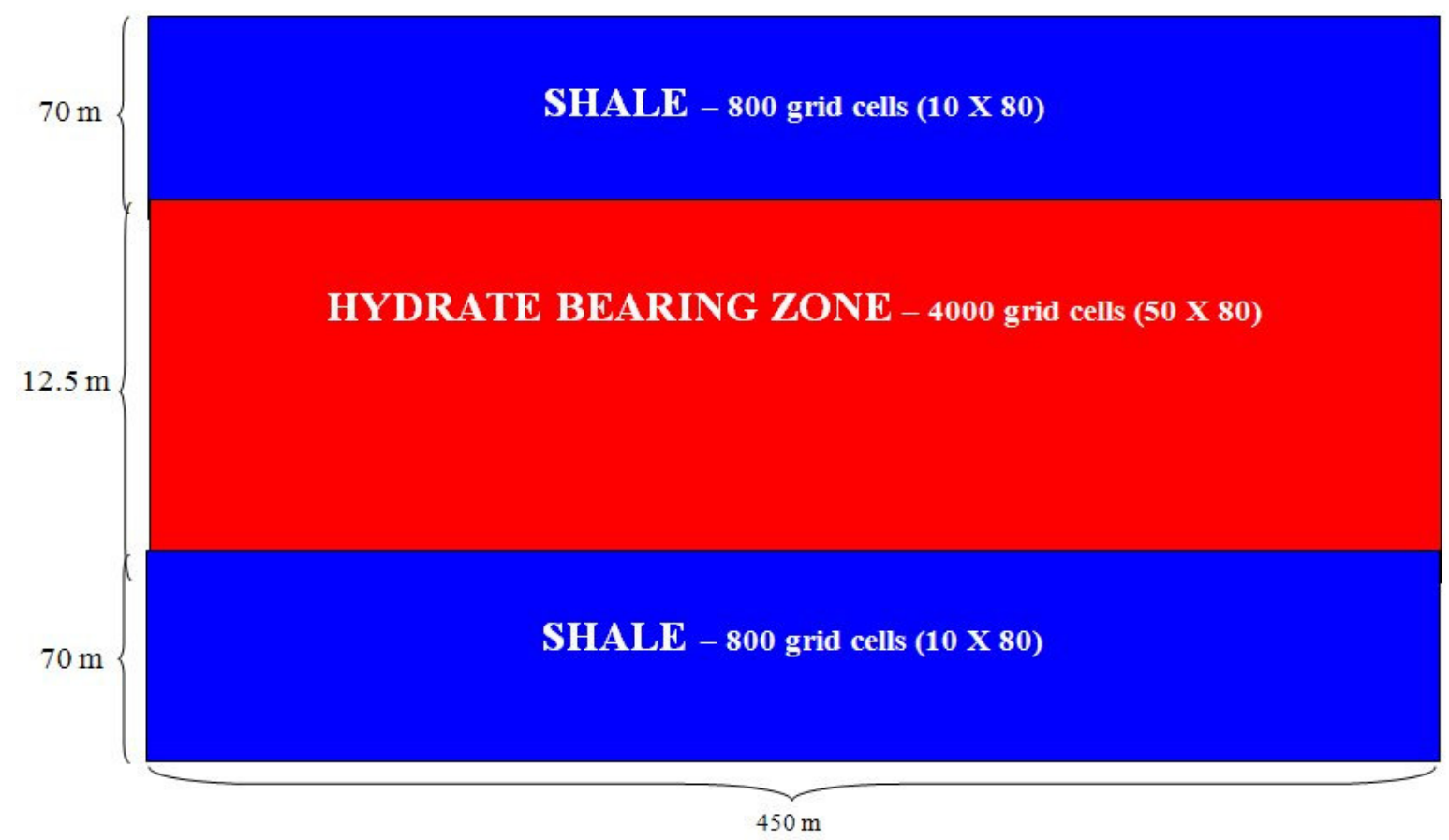

Figure 5-1 Schematic view of the grid for problem 7a. 


\section{Discretization of the grid:}

r-direction: There are 80 cells distributed logarithmically from $r=r_{\mathrm{w}}=0.111 \mathrm{~m} .\left(r_{\mathrm{w}}=\right.$ well bore radius) to $r=450 \mathrm{~m}$. The radius of the individual cells is given in Table 5-1.

Table 5-1 Radius of the individual cells

\begin{tabular}{|c|c|c|c|c|c|c|c|}
\hline Cell & Radius, m & Cell & Radius, m & Cell & Radius, m & Cell & Radius, m \\
\hline$r 1$ & 0.131 & r21 & 1.414 & r41 & 10.287 & r61 & 71.627 \\
\hline r2 & 0.153 & r22 & 1.567 & r42 & 11.340 & r62 & 78.906 \\
\hline r3 & 0.177 & r23 & 1.735 & $r 43$ & 12.500 & r63 & 86.923 \\
\hline$r 4$ & 0.204 & r24 & 1.919 & r44 & 13.777 & r64 & 95.755 \\
\hline r5 & 0.233 & r25 & 2.123 & $r 45$ & 15.184 & r65 & 105.482 \\
\hline r6 & 0.266 & r26 & 2.347 & $r 46$ & 16.734 & r66 & 116.198 \\
\hline r7 & 0.302 & r27 & 2.594 & r47 & 18.442 & r67 & 128.000 \\
\hline 18 & 0.341 & r28 & 2.866 & $r 48$ & 20.322 & r68 & 141.001 \\
\hline r9 & 0.384 & r29 & 3.166 & r49 & 22.394 & r69 & 155.321 \\
\hline r10 & 0.432 & r30 & 3.496 & r50 & 24.675 & r70 & 171.095 \\
\hline r11 & 0.485 & r31 & 3.859 & r51 & 27.188 & r71 & 188.469 \\
\hline r12 & 0.543 & r32 & 4.260 & r52 & 29.957 & r72 & 207.607 \\
\hline r13 & 0.606 & r33 & 4.701 & r53 & 33.006 & r73 & 228.688 \\
\hline r14 & 0.677 & r34 & 5.187 & r54 & 36.365 & r74 & 251.909 \\
\hline r15 & 0.754 & r35 & 5.722 & r55 & 40.065 & r75 & 277.486 \\
\hline r16 & 0.839 & r36 & 6.311 & r56 & 44.140 & r76 & 305.659 \\
\hline r17 & 0.933 & r37 & 6.961 & r57 & 48.629 & r77 & 336.692 \\
\hline r18 & 1.037 & r38 & 7.676 & r58 & 53.573 & r78 & 370.874 \\
\hline r19 & 1.151 & r39 & 8.464 & r59 & 59.020 & r79 & 408.526 \\
\hline r20 & 1.276 & r40 & 9.331 & r60 & 65.019 & r80 & 450.000 \\
\hline
\end{tabular}




\section{-direction:}

The cells in the hydrate bearing sediment are uniform in thickness and there are total of 50 cells in the hydrate layer. In each shale layer, there are 10 cells and the cell adjacent to the hydrate layer has a thickness of $0.25 \mathrm{~m}$. From the center to the periphery, the cells increase in size logarithmically according to the equation $d z_{\mathrm{i}}=d z_{\mathrm{i}-1} * 1.694831$. Values of thickenss of the cells in the $z$ direction are given in Table 5-2

Table 5-2 Cell discretization in the $z$-direction for Problem 7a

\begin{tabular}{|c|c|c|c|}
\hline $\begin{array}{c}\text { Cell } \\
\text { Number }\end{array}$ & $\mathbf{d z}$ & $\mathbf{z}$ (outer boundary) & $\mathbf{z}$ (center) \\
\hline 1 & 0.250 & 0.250 & 0.125 \\
2 & 0.424 & 0.674 & 0.462 \\
3 & 0.718 & 1.392 & 1.033 \\
4 & 1.217 & 2.609 & 2.000 \\
5 & 2.063 & 4.672 & 3.640 \\
6 & 3.496 & 8.168 & 6.420 \\
7 & 5.925 & 14.093 & 11.130 \\
8 & 10.042 & 24.135 & 19.114 \\
9 & 17.020 & 41.155 & 32.645 \\
10 & 28.846 & 70.000 & 55.577 \\
\hline
\end{tabular}

\section{Initial conditions:}

\section{Hydrate Saturation and Water Saturation:}

The hydrate saturation is $65 \%$ in the hydrate layer and water saturation is $35 \%$. This $65 \%$ is the average of the hydrate saturation data obtained from the NMR well log data obtained from Mt. Elbert site. In the shale layer, there is no hydrate and water saturation is $100 \%$. In the z-direction, there is a geothermal gradient of $35.5 \mathrm{~K} / \mathrm{km}$ and a hydrostatic pressure gradient of $9792 \mathrm{~Pa} / \mathrm{m}$. Following these gradients the pressures and temperatures at different depths are calculated and tabulated in Table 5-3. 
Table 5- 3 Pressure and Temperature values for the reservoir modeled in Problem 7a

\begin{tabular}{|c|c|c|c|c|c|c|c|}
\hline \multirow[b]{2}{*}{ Cell } & \multirow[b]{2}{*}{ Region } & \multirow{2}{*}{$\frac{Z}{\text { (boundary) }}$} & \multirow{2}{*}{$\frac{Z}{\text { (center) }}$} & \multirow{2}{*}{$\begin{array}{c}\mathrm{T} \\
\text { (boundary) }\end{array}$} & \multirow{2}{*}{$\frac{\mathbf{T}}{\text { (center) }}$} & \multirow{2}{*}{$\frac{\mathrm{P} / \mathrm{MPa}}{\text { (boundary) }}$} & \multirow{2}{*}{$\frac{\mathrm{P} / \mathrm{MPa}}{\text { (center) }}$} \\
\hline & & & & & & & \\
\hline & & 0.000 & & 273.295 & & 6.035 & \\
\hline 1 & Shale & 28.845 & 14.423 & 274.319 & 273.807 & 6.317 & 6.176 \\
\hline 2 & Shale & 45.865 & 37.355 & 274.923 & 274.621 & 6.484 & 6.400 \\
\hline 3 & Shale & 55.907 & 50.886 & 275.280 & 275.101 & 6.582 & 6.533 \\
\hline 4 & Shale & 61.832 & 58.870 & 275.490 & 275.385 & 6.640 & 6.611 \\
\hline 5 & Shale & 65.328 & 63.580 & 275.614 & 275.552 & 6.674 & 6.657 \\
\hline 6 & Shale & 67.391 & 66.360 & 275.687 & 275.651 & 6.694 & 6.684 \\
\hline 7 & Shale & 68.608 & 68.000 & 275.731 & 275.709 & 6.706 & 6.700 \\
\hline 8 & Shale & 69.326 & 68.967 & 275.756 & 275.743 & 6.713 & 6.710 \\
\hline 9 & Shale & 69.750 & 69.538 & 275.771 & 275.764 & 6.718 & 6.715 \\
\hline 10 & Shale & 70.000 & 69.875 & 275.780 & 275.776 & 6.720 & 6.719 \\
\hline 11 & Hydrate & 70.250 & 70.125 & 275.789 & 275.784 & 6.722 & 6.721 \\
\hline 12 & Hydrate & 70.500 & 70.375 & 275.798 & 275.793 & 6.725 & 6.724 \\
\hline 13 & Hydrate & 70.750 & 70.625 & 275.807 & 275.802 & 6.727 & 6.726 \\
\hline 14 & Hydrate & 71.000 & 70.875 & 275.816 & 275.811 & 6.730 & 6.729 \\
\hline 15 & Hydrate & 71.250 & 71.125 & 275.824 & 275.820 & 6.732 & 6.731 \\
\hline 16 & Hydrate & 71.500 & 71.375 & 275.833 & 275.829 & 6.735 & 6.733 \\
\hline 17 & Hydrate & 71.750 & 71.625 & 275.842 & 275.838 & 6.737 & 6.736 \\
\hline 18 & Hydrate & 72.000 & 71.875 & 275.851 & 275.847 & 6.740 & 6.738 \\
\hline 19 & Hydrate & 72.250 & 72.125 & 275.860 & 275.855 & 6.742 & 6.741 \\
\hline 20 & Hydrate & 72.500 & 72.375 & 275.869 & 275.864 & 6.744 & 6.743 \\
\hline 21 & Hydrate & 72.750 & 72.625 & 275.878 & 275.873 & 6.747 & 6.746 \\
\hline 22 & Hydrate & 73.000 & 72.875 & 275.887 & 275.882 & 6.749 & 6.748 \\
\hline 23 & Hydrate & 73.250 & 73.125 & 275.895 & 275.891 & 6.752 & 6.751 \\
\hline 24 & Hydrate & 73.500 & 73.375 & 275.904 & 275.900 & 6.754 & 6.753 \\
\hline 25 & Hydrate & 73.750 & 73.625 & 275.913 & 275.909 & 6.757 & 6.755 \\
\hline 26 & Hydrate & 74.000 & 73.875 & 275.922 & 275.918 & 6.759 & 6.758 \\
\hline 27 & Hydrate & 74.250 & 74.125 & 275.931 & 275.926 & 6.762 & 6.760 \\
\hline 28 & Hydrate & 74.500 & 74.375 & 275.940 & 275.935 & 6.764 & 6.763 \\
\hline 29 & Hydrate & 74.750 & 74.625 & 275.949 & 275.944 & 6.767 & 6.765 \\
\hline 30 & Hydrate & 75.000 & 74.875 & 275.958 & 275.953 & 6.769 & 6.768 \\
\hline 31 & Hydrate & 75.250 & 75.125 & 275.966 & 275.962 & 6.771 & 6.770 \\
\hline 32 & Hydrate & 75.500 & 75.375 & 275.975 & 275.971 & 6.774 & 6.773 \\
\hline 33 & Hydrate & 75.750 & 75.625 & 275.984 & 275.980 & 6.776 & 6.775 \\
\hline 34 & Hydrate & 76.000 & 75.875 & 275.993 & 275.989 & 6.779 & 6.778 \\
\hline 35 & Hydrate & 76.250 & 76.125 & 276.002 & 275.997 & 6.781 & 6.780 \\
\hline
\end{tabular}


Table 5- 3 (contd....)

\begin{tabular}{|c|c|c|c|c|c|c|c|}
\hline \multirow[b]{2}{*}{ Cell } & \multirow[b]{2}{*}{ Region } & \multirow{2}{*}{$\frac{Z}{\text { (boundary) }}$} & \multirow{2}{*}{$\frac{Z}{\text { (center) }}$} & \multirow{2}{*}{$\begin{array}{c}\mathrm{T} \\
\text { (boundary) }\end{array}$} & \multirow{2}{*}{$\begin{array}{c}\mathbf{T} \\
\text { (center) }\end{array}$} & \multirow{2}{*}{$\begin{array}{c}\mathrm{P} / \mathrm{MPa} \\
\text { (boundary) }\end{array}$} & \multirow{2}{*}{$\begin{array}{r}\mathrm{P} / \mathrm{MPa} \\
\text { (center) }\end{array}$} \\
\hline & & & & & & & \\
\hline 36 & Hydrate & 76.500 & 76.375 & 276.011 & 276.006 & 6.784 & 6.782 \\
\hline 37 & Hydrate & 76.750 & 76.625 & 276.020 & 276.015 & 6.786 & 6.785 \\
\hline 38 & Hydrate & 77.000 & 76.875 & 276.029 & 276.024 & 6.789 & 6.787 \\
\hline 39 & Hydrate & 77.250 & 77.125 & 276.037 & 276.033 & 6.791 & 6.790 \\
\hline 40 & Hydrate & 77.500 & 77.375 & 276.046 & 276.042 & 6.793 & 6.792 \\
\hline 41 & Hydrate & 77.750 & 77.625 & 276.055 & 276.051 & 6.796 & 6.795 \\
\hline 42 & Hydrate & 78.000 & 77.875 & 276.064 & 276.060 & 6.798 & 6.797 \\
\hline 43 & Hydrate & 78.250 & 78.125 & 276.073 & 276.068 & 6.801 & 6.800 \\
\hline 44 & Hydrate & 78.500 & 78.375 & 276.082 & 276.077 & 6.803 & 6.802 \\
\hline 45 & Hydrate & 78.750 & 78.625 & 276.091 & 276.086 & 6.806 & 6.804 \\
\hline 46 & Hydrate & 79.000 & 78.875 & 276.100 & 276.095 & 6.808 & 6.807 \\
\hline 47 & Hydrate & 79.250 & 79.125 & 276.108 & 276.104 & 6.811 & 6.809 \\
\hline 48 & Hydrate & 79.500 & 79.375 & 276.117 & 276.113 & 6.813 & 6.812 \\
\hline 49 & Hydrate & 79.750 & 79.625 & 276.126 & 276.122 & 6.815 & 6.814 \\
\hline 50 & Hydrate & 80.000 & 79.875 & 276.135 & 276.131 & 6.818 & 6.817 \\
\hline 51 & Hydrate & 80.250 & 80.125 & 276.144 & 276.139 & 6.820 & 6.819 \\
\hline 52 & Hydrate & 80.500 & 80.375 & 276.153 & 276.148 & 6.823 & 6.822 \\
\hline 53 & Hydrate & 80.750 & 80.625 & 276.162 & 276.157 & 6.825 & 6.824 \\
\hline 54 & Hydrate & 81.000 & 80.875 & 276.171 & 276.166 & 6.828 & 6.826 \\
\hline 55 & Hydrate & 81.250 & 81.125 & 276.179 & 276.175 & 6.830 & 6.829 \\
\hline 56 & Hydrate & 81.500 & 81.375 & 276.188 & 276.184 & 6.833 & 6.831 \\
\hline 57 & Hydrate & 81.750 & 81.625 & 276.197 & 276.193 & 6.835 & 6.834 \\
\hline 58 & Hydrate & 82.000 & 81.875 & 276.206 & 276.202 & 6.838 & 6.836 \\
\hline 59 & Hydrate & 82.250 & 82.125 & 276.215 & 276.210 & 6.840 & 6.839 \\
\hline 60 & Hydrate & 82.500 & 82.375 & 276.224 & 276.219 & 6.842 & 6.841 \\
\hline 61 & Shale & 82.750 & 82.625 & 276.233 & 276.228 & 6.845 & 6.844 \\
\hline 62 & Shale & 83.174 & 82.962 & 276.248 & 276.240 & 6.849 & 6.847 \\
\hline 63 & Shale & 83.892 & 83.533 & 276.273 & 276.260 & 6.856 & 6.853 \\
\hline 64 & Shale & 85.109 & 84.500 & 276.316 & 276.295 & 6.868 & 6.862 \\
\hline 65 & Shale & 87.172 & 86.140 & 276.390 & 276.353 & 6.888 & 6.878 \\
\hline 66 & Shale & 90.668 & 88.920 & 276.514 & 276.452 & 6.922 & 6.905 \\
\hline 67 & Shale & 96.593 & 93.630 & 276.724 & 276.619 & 6.980 & 6.951 \\
\hline 68 & Shale & 106.635 & 101.614 & 277.081 & 276.902 & 7.079 & 7.030 \\
\hline 69 & Shale & 123.655 & 115.145 & 277.685 & 277.383 & 7.245 & 7.162 \\
\hline 70 & Shale & 152.500 & 138.077 & 278.709 & 278.197 & 7.528 & 7.387 \\
\hline
\end{tabular}




\section{Boundary Conditions:}

There is no net mass transport between the reservoir and the surroundings. The upper boundary temperature is held constant at $274.715 \mathrm{~K}$ and the lower boundary temperature is held at constant at $277.271 \mathrm{~K}$.

\section{Medium properties:}

Medium properties like permeability porosity are specified in Table 5-4.

Table 5-4 Medium Properties for the Problem 5

\begin{tabular}{|l|l|}
\hline \multicolumn{1}{|c|}{ Property } & \multicolumn{1}{c|}{ Value } \\
\hline Permeability, $\mathrm{mD}$ & Shale -0.0 \\
\cline { 2 - 2 } & Hydrate layer - 1000 (r direction) \\
\cline { 2 - 2 } & Hydrate layer - 100 (z direction) \\
\hline Porosity, \% & Shale - 10 \\
\cline { 2 - 2 } & Hydrate zone - 35 \\
\hline pore Compressibility $(1 / \mathrm{Pa})$ & $1.00 \mathrm{E}-08$ \\
\hline Rock Density $\left(\mathrm{kg} / \mathrm{m}^{3}\right)$ & 2650 \\
\hline Rock Specific Heat $(\mathrm{J} / \mathrm{kg} / \mathrm{K})$ & 1000 \\
\hline
\end{tabular}

\section{Relative Permeability Models:}

A relative permeability model developed by Stone + Aziz is used in this problem. The parameters were fixed so that every simulator has the same values.

\section{Water Relative Permeability}

$$
k_{r w}=\left\{\frac{\left(S_{W}-S_{W i r}\right)}{\left(1-S_{W i r}\right)}\right\}^{4.52} ; S_{W i r}=0.248
$$


$k_{r g}=\left\{\frac{\left(S_{G}-S_{G i r}\right)}{\left(1-S_{W i r}\right)}\right\}^{3.16} S_{W i r}=0 . \quad S G_{i r}=0$.

$S_{W i r}$ and $S_{G i r}$ represents irreducible water and gas saturation. Gas and water relative permeability curves are shown in Figure 5-2.

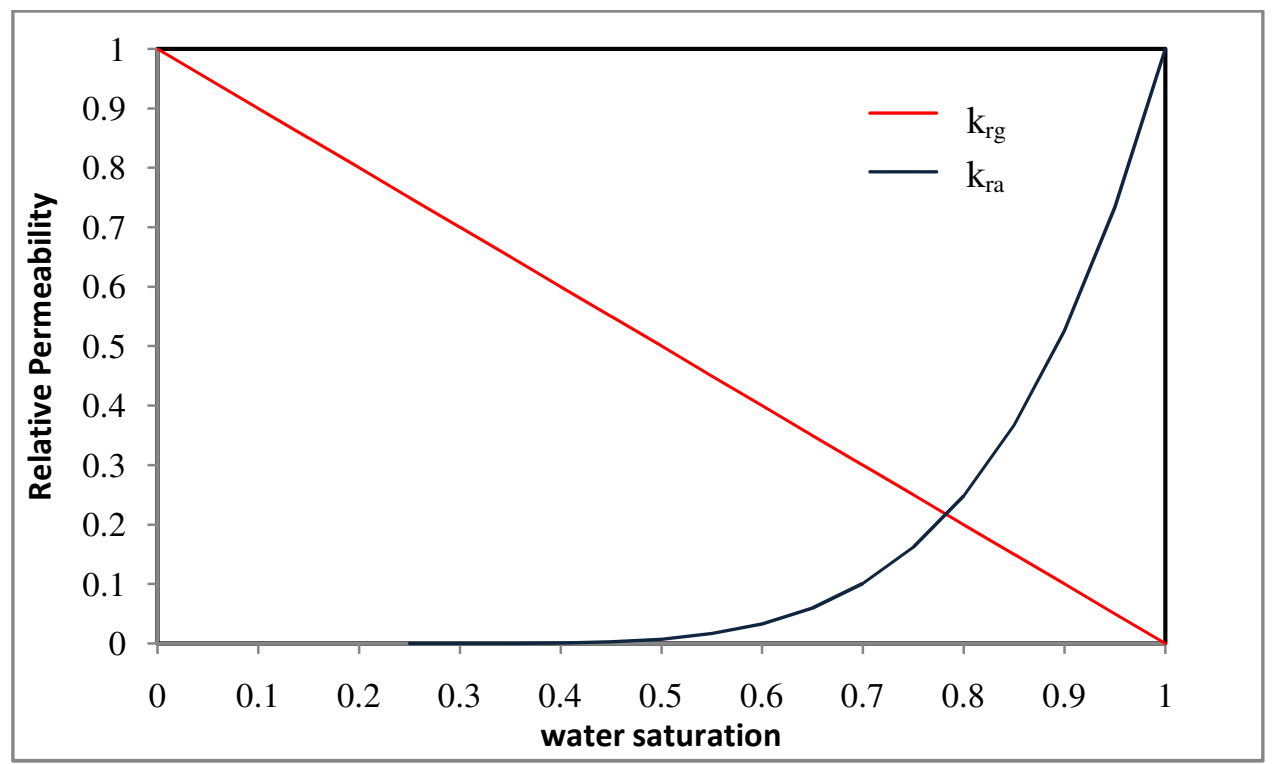

Figure 5- 2 Aqueous and Gas relative Permeability curves for Problem 7a.

\section{Capillary Pressure Model:}

Van Genuchten Capillary pressure Model is used just like in other problems.

$$
\begin{aligned}
& \bar{s}_{l}=\frac{\left(s_{l}-s_{l r}\right)}{\left(1-s_{l r}\right)}=\left(1-\left(\alpha \beta_{g l}\left\{\frac{\left(P_{g}-P_{l}\right)}{\rho_{l} g}\right\}\right)^{n}\right)^{-m}: \\
& \alpha=10.2041 / \mathrm{m}, \beta_{g l}=1.0, n=4.432, m=0.7744, s_{l r}=0.28
\end{aligned}
$$


where $\bar{s}_{l}$ is the effective aqueous saturation, $s_{l}$ is the aqueous saturation, $\beta_{g l}$ is the interfacial tension scaling factor, and $h_{g l}$ is the gas-aqueous capillary pressure head. Figure 5-3 shows the variation of capillary pressure with water saturation.

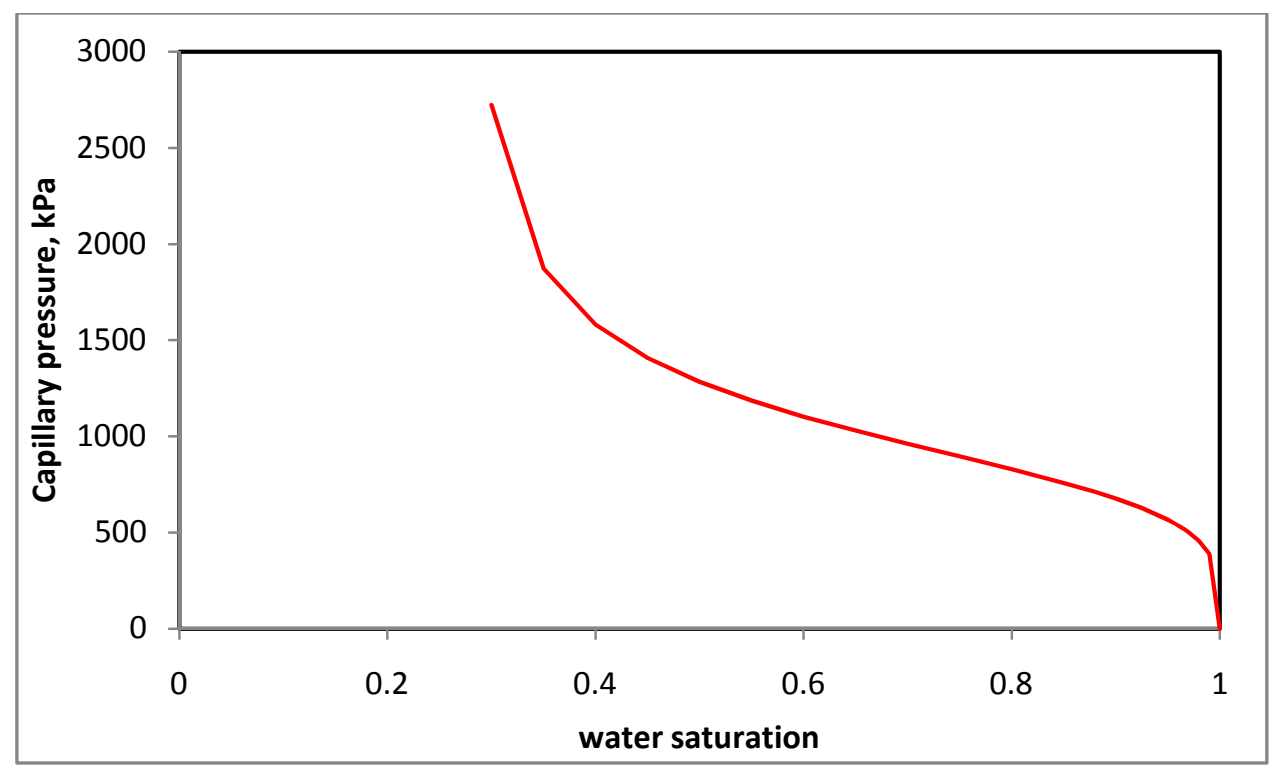

Figure 5-3 Capillary Pressure as a function of water saturation

\section{Well Information:}

Wellbore Radius is selected to be $0.111 \mathrm{~m}$. The Bottom hole pressure is chosen to be $2.7 \mathrm{MPa}$ to avoid ice formation in the system.

\section{Data and Sampling Frequency:}

The simulations are carried out until all the hydrate dissociates and equilibrium is reached or over a time period of 50 years. Data for gas production rate, water production rate, cumulative gas production and cumulative water production is recorded with a time step of 90 days for 50 years. 


\subsubsection{Solution to Problem 7a}

The input data file for the problem starts with the definition of the cylindrical grid.

Permeability porosity are specified as per the problem description.

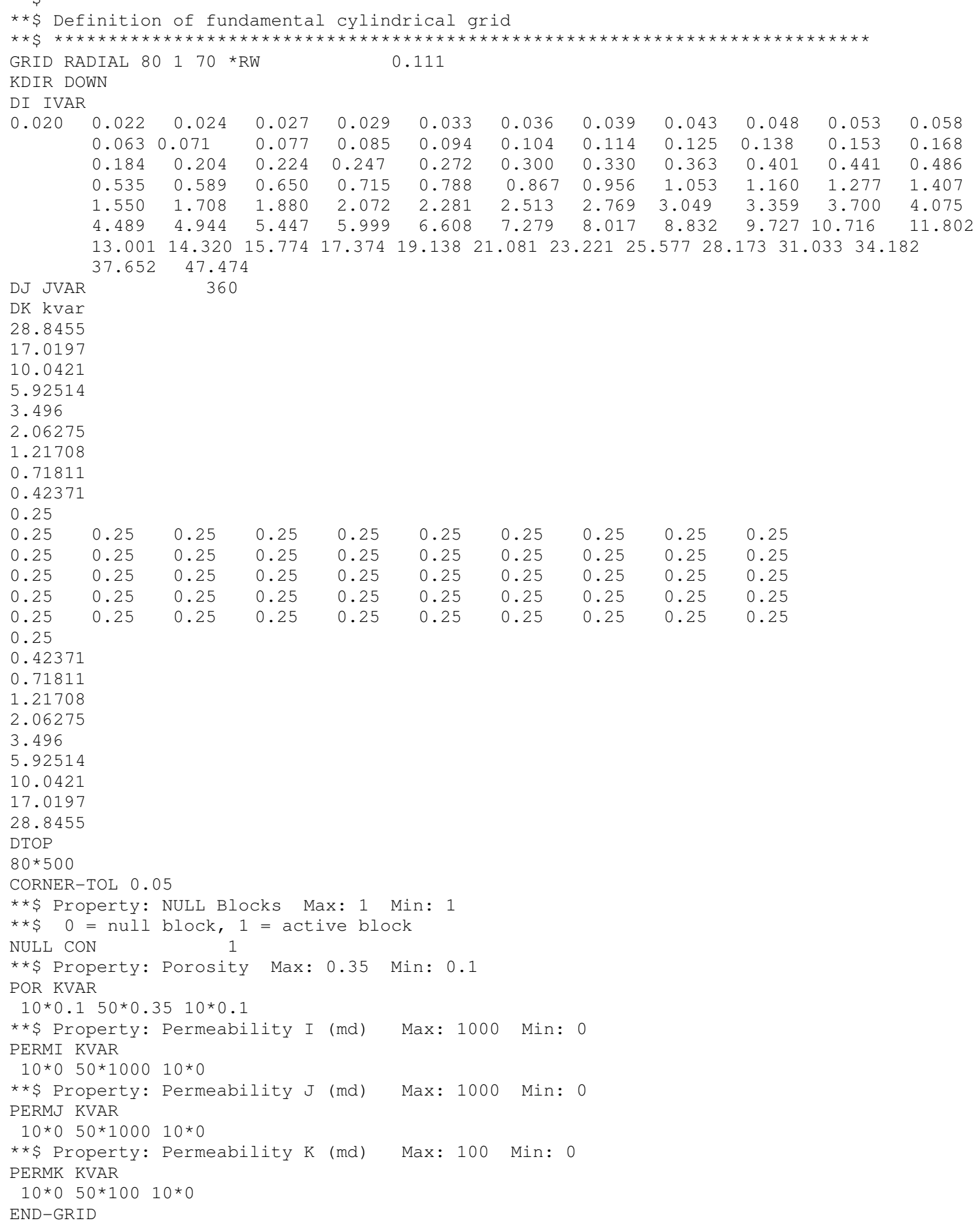

Thermal properties, components description are as per the problem description. 


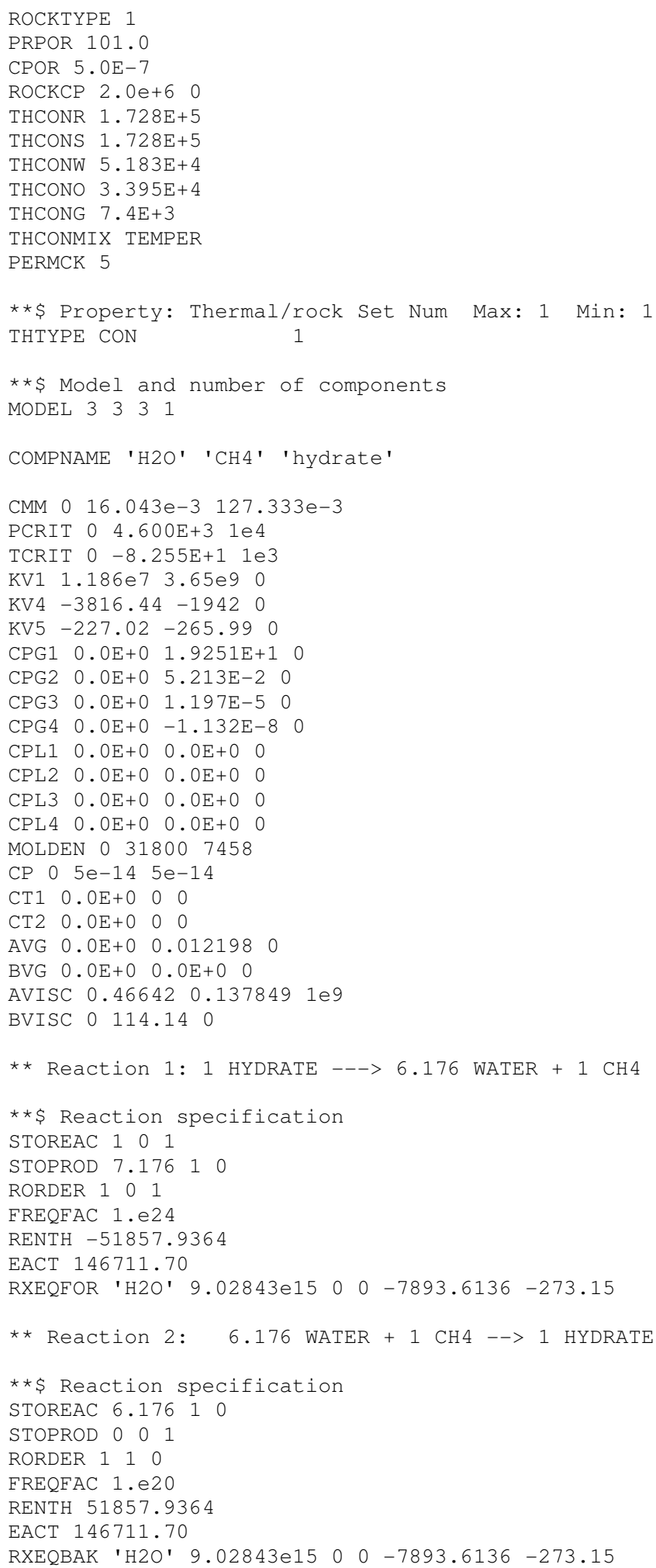


Rock fluid properties, initial conditions such as pressure, temperature, and saturations are calculated based on models specified in the problem description.

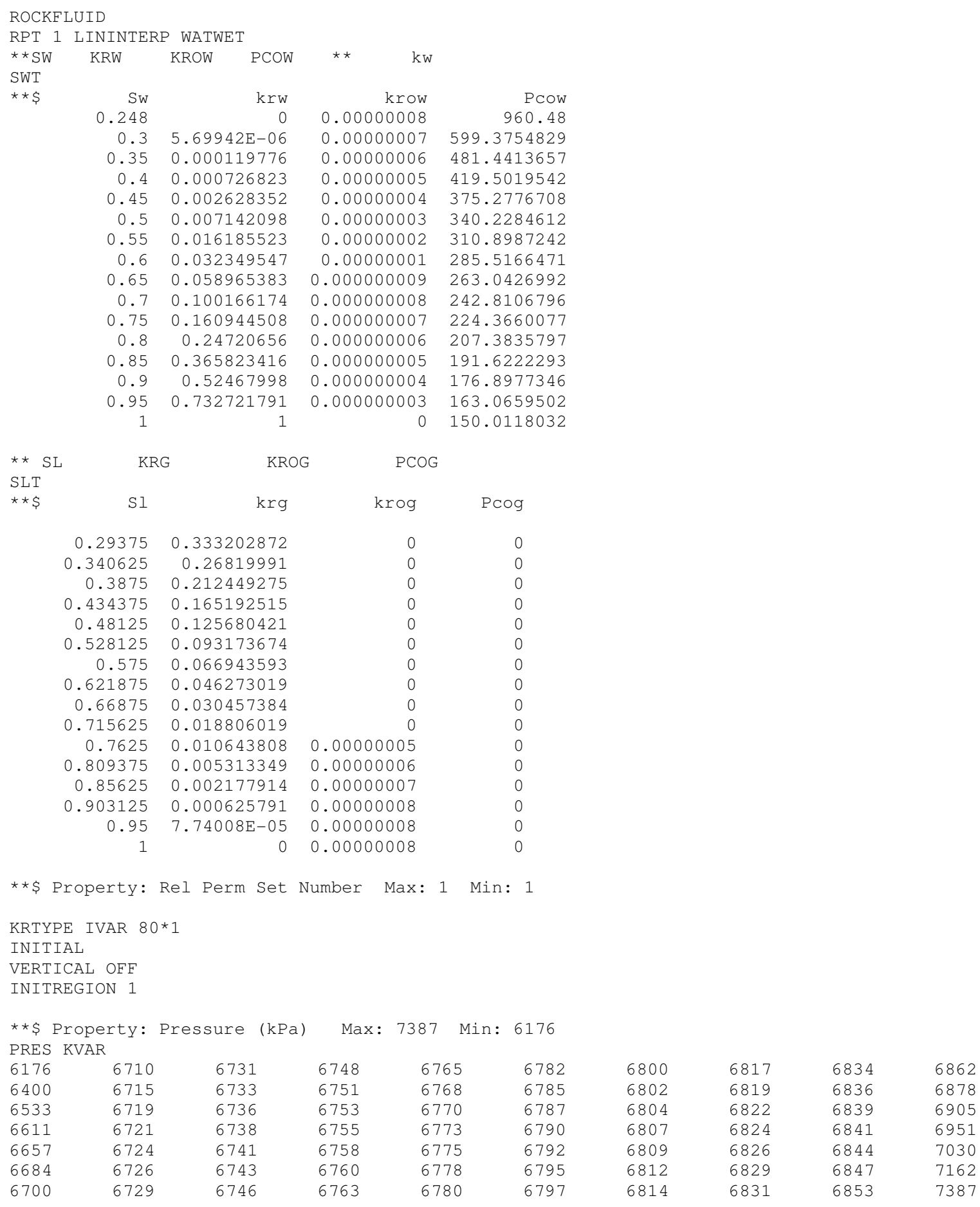

$* * \$$ Property: Temperature (C) Max: 5.047 Min: 0.85 


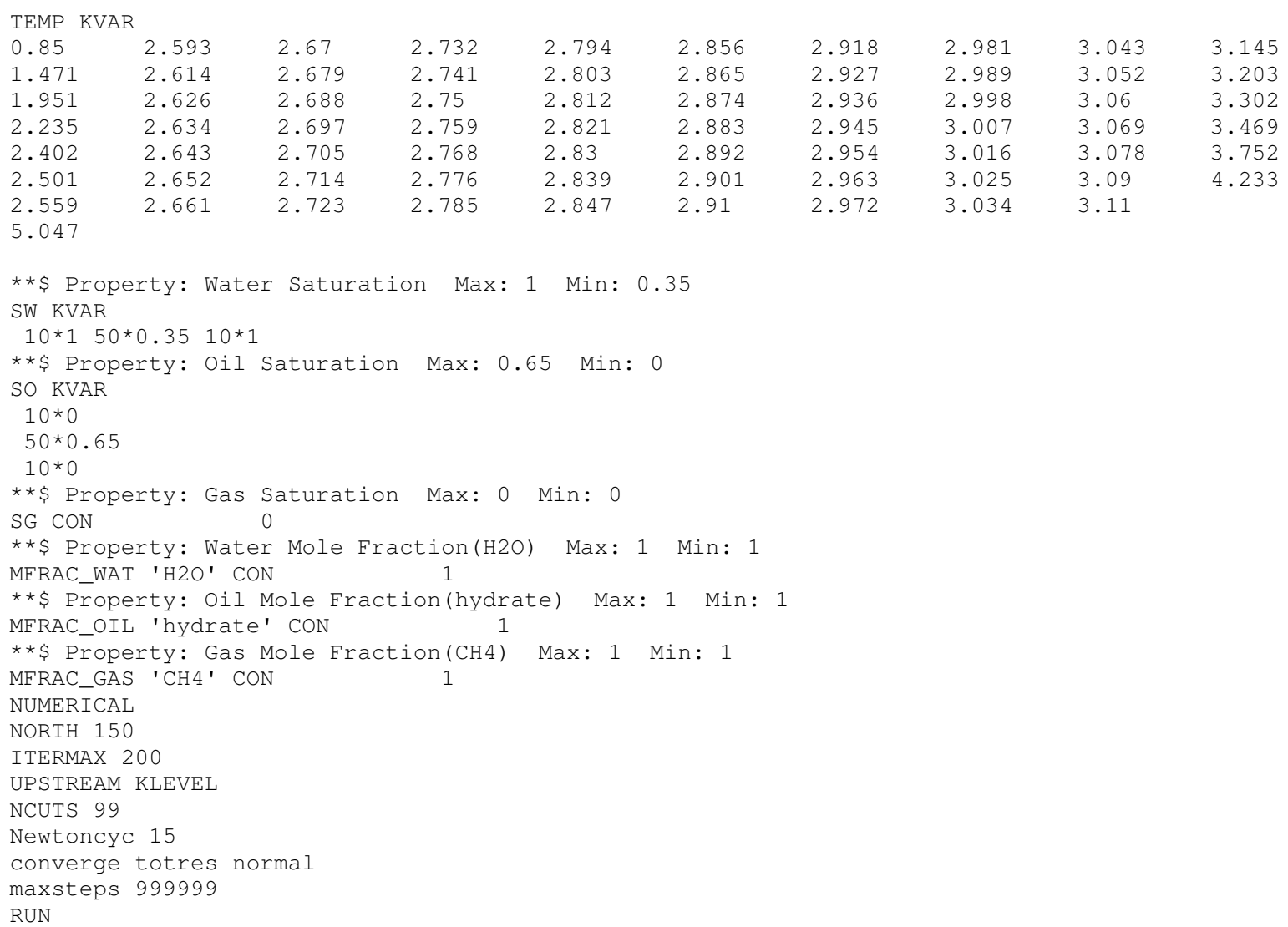

Simulation is started at time $=0$, and is run for 50 years. Reservoir is depressurized at a bottom hole pressure of $2700 \mathrm{kPa}$. This low bottom hole pressure is slowly put in practice by depressurizing first at time $=0, \mathrm{BHP}=4160 \mathrm{kPa}$ and then to $\mathrm{BHP}=2700 \mathrm{kPa}$ at time $=2$ days

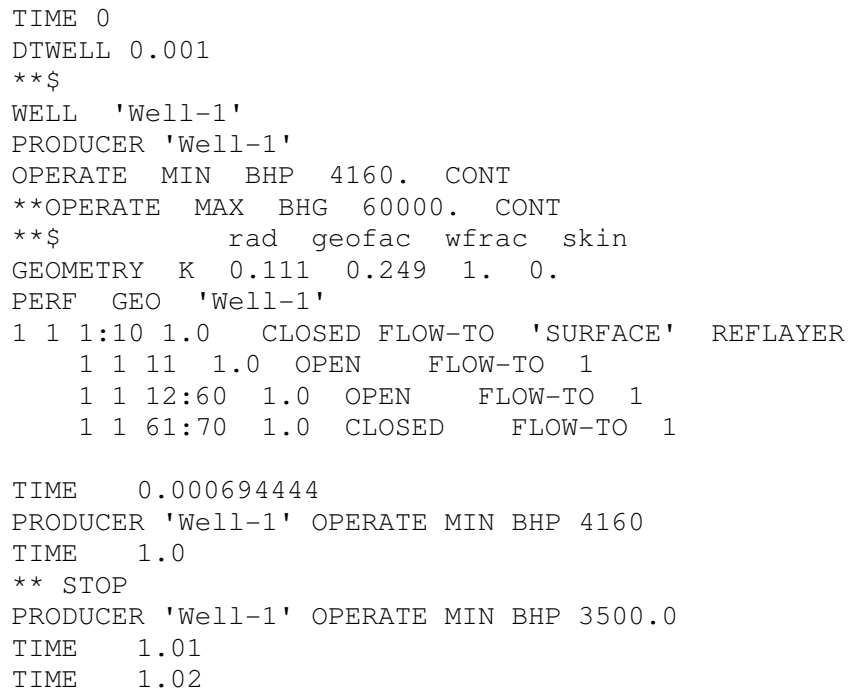




\begin{tabular}{|c|c|c|c|c|c|c|c|}
\hline TIME & 1.09 & & & & & & \\
\hline TIME & 1.1 & & & & & & \\
\hline TIME & 1.11 & & & & & & \\
\hline TIME & 1.12 & & & & & & \\
\hline TIME & 1.19 & & & & & & \\
\hline TIME & 1.2 & & & & & & \\
\hline \multicolumn{8}{|c|}{ PRODUCER 'Well-1' OPERATE MIN BHP 3000.0} \\
\hline \multicolumn{8}{|c|}{ DTMAX .1} \\
\hline TIME & 1.21 & & & & & & \\
\hline TIME & 1.51 & & & & & & \\
\hline TIME & 1.75 & & & & & & \\
\hline TIME & 1.76 & & & & & & \\
\hline TIME & 1.77 & & & & & & \\
\hline TIME & 2 & & & & & & \\
\hline \multicolumn{8}{|c|}{ PRODUCER 'Well-1' OPERATE MIN BHP 2700.0} \\
\hline TIME & 3 & TIME & 1247.22 & TIME & 5295 & TIME & 10226 \\
\hline TIME & 4 & TIME & 1277.64 & TIME & 5386 & TIME & 10317 \\
\hline TIME & 5 & TIME & 1308.06 & TIME & 5478 & TIME & 10409 \\
\hline TIME & 6 & TIME & 1338.48 & TIME & 5569 & TIME & 10500 \\
\hline TIME & 8 & TIME & 1368.9 & TIME & 5660 & TIME & 10591 \\
\hline DTMAX 3 & 30.42 & TIME & 1399.32 & TIME & 5752 & TIME & 10683 \\
\hline TIME & 12 & TIME & 1429.74 & TIME & 5843 & TIME & 10774 \\
\hline TIME & 20 & TIME & 1460.16 & TIME & 5934 & TIME & 10865 \\
\hline TIME & 30.42 & TIME & 1490.58 & TIME & 6026 & TIME & 10957 \\
\hline TIME & 40 & TIME & 1521 & TIME & 6117 & TIME & 11048 \\
\hline TIME & 50.42 & TIME & 1551.42 & TIME & 6208 & TIME & 11139 \\
\hline TIME & 55.42 & TIME & 1581.84 & TIME & 6300 & TIME & 11230 \\
\hline TIME & 60.84 & TIME & 1612.26 & TIME & 6391 & TIME & 11322 \\
\hline TIME & 60.9 & TIME & 1642.68 & TIME & 6482 & TIME & 11413 \\
\hline TIME & 91.26 & TIME & 1643 & TIME & 6574 & TIME & 11504 \\
\hline TIME & 121.68 & TIME & 1734 & TIME & 6665 & TIME & 11596 \\
\hline TIME & 152.1 & TIME & 1825 & TIME & 6756 & TIME & 11687 \\
\hline TIME & 182.52 & TIME & 1917 & TIME & 6847 & TIME & 11778 \\
\hline TIME & 212.8 & TIME & 2008 & TIME & 6939 & TIME & 11870 \\
\hline TIME & 231. & TIME & 2099 & TIME & 7030 & TIME & 11961 \\
\hline TIME & 243.36 & TIME & 2191 & TIME & 7121 & TIME & 12052 \\
\hline TIME & 273.78 & TIME & 2282 & TIME & 7213 & TIME & 12144 \\
\hline TIME & 304.2 & TIME & 2373 & TIME & 7304 & TIME & 12235 \\
\hline TIME & 334.62 & TIME & 2464 & TIME & 7395 & TIME & 12326 \\
\hline TIME & 365.04 & TIME & 2556 & TIME & 7487 & TIME & 12418 \\
\hline DTMAX & 90 & TIME & 2647 & TIME & 7578 & TIME & 12509 \\
\hline TIME & 395.46 & TIME & 2738 & TIME & 7669 & TIME & 12600 \\
\hline TIME & 425.88 & TIME & 2830 & TIME & 7761 & TIME & 12691 \\
\hline TIME & 456.3 & TIME & 2921 & TIME & 7852 & TIME & 12783 \\
\hline TIME & 486.72 & TIME & 3012 & TIME & 7943 & TIME & 12874 \\
\hline TIME & 517.14 & TIME & 3104 & TIME & 8035 & TIME & 12965 \\
\hline TIME & 547.56 & TIME & 3195 & TIME & 8126 & TIME & 13057 \\
\hline TIME & 577.98 & TIME & 3286 & TIME & 8217 & TIME & 13148 \\
\hline TIME & 608.4 & TIME & 3378 & TIME & 8308 & TIME & 13239 \\
\hline TIME & 638.82 & TIME & 3469 & TIME & 8400 & TIME & 13331 \\
\hline TIME & 669.24 & TIME & 3560 & TIME & 8491 & TIME & 13422 \\
\hline TIME & 699.66 & TIME & 3652 & TIME & 8582 & TIME & 13513 \\
\hline TIME & 730.08 & TIME & 3743 & TIME & 8674 & TIME & 13605 \\
\hline TIME & 760.5 & TIME & 3834 & TIME & 8765 & TIME & 13696 \\
\hline TIME & 790.92 & TIME & 3925 & TIME & 8856 & TIME & 13787 \\
\hline TIME & 821.34 & TIME & 4017 & TIME & 8948 & TIME & 13879 \\
\hline TIME & 851.76 & TIME & 4108 & TIME & 9039 & TIME & 13970 \\
\hline TIME & 882.18 & TIME & 4199 & TIME & 9130 & TIME & 14061 \\
\hline TIME & 912.6 & TIME & 4291 & TIME & 9222 & TIME & 14152 \\
\hline TIME & 943.02 & TIME & 4382 & TIME & 9313 & TIME & 14244 \\
\hline TIME & 973.44 & TIME & 4473 & TIME & 9404 & TIME & 14335 \\
\hline TIME & 1003.86 & TIME & 4565 & TIME & 9496 & TIME & 14426 \\
\hline TIME & 1034.28 & TIME & 4656 & TIME & 9587 & TIME & 14518 \\
\hline TIME & 1064.7 & TIME & 4747 & TIME & 9678 & TIME & 14609 \\
\hline TIME & 1095.12 & TIME & 4839 & TIME & 9769 & TIME & 14700 \\
\hline TIME & 1125.54 & TIME & 4930 & TIME & 9861 & TIME & 14792 \\
\hline TIME & 1155.96 & TIME & 5021 & TIME & 9952 & TIME & 14883 \\
\hline TIME & 1186.38 & TIME & 5113 & TIME & 10043 & TIME & 14974 \\
\hline TIME & 1216.8 & TIME & 5204 & TIME & 10135 & TIME & 15066 \\
\hline
\end{tabular}




$\begin{array}{ll}\text { TIME } & 15157 \\ \text { TIME } & 15248 \\ \text { TIME } & 15340 \\ \text { TIME } & 15431 \\ \text { TIME } & 15522 \\ \text { TIME } & 15613 \\ \text { TIME } & 15705 \\ \text { TIME } & 15796 \\ \text { TIME } & 15887\end{array}$

$\begin{array}{ll}\text { TIME } & 15979 \\ \text { TIME } & 16070 \\ \text { TIME } & 16161 \\ \text { TIME } & 16253 \\ \text { TIME } & 16344 \\ \text { TIME } & 16435 \\ \text { TIME } & 16527 \\ \text { TIME } & 16618 \\ \text { TIME } & 16709\end{array}$

$\begin{array}{ll}\text { TIME } & 16801 \\ \text { TIME } & 16892 \\ \text { TIME } & 16983 \\ \text { TIME } & 17074 \\ \text { TIME } & 17166 \\ \text { TIME } & 17257 \\ \text { TIME } & 17348 \\ \text { TIME } & 17440 \\ \text { TIME } & 17531\end{array}$

$\begin{array}{ll}\text { TIME } & 17622 \\ \text { TIME } & 17714 \\ \text { TIME } & 17805 \\ \text { TIME } & 17896 \\ \text { TIME } & 17988 \\ \text { TIME } & 18079 \\ \text { TIME } & 18170 \\ \text { TIME } & 18262\end{array}$

Simulation is stopped after 50 years.

Results of gas rate, water rate, cumulative gas rate, cumulative water rate are compared with other codes. To simplify the project CMG STARS results are compared with only MH21.

The characteristic part of Problem $7 \mathrm{a}$ is there is no gas for $1^{\text {st }} 10$ years. HydrateResim, TOUGH and CMG STARS agreed on this result. MH21 and STOMP took a little longer time to produce gas. However there is a small change in the magnitude of gas rates during the course of the simulation, the cumulative gas at the end of 50 years is almost same for all reservoir simulators. Every simulator is different in the way it calculates all the properties at each time step. So this small difference in magnitude can be expected from each simulator as the problem becomes more complex. Gas rate and Cumulative gas rate for STARS and MH21 are shown in Figure 5-4 and Figure 5-5. 


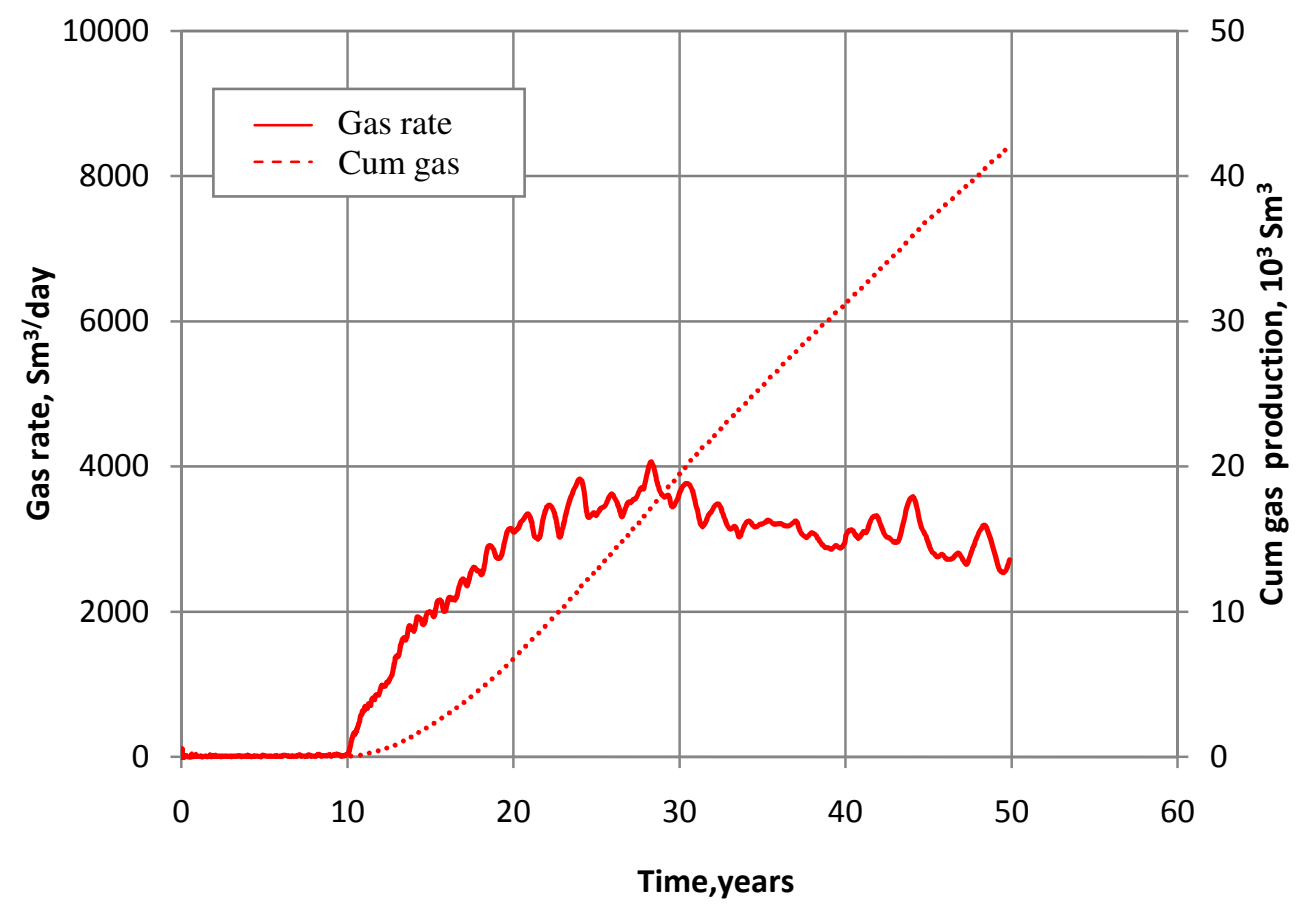

Figure 5-4 Gas rate and cumulative gas rate for 50 years using CMG STARS

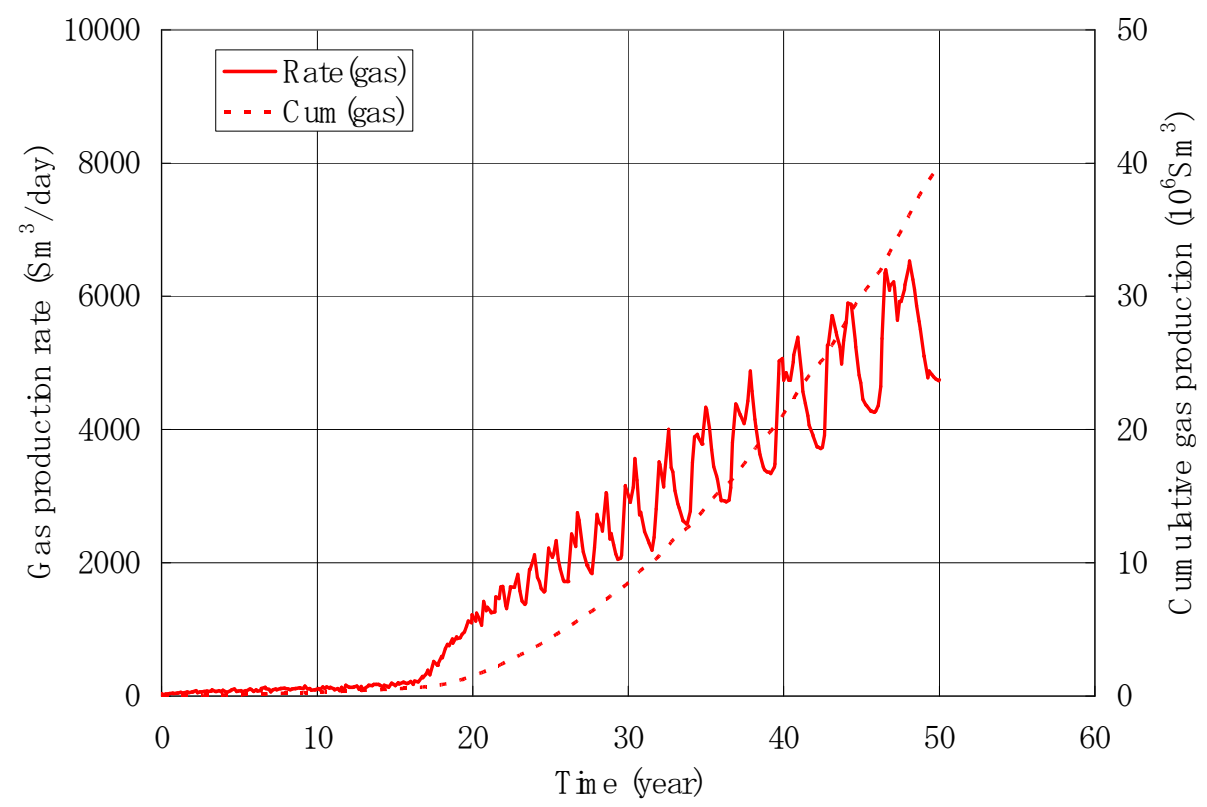

Figure 5- 5 Gas rate and cumulative gas rate for 50 years using MH21 
Water rates and cumulative water rates for CMG STARS and MH21 are in good agreement. Figures 5-6 and 5-7 show results for CMG STARS and MH21.

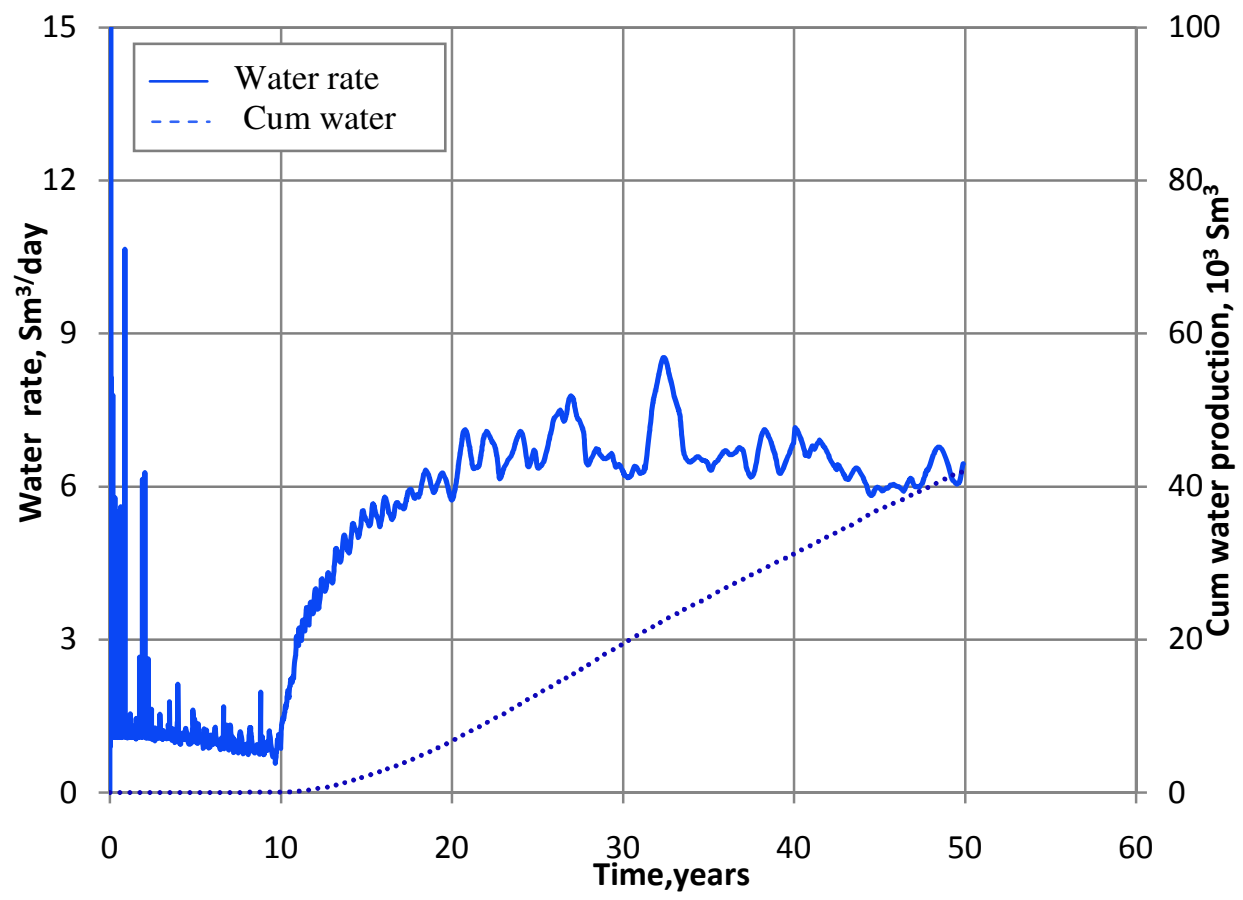

Figure 5-6 Water rate and cumulative water rate for 50 years using CMG STARS

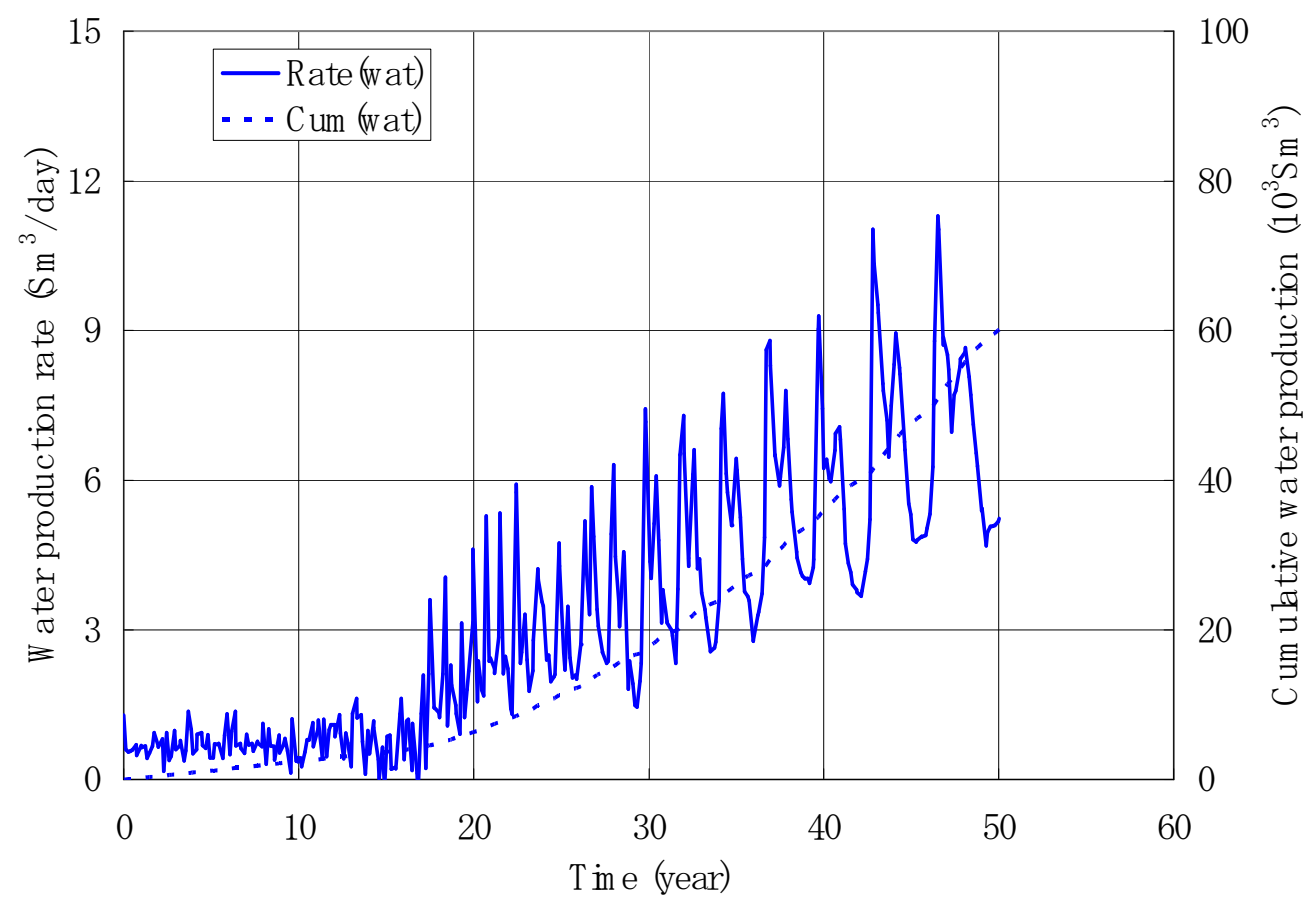

Figure 5-7 Water rate and cumulative water rate for 50 years using MH21 


\subsection{Problem 7b: PBU L-Pad}

\section{Geometry of the Grid}

A radial grid of outer radius $450 \mathrm{~m}$ and $240 \mathrm{~m}$ deep is considered in this problem. Unlike

Problem 7a there are two hydrate bearing layers bounded by three shale zones. A schematic view of the grid is shown in Figure 5-8.

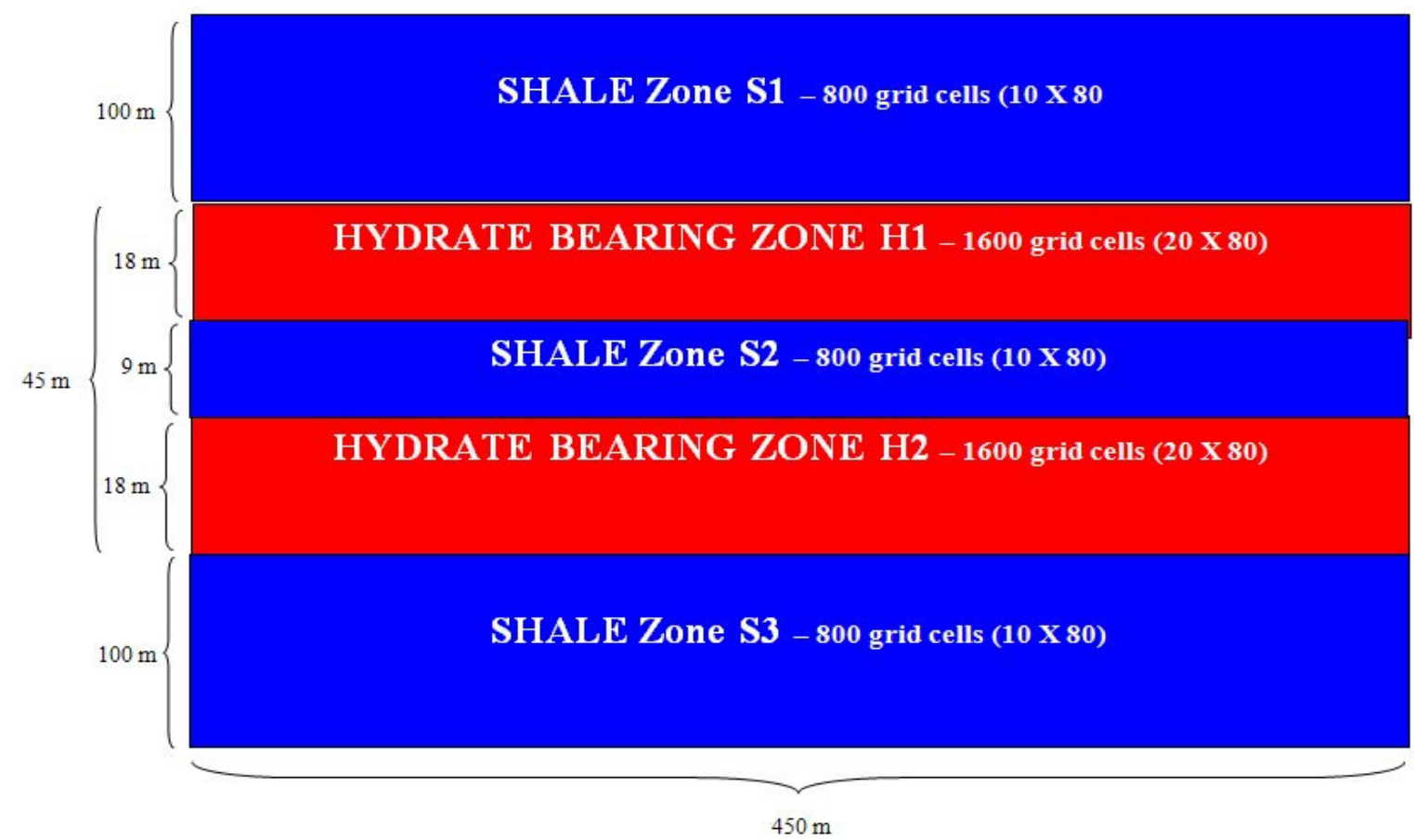

Figure 5- 8 Schematic view of the grid for Problem 7b.

\section{Discretization of the Grid:}

$\boldsymbol{r}$-direction: The radial discretization is same as in Problem 7a.

z-direction: The hydrate bearing zones $(\mathrm{H} 1 \& \mathrm{H} 2)$ and the shale layer between them (S2) are uniformly discretized and the upper and lower shale zones (S1 \& S3) are logarithmically discretized. 
In both of these shale zones, the first grid block (next to the hydrate zone) is the same size as those in the hydrate bearing zone $(0.9 \mathrm{~m})$. For each subsequent cell, the $\mathrm{dz}$ obeys $d z_{\mathrm{i}}=d z_{\mathrm{i}-1} *$ 1.49587 (as one moves away from the hydrate zome). This leads to the following $z$ values given in Table 5-5

Table 5-5 Discretization of the grid in $\mathrm{z}$ direction

\begin{tabular}{|c|c|c|c|}
\hline Cell number & $\mathbf{d z}$ & $\mathbf{z}$ (boundary) & $\begin{array}{c}\mathbf{z} \\
\text { (center) }\end{array}$ \\
\hline 1 & 0.900 & 0.900 & 0.450 \\
2 & 1.346 & 2.246 & 1.573 \\
3 & 2.014 & 4.260 & 3.253 \\
4 & 3.012 & 7.273 & 5.766 \\
5 & 4.506 & 11.779 & 9.526 \\
6 & 6.741 & 18.520 & 15.149 \\
7 & 10.083 & 28.603 & 23.561 \\
8 & 15.083 & 43.686 & 36.145 \\
9 & 22.563 & 66.249 & 54.968 \\
10 & 33.751 & 100.000 & 83.125 \\
\hline
\end{tabular}

\section{Initial Conditions}

\section{Hydrate Saturation and Water Saturation:}

The hydrate saturation in hydrate bearing zones $(\mathrm{H} 1 \& \mathrm{H} 2)$ is $75 \%$ and water saturation is $25 \%$.

In the shale zones (S1, S2 \& S3), there is no hydrate and water saturation is $100 \%$.

\section{Pressure \& Temperature:}

The top of hydrate bearing zone (H1) is $62 \mathrm{~m}$ below the top of the hydrate bearing zone. Pressure temperature of the Hydrate bearing zone are 7.327 MPa and 278.15 K. Pressure and temperature values for each cell are calculated using a hydrostatic pressure gradient of 9792 $\mathrm{Pa} / \mathrm{m}$ and geothermal gradient of $0.03 \mathrm{~K} / \mathrm{m}$ as given in Table $5-6$. 
Table 5-6 Pressure and Temperature values for Problem 7b

\begin{tabular}{|c|c|c|c|c|c|c|c|}
\hline Cell & Region & $\begin{array}{c}\mathrm{Z} \\
\text { (boundary) }\end{array}$ & $\begin{array}{c}\mathrm{Z} \\
\text { (center) }\end{array}$ & $\begin{array}{c}\mathrm{T} \\
\text { (boundary) }\end{array}$ & $\begin{array}{c}\mathbf{T} \\
\text { (center) }\end{array}$ & $\begin{array}{c}\text { P/Mpa } \\
\text { (boundary) }\end{array}$ & $\begin{array}{l}\text { P/MPa } \\
\text { (center) }\end{array}$ \\
\hline & & 0.000 & & 275.150 & & 6.348 & \\
\hline 1 & Shale & 33.751 & 16.875 & 276.163 & 275.656 & 6.678 & 6.513 \\
\hline 2 & Shale & 56.314 & 45.032 & 276.839 & 276.501 & 6.899 & 6.789 \\
\hline 3 & Shale & 71.397 & 63.855 & 277.292 & 277.066 & 7.047 & 6.973 \\
\hline 4 & Shale & 81.480 & 76.439 & 277.594 & 277.443 & 7.146 & 7.096 \\
\hline 5 & Shale & 88.221 & 84.851 & 277.797 & 277.696 & 7.212 & 7.179 \\
\hline 6 & Shale & 92.727 & 90.474 & 277.932 & 277.864 & 7.256 & 7.234 \\
\hline 7 & Shale & 95.740 & 94.234 & 278.022 & 277.977 & 7.285 & 7.271 \\
\hline 8 & Shale & 97.754 & 96.747 & 278.083 & 278.052 & 7.305 & 7.295 \\
\hline 9 & Shale & 99.100 & 98.427 & 278.123 & 278.103 & 7.318 & 7.312 \\
\hline 10 & Shale & 100.000 & 99.550 & 278.150 & 278.137 & 7.327 & 7.323 \\
\hline 11 & Hydrate & 100.900 & 100.450 & 278.177 & 278.164 & 7.336 & 7.331 \\
\hline 12 & Hydrate & 101.800 & 101.350 & 278.204 & 278.191 & 7.345 & 7.340 \\
\hline 13 & Hydrate & 102.700 & 102.250 & 278.231 & 278.218 & 7.353 & 7.349 \\
\hline 14 & Hydrate & 103.600 & 103.150 & 278.258 & 278.245 & 7.362 & 7.358 \\
\hline 15 & Hydrate & 104.500 & 104.050 & 278.285 & 278.272 & 7.371 & 7.367 \\
\hline 16 & Hydrate & 105.400 & 104.950 & 278.312 & 278.299 & 7.380 & 7.375 \\
\hline 17 & Hydrate & 106.300 & 105.850 & 278.339 & 278.326 & 7.389 & 7.384 \\
\hline 18 & Hydrate & 107.200 & 106.750 & 278.366 & 278.353 & 7.398 & 7.393 \\
\hline 19 & Hydrate & 108.100 & 107.650 & 278.393 & 278.380 & 7.406 & 7.402 \\
\hline 20 & Hydrate & 109.000 & 108.550 & 278.420 & 278.407 & 7.415 & 7.411 \\
\hline 21 & Hydrate & 109.900 & 109.450 & 278.447 & 278.434 & 7.424 & 7.420 \\
\hline 22 & Hydrate & 110.800 & 110.350 & 278.474 & 278.461 & 7.433 & 7.428 \\
\hline 23 & Hydrate & 111.700 & 111.250 & 278.501 & 278.488 & 7.442 & 7.437 \\
\hline 24 & Hydrate & 112.600 & 112.150 & 278.528 & 278.515 & 7.450 & 7.446 \\
\hline 25 & Hydrate & 113.500 & 113.050 & 278.555 & 278.542 & 7.459 & 7.455 \\
\hline
\end{tabular}


Table 5-6 (contd....)

\begin{tabular}{|c|c|c|c|c|c|c|c|}
\hline Cell & Region & $\begin{array}{c}\mathrm{Z} \\
\text { (boundary) }\end{array}$ & $\begin{array}{c}\mathrm{Z} \\
\text { (center) }\end{array}$ & $\begin{array}{c}\mathbf{T} \\
\text { (boundary) }\end{array}$ & $\begin{array}{c}\mathbf{T} \\
\text { (center) }\end{array}$ & $\begin{array}{c}\text { P/Mpa } \\
\text { (boundary) }\end{array}$ & $\begin{array}{l}\text { P/MPa } \\
\text { (center) }\end{array}$ \\
\hline 26 & Hydrate & 114.400 & 113.950 & 278.582 & 278.569 & 7.468 & 7.464 \\
\hline 27 & Hydrate & 115.300 & 114.850 & 278.609 & 278.596 & 7.477 & 7.472 \\
\hline 28 & Hydrate & 116.200 & 115.750 & 278.636 & 278.623 & 7.486 & 7.481 \\
\hline 29 & Hydrate & 117.100 & 116.650 & 278.663 & 278.650 & 7.494 & 7.490 \\
\hline 30 & Hydrate & 118.000 & 117.550 & 278.690 & 278.677 & 7.503 & 7.499 \\
\hline 31 & Shale & 118.900 & 118.450 & 278.717 & 278.704 & 7.512 & 7.508 \\
\hline 32 & Shale & 119.800 & 119.350 & 278.744 & 278.731 & 7.521 & 7.516 \\
\hline 33 & Shale & 120.700 & 120.250 & 278.771 & 278.758 & 7.530 & 7.525 \\
\hline 34 & Shale & 121.600 & 121.150 & 278.798 & 278.785 & 7.539 & 7.534 \\
\hline 35 & Shale & 122.500 & 122.050 & 278.825 & 278.812 & 7.547 & 7.543 \\
\hline 36 & Shale & 123.400 & 122.950 & 278.852 & 278.839 & 7.556 & 7.552 \\
\hline 37 & Shale & 124.300 & 123.850 & 278.879 & 278.866 & 7.565 & 7.561 \\
\hline 38 & Shale & 125.200 & 124.750 & 278.906 & 278.893 & 7.574 & 7.569 \\
\hline 45 & Hydrate & 131.500 & 131.050 & 279.095 & 279.082 & 7.635 & 7.631 \\
\hline 46 & Hydrate & 132.400 & 131.950 & 279.122 & 279.109 & 7.644 & 7.640 \\
\hline 47 & Hydrate & 133.300 & 132.850 & 279.149 & 279.136 & 7.653 & 7.649 \\
\hline 48 & Hydrate & 134.200 & 133.750 & 279.176 & 279.163 & 7.662 & 7.657 \\
\hline 49 & Hydrate & 135.100 & 134.650 & 279.203 & 279.190 & 7.671 & 7.666 \\
\hline 50 & Hydrate & 136.000 & 135.550 & 279.230 & 279.217 & 7.680 & 7.675 \\
\hline 51 & Hydrate & 136.900 & 136.450 & 279.257 & 279.244 & 7.688 & 7.684 \\
\hline 52 & Hydrate & 137.800 & 137.350 & 279.284 & 279.271 & 7.697 & 7.693 \\
\hline 53 & Hydrate & 138.700 & 138.250 & 279.311 & 279.298 & 7.706 & 7.702 \\
\hline 54 & Hydrate & 139.600 & 139.150 & 279.338 & 279.325 & 7.715 & 7.710 \\
\hline 55 & Hydrate & 140.500 & 140.050 & 279.365 & 279.352 & 7.724 & 7.719 \\
\hline 56 & Hydrate & 141.400 & 140.950 & 279.392 & 279.379 & 7.732 & 7.728 \\
\hline 57 & Hydrate & 142.300 & 141.850 & 279.419 & 279.406 & 7.741 & 7.737 \\
\hline 58 & Hydrate & 143.200 & 142.750 & 279.446 & 279.433 & 7.750 & 7.746 \\
\hline 59 & Hydrate & 144.100 & 143.650 & 279.473 & 279.460 & 7.759 & 7.754 \\
\hline 60 & Hydrate & 145.000 & 144.550 & 279.500 & 279.487 & 7.768 & 7.763 \\
\hline
\end{tabular}


Table 5-6 (contd....)

\begin{tabular}{|c|l|c|c|c|c|c|c|}
\hline $\mathbf{C e l l}$ & Region & $\begin{array}{c}\mathbf{Z} \\
\text { (boundary) }\end{array}$ & $\begin{array}{c}\mathbf{Z} \\
\text { (center) }\end{array}$ & $\begin{array}{c}\mathbf{T} \\
\text { (boundary) }\end{array}$ & $\begin{array}{c}\mathbf{T} \\
\text { (center) }\end{array}$ & $\begin{array}{c}\text { P/Mpa } \\
\text { (boundary) }\end{array}$ & $\begin{array}{c}\text { P/MPa } \\
\text { (center) }\end{array}$ \\
\hline $\mathbf{6 1}$ & Shale & 145.900 & 145.450 & 279.527 & 279.514 & 7.776 & 7.772 \\
\hline $\mathbf{6 2}$ & Shale & 147.246 & 146.573 & 279.567 & 279.547 & 7.790 & 7.783 \\
\hline $\mathbf{6 3}$ & Shale & 149.260 & 148.253 & 279.628 & 279.598 & 7.809 & 7.799 \\
\hline $\mathbf{6 4}$ & Shale & 152.273 & 150.766 & 279.718 & 279.673 & 7.839 & 7.824 \\
\hline $\mathbf{6 5}$ & Shale & 156.779 & 154.526 & 279.853 & 279.786 & 7.883 & 7.861 \\
\hline $\mathbf{6 6}$ & Shale & 163.520 & 160.149 & 280.056 & 279.954 & 7.949 & 7.916 \\
\hline $\mathbf{6 7}$ & Shale & 173.603 & 168.561 & 280.358 & 280.207 & 8.048 & 7.998 \\
\hline $\mathbf{6 8}$ & Shale & 188.686 & 181.145 & 280.811 & 280.584 & 8.195 & 8.122 \\
\hline $\mathbf{6 9}$ & Shale & 211.249 & 199.968 & 281.487 & 281.149 & 8.416 & 8.306 \\
\hline $\mathbf{7 0}$ & Shale & 245.000 & 228.125 & 282.500 & 281.994 & 8.747 & 8.582 \\
\hline
\end{tabular}

\section{Boundary Conditions:}

There is no net mass transport between the reservoir and the surroundings. The upper boundary temperature is held constant at $275.150 \mathrm{~K}$ and the lower boundary temperature is held at constant at $282.500 \mathrm{~K}$.

\section{Relative Permeability Models:}

A relative permeability model developed by $\mathrm{Stone}^{36}+\mathrm{Aziz}^{37}$ is used in this problem. The parameters were fixed so that every simulator has the same values.

\section{Water Relative Permeability}

$k_{r w}=\left\{\frac{\left(S_{w}-S_{w i r}\right)}{\left(1-S_{W i r}\right)}\right\}^{5.04} ; S_{W i r}=0.10$ 


\section{Gas Relative Permeability}

$k_{r g}=\left\{\frac{\left(S_{G}-S_{G i r}\right)}{\left(1-S_{W i r}\right)}\right\}^{3.16} S_{W i r}=0 . \quad S G_{i r}=0 . S_{W i r}$ and $S_{G i r}$ represents irreducible water and gas saturation. Gas and water relative permeability curves are shown in Figure 5-9.

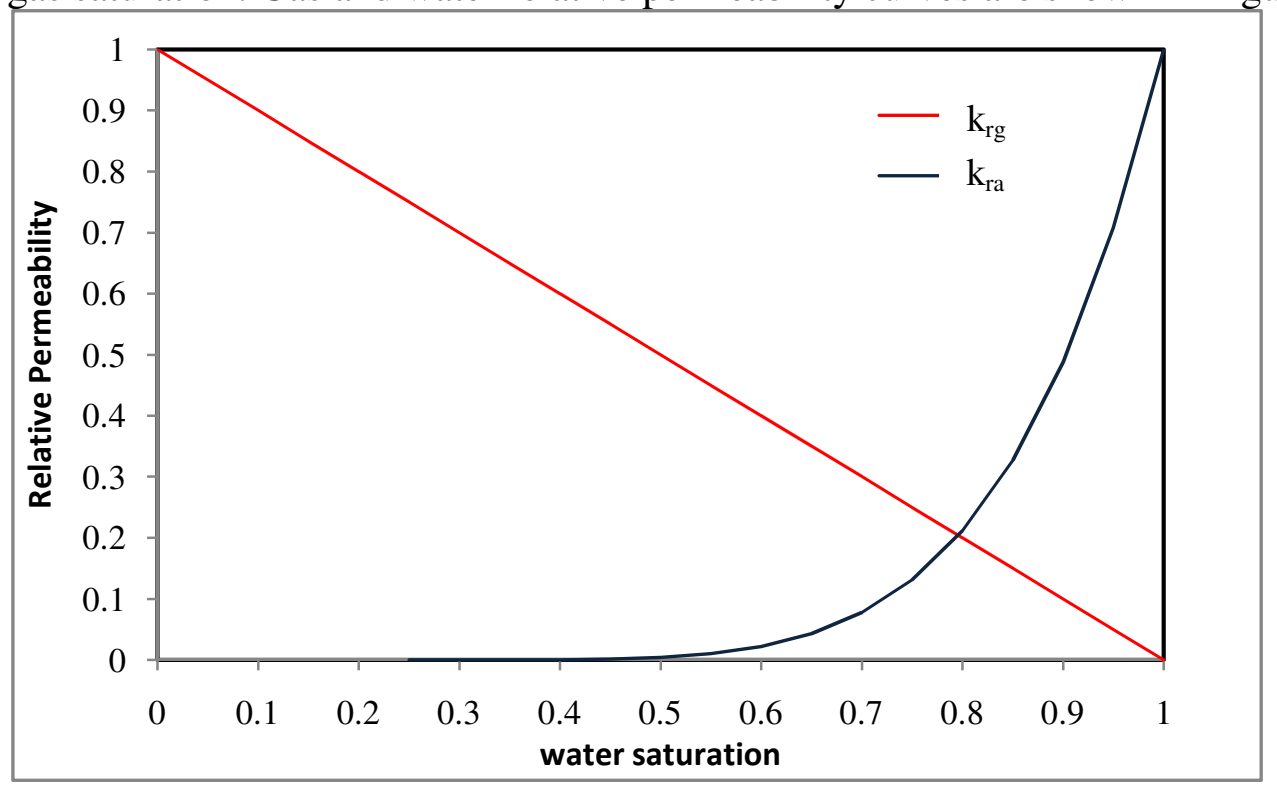

Figure 5- 9 Aqueous and Gas relative Permeability curves for problem $7 \mathrm{~b}$.

\section{Medium properties:}

Medium properties like permeability porosity are specified in Table 5-7

Table 5-7 Medium Properties for Problem 7b

\begin{tabular}{|l|l|}
\hline \multicolumn{1}{|c|}{ Property } & \multicolumn{1}{c|}{ Value } \\
\hline Permeability, $\mathrm{mD}$ & Shale -0.0 \\
\cline { 2 - 2 } & Hydrate layer - 1000 (r direction) \\
\cline { 2 - 2 } & Hydrate layer - 100 (z direction) \\
\hline Porosity, \% & Shale - 10 \\
\cline { 2 - 2 } & Hydrate zone - 35 \\
\hline Pore Compressibility $(1 / \mathrm{Pa})$ & $1.00 \mathrm{E}-08$ \\
\hline Rock Density $\left(\mathrm{kg} / \mathrm{m}^{3}\right)$ & 2650 \\
\hline Rock Specific Heat $(\mathrm{J} / \mathrm{kg} / \mathrm{K})$ & 1000 \\
\hline
\end{tabular}




\section{Capillary Pressure Model:}

The capillary Pressure Model used in this problem is the same as in Problem 7a.

\section{Well Information:}

The wellbore Radius is selected to be $0.111 \mathrm{~m}$. The bottom- hole pressure is chosen to be

2.7MPa to avoid ice formation in the system.

\section{Data and Sampling Frequency:}

The simulations are carried out until all the hydrate dissociates and equilibrium is reached or over a time period of 50 years. Data for gas production rate, water production rate, cumulative gas production and cumulative water production is recorded with a frequency of 90 days for 50 years. 


\subsubsection{Solution to Problem 7b}

The grid description in this problem is different from Problem 7a.

The grid has two hydrate layers bounded by shale zones. The discretization in the $r$ direction is same as in 7a but is different in the $\mathrm{z}$ direction. Porosity, permeability and rock fluid properties are specified as per the problem description. The properties that are same as in Problem $7 \mathrm{a}$ are not included in the data file given below.

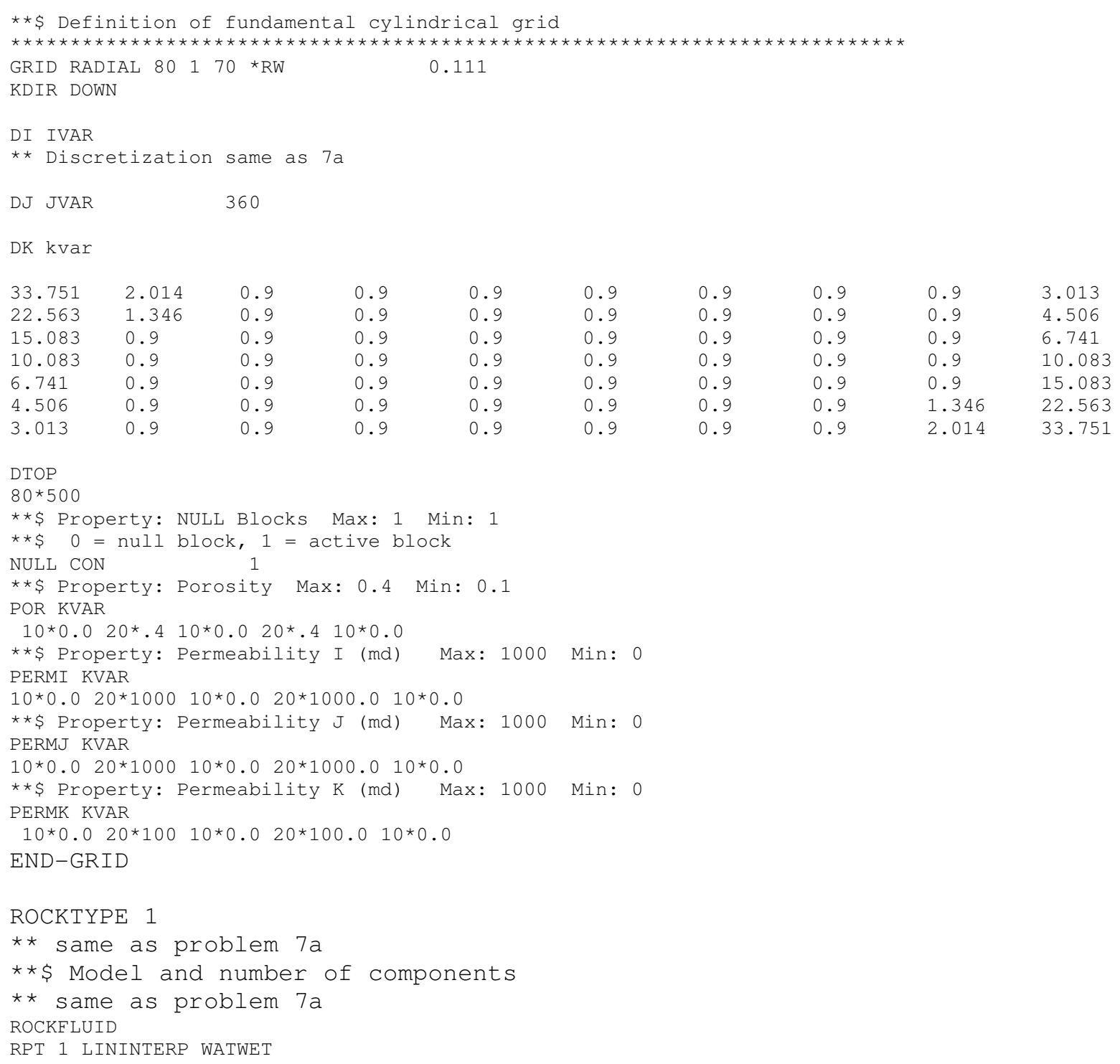




\begin{tabular}{|c|c|c|c|c|}
\hline $\begin{array}{l}\star \star \text { SW } \\
\text { SWT }\end{array}$ & KRW & KROW & ** & \\
\hline \multirow[t]{20}{*}{$\star \star \$$} & Sw & $\mathrm{krw}$ & krow & Pcow \\
\hline & 0.1 & 0 & 0.00000008 & 599.3754829 \\
\hline & 0.15 & $4.7144 \mathrm{E}-07$ & 0.00000007 & 599.3754829 \\
\hline & 0.2 & $1.55102 \mathrm{E}-05$ & 0.00000007 & 599.3754829 \\
\hline & 0.248 & 0.000111876 & 0.00000007 & 599.3754829 \\
\hline & 0.3 & 0.00051028 & 0.00000007 & 599.3754829 \\
\hline & 0.35 & 0.001571214 & 0.00000006 & 481.4413657 \\
\hline & 0.4 & 0.003938301 & 0.00000005 & 419.5019542 \\
\hline & 0.45 & 0.008564868 & 0.00000004 & 375.2776708 \\
\hline & 0.5 & 0.016788044 & 0.00000003 & 340.2284612 \\
\hline & 0.55 & 0.030395467 & 0.00000002 & 310.8987242 \\
\hline & 0.6 & 0.051692385 & 0.00000001 & 285.5166471 \\
\hline & 0.65 & 0.083569097 & 0.000000009 & 263.0426992 \\
\hline & 0.7 & 0.129568686 & 0.000000008 & 242.8106796 \\
\hline & 0.75 & 0.19395504 & 0.000000007 & 224.3660077 \\
\hline & 0.8 & 0.281781109 & 0.000000006 & 207.3835797 \\
\hline & 0.85 & 0.398957395 & 0.000000005 & 191.6222293 \\
\hline & 0.9 & 0.552320658 & 0.000000004 & 176.8977346 \\
\hline & 0.95 & 0.749702809 & 0.000000003 & 163.0659502 \\
\hline & 1 & & 0 & 150.0118032 \\
\hline
\end{tabular}

** SL $\quad$ KRG $\quad$ KROG $\quad$ PCOG

**\$ $\quad \mathrm{Sl} \quad \mathrm{krg} \quad \mathrm{krog} \quad$ Pcog

$\begin{array}{lll}0.29375 & 0.333202872\end{array}$

$0.340625 \quad 0.26819991$

$\begin{array}{ll}0.3875 & 0.212449275\end{array}$

$0.434375 \quad 0.165192515$

$0.48125 \quad 0.125680421$

$0.528125 \quad 0.093173674$

$0.575 \quad 0.066943593$

$0.621875 \quad 0.046273019$

$0.66875 \quad 0.030457384$

$0.715625 \quad 0.018806019$

$0.7625 \quad 0.010643808$

$\begin{array}{lll}0.809375 & 0.005313349 & 0.00000006\end{array}$

$\begin{array}{lll}0.85625 & 0.002177914 & 0.00000007\end{array}$

$0.903125 \quad 0.0006257910 .00000008$

$0.95 \quad 7.74008 \mathrm{E}-05 \quad 0.00000008$

1

0

0.00000008

$P C O g$
0
0
0
0
0
0
0
0
0
0
0
0
0
0
0
0

**\$ Property: Rel Perm Set Number Max: 1 Min: 1

KRTYPE IVAR $80 * 1$

INITIAL

VERTICAL OFF

The pressure, temperature and saturations are specified as per the problem description. Well

conditions are same as per the previous problem.

INITREGION 1

**\$ Property: Pressure (kPa) Max: 7387 Min: 6176

PRES KVAR

$\begin{array}{llllllllll}6513 & 7295 & 7367 & 7428 & 7490 & 7552 & 7613 & 7675 & 7737 & 7824 \\ 6789 & 7312 & 7375 & 7437 & 7499 & 7561 & 7622 & 7684 & 7746 & 7861 \\ 6973 & 7323 & 7384 & 7446 & 7508 & 7569 & 7631 & 7693 & 7754 & 7916 \\ 7096 & 7331 & 7393 & 7455 & 7516 & 7578 & 7640 & 7702 & 7763 & 7998 \\ 7179 & 7340 & 7402 & 7464 & 7525 & 7587 & 7649 & 7710 & 7772 & 8122 \\ 7234 & 7349 & 7411 & 7472 & 7534 & 7596 & 7657 & 7719 & 7783 & 8306 \\ 7271 & 7358 & 7420 & 7481 & 7543 & 7605 & 7666 & 7728 & 7799 & 8582\end{array}$




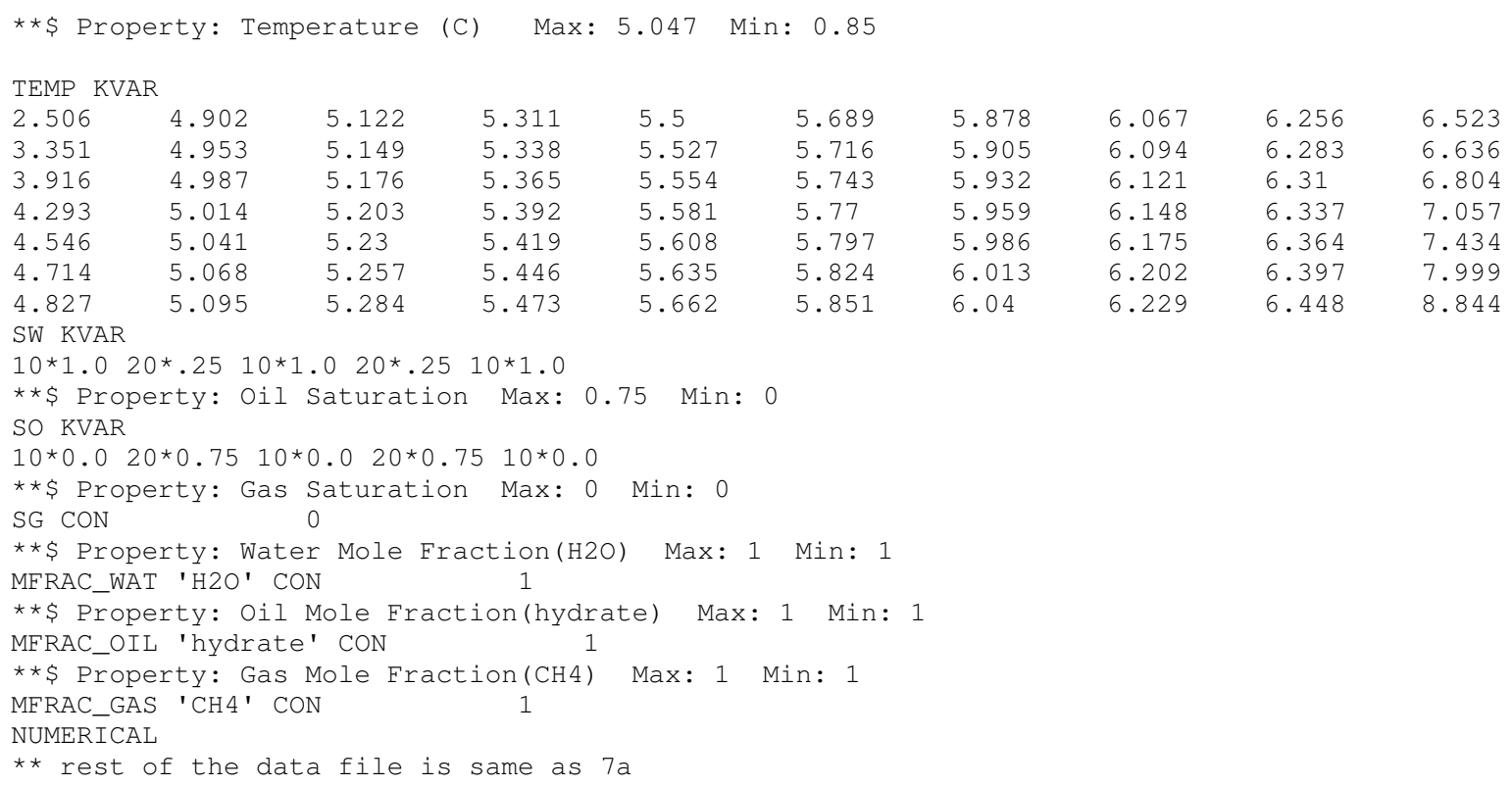

The gas rate and cumulative gas rates for CMG STARS are in good agreement with other codes. This reservoir is warmer than the previous case leading to higher production rates.

Figure 5-10 and Figure 5-11 shows cumulative gas and gas rates for CMG STARS and MH21. Cumulative water and water rate are given in Figure 5-12 and 5-13.

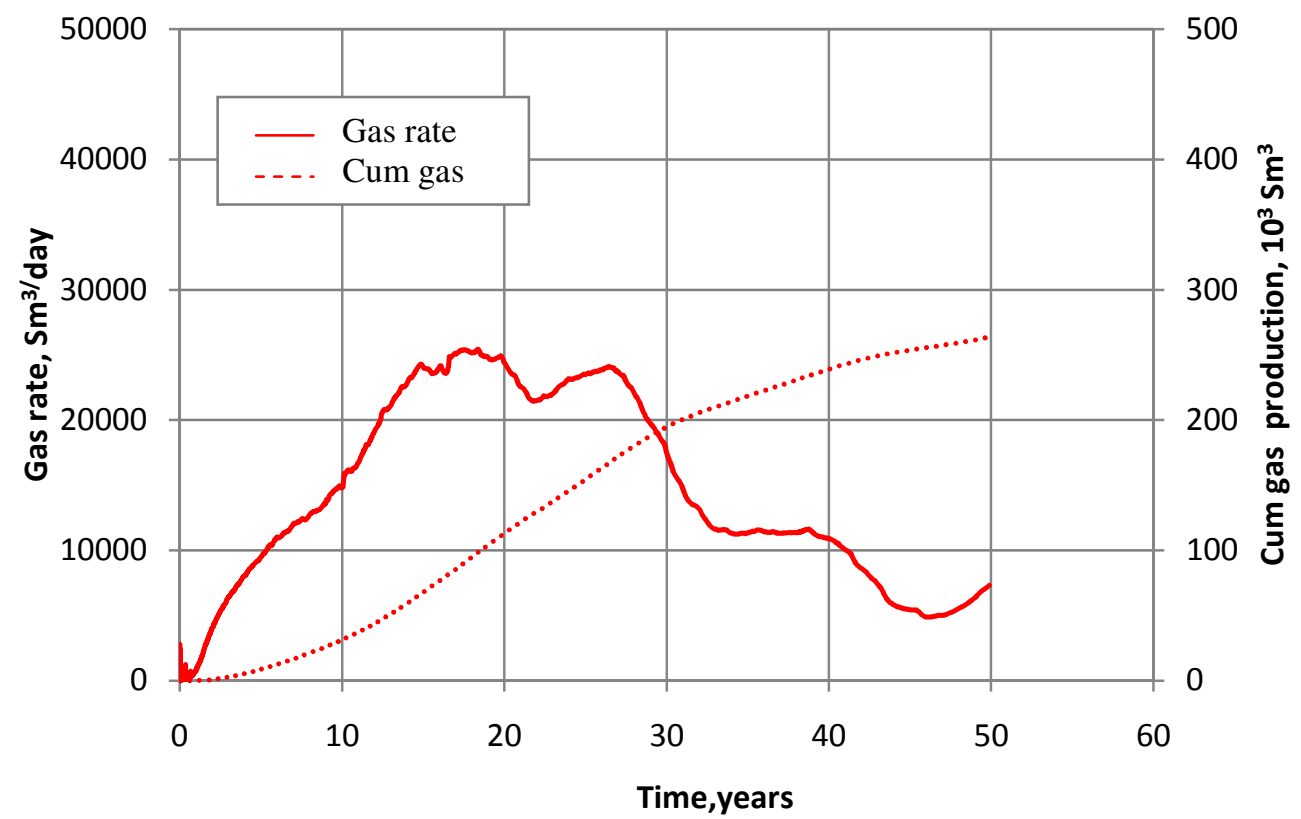

Figure 5-10 Gas rate and cumulative gas rate for 50 years using CMG STARS 


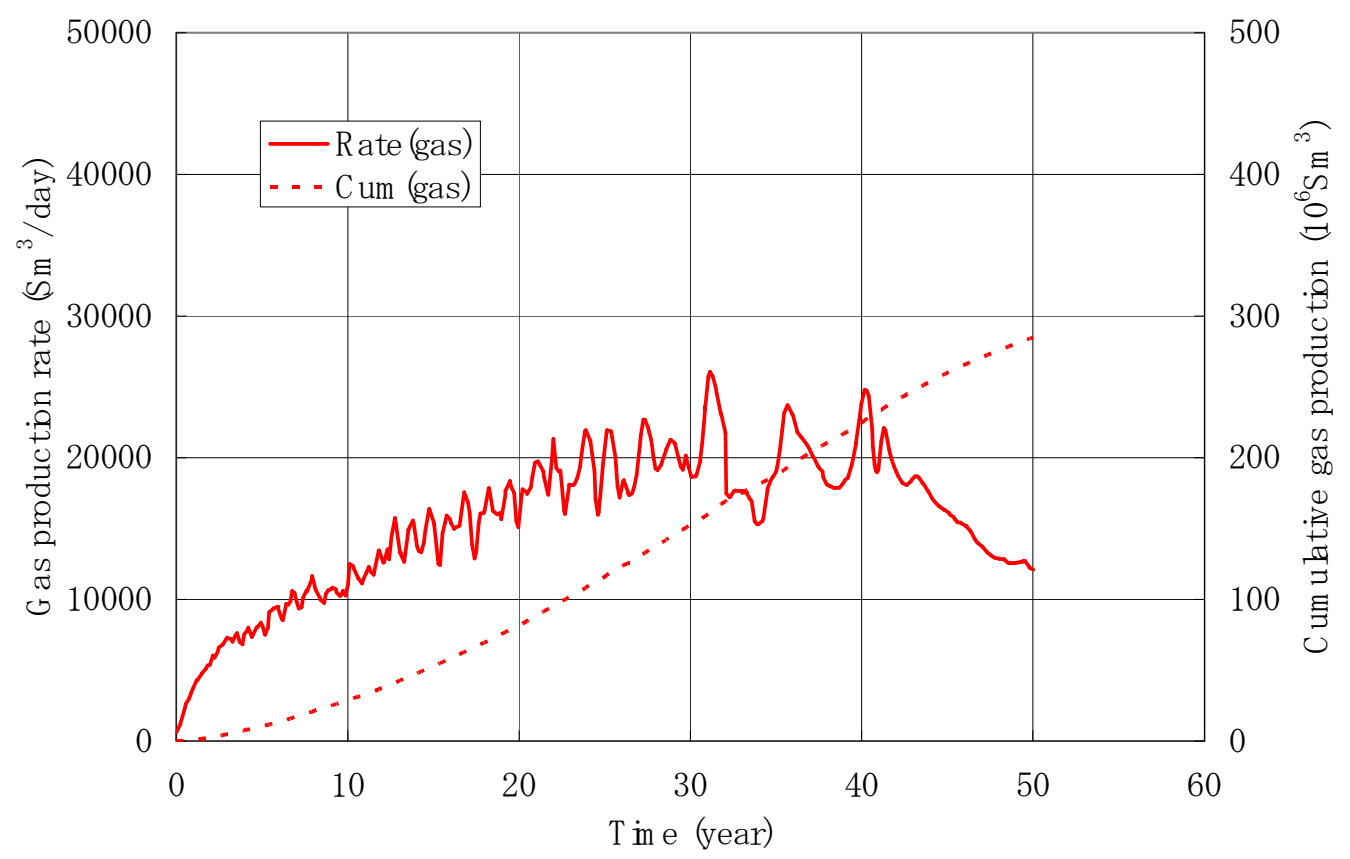

Figure 5-11 Gas rate and cumulative gas rate for 50 years using MH21

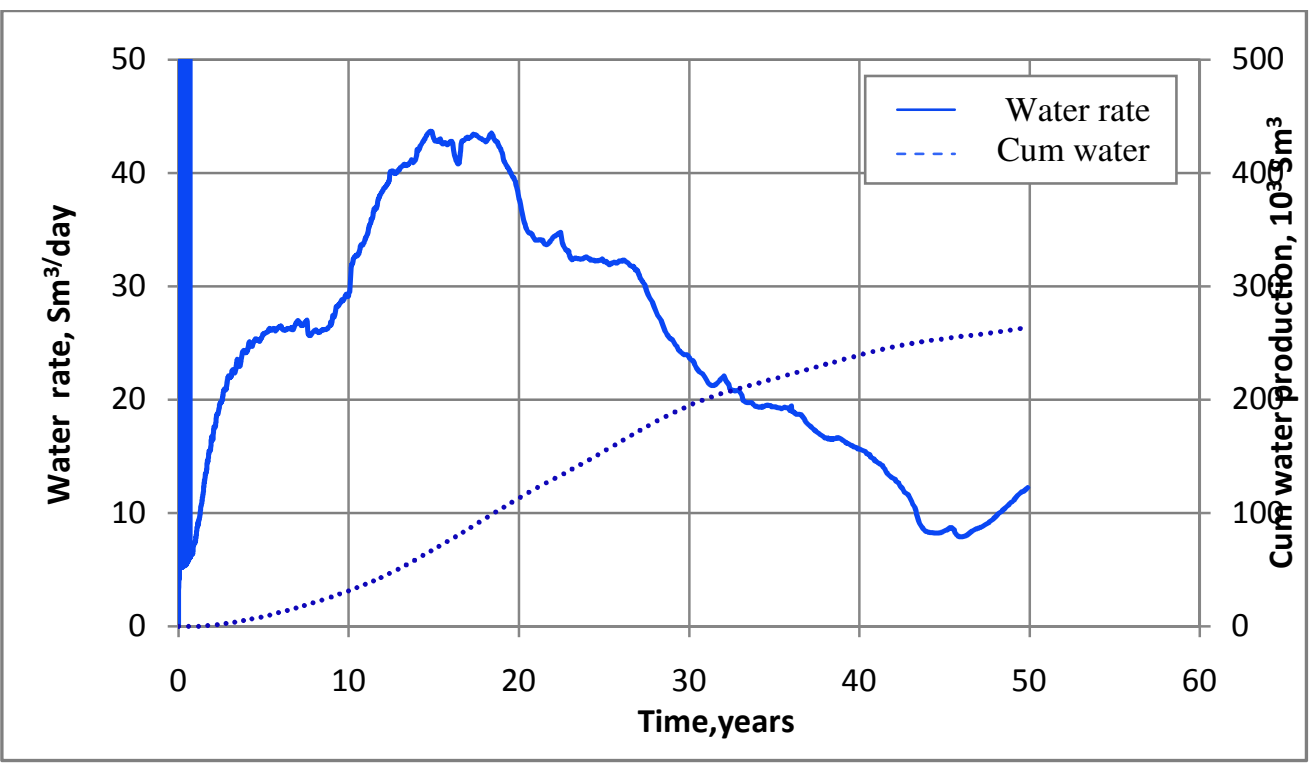

Figure 5-12 Water rate and cumulative water rate for 50 years using CMG STARS 


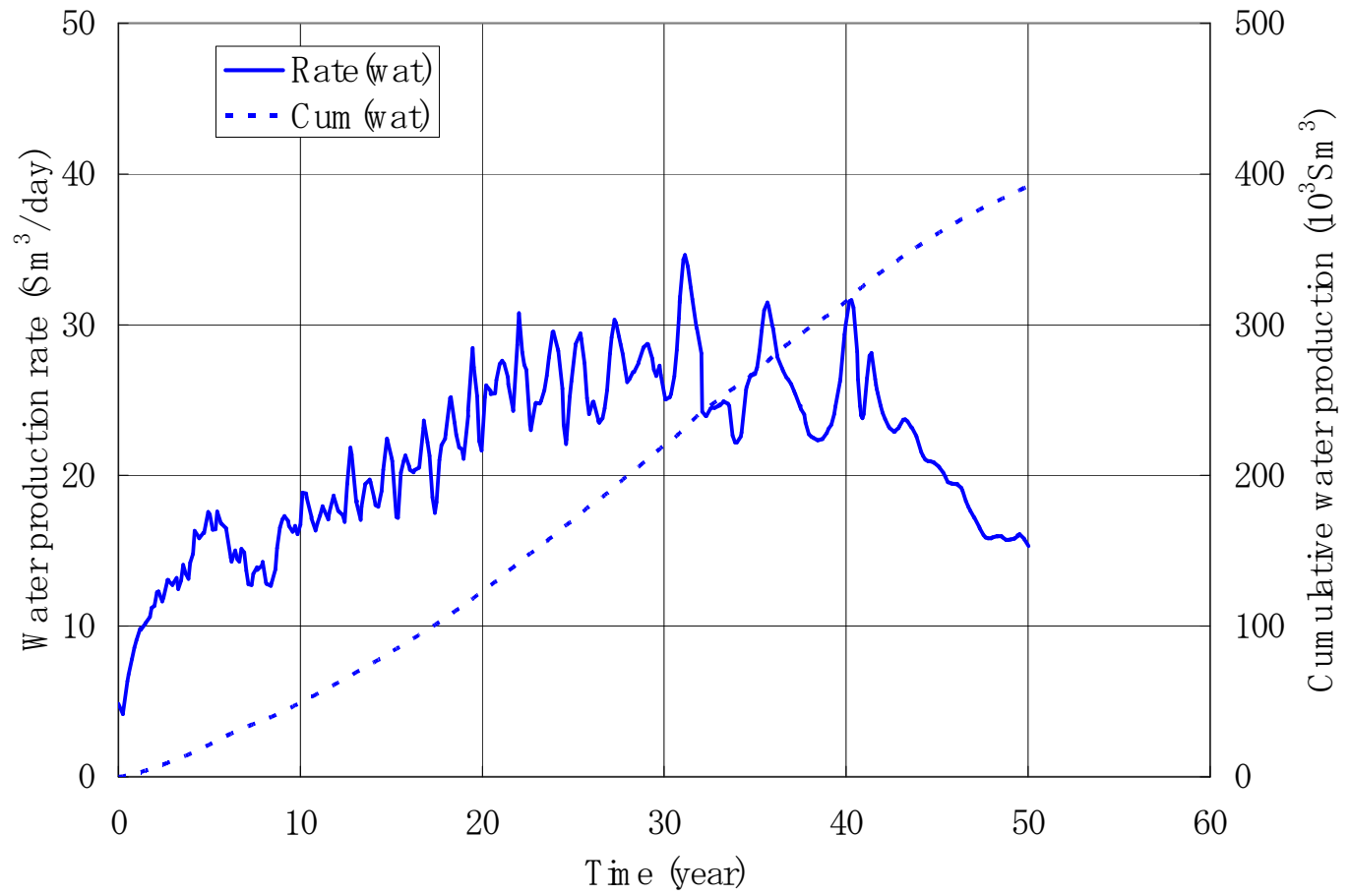

Figure 5-13 Water rate and cumulative water rate for 50 years using MH21 


\subsection{Problem 7c}

Reservoir grid in this problem is same as in Problem 7b. All Parameters and conditions are the same as problem $7 \mathrm{~b}$ except those that are modified are discussed in this part of the study.

Boundary Conditions: There is no net mass transport between the reservoir and the surroundings. The upper boundary temperature is held constant at $280.800 \mathrm{~K}$ and the lower boundary temperature is held at constant at $288.150 \mathrm{~K}$.

Initial Conditions: A reservoir warmer than in previous cases is considered in this problem. The pressure and temperature of the bottom of the hydrate bearing zone are chosen as $12^{\circ} \mathrm{C}$ and 9.1 MPa. These high values are chosen considering the base of the hydrate stability zone. Pressure and temperature values of the entire reservoir are calculated based on the gradients specified in Problem 7b.

Table 5-8 Pressure and Temperature values for Problem 7c

\begin{tabular}{|l|l|c|c|c|c|c|c|}
\hline Cell & Region & $\begin{array}{c}\mathbf{Z} \\
\text { (boundary) }\end{array}$ & $\begin{array}{c}\mathbf{Z} \\
\text { (center) }\end{array}$ & $\begin{array}{c}\mathbf{T} \\
\text { (boundary) }\end{array}$ & $\begin{array}{c}\mathbf{T} \\
\text { (center) }\end{array}$ & $\begin{array}{c}\text { P/MPa } \\
\text { (boundary) }\end{array}$ & $\begin{array}{c}\text { P/MPa } \\
\text { (center) }\end{array}$ \\
\hline & & $\mathbf{0 . 0 0 0}$ & & 280.800 & & 7.680 & \\
\hline $\mathbf{1}$ & Shale & 33.751 & 16.875 & 281.813 & 281.306 & 8.011 & 7.845 \\
\hline $\mathbf{2}$ & Shale & 56.314 & 45.032 & 282.489 & 282.151 & 8.232 & 8.121 \\
\hline $\mathbf{3}$ & Shale & 71.397 & 63.855 & 282.942 & 282.716 & 8.379 & 8.305 \\
\hline $\mathbf{4}$ & Shale & 81.480 & 76.439 & 283.244 & 283.093 & 8.478 & 8.429 \\
\hline $\mathbf{5}$ & Shale & 88.221 & 84.851 & 283.447 & 283.346 & 8.544 & 8.511 \\
\hline $\mathbf{6}$ & Shale & 92.727 & 90.474 & 283.582 & 283.514 & 8.588 & 8.566 \\
\hline $\mathbf{7}$ & Shale & 95.740 & 94.234 & 283.672 & 283.627 & 8.618 & 8.603 \\
\hline $\mathbf{8}$ & Shale & 97.754 & 96.747 & 283.733 & 283.702 & 8.637 & 8.628 \\
\hline $\mathbf{9}$ & Shale & 99.100 & 98.427 & 283.773 & 283.753 & 8.651 & 8.644 \\
\hline
\end{tabular}


Table 5-8 (contd....)

\begin{tabular}{|c|c|c|c|c|c|c|c|}
\hline Cell & Region & $\begin{array}{c}\mathrm{Z} \\
\text { (boundary) }\end{array}$ & $\begin{array}{c}\mathrm{Z} \\
\text { (center) }\end{array}$ & $\begin{array}{c}\mathrm{T} \\
\text { (boundary) }\end{array}$ & $\begin{array}{c}\mathbf{T} \\
\text { (center) }\end{array}$ & $\begin{array}{c}\text { P/MPa } \\
\text { (boundary) }\end{array}$ & $\begin{array}{l}\text { P/MPa } \\
\text { (center) }\end{array}$ \\
\hline 11 & Hydrate & 100.900 & 100.450 & 283.827 & 283.814 & 8.668 & 8.664 \\
\hline 12 & Hydrate & 101.800 & 101.350 & 283.854 & 283.841 & 8.677 & 8.673 \\
\hline 13 & Hydrate & 102.700 & 102.250 & 283.881 & 283.868 & 8.686 & 8.681 \\
\hline 14 & Hydrate & 103.600 & 103.150 & 283.908 & 283.895 & 8.695 & 8.690 \\
\hline 15 & Hydrate & 104.500 & 104.050 & 283.935 & 283.922 & 8.703 & 8.699 \\
\hline 16 & Hydrate & 105.400 & 104.950 & 283.962 & 283.949 & 8.712 & 8.708 \\
\hline 17 & Hydrate & 106.300 & 105.850 & 283.989 & 283.976 & 8.721 & 8.717 \\
\hline 18 & Hydrate & 107.200 & 106.750 & 284.016 & 284.003 & 8.730 & 8.725 \\
\hline 19 & Hydrate & 108.100 & 107.650 & 284.043 & 284.030 & 8.739 & 8.734 \\
\hline 20 & Hydrate & 109.000 & 108.550 & 284.070 & 284.057 & 8.747 & 8.743 \\
\hline 21 & Hydrate & 109.900 & 109.450 & 284.097 & 284.084 & 8.756 & 8.752 \\
\hline 22 & Hydrate & 110.800 & 110.350 & 284.124 & 284.111 & 8.765 & 8.761 \\
\hline 23 & Hydrate & 111.700 & 111.250 & 284.151 & 284.138 & 8.774 & 8.770 \\
\hline 24 & Hydrate & 112.600 & 112.150 & 284.178 & 284.165 & 8.783 & 8.778 \\
\hline 25 & Hydrate & 113.500 & 113.050 & 284.205 & 284.192 & 8.792 & 8.787 \\
\hline 26 & Hydrate & 114.400 & 113.950 & 284.232 & 284.219 & 8.800 & 8.796 \\
\hline 27 & Hydrate & 115.300 & 114.850 & 284.259 & 284.246 & 8.809 & 8.805 \\
\hline 28 & Hydrate & 116.200 & 115.750 & 284.286 & 284.273 & 8.818 & 8.814 \\
\hline 29 & Hydrate & 117.100 & 116.650 & 284.313 & 284.300 & 8.827 & 8.822 \\
\hline 30 & Hydrate & 118.000 & 117.550 & 284.340 & 284.327 & 8.836 & 8.831 \\
\hline 31 & Shale & 118.900 & 118.450 & 284.367 & 284.354 & 8.844 & 8.840 \\
\hline 32 & Shale & 119.800 & 119.350 & 284.394 & 284.381 & 8.853 & 8.849 \\
\hline 33 & Shale & 120.700 & 120.250 & 284.421 & 284.408 & 8.862 & 8.858 \\
\hline 34 & Shale & 121.600 & 121.150 & 284.448 & 284.435 & 8.871 & 8.866 \\
\hline 35 & Shale & 122.500 & 122.050 & 284.475 & 284.462 & 8.880 & 8.875 \\
\hline 36 & Shale & 123.400 & 122.950 & 284.502 & 284.489 & 8.888 & 8.884 \\
\hline 37 & Shale & 124.300 & 123.850 & 284.529 & 284.516 & 8.897 & 8.893 \\
\hline 38 & Shale & 125.200 & 124.750 & 284.556 & 284.543 & 8.906 & 8.902 \\
\hline 39 & Shale & 126.100 & 125.650 & 284.583 & 284.570 & 8.915 & 8.911 \\
\hline
\end{tabular}


Table 5-8 (contd....)

\begin{tabular}{|c|c|c|c|c|c|c|c|}
\hline Cell & Region & $\begin{array}{c}\mathrm{Z} \\
\text { (boundary) }\end{array}$ & $\begin{array}{c}\mathbf{Z} \\
\text { (center) }\end{array}$ & $\begin{array}{c}\mathbf{T} \\
\text { (boundary) }\end{array}$ & $\begin{array}{c}\mathbf{T} \\
\text { (center) }\end{array}$ & $\begin{array}{c}\text { P/MPa } \\
\text { (boundary) }\end{array}$ & $\begin{array}{l}\text { P/MPa } \\
\text { (center) }\end{array}$ \\
\hline 40 & Shale & 127.000 & 126.550 & 284.610 & 284.597 & 8.924 & 8.919 \\
\hline 41 & Hydrate & 127.900 & 127.450 & 284.637 & 284.624 & 8.933 & 8.928 \\
\hline 42 & Hydrate & 128.800 & 128.350 & 284.664 & 284.651 & 8.941 & 8.937 \\
\hline 43 & Hydrate & 129.700 & 129.250 & 284.691 & 284.678 & 8.950 & 8.946 \\
\hline 44 & Hydrate & 130.600 & 130.150 & 284.718 & 284.705 & 8.959 & 8.955 \\
\hline 45 & Hydrate & 131.500 & 131.050 & 284.745 & 284.732 & 8.968 & 8.963 \\
\hline 46 & Hydrate & 132.400 & 131.950 & 284.772 & 284.759 & 8.977 & 8.972 \\
\hline 47 & Hydrate & 133.300 & 132.850 & 284.799 & 284.786 & 8.985 & 8.981 \\
\hline 48 & Hydrate & 134.200 & 133.750 & 284.826 & 284.813 & 8.994 & 8.990 \\
\hline 49 & Hydrate & 135.100 & 134.650 & 284.853 & 284.840 & 9.003 & 8.999 \\
\hline 50 & Hydrate & 136.000 & 135.550 & 284.880 & 284.867 & 9.012 & 9.007 \\
\hline 51 & Hydrate & 136.900 & 136.450 & 284.907 & 284.894 & 9.021 & 9.016 \\
\hline 52 & Hydrate & 137.800 & 137.350 & 284.934 & 284.921 & 9.029 & 9.025 \\
\hline 53 & Hydrate & 138.700 & 138.250 & 284.961 & 284.948 & 9.038 & 9.034 \\
\hline 54 & Hydrate & 139.600 & 139.150 & 284.988 & 284.975 & 9.047 & 9.043 \\
\hline 55 & Hydrate & 140.500 & 140.050 & 285.015 & 285.002 & 9.056 & 9.052 \\
\hline 56 & Hydrate & 141.400 & 140.950 & 285.042 & 285.029 & 9.065 & 9.060 \\
\hline 57 & Hydrate & 142.300 & 141.850 & 285.069 & 285.056 & 9.074 & 9.069 \\
\hline 58 & Hydrate & 143.200 & 142.750 & 285.096 & 285.083 & 9.082 & 9.078 \\
\hline 59 & Hydrate & 144.100 & 143.650 & 285.123 & 285.110 & 9.091 & 9.087 \\
\hline 60 & Hydrate & 145.000 & 144.550 & 285.150 & 285.137 & 9.100 & 9.096 \\
\hline 61 & Shale & 145.900 & 145.450 & 285.177 & 285.164 & 9.109 & 9.104 \\
\hline 62 & Shale & 147.246 & 146.573 & 285.217 & 285.197 & 9.122 & 9.115 \\
\hline 63 & Shale & 149.260 & 148.253 & 285.278 & 285.248 & 9.142 & 9.132 \\
\hline 64 & Shale & 152.273 & 150.766 & 285.368 & 285.323 & 9.171 & 9.156 \\
\hline 65 & Shale & 156.779 & 154.526 & 285.503 & 285.436 & 9.215 & 9.193 \\
\hline 66 & Shale & 163.520 & 160.149 & 285.706 & 285.604 & 9.281 & 9.248 \\
\hline 67 & Shale & 173.603 & 168.561 & 286.008 & 285.857 & 9.380 & 9.331 \\
\hline 68 & Shale & 188.686 & 181.145 & 286.461 & 286.234 & 9.528 & 9.454 \\
\hline 69 & Shale & 211.249 & 199.968 & 287.137 & 286.799 & 9.749 & 9.638 \\
\hline 70 & Shale & 245.000 & 228.125 & 288.150 & 287.644 & 10.079 & 9.914 \\
\hline
\end{tabular}


Permeability models, Capillary pressure model, medium properties, well specifications, data and sampling frequency are same as in Problem $7 \mathrm{~b}$.

\subsubsection{Solution to Problem 7c}

A warmer reservoir is considered in this problem. Pressure, temperature, saturations are different from the previous case. Every other property including grid and well properties are same as Problem 7b. Only the parameters that need to be changed and that are different from the previous problem are specified below.

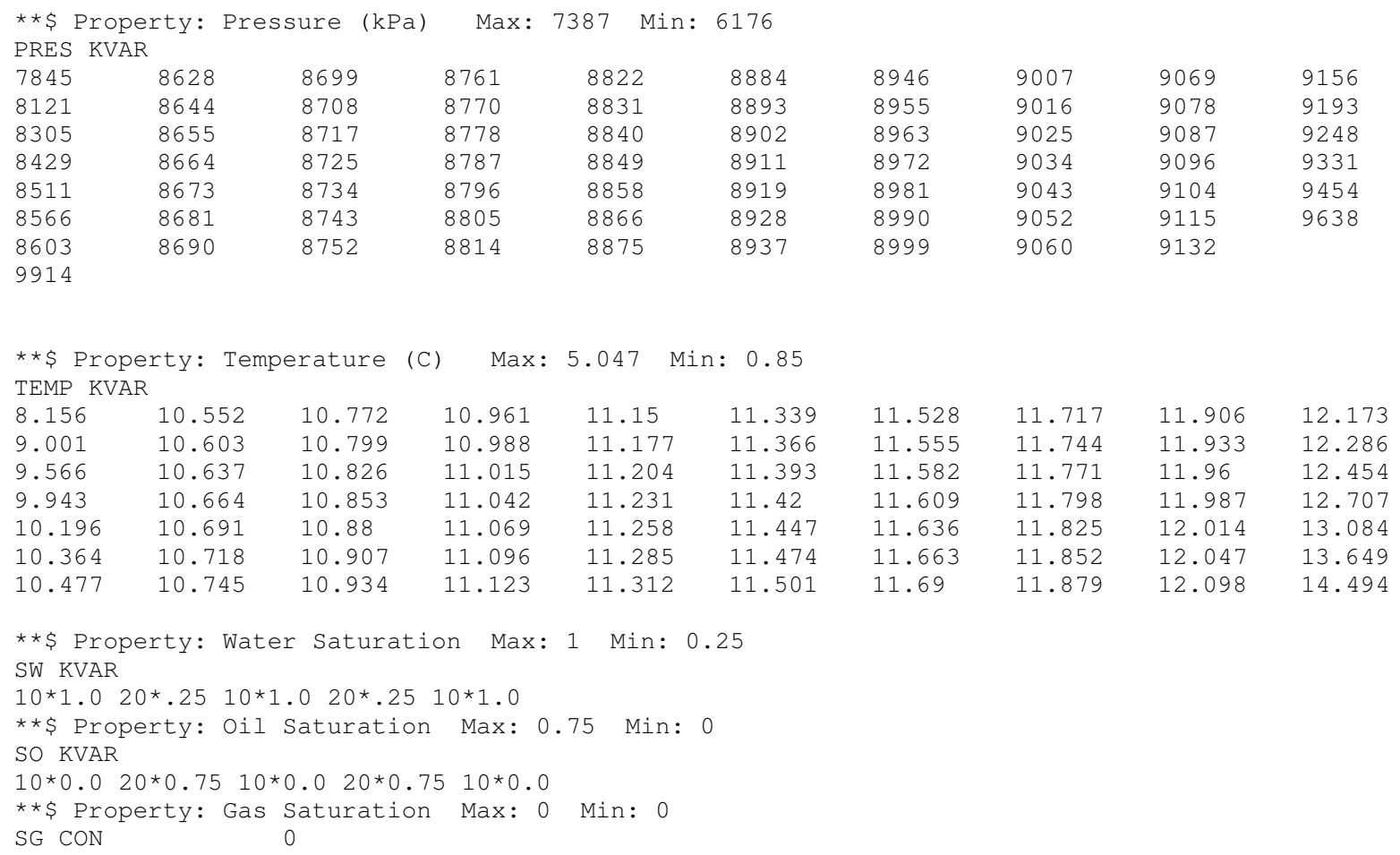


Gas rate and cumulative gas rates shows good agreement with other codes

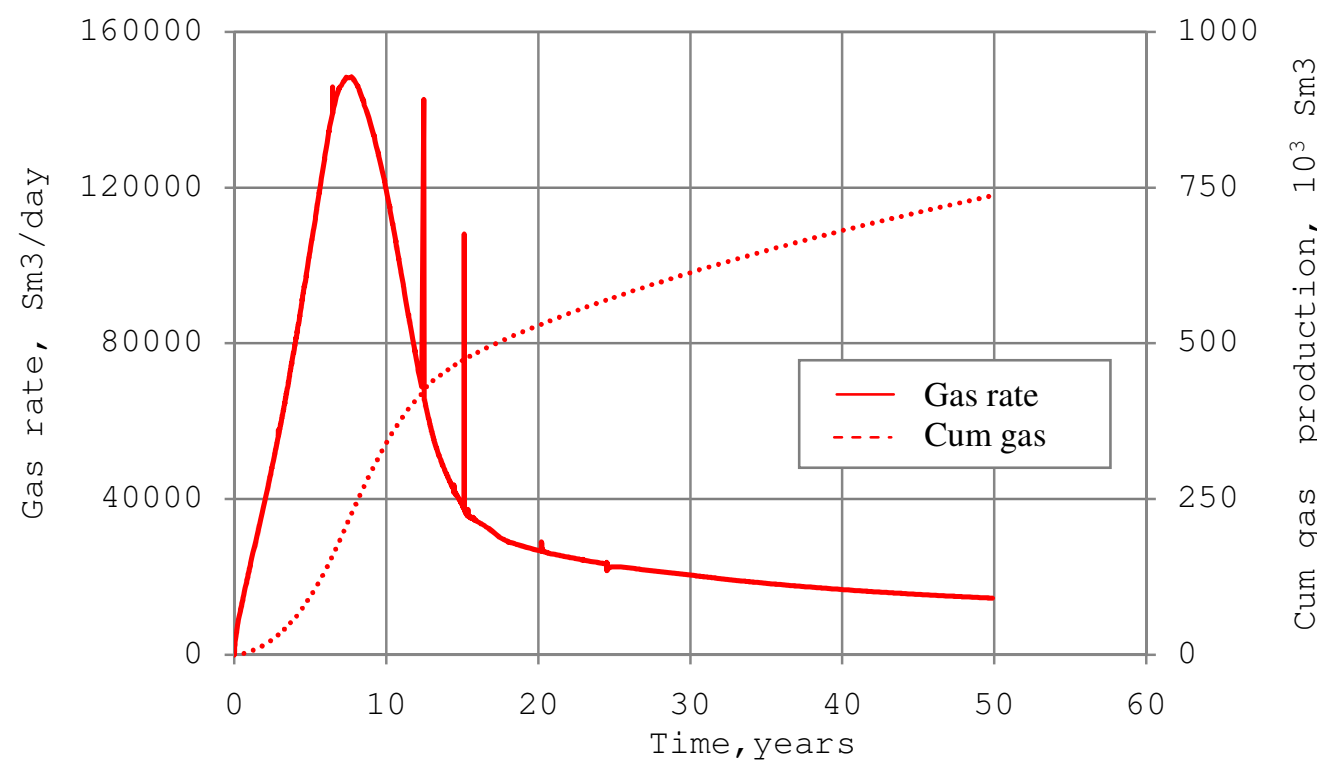

Figure 5-14 Gas rate and cumulative gas production for 50 years using CMG STARS

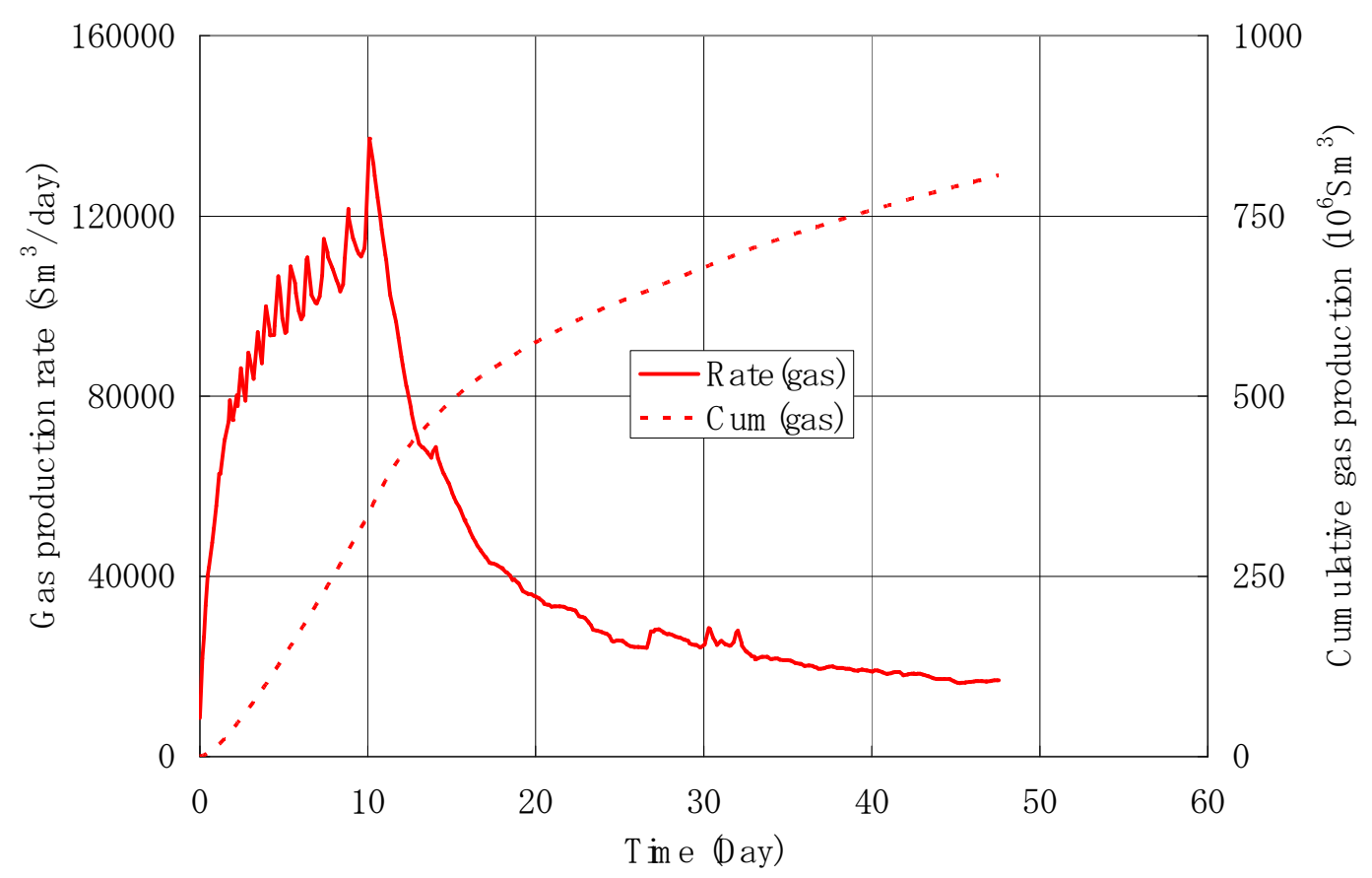

Figure 5-15 Gas production rate and cumulative gas production for 50 years using MH21 


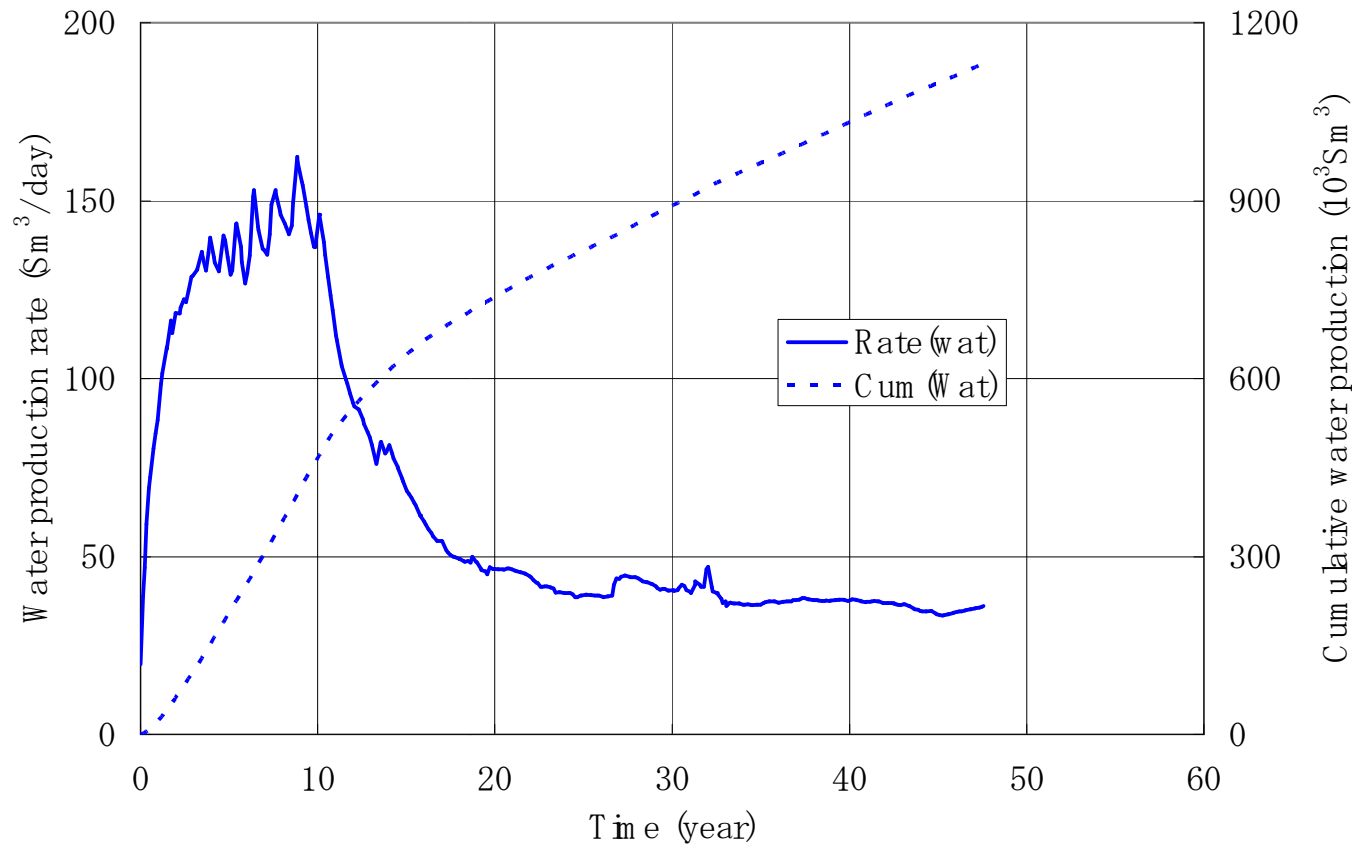

Figure 5-16 Water rate and Cumulative water production for 50 years using MH21

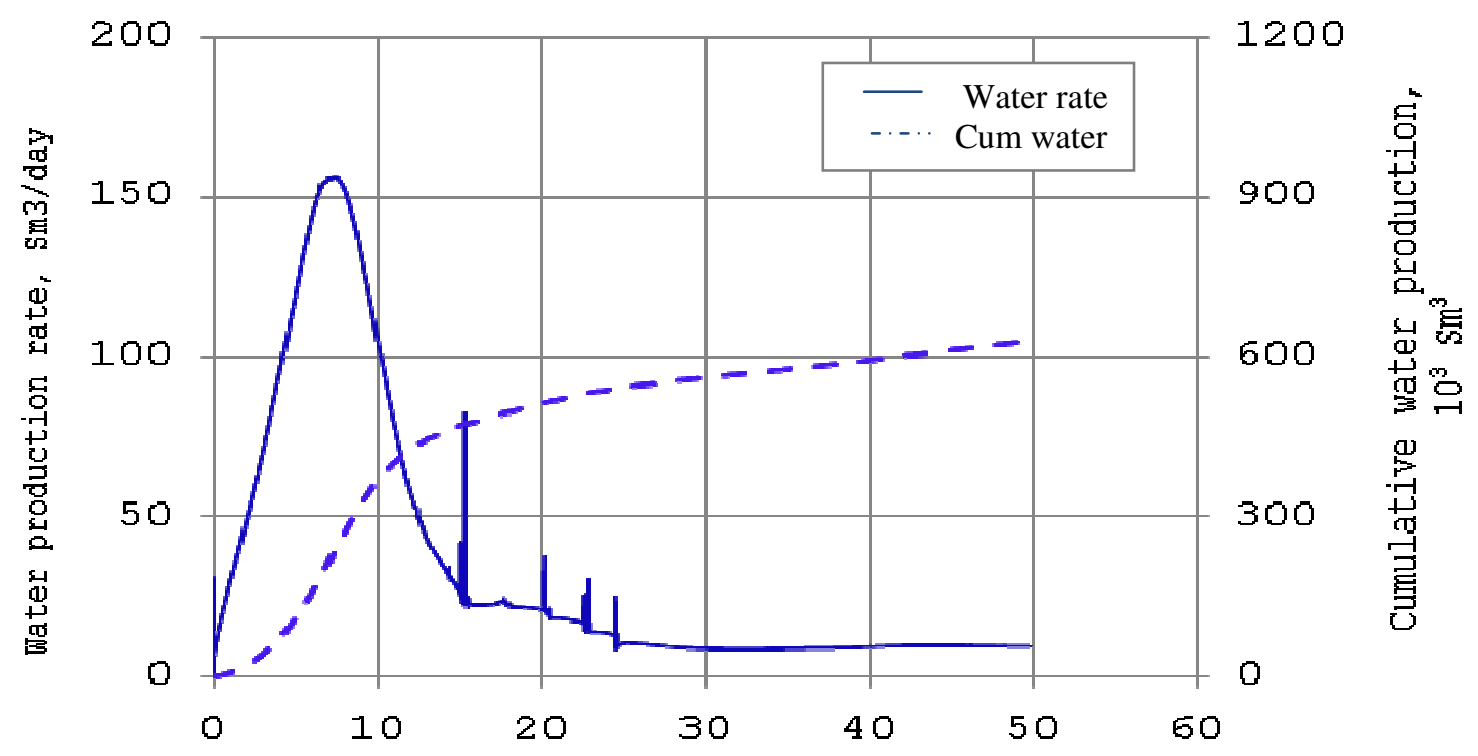

Figure 5-17 Water rate and Cumulative water production for 50 years using CMG STARS 


\section{Sensitivity Analysis of Reservoir Parameters}

Typically in a reservoir simulation, all the parameters are recalculated for every time step. Various parameters influence the production of gas from methane hydrates. If the production rates are correlated parametrically, the correlation can be generalized and can be applied to another situation with much more confidence. This could potentially save time and money. Sensitivity analysis helps in reaching a consensus on such a correlation. That is why sensitivity analysis for this case is considered important.

Sensitivity analysis is done to systematically prove the relative importance of the model's parameters, here in this case the simulation's parameters. It highlights the impact of independent variables on a dependent variable. There are many universally accepted procedures for doing sensitivity analysis; a common approach is to explore the effects of changing parameters one at a time on the production rates. For the sensitivity analysis, seven factors have been chosen. They are pressure, temperature, Hydrate saturation, permeability, Bottom-hole pressure, Porosity and Free Water saturation.

There are various ways to conduct a sensitivity analysis and two methods chosen here are

1. One at a Time Effect ${ }^{38}$ (OAAT): In OAAT one parameter is varied keeping the rest of the factors constant.

2. Plackett-Burman Design ${ }^{38}$ : This method allows simultaneous examination of the entire suite of parameters. Effects of individual parameters and 2-way interaction of the pairs of parameters is also studied in this method. All the parameters are changed in a certain design that will be discussed in the section 6.2. 


\subsection{One at a Time Effect:}

The One At A Time effect (OAAT) is studied by changing one parameter at a time and other simulation properties are same as the base case problem.

\section{Base Case Description:}

Base case problem is Problem 7b except that the hydrate saturation, water saturation in the hydrate bearing zone and the bottom-hole pressure applied in the reservoir are changed. Hydrate saturation and water saturation in the hydrate bearing zone are 0.7 and 0.3 . Bottomhole pressure is considered to be $2900 \mathrm{kPa}$. All the parameters are changed from base case to lower or higher end, also preset by judgment, one at a time. Table 5.1 illustrates the factors and their values used in this study. Pressure and temperature values given below are for the uppermost part of the shale zone.

Table 6-1 Factors and their values used for OAAT effect calculations

\begin{tabular}{|c|c|c|c|}
\hline Factor & Lower end & Base Case & Upper end \\
\hline Porosity, $\%$ & 30 & 40 & 50 \\
\hline Permeability(r/Z), mD & $750 / 75$ & $1000 / 100$ & $1250 / 125$ \\
\hline Hydrate saturation, \% & 60 & 70 & 80 \\
\hline Free Water Saturation, \% & 13 & 15 & 18 \\
\hline Temperature, ${ }^{\circ} \mathrm{C}$ & 0.85 & 2.5 & 4.5 \\
\hline Pressure, $\mathrm{kPa}$ & 5800 & 6513 & 7200 \\
\hline Bottom-hole Pressure, $\mathrm{kPa}$ & 2700 & 2900 & 3000 \\
\hline
\end{tabular}

Simulations are carried for 20 years with a data sampling frequency of 1 year and cumulative gas production are compared to evaluate the effect of each parameter. 


\section{Effect of Porosity:}

As porosity increases, it is expected that the ability to flow should increase. Porosity is varied from a reference value of 0.4 to $0.3 \& 0.5$. All other parameters like permeability, water saturation, hydrate saturation, free water saturation, bottom hole pressure, temperature and pressure of the reservoir are held constant and are same as that of the base case. No particular trend is observed in the reservoir behavior with respect to porosity changes as shown in Fig. 6-1.

Effect of porosity on gas production rates depends upon the variation chosen. If porosity is varied from 0.3 to 0.2 and 0.4 a different result can be expected. Conventional thought would suggest that higher porosity gives high production rates due to more available pore volume in the reservoir. Depending on the value picked for porosity in the simulation, there is a change in the output from the reservoir. There is ample uncertainty associated with porosity changes.

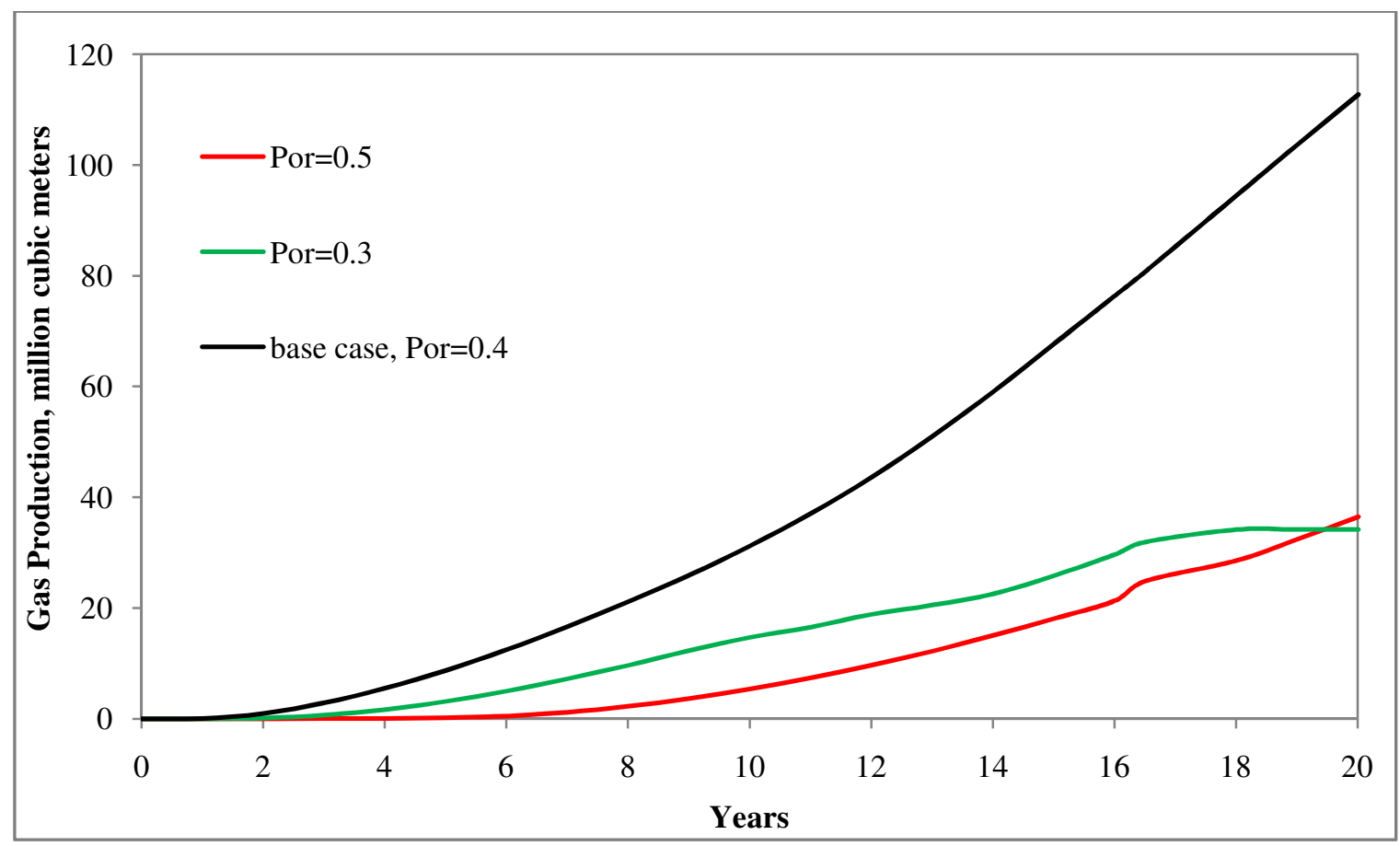

Figure 6-1 Effect of Porosity on gas production 


\section{Effect of Permeability:}

Permeability for the base case is $1000 \mathrm{mD}$ in the radial direction and $100 \mathrm{mD}$ in the vertical direction. Two cases are considered in which absolute permeability is changed from $1000 / 100 \mathrm{mD}(r / z$ direction) to $1250 / 125 \mathrm{mD}$ and $750 / 75 \mathrm{mD}$. Increasing permeability has increased production rates as shown in Figure 6-2.

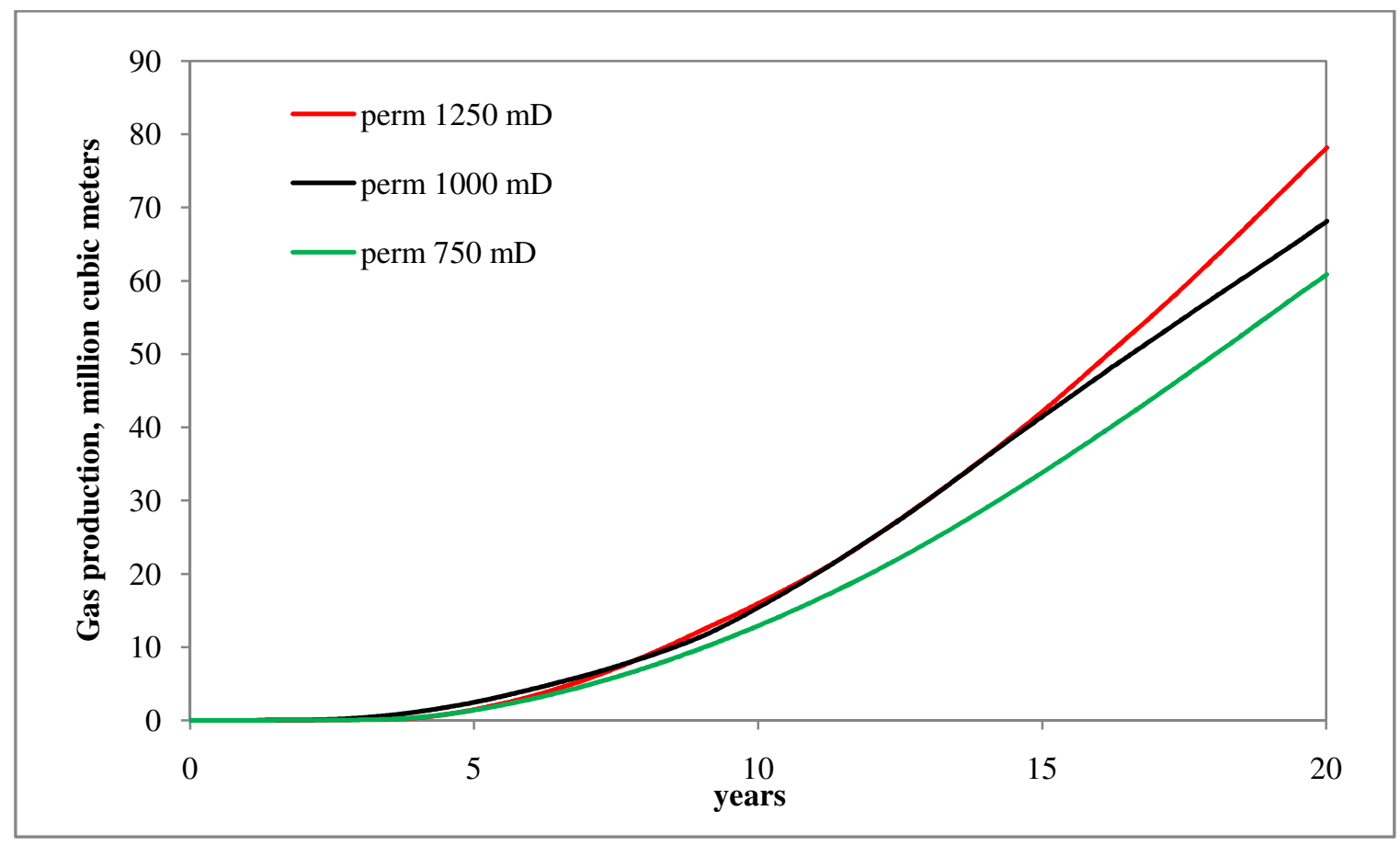

Figure 6-2 Effect of permeability on gas production

\section{Effect of Hydrate saturation:}

Higher the hydrate saturation, more the methane in the reservoir. This might be an interesting factor to consider seeing if higher hydrate saturations yielded higher gas. Hydrate saturation is assumed to be uniform in the hydrate bearing zone. It is varied from 0.7 (base case) to 0.6 and 0.8 . 
This is an interesting and informative result obtained. Higher hydrate saturation gave lesser production rates. Hydrate dissociation is endothermic and it cools the reservoir. Hence, higher hydrate saturation rapidly cools the reservoir preventing further hydrate dissociation and contributes to fall in gas production rates. These production rates however depend on the values of the hydrate saturation chosen. Therefore, a detailed experiment has to be designed in order to study the reservoir behavior in total. In Figure 6-3, decrease in hydrate saturation shows an increase in production rates.

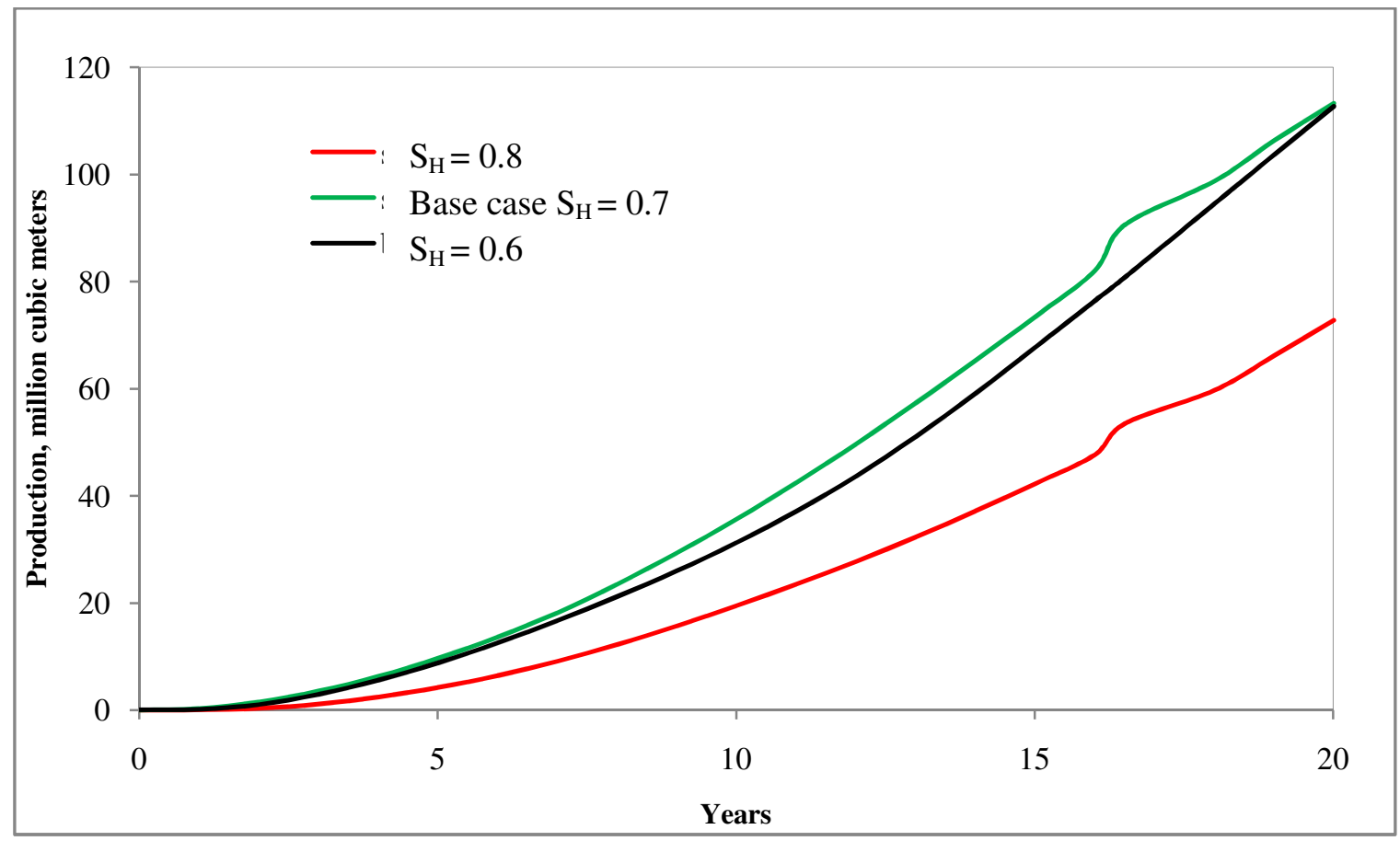

Figure 6-3 Effect of hydrate saturation on gas production

\section{Effect of temperature:}

At high temperature, the hydrate is perturbed from its equilibrium and easier becomes dissociation. So, warmer reservoirs could lead to higher gas rates. In the base case, the temperature at the uppermost part of the shale zone is $2.5^{\circ} \mathrm{C}$. The geothermal gradient is 
$+0.03^{\circ} \mathrm{C} / \mathrm{m}$ and the temperature of the remaining cells is calculated using the geothermal gradient. This temperature is changed to $0.85^{\circ} \mathrm{C}$ and $4.5^{\circ} \mathrm{C}$ for the OAAT effect calculation. The geothermal gradient remains the same.

As expected, higher reservoir temperature lead to higher gas production and this can be attributed to more available heat in the system as shown in Figure 6-4.

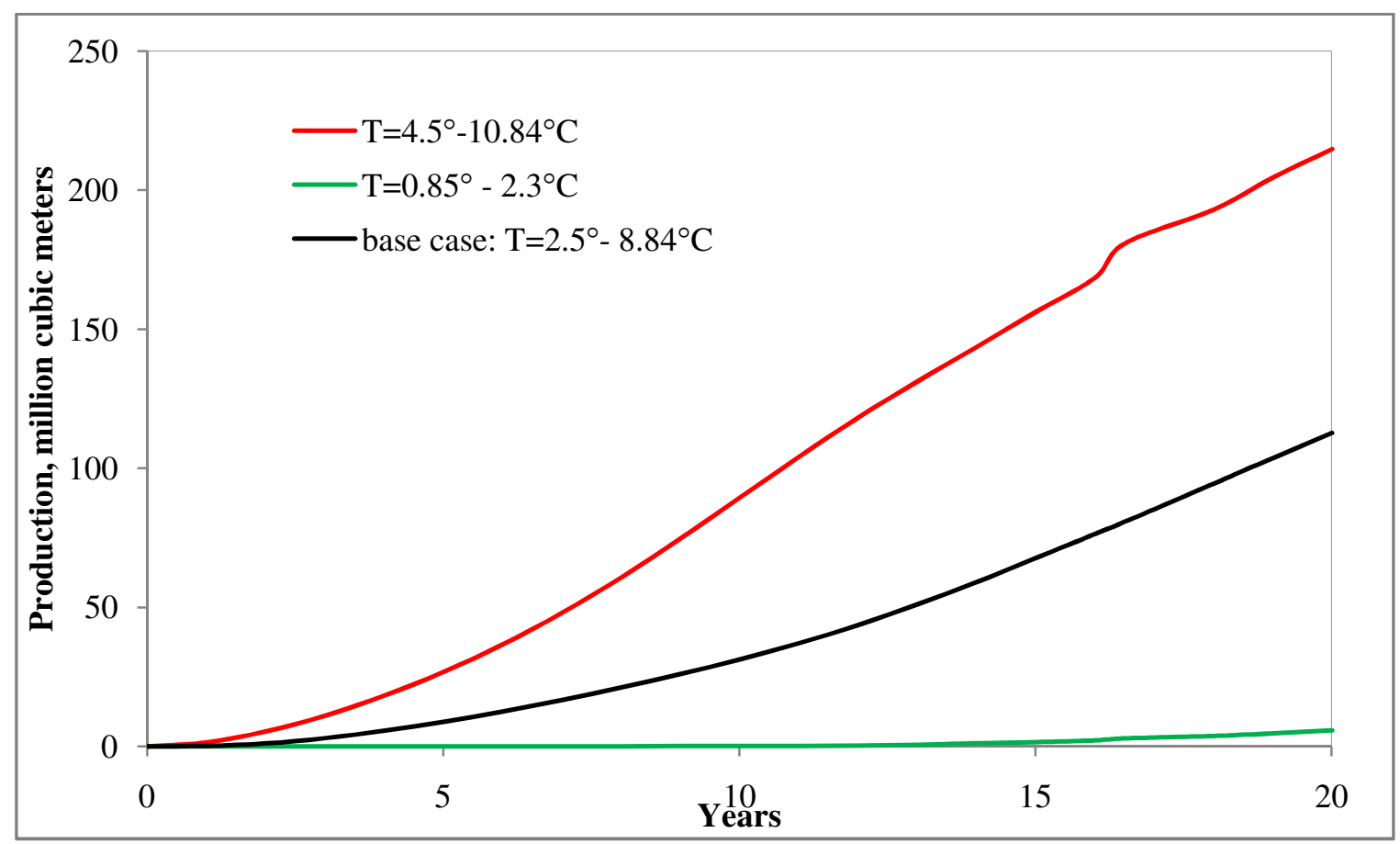

Figure 6-4 Effect of temperature on gas production

\section{Effect of Pressure:}

In the base case, the pressure at the uppermost part of the Shale zone is $6513 \mathrm{kPa}$. The hydrostatic pressure gradient is $9792 \mathrm{~Pa} / \mathrm{m}$ and the pressure of the remaining cells is calculated using the hydrostatic pressure gradient. This pressure is changed to $5800 \mathrm{kPa}$ and $7200 \mathrm{kPa}$ for the OAAT effect calculation. The hydrostatic pressure gradient remains the same. These values of temperature and pressure are chosen to ensure the stability of the 
hydrate. Hydrate can also form in the reservoir depending upon the pressure and temperature values, which also can reduce gas production rates. In this case higher gas production rates are found with increase in the difference between the pressure of the reservoir and the bottom hole pressure applied in the reservoir. Figure 6-5 shows the cumulative gas production at different pressures.

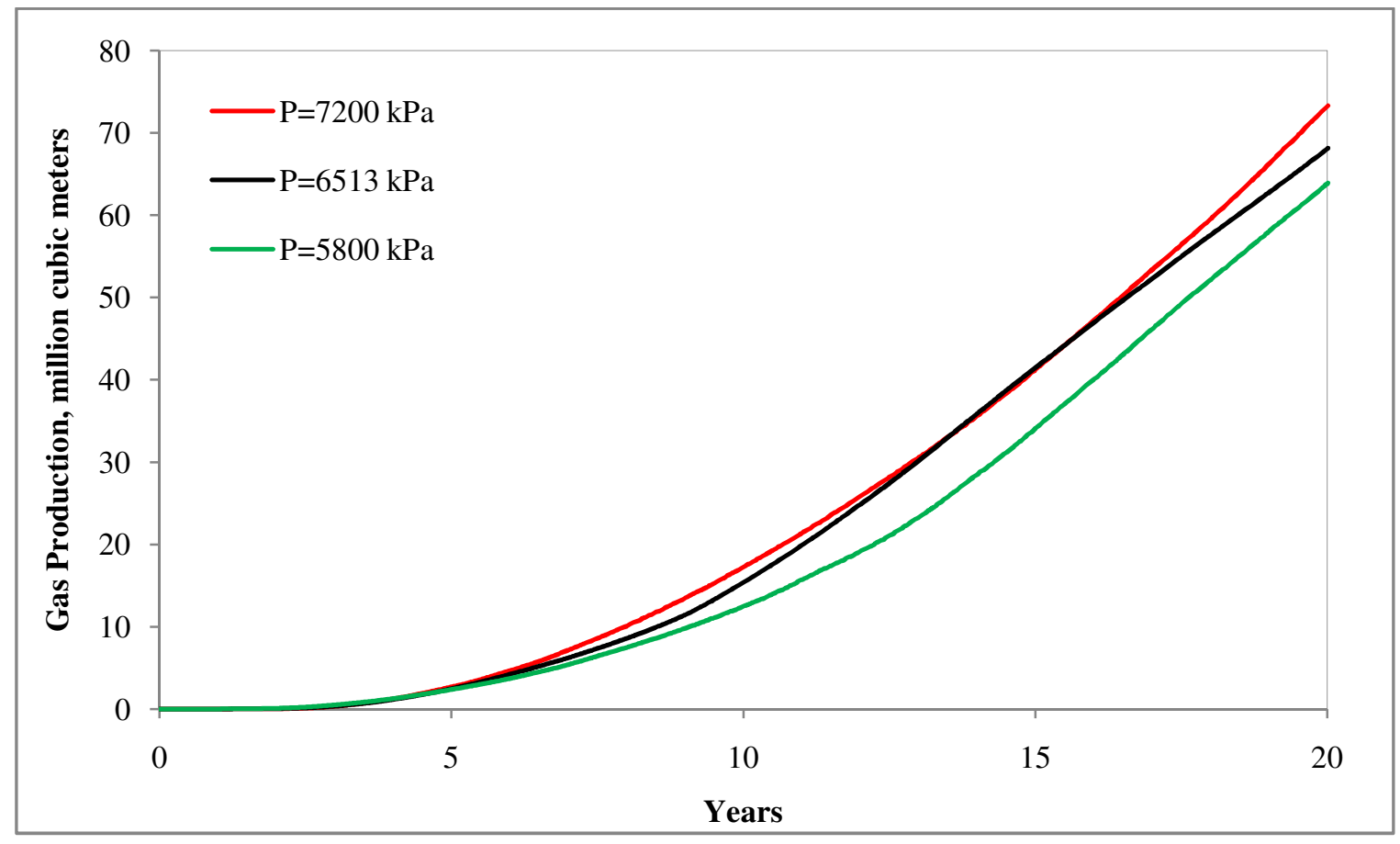

Figure 6-5 Effect of pressure on gas production

\section{Effect of Bottom-hole Pressure:}

A lower bottom-hole pressure (BHP) is ideal to produce gas because it depressurizes more. But there is also a limitation to this. At BHP lower than $2700 \mathrm{kPa}$, Ice formation is seen and hence the least value of BHP that could be possible is $2700 \mathrm{kPa}$. Bottom-hole pressure is changed from $2900 \mathrm{kPa}$ in the base case to $2700 \mathrm{kPa}$ and $3000 \mathrm{kPa}$. 
Production rates for $\mathrm{BHP}$ of $2900 \mathrm{kPa}$ and $2700 \mathrm{kPa}$ are nearly the same as shown in the Figure 6-6 Increase in the BHP means there is lesser depressurization in the reservoir owing to lesser production rates.

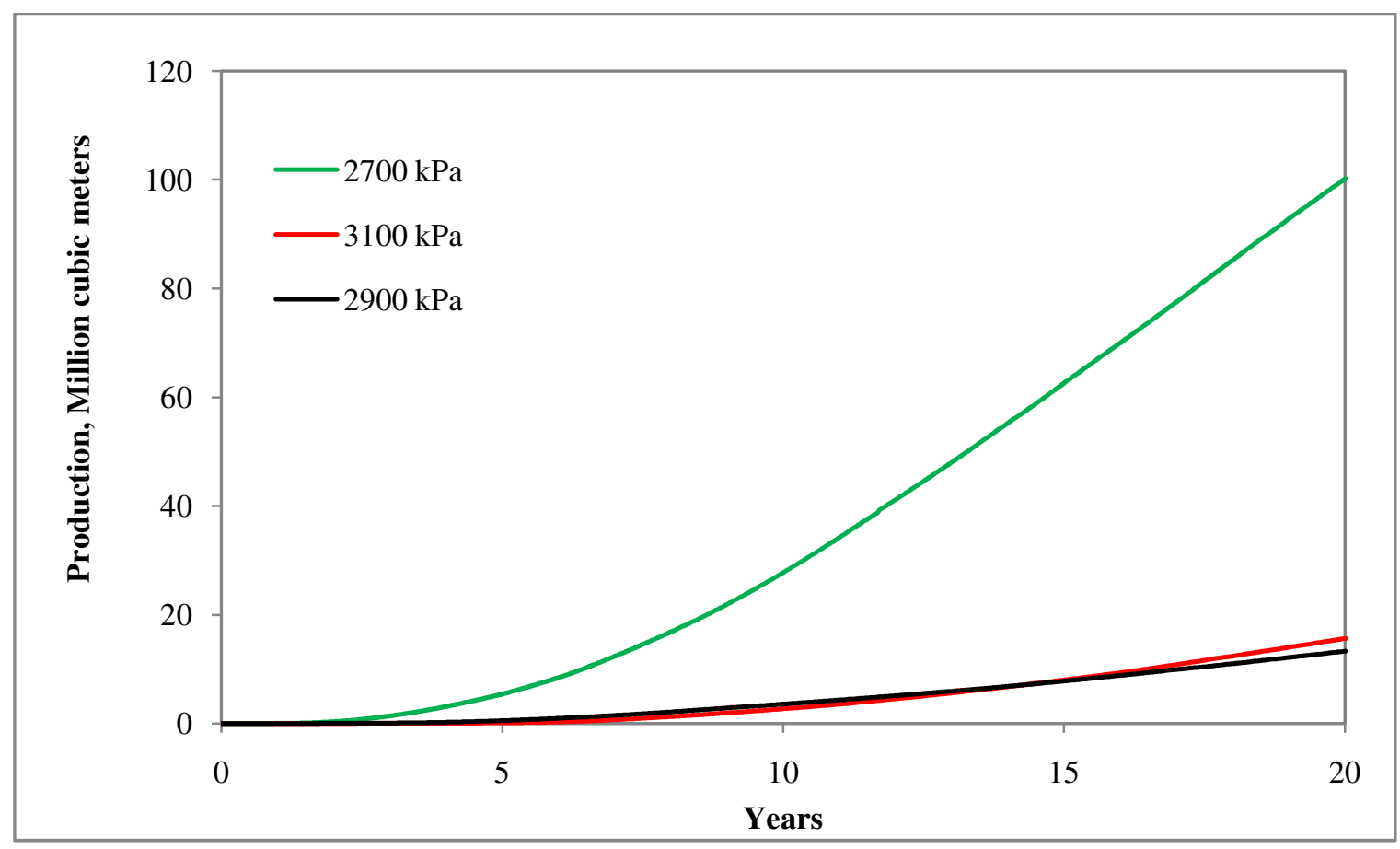

Figure 6-6 Effect of bottom- hole pressure on gas production

\section{Effect of free water saturation:}

Free water saturation for the base case is $15 \%$. It is changed to $13 \%$ and $18 \%$ for the OAAT effect calculation. Free water saturation is related to the irreducible water saturation as seen in the following equation, $S_{i r w}=S_{w}-S_{f r e e}$. Changing irreducible water saturation changes all the permeability properties of the reservoir. So, free water saturation is a very important factor to be taken care of. Table 6-1 lists all the factors and changes in the factors from the base case. 
Keeping the water saturation constant, if free water saturation is changed, irreducible water saturation also changes which affects the permeability curves. So, increase in gas production is observed with increase in free water saturation as shown in Figure 6-7.

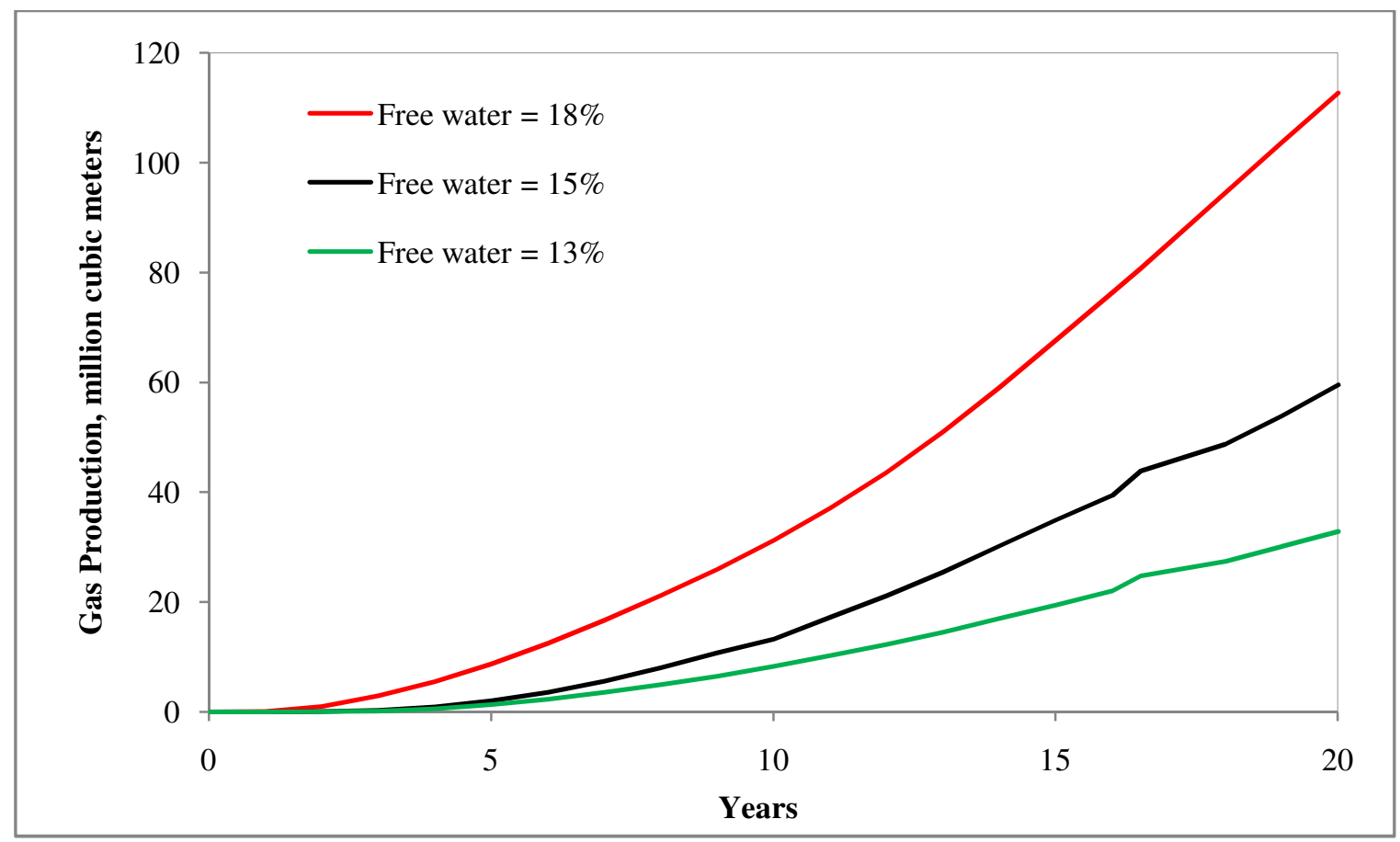

Figure 6-7 Effect of free water saturation on gas production 


\subsection{Plackett Burman Design.}

One common way to obtain interactions between the parameters is to perform a complete factorial design. A complete factorial design consists of all possible permutations of the parameters starting from a high and low value for each parameter. The number of scenarios required for completing the factorial design is $2^{n}$ where $n$ is the number of parameters and "2" is a consequence of using 2 values (high, low) for each parameter. To perform one complete factorial design, a cumbersome $128\left(2^{7}\right)$ runs are to be conducted.

The Plackett Burman design is an alternative method which is convenient and informative. The design specifies a subset of scenarios used for a complete factorial design. The number of scenarios for the design is 2 times that multiple of 4 , which is greater than the number of parameters. In this case 16 runs are conducted for seven reservoir parameters. The algorithm to implement the sensitivity analysis involves the following steps.

- Select a base case

- Determine the possible upper and lower ends of the parameters.

- Create Plackett-Burman sensitivity analysis matrix.

- Run the scenarios.

- Calculate effect of each parameter on production rates.

- Interpret the results.

The base case for this sensitivity analysis is problem $7 \mathrm{~b}$. Problem $7 \mathrm{~b}$ has been validated with all other simulators that participated in the study. The same input data file is used in the following sensitivity analysis changing certain parameters in the problem according to the design. The details of the design are given later in this chapter. 
Upper and lower values for each parameter are selected. These values are obtained by increasing or decreasing the value of the parameter by certain fixed percentage in order to gain maximum benefit from this design. Eight different reservoir scenarios (designs) are considered in this study because seven factors are being studied for sensitivity and 8 is the least multiple of 4 greater than 7 . The seven reservoir parameters with their higher and lower values for Design 1 are shown in Figure 5.1. All the parameter values for different designs are given in Table 5.2. Pressure and temperature values specified in Table 5.2 are for the uppermost part of the shale zone. The corresponding values of pressure and temperature are calculated using the gradients specified in the base case.

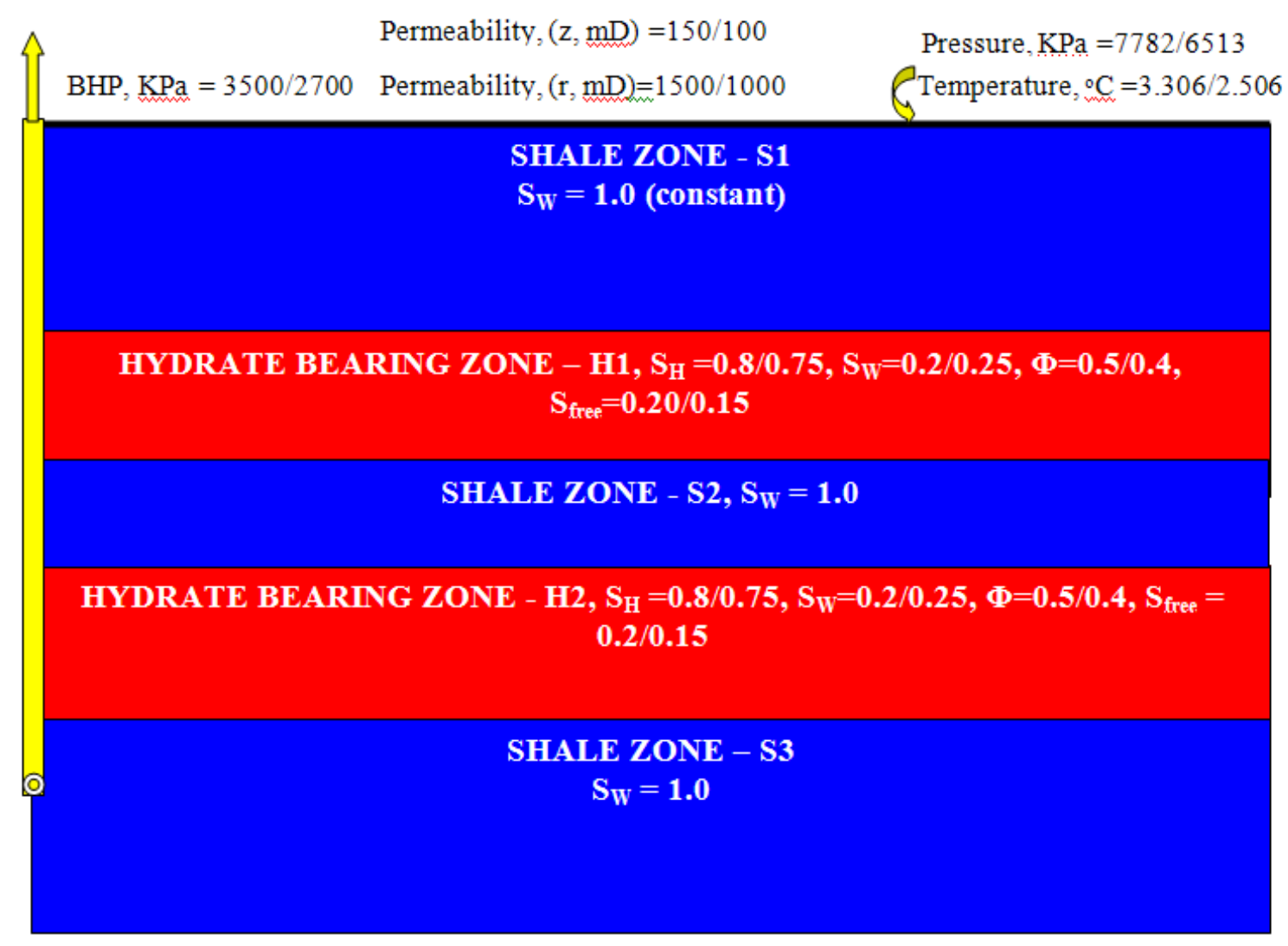

Figure 6-8 Parameter specifications for Design 1 
Table 6- 2 Parameter specifications for different scenarios

\begin{tabular}{|l|rr|rr|rr|}
\hline \multicolumn{1}{|c|}{ Parameters } & \multicolumn{2}{|c|}{ Design 1 } & \multicolumn{2}{c|}{ Design 2 } & \multicolumn{2}{c|}{ Design 3 } \\
\hline Pressure $(\mathrm{kPa})$ & 7782 & 6513 & 5243 & 6513 & 5878 & 6513 \\
Temperature $\left({ }^{\circ} \mathrm{C}\right)$ & 3.306 & 2.506 & 1.706 & 2.506 & 2.306 & 2.506 \\
Hydrate Sat. & 0.8 & 0.75 & 0.5 & 0.75 & 0.65 & 0.75 \\
Permeability $(\mathrm{mD})$ & $1500 / 150$ & $1000 / 100$ & $500 / 50$ & $1000 / 100$ & $750 / 75$ & $1000 / 100$ \\
BHP $(\mathrm{kPa})$ & 3500 & 2700 & 2700 & 3000 & 2700 & 2900 \\
Porosity & 0.5 & 0.4 & 0.3 & 0.4 & 0.3 & 0.4 \\
Free Water & 0.2 & 0.15 & 0.1 & 0.15 & 0.12 & 0.15 \\
\hline
\end{tabular}

Table 6-2 (contd...)

\begin{tabular}{|l|rr|rr|rr|}
\hline \multicolumn{1}{|c|}{ Parameters } & \multicolumn{2}{|c|}{ Design 4 } & \multicolumn{2}{c|}{ Design 5 } & \multicolumn{2}{c|}{ Design 6 } \\
\hline Pressure $(\mathrm{kPa})$ & 5878 & 6513 & 7148 & 6513 & 5878 & 6513 \\
Temperature $\left({ }^{\circ} \mathrm{C}\right)$ & 7.391 & 8.157 & 5.56 & 5.11 & 4.65 & 5.11 \\
Hydrate Sat. & 0.65 & 0.75 & 0.8 & 0.7 & 0.6 & 0.7 \\
Permeability $(\mathrm{mD})$ & $750 / 75$ & $1000 / 100$ & $1250 / 125$ & $1000 / 100$ & $750 / 75$ & $1000 / 100$ \\
BHP $(\mathrm{kPa})$ & 2700 & 2900 & 3000 & 2900 & 2700 & 2900 \\
Porosity & 0.3 & 0.4 & 0.5 & 0.4 & 0.3 & 0.4 \\
Free Water & 0.12 & 0.15 & 0.18 & 0.15 & 0.12 & 0.15 \\
\hline
\end{tabular}

Table 6-2 (contd...)

\begin{tabular}{|l|rr|rr|}
\hline \multicolumn{1}{|c|}{ Parameters } & \multicolumn{2}{|c|}{ Design 7 } & \multicolumn{2}{c|}{ Design 8 } \\
\hline Pressure $(\mathrm{kPa})$ & 5878 & 6513 & 7148 & 6513 \\
Temperature $\left({ }^{\circ} \mathrm{C}\right)$ & 4.65 & 5.11 & 8.92 & 8.157 \\
Hydrate Sat. & 0.6 & 0.7 & 0.5 & 0.4 \\
Permeability $(\mathrm{mD})$ & $750 / 75$ & $1000 / 100$ & $1250 / 125$ & $1000 / 100$ \\
BHP $(\mathrm{kPa})$ & 2700 & 2900 & 2900 & 2700 \\
Porosity & 0.3 & 0.4 & 0.4 & 0.3 \\
Free Water & 0.12 & 0.15 & 0.18 & 0.15 \\
\hline
\end{tabular}

Considering seven factors, a design of size eight is needed and the design matrix is given in Table 6-3. The 'plus' and the 'minus' in the matrix is replaced with higher and lower values for each parameter elaborated in Table 6-2. 
Table 6-3 Plackett-Burman sensitivity analysis matrix

\begin{tabular}{|c|c|c|c|c|c|c|c|}
\hline $\begin{array}{c}\text { Run } \\
\text { Number }\end{array}$ & Pressure & Temperature & $\begin{array}{l}\text { Hydrate } \\
\text { Saturation }\end{array}$ & Permeability & $\begin{array}{c}\text { Bottom } \\
\text { hole } \\
\text { Pressure }\end{array}$ & Porosity & $\begin{array}{c}\text { Free } \\
\text { water }\end{array}$ \\
\hline 1 & + & + & + & - & + & - & - \\
\hline 2 & - & + & + & + & - & + & - \\
\hline 3 & - & - & + & + & + & - & + \\
\hline 4 & + & - & - & + & + & + & - \\
\hline 5 & - & + & - & - & + & + & + \\
\hline 6 & + & - & + & - & - & + & + \\
\hline 7 & + & + & - & + & - & - & + \\
\hline 8 & - & - & - & - & - & - & - \\
\hline 9 & - & - & - & + & - & + & + \\
\hline 10 & + & - & - & - & + & - & + \\
\hline 11 & + & + & - & - & - & + & - \\
\hline 12 & - & + & + & - & - & - & + \\
\hline 13 & + & - & + & + & - & - & - \\
\hline 14 & - & + & - & + & + & - & - \\
\hline 15 & - & - & + & - & + & + & - \\
\hline 16 & + & + & + & + & + & + & + \\
\hline
\end{tabular}

A total of 16 runs are conducted for each design by changing the parameters for every run as shown in Tables 6-2 \& 6-3. Hydrate saturation, water saturation, free water saturation and irreducible water saturation are linked together by the following equations.

$S_{w}+S_{H}=1, \mathrm{~S}_{\mathrm{G}}=0$ (initially), $S_{\text {irw }}=S_{w}-S_{\text {free }}$

For example in Run 1 (Table 6-3) hydrate saturation has a 'plus' sign and free water saturation has a 'minus' sign which indicates that the higher value among the two, for hydrate saturation and lower value of the two, for free water saturation is used. Water saturation and irreducible water saturation are recalculated from the above equations which in turn change the relative permeability curves. All these direct or indirect effects are taken 
into consideration for each run. All other properties not mentioned in this chapter are same as that of the base case.

Simulations are run using CMG STARS for 20 years with a data sampling frequency of 1 year.

\section{Results}

A range of production rates were obtained in each design. The Figure 6-9 gives a visual description of the range of production rates observed in each design. Each of the area plots show how sensitive the production rates are with respect to the parameter changes. Designs 1,2 and 3 especially showed lower production rates. This is because they are cold reservoirs. Warmer reservoirs, Designs $4-8$ showed better production rates than Designs $1-3$. 

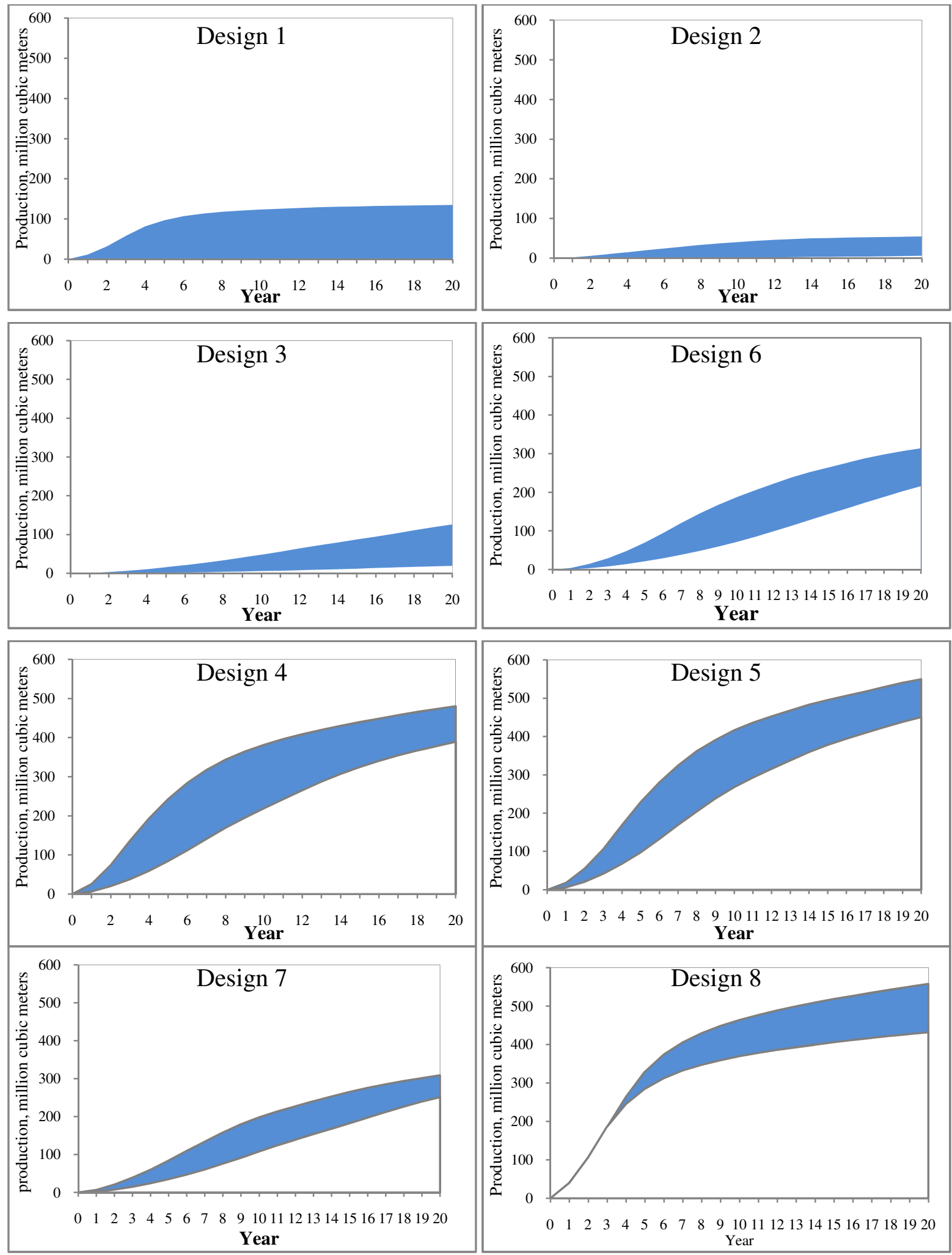

Figure 6- 9 Cumulative gas production for designs 1-8 
The effects of the PB design are found out as follows. For the run $n,(n=1,2,3 \ldots 16)$

$$
S_{n}=\sum_{i=0}^{20} \frac{P_{i}}{(1+0.15)^{i}}
$$

where $P_{i}=$ Annual Production and the factor 0.15 is used to discount the future production rate to a number that can be added to today's value to give a present value of the total production in the predicted future. Thus, $S_{n} s\left(S_{1}, S_{2} \ldots S_{16}\right)$ are calculated. In order to calculate the effect of a parameter, the following equation is used.

$$
E_{j}=\sum \frac{ \pm S_{n}}{8 * \% \text { change in } E_{j}}
$$

where $j=1,2 \ldots 7$, ' + ' is taken before the $S_{n}$ when there is a corresponding ' + ' in the matrix column for that specific parameter and '-" is taken before the $S_{n}$ when there is a corresponding '-' in the matrix column for that specific parameter.

For example, in Design 1, the effect of pressure is given as $\mathrm{E}_{1}=\left(+S_{1}-S_{2}-S_{3}+S_{4}-S_{5}+S_{6}+S_{7-} S_{8^{-}}\right.$ $\left.S_{9}+S_{10}+S_{11}-S_{12}+S_{13}-S_{14}-S_{15}+S_{16}\right) \div(8 * \%$ Change in Pressure $)$

\section{Results}

The effects are calculated using equation for $E_{j}$. The effects of various factors/parameters are plotted against those factors. A positive higher effect indicates that an increase in that factor increases the production rate and a negative effect value means that an increase in that factor decreases the production rate. The effects of all the design parameters are shown in Figure 610. For pressure, some effects were higher and some effects were lower than zero. This means that it depends on the other factors in the scenario. 


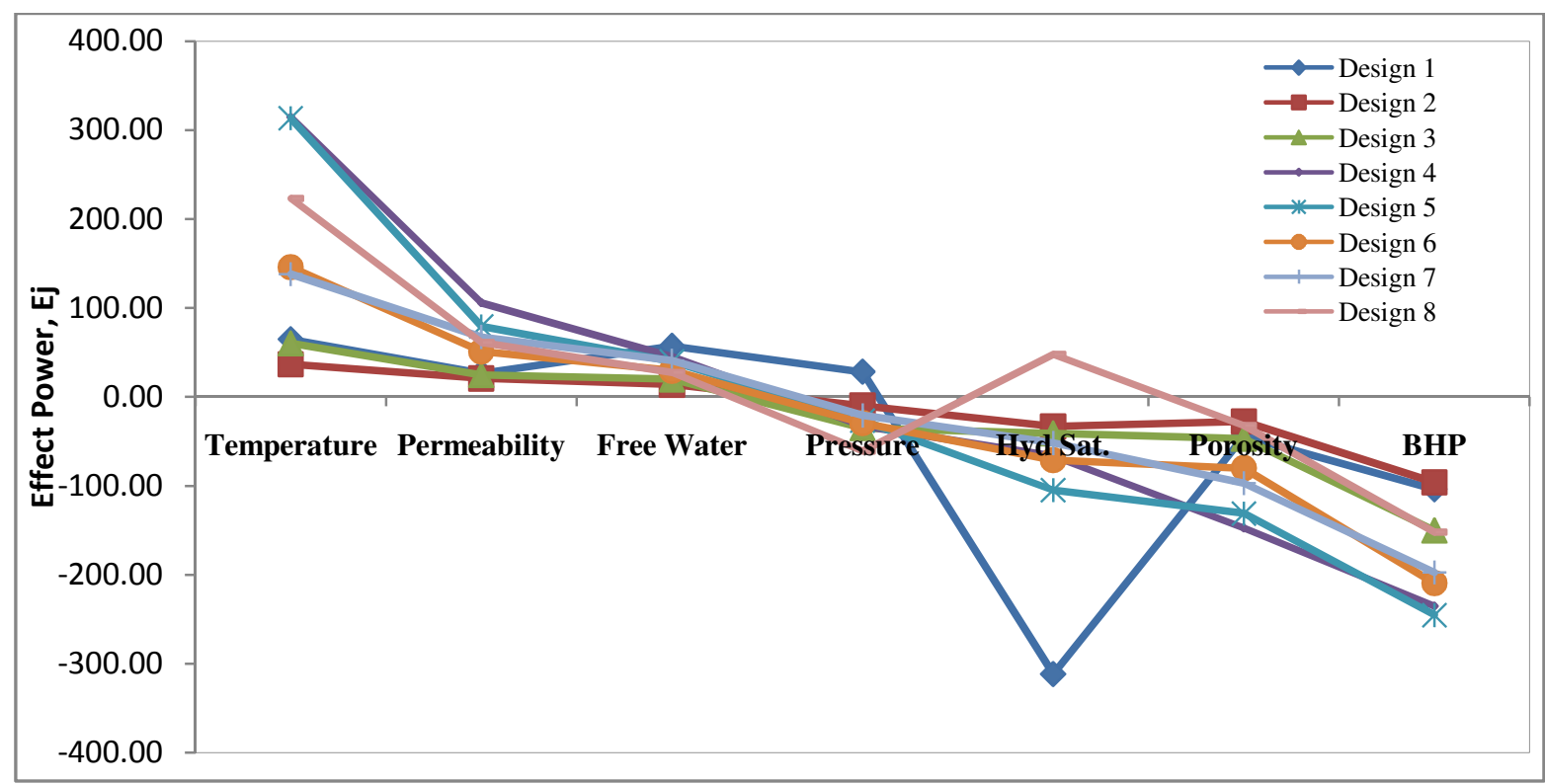

Figure 6- 10 Effects of the parameters on gas production.

Table 6-4 Effects of variable input parameters on cumulative gas production

\begin{tabular}{|c|c|c|c|c|c|c|c|}
\hline Design & Temp. & Perm. & Free Water & Pressure & Hyd Sat. & Porosity & BHP \\
\hline $\mathbf{1}$ & 64.66 & 26.71 & 57.03 & 28.26 & -311.77 & -44.11 & -103.86 \\
$\mathbf{2}$ & 36.61 & 20.78 & 13.79 & -9.87 & -33.17 & -27.68 & -96.00 \\
$\mathbf{3}$ & 60.44 & 24.76 & 19.99 & -35.11 & -40.90 & -46.93 & -150.28 \\
$\mathbf{4}$ & 314.49 & 105.64 & 45.19 & -32.31 & -66.14 & -147.40 & -235.17 \\
$\mathbf{5}$ & 313.07 & 79.09 & 39.82 & -26.64 & -104.86 & -131.06 & -245.29 \\
$\mathbf{6}$ & 145.70 & 50.83 & 29.43 & -29.56 & -71.31 & -80.28 & -209.52 \\
$\mathbf{7}$ & 138.16 & 67.59 & 40.99 & -20.70 & -51.75 & -96.93 & -197.27 \\
$\mathbf{8}$ & 223.30 & 61.41 & 27.65 & -60.86 & 47.83 & -32.27 & -152.03 \\
\hline
\end{tabular}

Each of the parameters has been ranked based on the magnitude of the effect calculated. BHP was ranked the strongest in all the designs except design 8 , which is warm reservoir and has less hydrate saturation. Temperature is observed to the next most important factor in determining the productivity of the reservoir. 
Table 6-5 Rankings for different parameters involved in each design

\begin{tabular}{|l|l|l|l|l|l|l|l|l|}
\hline Design & $\mathbf{1}$ & $\mathbf{2}$ & $\mathbf{3}$ & $\mathbf{4}$ & $\mathbf{5}$ & $\mathbf{6}$ & $\mathbf{7}$ & $\mathbf{8}$ \\
\hline Pressure & 6 & 7 & 5 & 7 & 7 & 6 & 7 & 4 \\
Temperature & 3 & 2 & 2 & 1 & 1 & 2 & 2 & 7 \\
Hyd. Sat. & 1 & 3 & 4 & 4 & 4 & 4 & 5 & 3 \\
Permeability & 7 & 5 & 6 & 5 & 5 & 5 & 4 & 6 \\
BHP & 2 & 1 & 1 & 2 & 2 & 1 & 1 & 5 \\
Porosity & 5 & 4 & 3 & 3 & 3 & 3 & 3 & 1 \\
Free water & 4 & 6 & 7 & 6 & 6 & 7 & 6 & 2 \\
\hline
\end{tabular}




\section{Importance and Incorporation of Heterogeneity in Reservoirs}

Heterogeneities in the characteristic of geologic systems are commonly seen. It is true that everywhere in nature, there is diversity. We have incorporated heterogeneity into the reservoir models to make it resemble a natural reservoir. So far, homogeneous properties have been assumed throughout the reservoir. These homogeneous property values are actually the average values of the distribution of the parameters. Measured data for these properties are obtained from the distribution of properties from the Mt Elbert Stratigraphic test well. This data is generally specified with respect to the depth of the reservoir. The variability in permeability, porosity, hydrate saturation, water saturation and irreducible water saturation is taken into account in this part of the study. Figure 7-1 and 7-2 show a distribution of hydrate saturation, permeability, porosity and irreducible water saturation from a depth of $2130 \mathrm{ft}$ to $2170 \mathrm{ft}$ which is obtained from Mt. Elbert site ${ }^{39}$.

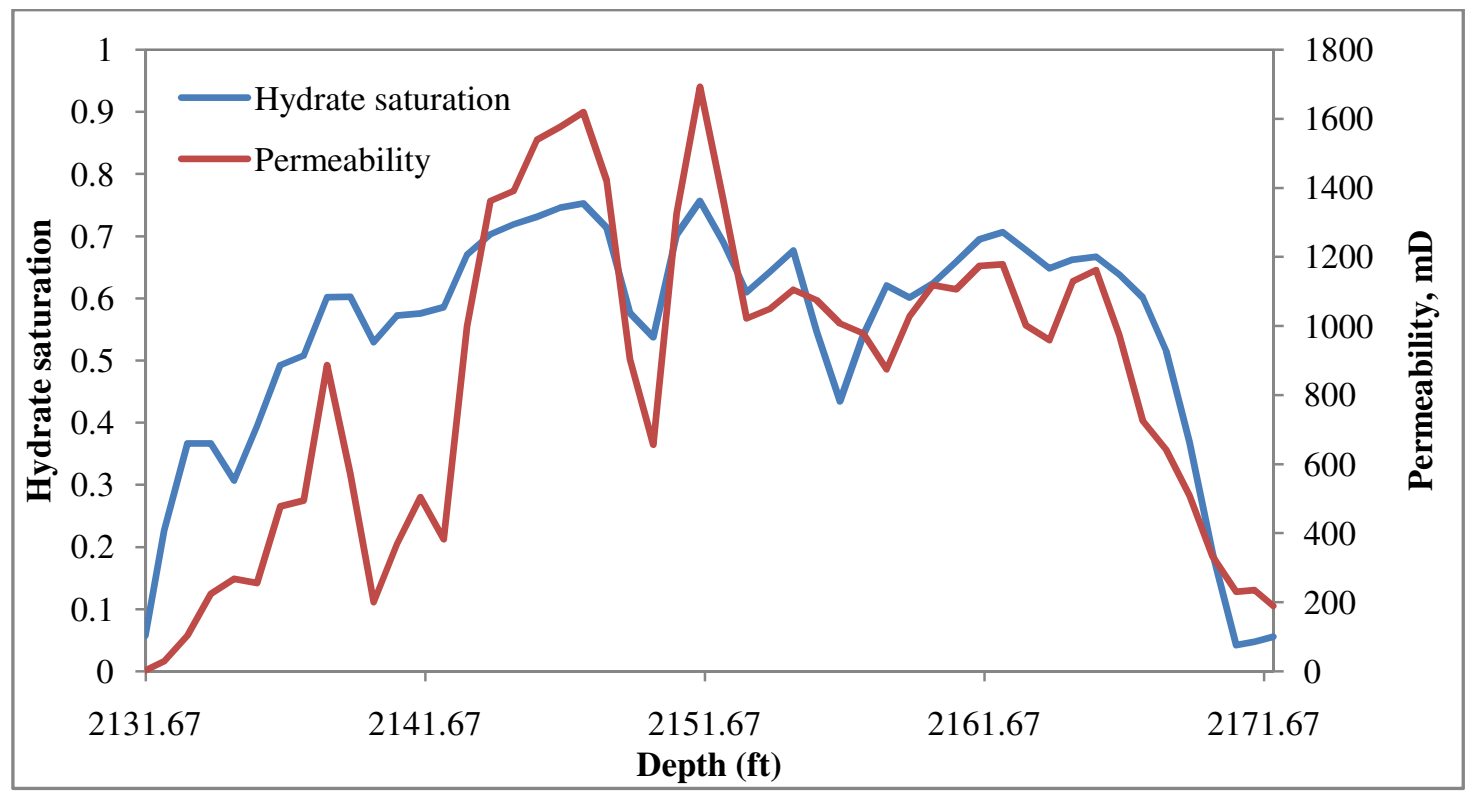

Figure 7-1 Hydrate saturation and Permeability distribution data from Mt Elbert Stratigraphic test well 


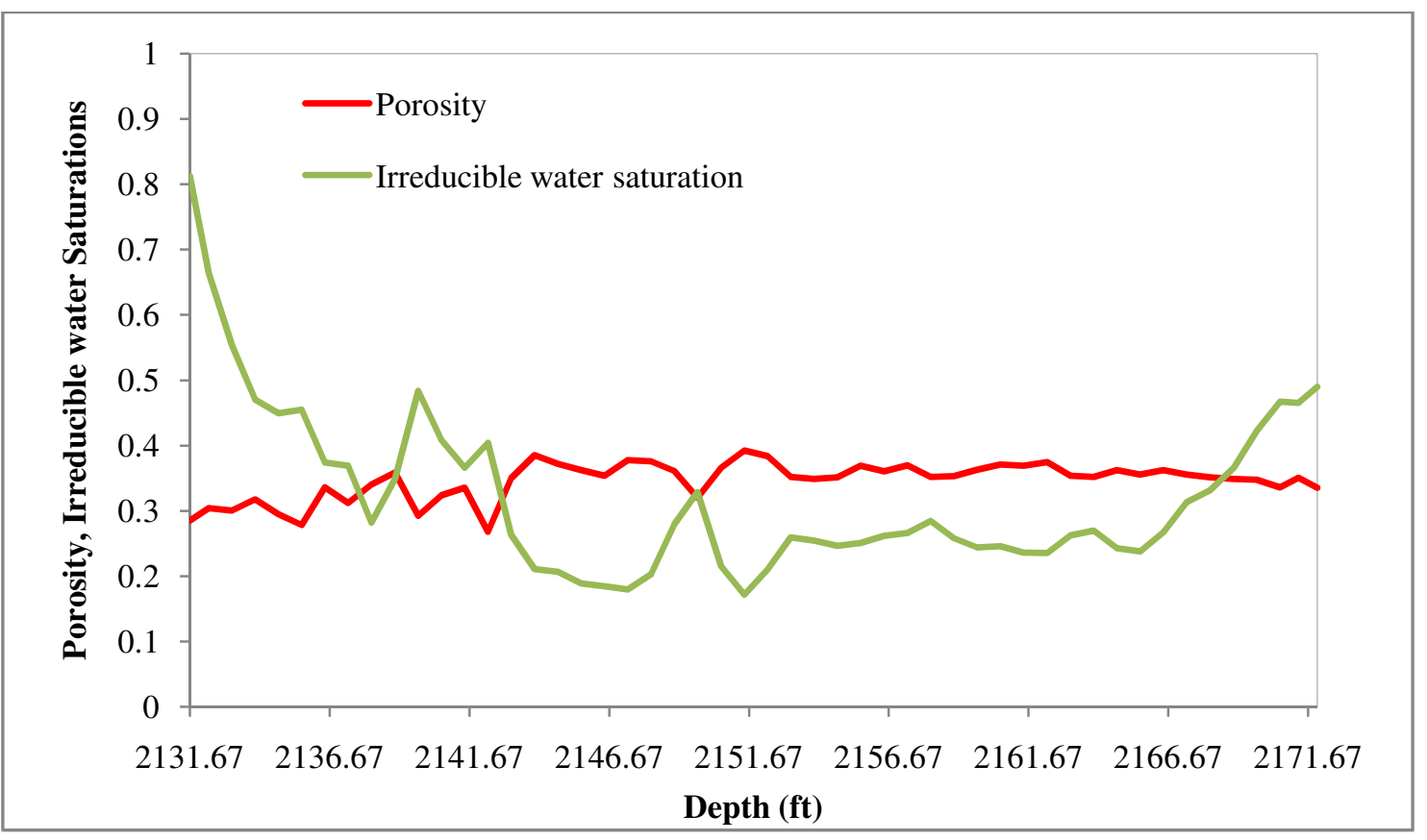

Figure 7-2 Porosity and Irreducible water saturation data from Mt Elbert Stratigraphic test well

It can be seen from Figure 7-1 that hydrate saturation and permeability are low at $2130 \mathrm{ft}$ and $2170 \mathrm{ft}$ and higher at other points. This can be due to higher clay concentrations at those points which is shown in Figure 7-2 in the form of higher irreducible water saturation. Instead of specifying a constant uniform property in the entire reservoir these variations in properties are specified in the input data file and variations in gas production are studied.

\section{Base case}

As seen in the results of Problem 7a (Figure 7-3) no gas was produced for the first 10 years. It is very important to check whether the production rates are same even after introducing heterogeneity in the system. This made us to choose Problem 7a (Mt Elbert like deposit) as the base case and heterogeneities in different properties are incorporated using the Mt Elbert 
Stratigraphic test well data. Three different cases with difference in the heterogeneity of properties are being studied.

\section{Case 1}

In Problem 7a, Porosity (0.1-Shale Zone, 0.35-Hydrate Zone), Hydrate saturation (0.0-Shale Zone, 0.65-Hydrate Zone), Permeability $(1000 \mathrm{mD} / 100 \mathrm{mD})$, Irreducible water saturation $(0.248)$ are constant for the entire reservoir. In this case variability in properties like hydrate saturation, permeability, porosity and irreducible water saturation as shown in Figures 7-1 and 7-2 are included in Problem 7a data file. Irreducible water saturation for each layer is different and so 50 relative permeability tables have been included for 50 layers in the hydrate bearing zone of Problem 7a. Variations in Porosity, Permeability, hydrate saturation and irreducible water saturations are specified in the data file as below.

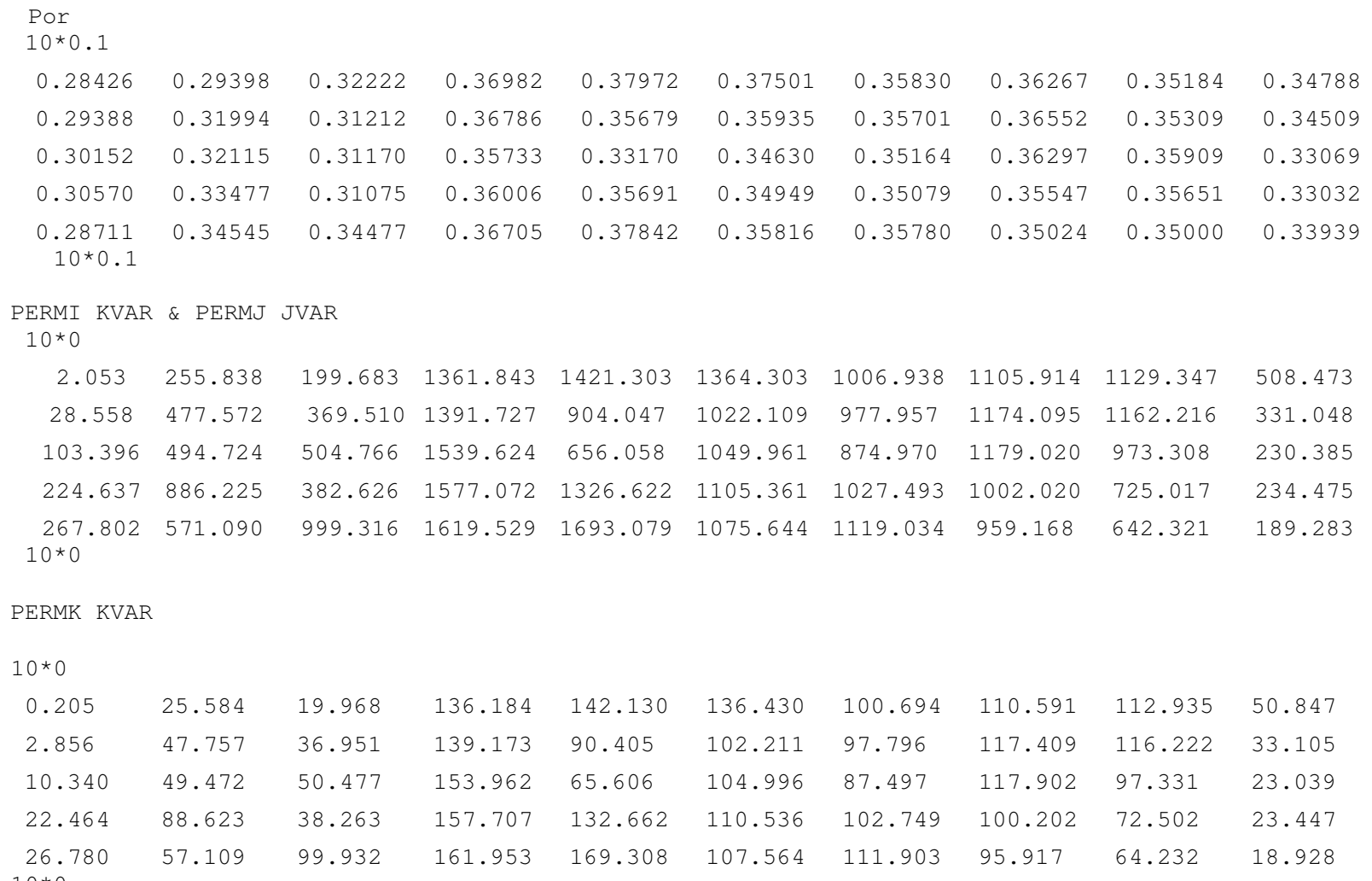




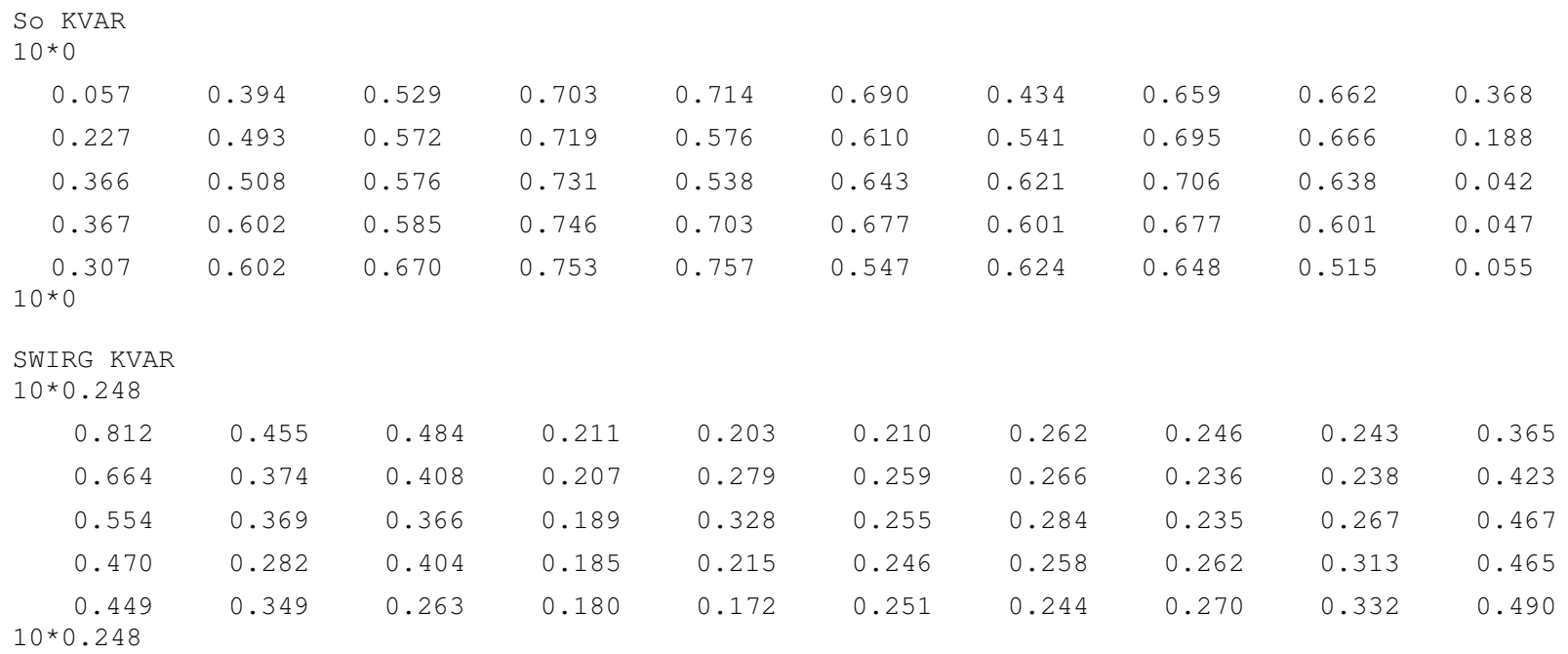

\section{Case 2}

In this case the effect of heterogeneity in hydrate saturation on production rates is studied. Other Properties like porosity permeability irreducible water saturation are set constant as the base case.

\section{Case 3}

This case is similar to case 1 except that, a uniform permeability of $1000 \mathrm{mD}$ and $100 \mathrm{mD}$ in the radial and horizontal direction are considered. This case is studied to understand the effect of variable permeability on production rates.

\section{Results}

All the cases were run for 10 years. It was noticed from the simulations that in all cases gas was produced in the first 10 years as shown in Figure 7.3. 


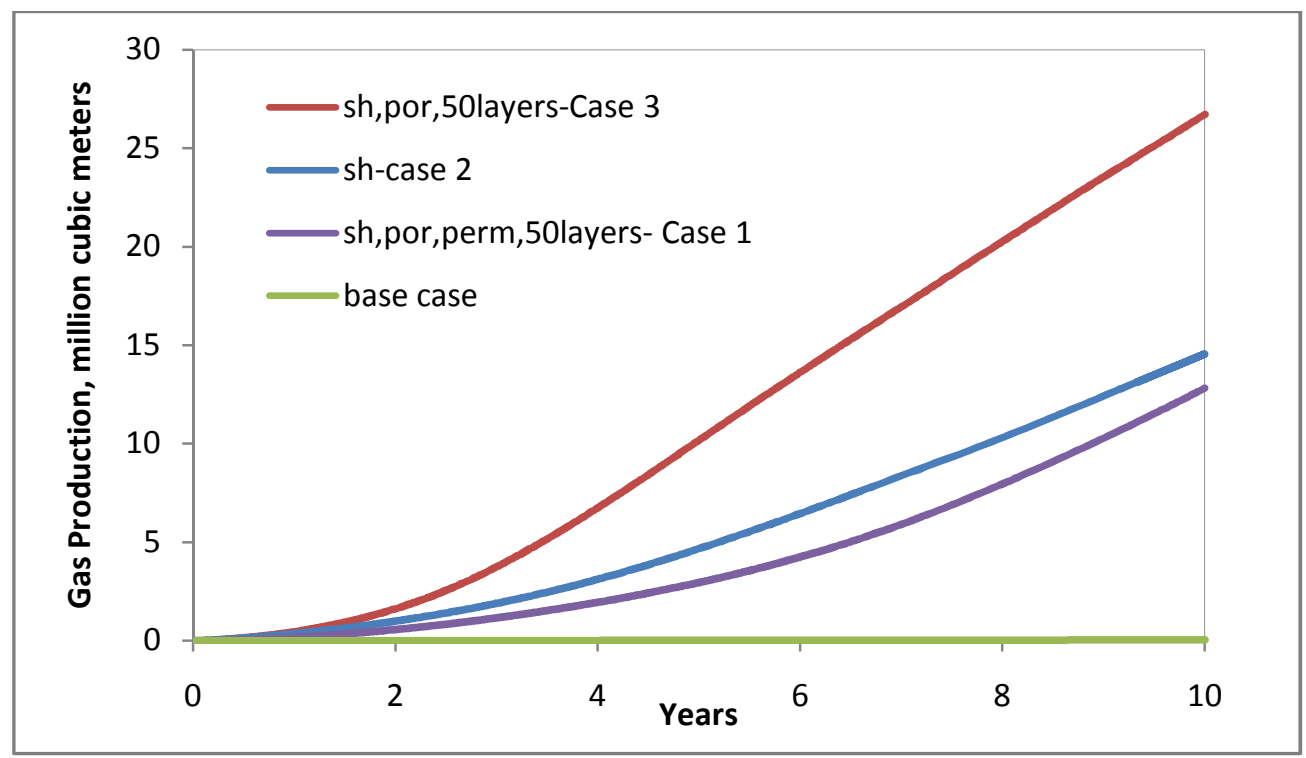

Figure 7-3 Gas production for Case 1, 2 and 3. Case 1 refers to the reservoir which includes anisotropy in permeability, porosity, hydrate saturation and irreducible water saturation. Only heterogeneity in hydrate saturation is considered in Case 2. Anisotropy in hydrate saturation, porosity and irreducible water saturation (50 layers) is considered in Case 3 


\section{Conclusions Recommendations and Future work}

\subsection{Conclusions}

- Depressurization is better method for gas hydrate production yielding higher production rates than in the case of thermal stimulation.

- Capillary pressure of water-gas is introduced in the water-oil table as PCOW when the oil phase is absent. Gas-water capillary pressure is introduced as PCOG in the gas-oil table when hydrate is modeled as an oil phase. These differences in the specification of gas-water capillary pressure have created problems matching the results of capillary pressure for CMG STARS with other codes.

- Capillary pressure and gas phase relative permeability are a function of water saturation but they can be specified only as a function of liquid saturation (water + oil) in STARS input data file. This has created problems in matching the relative permeability curves with other simulators.

- Results for hydrate modeled as an oil phase with the exception of problems resulting in the formation of ice in the system for all the reservoir simulators are in good agreement.

- Using the inbuilt ICE model in STARS can lead to differences in the results. Specifying ICE as a component is preferred to encounter the ice formation in the system.

- Sharp hydrate dissociation is not observed for CMG STARS when hydrate is specified as an oil component. 
- Incorporating heterogeneities in properties like porosity, permeability, hydrate saturation, irreducible water saturation has increased production rates.

- Sensitivity analysis was performed using Placket-Burman Design and results showed that temperature, bottom-hole pressure are the most sensitive parameters. Hydrate saturations above $60 \%$ have a negative impact on production rates. Hydrate saturations of about $40-50 \%$ has showed a positive impact on gas production rates.

\subsection{Recommendations and Future work}

- The ICE model inbuilt in CMG STARS could be compared / validated by conducting several small runs with the reaction chemistry specified and to find out the difference between the model used in STARS and other codes.

- Definition of more cases with ice as a part of the system and solving them in comparison with other hydrate codes being used.

- Lab scale experiments on hydrate core samples could be conducted and the situation can be converted to a code comparison problem, thus provides a controlled comparison to experimental data.

- The introduction of horizontal wells into the reservoir scenario and comparison with vertical wells should be performed.

- So far, only one method of hydrate dissociation has been used in this study at a time. It would be of interest to use more than one method of hydrate dissociation for the same system at different times and this could lead to knowledge of the best combination of methods of hydrate dissociation for that particular system. 
- Conducting Plackett Burman design for different scenarios including anisotropy in all the parameters and to compare with the case already studied in the project.

- Implementation of different techniques of design of experiments like Monte-Carlo, taguchi, full factorial, half factorial and studies of the effects of different factors in a reservoir simulation should be performed.

- An economic model can be developed to cross check the economic feasibility of the gas hydrate wells in order to gain confidence over the production rates obtained from reservoir simulations.

- Effect of different variables like reservoir thickness, well completion, well spacing on production rates should be studied. 


\section{References}

1. Kvenvolden, K. A. (1993) Gas hydrates-Geological Perspective and global change. Reviews of Geophysics 31, 173-187

2. National Energy Technology Laboratory, http://www.netl.doe.gov/technologies/oilgas/FutureSupply/MethaneHydrates/MH_CodeCompare/MH_CodeCompare.html. $\underline{2008}$.

3. Moridis, G.J., M.B. Kowalsky, and K. Pruess, TOUGH-Fx/HYDRATE v1. O User's Manual: A code for the simulation of system behavior in hydrate-bearing geologic media. Report LBNL-58950. Lawrence Berkeley National Laboratory, Berkeley, CA, 2005.

4. MH-21 Research Consortium, http://www.mh21japan.gr.jp/english/.

5. Moridis, G.J., M.B. Kowalsky, and K. Pruess, HydrateResSim Users Manual: A Numerical Simulator for Modeling the Behavior of Hydrates in Geologic Media. Department of Energy, Contract No. DE-AC03-76SF00098. Lawrence Berkeley National Laboratory, Berkeley, CA, 2005.

6. Computer Modeling Group Ltd, CMG STARS. 2007: Calgary, Alberta, Canada.

7. White, M.D. and M. Oostrom., STOMP Subsurface Transport Over Multiple Phase: User's Guide PNNL-15782 (UC-2010). Pacific Northwest National Laboratory, Richland, Washington, 2006.

8. EIA (U.S. Energy Information Administration), Annual Energy Outlook 2008 http://www.eia.doe.gov/oil_gas/natural_gas/info_glance/natural_gas.html 
9. Forests and energy, Key Issues, Food and Agriculture Organization of the United States, 2008. ftp://ftp.fao.org/docrep/fao/010/i0139e/i0139e00.pdf

10. EIA (U.S. Energy Information Administration), Annual Energy Outlook 2007, Report: DOE/EIA 0383-2007, February 2006.

11. U.S. Department of Energy, Office of Fossil Energy Overview of Methane Hydrate: Future Energy Within Our Grasp http://fossil.energy.gov/programs/oilgas/publications/methane_hydrates/MHydrate_o verview_06-2007.pdf

12. Michael D. Max et al. (eds.), Economic Geology of Natural Gas Hydrate, 191-206. () 2006 Springer. Printed in the Netherlands.

13. Collett T.S. et al., Occurrence of Marine gas hydrates in the Indian continental margin. Results of the Indian national gas hydrate program (NGHP). American Geophysical Union, Fall Meeting 2007.

14. Alaska Gas hydrate Studies With The BPXA-USDOE-USGS Resource Studies http://www.netl.doe.gov/technologies/oil-gas/FutureSupply/MethaneHydrates/rdprogram/ANSWell/ANSWell_main.html.

15. New Energy and Fuel, Apr 23, 2008 http://hewenergyandfuel.com/http:/newenergyandfuel/com/2008/04/23/a-breakthrough-infuel-supplying-from-methane-hydrates/

16. Michael D. Max. Natural Gas Hydrate: In Oceanic and Permafrost Environments,2000 P-1 
17. Yuri F. Makogon, Hydrates of Hydrocarbons, 1997

18. Hammerschidt, E. G. Ind. Eng. Chem. 1934, 26, 851.

19. Tofimuk,A.A., Cherskiy, N.V., Tsarev, V.P., Future Supply of Nature-Made Petroleum and Gas (Meyer, R.F.,ed.), Pergamon Press, New York, 919 (1977).

20. Klauda, J.B., Sandler,S.I.,Energy and Fuels, 19,469 (2005).

21. Mineral Management Service: Methane gas hydrates (USGS) http://geology.usgs.gov/connections/mms/joint_projects/methane.htm

22. Clatharate Hydrates of Natural Gases p-540 Dendy sloan estimates

23. Kvenvolden, K.A..”'Gas Hydrates as a Potential Energy Resource”, U.S. Geological Survey Professional Paper 1570, pg.555-561, 1993.

24. Mc Mullan, R.K., Jeffrey,GA., J. Chem. Phys., 42, 2725 (1965).

25. Ripmeester, J.A., Tse, J.S., Ratcliffe, C.T., Powell, B.M., Nature, 325, 135 (1987).

26. Sloan, E.D.; Koh, C. A.Clathrate hydrates of natural gases, $3^{\text {rd }}$ ed, 2007 p-70

27. Sloan, E.D.; Koh, C. A.Clathrate hydrates of natural gases, $3^{\text {rd }}$ ed, 2007 p-540

28. Williams, E. T., Millheim. K., and Liddell. B..”Methane Hydrate Production from Alaskan Permafrost,'DOE final report, Maurer Technology Inc. and Andarko Petroleum Corp., TX, March 2005.

29. Michael D. Max. Natural Gas Hydrate: In Oceanic and Permafrost Environments,2000 P-5

30. United States Environmental Protection Agency: www.epa.gov/methane/

31. Khalil, M.A.K., C.L. Butenhoff, and R.A. Rasmussen, 2007, 41, 2131-2137. Atmospheric Methane: Trends and Cycles of Sources and Sinks. Environmental Science and Technology. 
32. D. Archer"Methane hydrate stability and anthropogenic climatic change",Biogeosciences,4,521-544,2007

33. Kelley, Joseph T., et al; "Giant Sea-Bed Pockmarks: Evidence for Gas Escape from Belfast Bay, Maine," Geology, 22:59, 1994.

34. Van Genuchten, M.T., A closed-form equation for predicting the hydraulic conductivity of unsaturated soils. Soil Sci. Soc. Am. J, 1980. 44(5): p. 892-898

35. Mualem, Y., A New Model for Predicting the Hydraulic Conductivity of Unsaturated Porous Media. 1976

36. Stone, H.L., Probability model for estimating three-phase relative permeability. J. Pet. Tech, 1970. 22(2): p. 214-218.

37. Aziz, K. and A. Settari, Petroleum Reservoir Simulation. 1979: Applied Science Publishers.

38. Diane L. Beres and Douglas M. Hawkins.," Plackett-Burman technique for sensitivity analysis of many-parameterd models” Ecological Modeling 141 (2001) 171-183.

39. Anderson, B., et al. Analysis of Modular Dynamic Formation Test Results from the "Mount Elbert" Stratigraphic Test Well, Milne Point, Alaska. in Proceedings of the 6th International Conference on Gas Hydrates. 2008. Vancouver, British Columbia, Canada. 